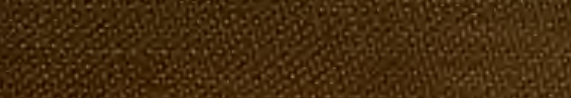

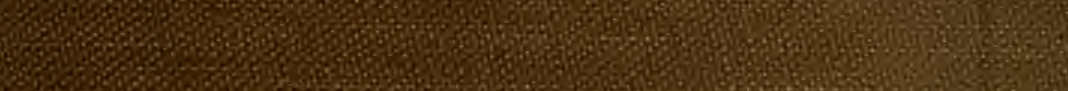

Q

20.50.

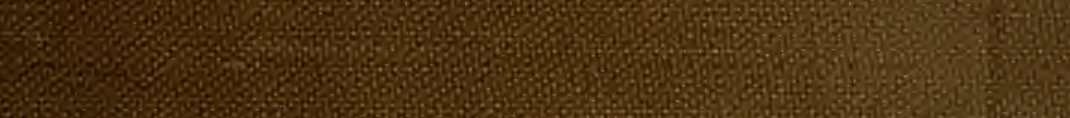

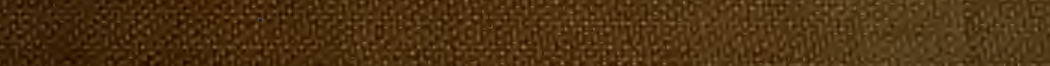
S.

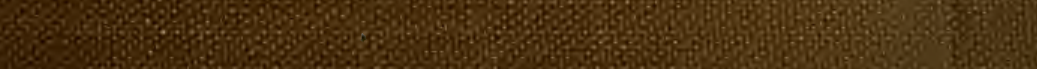

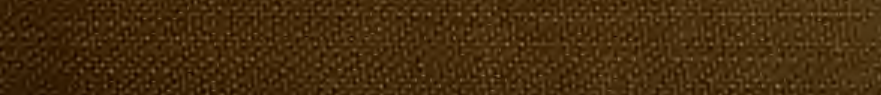




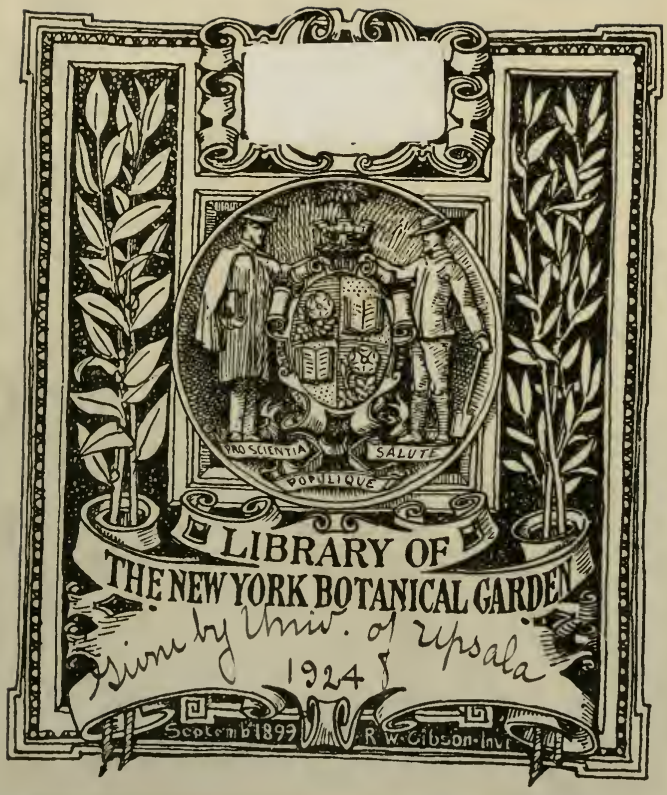




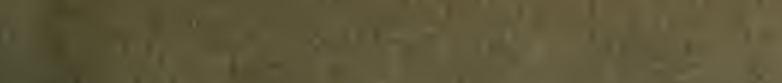

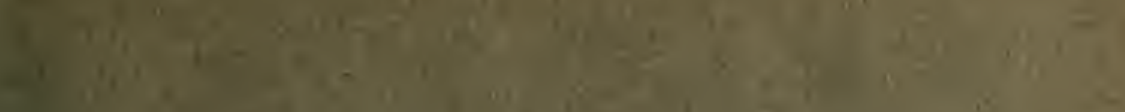

1.

(1)

1

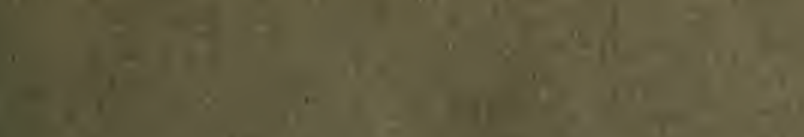

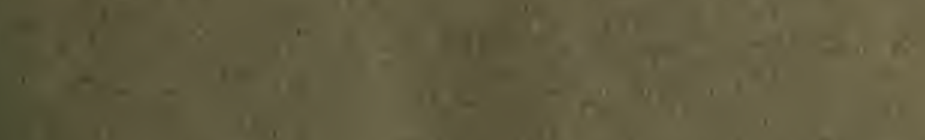

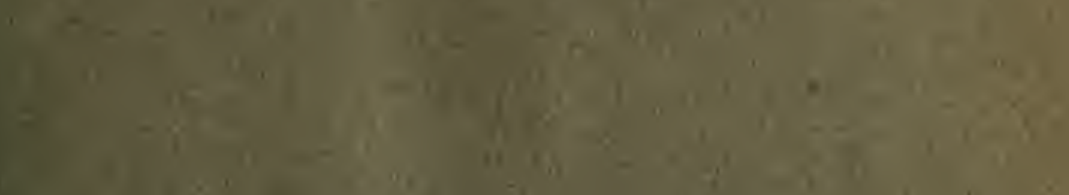

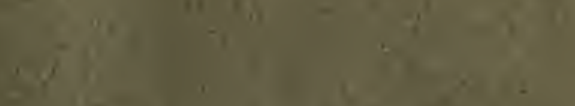

$+1$

8

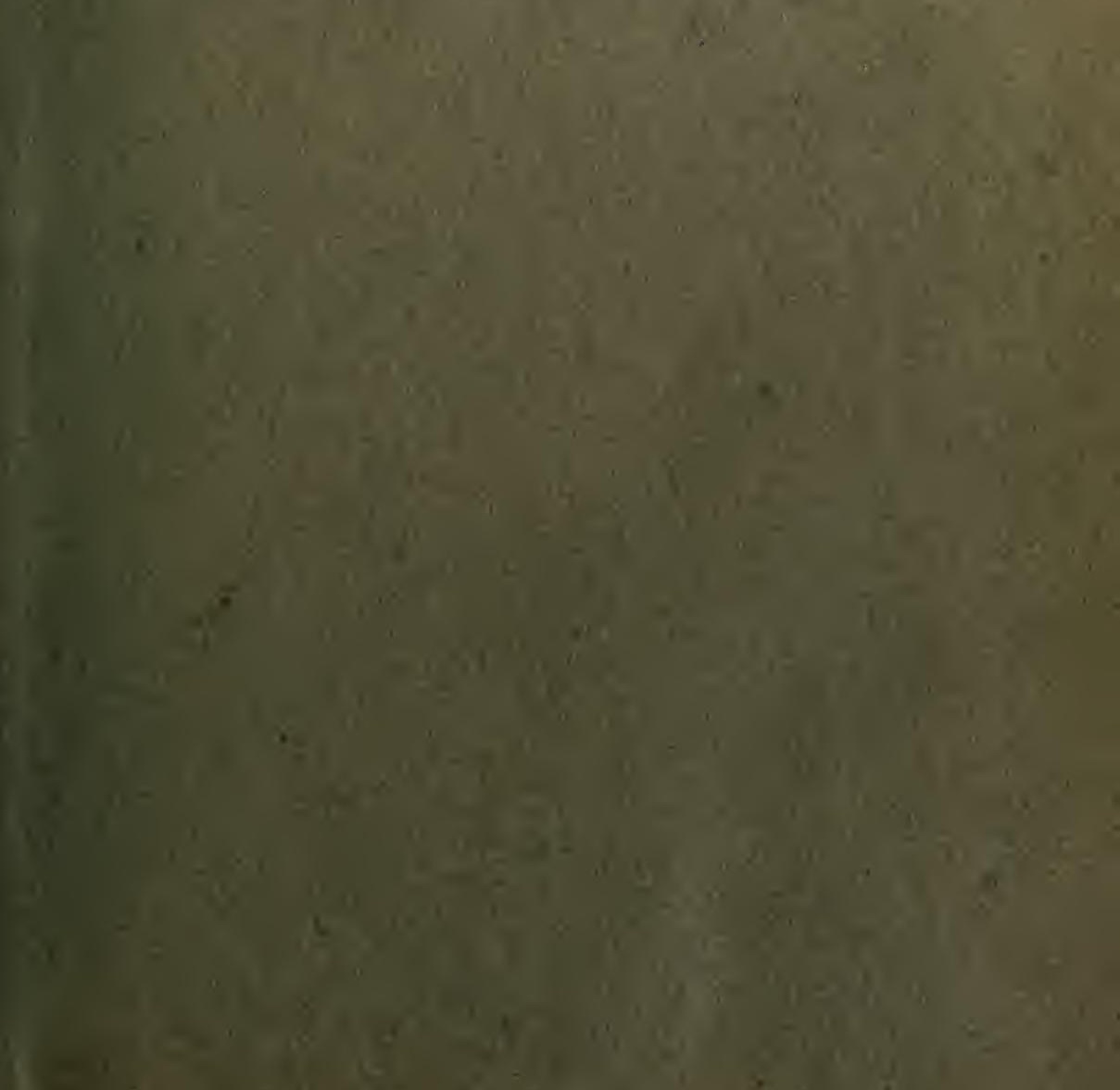


8

,

5.5 45

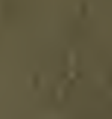

1)
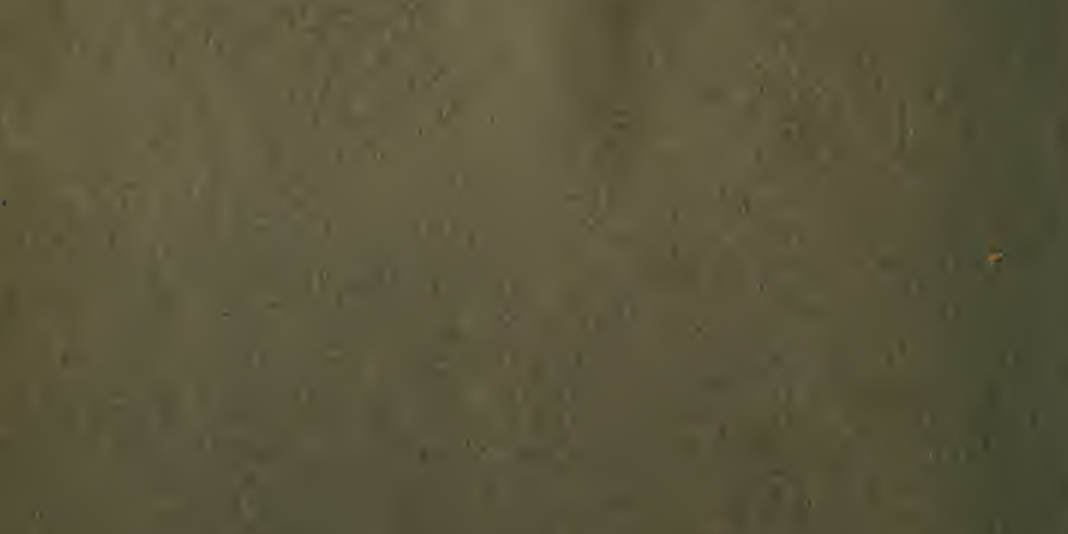


\section{THE CONTINENTAL ELEMENT IN THE FLORA OF SOUTH SWEDEN}

INAUGURAL DISSERTATION

BY

RIKARD STERNER

PHIL. LIC., KALM.

Reprinted from Geografiska Annaler 1922, $\mathrm{H} .3-4$. 



\title{
THE CONTINENTAL ELEMENT IN THE FLORA OF SOUTH SWEDEN
}

\author{
INAUGURAL, DISSERTATION \\ BY \\ R I K A R D S T E R N E R \\ Phir. Iic. Karm.
}

by due permission of the Philosophicas. Faculti, Nitural. Science Section, of the University of UPSAIA TO BE PUBLICly DISCUSSED AT THE IECTURE Hat. of THE Botanical Institution ON DECENBER I $3^{\text {TH }}$ I922, IT IO O'CLOCK A. M., FOR THE DEGREE OF DOCTOR OF PHILosophy.

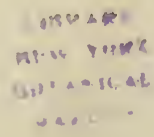





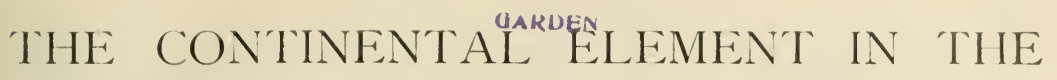 FLORA OF SOUTH SWEIEN.}

BY RIKARI) STER.VER.

\section{INTRODUCTION.}

The flora of the Middle European plain ${ }^{1}$ (as will be shown in detail in the course of this work) may with reason be regarded as being in a com-

1 paratively high degree homogeneous, if we consider the extent of the region and the heterogeneous geographical conditions within it. Among the breaks of uniformity that exist there should be noted the disappearance, towards the west of Europe, of species that are found in the east. The western limits of these continental species form a very pronounced characteristic of the flora of the central and western parts of Middle Europe.

An examination of the nature of these limits offers much that is of interest. The question as to whether there are other causes of the distribution of species than the existence of suitable localities becomes acute here in an interesting way. On the one hand, these species, which are widely distributed in continental districts, must have certain ecological features in keeping with the physical conditions in those regions; and it seems probable that certain species at any rate have ecological dcmands that would not have so many possibilities of satisfaction in maritime districts. On the other hand, the history of the Middle European flora during the Quarternary era tells us about various paths and dates of immigration and also about strong dislocations in the distribution of species, brought about by great changes in the climate and in the nature of the soil, which have been of specially great importance to continental species.

Much attention has been given to the western limits of continental species by phytogeographers. They have especially played a conspicuous part in discussions and examinations of the history of the Middle European flora.

The present work may be looked upon as a contribution to the analysis of the distribution of continental species in IVestern and Central Europe.

${ }^{1}$ Throughout the present work $I$ have made use of a distinction between the terms sMiddle Europes ancl Central Europe» as follows: Middle Europe comprises the European Boreal forest-zone south of the oak-limit; Central Europe comprises approximately the distribution area of Abies pectinata, the south-eastern parts of it excluded; thus it comprises Central and Eastern France, Central and South Germany, Switzerland, Austria, and Czechoslovakia.

16 Geografiska Annaler 1922. 
In Engler's survey of the flora districts of the world (Engler und Gilg 1912) South Sweden, in the north bounded by the northern limit of the oak or the sudden transition between the Central Swedish lowlands and the coniferous forestregion of Norrland, is for the most part classed with the Subarctic zone. Only its southernmost part is supposed to belong to the Middle European flora district. This part of South Sweden is divided between two different Middle European flora provinces. The south-western part (Skåne) is classed with a Subatlantic province of a maritime character, while the south-eastern part (Öland and Gotland) is classed with a Sarmatian province, attached to the Pontic province, which comprises the steppe districts of the South-East of Europe. This division indicates a continental-maritime dualism in the South Swedish flora. As a matter of fact, such a dualism in the flora must be looked upon as highly characteristic of almost the whole of South Sweden. The cleavage between a continental character and a maritime character, in fact, forms a highly conspicuous feature of the South Swedish flora.

The continental element in the South Swedish flora asserts itself distinctly. A comparatively great number of South Swedish species occur chiefly in the continental parts of Europe; and many of these species reach their definite western limits in South Sweden.

This feature of the South Swedish flora is in full agreement with the general geographical character of South Sweden as being a transition region between continental East Europe and maritime West Europe. This appears clearly in the climate.

The South Swedish climate, however, shows great irregularities in its continentalmaritime development. Topography - - in the first place the contrasts between the South Swedish highland ${ }^{1}$ and the surrounding lowlands - has a disturbing influence on the even transition from more continental to more maritime climate conditions in passing from the east to the west. Special stress should be laid on the comparatively strong development of the continental and maritime character which exists on the eastern and the western side of the highland respectively.

A close examination of the distribution of continental species in South Sweden will show how far they reflect the changes in the continental-maritime development of the countryside. Hence we get an opportunity of examining the importance of certain geographical factors for the distribution of species. Regarding the history of the flora and geographical conditions of former days we may at the same time get comparatively safe starting points. South Sweden would seem a very suitable area for a study of the distribution limits of continental species in Western Europe.

${ }^{1}$ In order to avoid a confusion with the Swedish province Uppland this may perhaps be regarded as the most suitable translation of "Sydsvenska höglandet». 
Hence in the first place the object of this study of the continental features in the South Sivedish flora has been to determine in detail the distribution of con tinental species in South Sweden and to explain the position of the limits as far as that is at present possible.

However, it should even here be pointed out that space does not permit me to treat the problems in as great detail as might have been desirable.

The study also purposes to give a contribution to the fixing of the position of the South Swedish flora in relation to that of the rest of Middle Europe. A pretty large space has therefore been allotted to a survey of the continental element in the Middle European flora; and the distribution and mode of occurrence of species in South Sweden have as far as possible been connected with the distribution and mode of occurrence in the rest of Middle Europe. I have considered it necessary to give this part of the study comparatively considerable space, as by far too little attention would seem to have been paid hitherto to non-Scandinavian relations in our floristic and phytogeographical investigations.

Some ten years ago, when I began my botanical studies at the University of Upsala, I had the great privilege of taking part in the work of the Plant Biology Seminar and of joining the flock of pupils that Professor RUTGER SERnander had gathered around him. This aroused my interest in the problems of phytogeography; and it is thanks to the excellent, suggestive and inspiring instruction which $I$ thus received that $I$ am now in a position to put forward some results of my own researches in phytogeography.

It is thus an agreeable duty to acknowledge in this place my great debt of gratitude to Professor Sernander.

I have very much pleasure in taking this opportunity of expressing my respectful thanks to my teacher in other branches of botany, Professor O. JUEL for the instruction I have received from him and for the kindness and interest he has shown in the pursuit of my botanical work. - I am also deeply indebted to Professor NiLs SvEDELius for botanical instruction and for the interest he has shown in my studies.

To several of my fellow-workers I am deeply indebted for much invaluable help in the working out of this study. In the first place I should like to mention Docent GunNar Saliuelsson, who, himself occupied with investigations in the sphere of taxonomic phytogeography, has given me a great deal of valuable advice and information.

To a large extent my work has consisted in the collection of information as to the distribution of certain species. In order to pursue these investigations a very considerable amount of material was necessary. It would have been impossible for me to procure sufficient material within a reasonable time if I had not received 
valuable assistance from a large number of persons: in fact, I have had the advantage of obtaining such help from more than a hundred persons. To all these 1 beg to express my warmest thanks for their great kindness towards me. Unfortunately space does not admit of my adding in this place a list of all these collaborators; but I hope to have an opportunity of doing so in a special part of this work which will appear before long. But I beg to mention with special gratitude some persons who have in a specially high degree made possible the present enquiry by permitting me to make use of their extensive, but still unpublishcd, lists of localities for large areas, namely: Docent G. SAmuelsson (Dalarne and Västmanland), Phil. Mag. ERIK Aluiquist (Uppland), Phil. Kand. HÅRD AV SEgerstad (western Småland, northern Skåne, and south-eastern Västergötland), Statsgeolog HaRAld Johansson (north-western Skåne, western Blekinge, certain parts of Vastergötland and Tjust etc.), and Telegratkommissarie C. E. Gustafsor (the Västervik district). The late Lector F. Ahlfvengren I hold in grateful memory for having permitted me to make use of his splendid list of plant localities in Halland, which has been placed at my disposal in manuscript.

In the laborious work of compiling lists of plant localities from museum herbaria several persons have had the kindness to give me assistance. I have to thank most warmly Professor Jens Holmboe (Bergen), Rolf Nordhagen, Ph. D., and Conservator Ove DAHL (Christiania), Conservator O. R. Holmberg (Lund), and Docent W. BRENNER (Helsingfors). I must also thank most cordially Lector J. A. \%. BRUNDin, who has gone through N. J. Scheutz's herbarium and lists at Växjö, and Phil. Stud. K. A. NANNFELDT, who has performed the tedious task of making a list of the plant localities in the comprehensive collection of the Linköping Botanical Society.

Mr. Selim Birger, Med. Dr., of Stockholm, has laid me under a deep debt of gratitude, by placing at my disposal his well-stored library of phytogeography and by giving me much good advice and information.

Professor HJ. HJELT, of Karkku, Finland, has earned my warmest thanks through his kindness in letting me see the as yet unpublished parts of „Conspectus FloraeFennicae».

A considerable amount of field work is included in this enquiry, carried out in the course of extensive journeys in different parts of South Sweden. These journeys have been rendered possible by liberal grants of money, for which I hereby return thanks to the following societies, associations and institutions: the University of Upsala (the Bjurzon Fund), the Royal Academy of Science, the Swedish Society for Anthropology and Geography (the Hedin Fund), the Society of Natural Science Students at Upsala and its Botanical Section.

I must respectfully express my thanks to the Swedish Society for Anthropology and Geography, and especially to its president, Professor GunNar Andersson, for valuable help and many facilities with regard to the printing of this work. 
Lector C. S. FEARENSIDE of Stockholm, who has revised and in part supplemented the translation of this work, I have also to thank for his advice and suggestions with regard to typographical details.

\section{CH.APTER I.}

\section{A few words about the history of taxonomic phytogeography and its present object and principles.}

When, at the beginning of the nineteenth century, phytogeography came up as an independent branch of botany, the distribution of species became a subject of keen interest. The investigators who paved the way for the new branch of science began to sum up the various single observations that had been made earlier relative to the distribution of species, and also to treat them from more general points of view. Men's views were widened with the aid of the numerous research expeditions to parts of the world thitherto unknown.

The lines along which the phytogeographers of that time were working are excellently brought out in the title of a work which perhaps may be designated as fundamental for all work achieved in the domain in question, viz. Alexander von Humboldt's $\gg$ De distributione geographica plantarum secundum coeli temperiem et altitudinem montium» (Paris 18r7). Consequently the object was to find out the correlation between the distribution of species on the one hand and the climate, more especially the temperature, on the other.

At the same time meteorology was in the midst of a grand development. The larger material in the way of temperature observations from widely separated parts of the world that was now being gradually placed at the disposal of scientists was subjected to a comparative study, isotherms could be constructed, and some definite idea of the general laws of the variations of temperature on the globe was obtainable.

The object of phytogeography was to try to explain the main features of the distribution of species and the general character of the flora by means of the knowledge gained about climate, especially about the variations of temperature. Later on, efforts were made to explain even more detailed problems regarding the distribution of species, especially with the help of the climate.

As other fundamental works on taxonomic phytogeography in this short introduction to be mentioned alongside the work of Humboldt are C. L. Willdenow's »Grundriss der Kräuterkunde», I79? (pp. 345 ff.), where we already find indicated several of the guiding lines for the research work of later times; and several works by Göran Wahlenberg (»Flora lapponica»1812, "Tentamen de vegetatione et climate Helvetiae septentrionalis" I813, "Flora Carpatorum principalium» 1814). 
During the twenties, thirties and forties of the last century a number of very important works appeared: Schouw's and Meyen's well-known synopses of the objects and methods of phytogeography; the problems of the causes of the distribution of species became a more universally treated as subject, as for instance in works by Heer (1835), Unger $(1836)$ and Thurmann (1849); in some works historical phytogeography began even to become visible (A. P. De Candolle, Heer).

The climax of taxonomic phytogeographical research, in the sense of Humboldt and Wahlenberg, was marked by the important activity of A. De Candolle and Grisebach at the middle of the nineteenth century. The latter may be said to have defined the views of the time most sharply.

Grisebach seeks the explanation of the distribution of species in now existing forces, known from experience (for instance, 1882, p. 200). He dismisses all "geological" causes for the present distribution of species, such as build on the "hypothesis» that the present flora has arisen out of an earlier one. The species have had the power of spreading their seeds over the area where they are to be found at the present time; and that area is limited by geophysical factors among which the climate is the most important one. Species may become extinct they may, for instance, be supplanted by other species - , and the extinction may take place with different rapidity in different parts of the area of distribution. In this way the disjunctive distribution of species is explained. - Grisebach was, as is well known, one of the foremost opponents of the evolution theory of Darwin.

Grisebach made detailed examinations of the distribution of species within minor areas. One of them is expounded in the work Ueber die Vegetationslinien des Nordwestlichen Deutschlands» (1847). It is in this book that Grisebach has perhaps exhibited most clearly his opinion as to the nature of the distribution limits of species. A couple of quotations from it ought therefore to be given here:

จ Sofern jene Grenzlinien den Vegetationscharakter der Gegend ausdrücken, welche sie umschliessen, nenne ich sie Vegetationslinien. Das Areal einer Pflanze hört also auf an ihrer Vegetationslinie. Fallen solche Linien in ihrer Lage mit climatischen Linien, z. B. mit Isothermen, mit Linien gleicher Temperaturextreme u. s. w. zusammen: so ist damit das Beweis geführt, dass in den hierdurch ausgedrückten climatischen Werthen die Ursache der örtlichen Begrenzung jener Gewächse liegt» (p. 465), and

»Diese regelmässige Gestalt der Pflanzenareale weist darauf hin, dass die Ursache der Vegetationslinien nicht in der Mannigfaltigkeit terrestrischer Bedingungen, sondern in den weit regelmässiger in bestimmten Richtungen wachsenden und abnehmenden, atmosphärischen Abstufungen liegt, welche die allgemeinen Erwärmungsgesetze der elastischen Hülle des Erdkörpers hervorbringen und wovon die Meteorologie durch ihre mittleren, climatischen Werthe Rechenschaft giebt.» 
In the book mentioned (for instance, on p. 562), however, Grisebach has pointed out that some species might be so young that they have not yet attained their full area.

In his later works Grisebaci has to some extent changed his opinion. In $\gg$ Die Vegetation der Erde" (1872) he says (p. 76): »Die Vegetationslinien entsprechen denmach nicht immer dem Verlauf bestimmter klimatischer Grenzwerthe, sondern dem \%usammenwirken mehrerer", and he points out that certain limits of distribution are »nicht bloss durch die Lage der Vegetationslinien, sondern zugleich durch Lntersuchungen über die Lebensbedingungen der einzelnen Arten zu erledigen» (p. 98).

Here attention may be drawn to a work of considerably later date, W. Koeppen, "Versuch einer Klassifikation der Klimate, vorzugsweise nach ihren Beziehungen zur Pflanzenwelt» (1900). Types of climate are in this work distinguished in accordance with the distribution of species and the character of the flora.

Even so early as the middle of the nineteenth century a new tendency appeared in floristic phytogeography. It is characterized by the view that many phenomena in the present distribution of species cannot possibly be explained solely by the aid of forces now existing; great importance must be attached to geological causes.

E. Forbes and the above-mentioned A. De Candolle must be looked upon as the originators of this trend of opinion. By studies in the flora of Great Britain Forbes had (1846) found a great number of disjunct areas, a fact which, he thought, could only be explained by the areas having been split up by revolutions in the distribution of water and land or by changes in the climate. Species might be relics of an earlier flora, and their present distribution is connected with the former one and that of their nearest forefathers; hence there are geological causes for the present distribution. ${ }^{1}$

In a somewhat modified form Forbes's opinion became prevalent during the latter part of the nineteenth century, and it may be said to be the opinion of the present day too. During that time Quarternary geology and palaeontology have passed through a grand evolution. The great results attained in these domains have naturally been able to clear up many obscure phytogeographical problems; and taxonomic phytogeography has of course been to a great extent concentrated on studies of the connection between the present distribution of species and their phylogeny or earlier geographical conditions.

Thus, the possible geological causes of the limits of distribution have above all attracted interest and have been accorded the greatest importance. In this connection, in fact, it may justly be said that phytogeography has many a time assumed a much too theoretical and speculative tendency. At the same time, however, a great number of new and valuable experiences have been made. Be-

\footnotetext{
1 As regards the divergent opinions of Forbes and Grisebach see further, for instance, Kerner I $\$ 79$.
} 
sides numerous facts concerning the history of the flora we may mention comprehensive examinations of the means of dispersal of plants, made by, for instance, Hildebrand (1873), Kerner (1863 and 1871), and Sernander ("I901 a》 and 1906) (see Sernander 》IgoI as). Through the contest between the different opinions as to the importance of the chemical composition of the ground and its physical structure, valuable observations have been made regarding the connection between the nature of the ground and the distribution of species (e. g. Kraus 1911). With the work of the last few decades within plant sociology attention has also been drawn to the fact that in their appearance in nature species may be so dependent one on another, that they have no opportunity of reacting freely against the outer world; the struggle for space between species may decide the distribution.

The continued research work on the distribution of species should probably, in the first place, be concentrated on close examinations of the distribution areas within minor regions, particularly such as are touched by important distribution limits. It seems to me that the investigations regarding causes of distribution should be carried out in accordance with the following formulation of the problem: To what extent is the distribution of species determined by their ecology? What factors have been able to prevent the species from attaining an area corresponding to their ecological demands?

The paths we have to follow in order to attain this object may be summarized as the following ones:

1. An examination of the present distribution, which ought to be as detailed as possible, especially in the limit districts of the distribution areas;

2. An examination of the species concerning their mode of occurrence in nature, their synecology, hence their sociology and their ecological demands, and, in connection with this, an analysis of the distribution in nature of suitable localities;

3. An examination of the dispersal-capacity of species;

4. An examination of the history of the flora;

5. An examination of the connection between the distribution of species and the influence of human activity on vegetation.

In order fully to carry out an investigation from these points of view, a thorough knowledge of the biology of the species and the history of the flora is necessary. Concerning these questions, however, our present knowledge suffers from great gaps. Our goal is still very distant. What should in the first instance be done is to determine the distribution of species and to study their mode of occurrence in nature. 
CHAPTEK II.

\section{Survey of the continental element in the European flora}

\section{Definition of the continental element.}

The contincntal element in the European flora is formed of such species as have a great distribution in Lastern liurope, and towards the West sooner or later reach their limits of distribution.

It should be pointed out that continental species are thus distinguished solely with regard to their distribution. No attention is here paid to what is from an ecological standpoint a continental character or to a possible immigration from a more continental district.

Continental species may be very different with regard to their distribution in Siberia. The distribution in Europe, especially the situation of the western limits, however, have hardly any direct connection with the possible Siberian distribution, so that may here be left aside. (Yet compare later on the "Siberian" species). - Species distributed only in sub-Arctic or Arctic parts of East Europe are not here included.

Naturally the continental element does not form any sharply defined part of the European flora. Through numerous transitions the continental types of distribution are connected with several others: the (South- and) Middle European type, the South European and Central European ones etc. Above all it is difficult to separate continental species from those evenly distributed in South and Middle Europe. I have found it most expedient to take the word "continental in the widest possible sense. Thus below are also included species that reach their western limits in Western Europe, in Norway, Denmark, North-Western Germany, Belgium, France, and South-Eastern England. Common to these species is above all the wide distribution in Eastern Europe.

\section{The continental element in the flora on the Middle European plain.}

In order to show to some extent the part played by the continental element in the European flora an examination will be made into the strength of the continental feature in different parts of that flora region which may be styled $»$ The Middle European plain» (Balticum» in accordance with Drude, e. g. 1890). Further we shall attempt to make an examination of the sociological appearances of different species within the same district.

The Middle European plain, taken as a flora district, comprises Middle Europe rom Eastern Russia in the east to the Welsh and North English mountain districts in the west, and from the limit of the oak in the north to Central France 
Tablc $I$. A comparison between the floras in certain

\begin{tabular}{|c|c|c|c|c|c|c|c|c|c|}
\hline \multirow[b]{4}{*}{ Kazan } & \multirow{3}{*}{$\begin{array}{c}\text { Total number } \\
\text { of species in } \\
\text { the special } \\
\text { districts }\end{array}$} & \multirow{2}{*}{\multicolumn{2}{|c|}{ Kazan }} & \multirow{2}{*}{\multicolumn{2}{|c|}{ Moscow }} & \multicolumn{4}{|c|}{ Number of species } \\
\hline & & & & & & Livon & & West Pri & ssia \\
\hline & & $\begin{array}{c}\text { Total } \\
\text { number }\end{array}$ & $\%$ & $\begin{array}{c}\text { Total } \\
\text { number }\end{array}$ & $\%$ & $\begin{array}{c}\text { Total } \\
\text { number }\end{array}$ & $\%$ & $\begin{array}{c}\text { Total } \\
\text { number }\end{array}$ & $\%$ \\
\hline & 774 & & & 685 & 89 & 612 & 79 & 653 & $s_{4}$ \\
\hline Moscow & 861 & 685 & so & & & 689 & 80 & 746 & $s_{7}$ \\
\hline Livonia ...... & 846 & 612 & 72 & 689 & $S_{I}$ & & & 782 & 92 \\
\hline West Prussia & 1,036 & 653 & 63 & 746 & 72 & 782 & 75 & & \\
\hline Silesia .......... & 1.104 & 620 & $5^{6}$ & 730 & 66 & 760 & 69 & 946 & $\$ 6$ \\
\hline Brandenburg & 1,059 & 631 & 60 & 715 & 68 & 765 & 72 & 945 & 89 \\
\hline South Sweden. & 940 & $5^{80}$ & 62 & 620 & 66 & 777 & $8_{3}$ & 845 & 90 \\
\hline IVestphalia ......................... & 934 & $55^{\circ}$ & 59 & 610 & 65 & 662 & 71 & So5 & 86 \\
\hline Northern France...................... & 1,103 & 515 & 47 & 605 & 55 & 647 & 59 & 778 & 71 \\
\hline South-Eastern England ............... & 975 & 490 & 50 & 545 & 56 & 629 & 65 & 744 & 76 \\
\hline
\end{tabular}

and the uplands of Middle Germany, the Carpathians, and the South Russian steppe district in the south.

The flora region, thus delimited, may seem rather heterogeneous; several important forest trees, for instance, reach their boundaries within these regions, such as beech, Scotch pine, spruce, hornbeam, Ulmus foliacea Gilib., Acer platanoides etc. In order further to examine the degree of homogeneity of the flora, and to find out to what extent possible lack of uniformity is to be traced back to the heterogeneous distribution of continental species, a comparison will be made between the floras of certain special districts in different parts of the region.

The special districts examined and the taxonomic works used in the examination are as follows:

1. The government of Kazan: Korshinsky 1898.

2. The government of Moscow: Herder 1892, Petunnikov 1896-I9oI.

3. Livonia (with Polish Livonia): Lehmann 1895 and 1897.

4. West Prussia: Ascherson und Graebner I898-1899.

5. Silesia: Fiek 1881 .

6. Brandenburg: Ascherson und Graebner 1898-1899.

7. South Sweden: Lindman 1918.

8. Westphalia: Beckhaus 1893 .

9. Northern France (the departments of Somme, Pas de Calais, Nord, Ardennes, and Aisne): Acloque 1903.

10. South-Eastern England (bounded on the west and on the north by an approximate line: Dorset - Nottingham - the mouth of the Humber; compare 
special districts on the Middle European plain.

\begin{tabular}{|c|c|c|c|c|c|c|c|c|c|c|c|c|c|}
\hline \multirow{2}{*}{\multicolumn{12}{|c|}{ common to two special districts }} & \multirow{3}{*}{\multicolumn{2}{|c|}{$\begin{array}{l}\text { Number of conti- } \\
\text { nental species in the } \\
\text { special districts }\end{array}$}} \\
\hline & & & & & & & & & & & & & \\
\hline \multicolumn{2}{|c|}{ Silesia } & \multicolumn{2}{|c|}{ Brandenburg } & \multicolumn{2}{|c|}{ South Sweden } & \multicolumn{2}{|c|}{ Westphalia } & \multicolumn{2}{|c|}{$\begin{array}{c}\text { Northern } \\
\text { France }\end{array}$} & \multicolumn{2}{|c|}{$\begin{array}{l}\text { South-eastern } \\
\text { England }\end{array}$} & & \\
\hline $\begin{array}{c}\text { lotal } \\
\text { number }\end{array}$ & $\%$ & $\begin{array}{c}\text { Total } \\
\text { number }\end{array}$ & $\%$ & $\begin{array}{c}\text { Total } \\
\text { number }\end{array}$ & $\%$ & $\begin{array}{c}\text { Total } \\
\text { number }\end{array}$ & $\%$ & $\begin{array}{c}\text { Total } \\
\text { number }\end{array}$ & $\%$ & $\begin{array}{c}\text { Total } \\
\text { number }\end{array}$ & $\%$ & $\begin{array}{c}\text { Total } \\
\text { number }\end{array}$ & $\%$ \\
\hline 620 & 80 & 631 & 83 & 5So & 75 & 550 & 71 & $5^{15}$ & 67 & 490 & 63 & 283 & 36.6 \\
\hline 730 & 85 & 715 & $8_{3}$ & 620 & 72 & 610 & 71 & 605 & 70 & 545 & 63 & 230 & 26.6 \\
\hline 760 & 90 & 765 & 90 & 777 & $9 \mathrm{I}$ & 662 & 78 & 647 & 76 & 629 & 74 & 135 & 16 \\
\hline \multirow[t]{2}{*}{940} & $9 \mathrm{I}$ & 945 & 91 & $8_{45}$ & 81 & 805 & $7 \mathrm{~S}$ & 778 & 75 & 744 & 72 & 187 & 18 \\
\hline & & 970 & ss & 800 & 72 & $\mathrm{~S}_{20}$ & 74 & 847 & 77 & 725 & 66 & 195 & 17.7 \\
\hline 970 & 91 & & & $\$ 49$ & 80 & $s_{56}$ & 80 & 835 & 79 & 778 & 73 & 160 & I $5 \cdot x$ \\
\hline 800 & 85 & $8+9$ & 90 & & & 720 & 77 & 788 & $8_{4}$ & 690 & 73 & 115 & 12.2 \\
\hline 820 & 88 & $8_{5} 6$ & 92 & 720 & 77 & & & 848 & $9 \mathrm{I}$ & 735 & 79 & 70 & $7 \cdot 5$ \\
\hline $8_{47}$ & 77 & 835 & 76 & 788 & 71 & 848 & 77 & & & 908 & 82 & 54 & 4.9 \\
\hline 725 & 74 & 778 & 80 & 690 & 71 & 735 & 75 & 908 & 93 & & & 12 & 1.2 \\
\hline
\end{tabular}

the map of the soil-types in Ramann I9II, p. 56I): Hooker I884, Watson 1883 - Of the provinces into which Watson has split up Great Britain, those he names Channel, Thames, Ouse, and Trent form the district in question.

In the statistics all those species have been excluded whose occurrence is decidedly dependent on the activity of man; that is to say, all casuals, all introduced and naturalized species and all species that occur only in cultivated fields, at roadsides and in other waste places etc. ("aliens", "colonists» and so on). Naturally it is sometimes difficult to judge if a species has been introduced by man, or if it is a real native, solely by means of the statements of floristic works. Hence the statistics cannot claim complete exactness. Some uncertainty in the calculations is also caused by the different modes of treatment of critical groups of species in different floristic works. To get the numbers of species as comparable as possible, the species have in such cases been taken very collectively, or they have been quite excluded.

The statistics have been brought together in Table $\mathrm{I}$, where there is also a list of the number of continental species in the special districts. From this table it appears in the first place that there is a probably unexpectedly great coincidence between the floras of the special districts. In most cases the percentage of species common to two special districts keeps between 70 and 90 , only in six cases does it sink below 6o. Furthermore the comparatively great uniformity is shown by the number of species common to all the districts, which has been found to be about 435 , forming $25 \%$ of the total number of species; it is also scen from the fact that the number of species occurring only in one special district is only 230 (Kazan 58, Moscow I3, Livonia I, West Prussia 4, Silesia 27 , 
Brandenburg 7, South Sweden I3, Westphalia I I, Northern France 40, SouthEastern England 57).

The defects in the uniformity appear most evidently in a comparison between the East and the West European districts. The continental and maritime elements stand out clearly. A Central or a South European flora element, however, can also easily be distinguished.

How far are the defects in the uniformity caused by the unequal distribution of continental species? A comparison between the East and the West European floras shows that the species in the former are fewer in number than those in the latter. This indicates that continental species are inferior in numbers to maritime ones. The central districts, where both elements are represented, have generally many more species in common with the West European districts than with those of East Europe. Hence the maritime element in these districts is preponderant.

The table also shows the number of continental species in each special district. It may be stated that many species in a certain district lacking in a more westerly one belong to continental species. Silesia has 284 species that do not occur in Westphalia, and of these 125 are continental. As the continental species of a more westerly district are generally found in a more easterly one, we are able to get a more exact idea of the rôle of the continental element, compared with others. If we compare the flora of Silesia with that of South Sweden, we shall find that the chief difference is not to be traced back to the continental element. In spite of this it cannot be denied that this element is rather conspicuous. Silesia has 304 species that do not occur in South Sweden, and of these 75 are continental. When the districts are situated in an almost straight easterly-westerly line from one another, the rôle of the continental element is naturally greater. As regards Silesia and Northern France, for instance, we get the figures 257 and I4I. But the number of species in the South Swedish flora which are not found in that of Northern France, is to no small degree formed by continental species: viz. 66 species out of 152 .

The total number of continental species in the districts is probably about 350 , i. e. $20 \%$ of all the species of the districts. The number of continental species in the whole of the region in question, in fact, the whole of Middle Europe, Czechoslovakia and Austria excluded, is probably not very much greater. For Hercynia (i. e. the whole of Central Germany, according to Drude, 1902), where the continental flora is well represented, we get only 25 species that are to be looked upon as new; and for Central Kussia Herder includes only 40 species not counted before. A few new species may be added, but the whole number of them will hardly exceed 80 . Hence in this part of Middle Europe the flora counts about 430 continental species. 
In order to furnish an idea of the way in which the continental species occur in the vegetation, five of the above-mentioned special districts have been investigated in order to show how continental species are represented in different types of vegetation.

The statements in floristic works regarding the mode of occurrence are the only material that can be obtained for these statistics. Hence the types of vegetation must be units of a very high rank: they are the main types of the regetation. They have been delimited with regard to the existence and strength of continental features in the character of the vegetation, above all the xeromorphous structure and the heliophily of the species.

The types of vegetation are as follows:

1. Yerophilous herb and grass associations: steppe associations, the 》Trift-formation», "rock-ground associations», "herb» or "grass heaths», » waste herbage» etc.

2. Open Scotch pine forest associations on dry sandy soil with a ground vegetation of sand-grass beaths, often rich in herbs. (This type of vegetation seems to have a decidedly continental distribution. Sand-grass heaths, rich in herbs, reach farther west.)

3. Open xerophytic foliferous forest and bush associations: "Steppe woods", "rock-ground woods", dry wood-edges, scrub associations (Swed. »backsnår») and so on.

+. Mesophytic grass and herb associations: flood meadows, certain cultivated meadows.

5. Closed coniferous forests (especially Scotch pine forests): coniferous forests rich in mosses and undershrubs.

6. Mesophytic foliferous forests with not very shady wood-layer: birch-, aspenand oak-forests, mesophytic wood-edges, forests of type 7 thinned by human activity.

7. Mesophytic foliferous forests with heavily shady wood-layer: beech-forests, certain mixed deciduous forests: "groves», Swed. »lundar», Germ. »Auenwälder», „Gemischte Laubholzformationen der Niederung und Hügelregion» Drude 1896, „Der mitteleuropäische Eichenmischwald» Sernander 1906, p. 372; Hayek 1916, and so on.

8. Helophytic grass and herb associations: marsh associations. Here are also the reed associations to be placed (compare Warming 1909).

9. Aquatic associations: associations of freely swimming species or of species whose assimilatory organs are submerged (compare Warming 1. c.).

10. Moor-associations: Sphagnum-moors, forest-moors (compare Warming 1. c.).

The statements of floristic works have not always furnished sufficient information, and consequently the statistics cannot claim complete accuracy. - The same species can, of course, form part of more than one type of vegetation. In such cases the species have been placed with the type where their normal existence seems to be. Some species, however, have been placed with two types. 
Table 2. The mode of occurrence of continental species in some special districts on the Middle European plain.

\begin{tabular}{|c|c|c|c|c|c|c|c|c|c|c|}
\hline \multirow{2}{*}{ Special districts } & \multicolumn{10}{|c|}{$\begin{array}{l}\text { Number of continental species in the ten types of vegetation, } \\
\text { described on p. } 233 .\end{array}$} \\
\hline & 1 & 2 & 3 & 4 & 5 & 6 & 7 & 8 & 9 & 10 \\
\hline Kazan & ${ }^{1} 3^{1}$ & 30 & 30 & 45 & 8 & $4^{2}$ & 27 & $2 \mathrm{I}$ & 4 & 3 \\
\hline Silesia & 75 & 25 & 25 & 25 & s & 25 & 29 & 17 & 4 & I \\
\hline South Sweden & 42 & 16 & 18 & I0 & 6 & 12 & 15 & 14 & 2 & 1 \\
\hline Westphalia...... & 34 & 5 & 8 & 2 & 2 & 12 & 6 & 12 & $\ldots$ & - \\
\hline South-East England ... & 8 & 3 & 1 & - & - & $\mathbf{I}$ & - & 2 & - & - \\
\hline
\end{tabular}

Table 2 shows the summary. From this it follows:

I. that the continental element has representatives in all the types of vegetation set up;

2. that - naturally - the great majority of species belong to the steppe or steppe-like vegetation. The few continental species of the western districts belong to a great extent to this type;

3. that out of the comparatively small number of species belonging to other types of vegetation, some (particularly those of the types 6 and 8) are found in a considerable part of the continent of Middle Europe, while others (especially those of the types 4,9 and Io) seem to have a conspicuously easterly distribution.

The great number of continental species of the type 7 may be remarkable. The type of forests in question has another character in more maritime parts of Middle Europe than in Central and East Europe. Certain trees that are important in the Central and East European mixed oak forests, are missing in western Europe, and in the ground vegetation this type of forests has several continental species which are so physiognomically conspicuous as to give it a special character (e. g. Anemone hepatica and ranunculoides, Corydalis-species, Gagea-species, Pulmonaria-species, and Viola mirabilis). On the other hand, several of the species characterizing the ground vegetation in the West European type have a more maritime distribution (e. g. Euphorbia amygdaloides, Carex laevigata, Lysimachia nemorum, Potentilla sterilis, Scilla non-scripta, Teucrium scorodonia, Veronica montana, Vinca minor). Moreover it should be pointed out that, from a biological point of view, some of the continental species occupy a separate position. They are early spring plants and are consequently adapted to a short vegetative season. The peculiar biology of these species has been treated by Hesselman 1904 (see, e. g., p. 451 ) and Sernander 1906 (pp. 381 ff.) among others. 
Here it will only be pointed out that the species, like other continental species, are rather heliophilous: that is to say, the most important of the life manifestations of the species take place at a time when the intensity of light is at its height, before the trees are covered with leaves and the shade has become too strong. It is remarkable that, in accordance with this, certain of the species may be comparatively widely spread in the South-East European steppe districts, where they are found in the thin »steppe woods» or steppe-scrubs (see, e. g., Alechin 1909 and I9ro).

The early flowering "grove» plants without continental distribution are chiefly species that reach far up into alpine regions, where they form part of an unshaded or hardly shaded ground vegetation.

\section{Survey of the distribution of continental species in Europe.}

With the great range here given to the continental element, the species belonging to it will show important differences in their distribution. A great number of continental types of distribution may be distinguished.

A grouping of continental species according to their general European distribution meets with great difficulties, transition types always being numerous. A primary ground of classification, which may a priori seem suitable, is the distribution of the species in East Europe: does it here belong to the steppe districts, or does it exist chiefly in the Central and North Russian forest district? This topographical classification would coincide fairly well with one founded on the mode of occurrence and would naturally involve considerable differences with regard to the distribution of the species in other parts of Europe also. I have decided to use this as a primary ground of classification. Hence in the first place we get a group of southerly species, which we style meridional, and a group of northerly ones, styled Boreal.

The latter, however, might vary much with regard to the extent of the distribution towards the north. Hence a division of the group into two would be necessary. One of these groups would comprise species whose northern limit of distribution coincides with that of the oak, the other would comprise species widely spread even in Subarctic Russia (in Engler's sense of the term). The former might be called Euboreal, the latter Subarctically Boreal.

The meridional species belong chiefly to the steppe vegetation. Among other types of vegetation represented in this group, the flood meadows should be specially pointed out. These are very conspicuous along the South Russian rivers and have a peculiar flora (e. g. Krassnov 1887, 1889; Kuznecov, 1901). The boreal species belong to a large number of vegetation types, in the first place forest associations of various kinds and marsh associations. 
Naturally no sharp border can be established between the meridional and the boreal species, as forest-oases occur in the whole of the steppe district as well as steppe-like associations in edaphically suitable localities, such as calcareous hillsides and rocky escarpments facing south high up in North Russia. (See especially Pohle 1903 and Korshinsky 1886 and 1888). It should also be noticed that steppe species have in a considerable way extended their range in Central Russia, thanks to the woods being cut down or thinned by the hand of man. (See, e. g., Flerov 1902.) As a matter of fact, there are also a considerable number of species that are so evenly distributed that it would be impossible to class them with either the meridional species or with the boreal ones. It will therefore be necessary to set up two more groups: One comprises species that are comparatively evenly distributed in the oak-zone of the boreal district and the steppe region; the other comprises species that are widely distributed in Subarctic Russia also. The former may be called Meridio-Boreal, and the latter Ibiquitous.

Besides these five main groups now mentioned there is yet another of quite a different character. It consists of species with their chief distribution in continental Siberia. They do not occur in Eastern Europe, but have a few very isolated occurrences or small areas of distribution in other parts of Europe, above all Central Europe. This group of species may be called Siberian.

Hence continental species might in the first instance be classified as follows:

I. Meridional species: in Eastern Europe chiefly distributed in the steppe zone.

II. Meridio-Boreal species: in Eastern Europe distributed in the steppe zone and the oak zone.

III. Euboreal species: in Eastern Europe distributed in the oak zone.

IV. Subarctically Borcal species: distributed throughout Eastern Europe north of the steppe districts.

V. Ubiquitous species: distributed in almost the whole of Eastern Europe.

VI. Siberian species.

It should be of interest to see how the species in a district on the boundary between the Russian steppe and forest districts are divided between these groups. An analysis of the Choripetalae in the flora of the comparatively well-explored government of Kazan gives the following results:

Meridional species: 67 .

Meridio-Boreal species: 43 .

Euboreal species: 29.

Subarctically Boreal species: about 20.

Ubiquitous species: about 125 .

The great number of ubiquitary species is remarkable. A pretty conspicuous characteristic of the East European flora is the fact that ubiquitary species are 
so numerous compared to those in Western Europe. The comparatively small number of Euboreal species is also remarkable. The reason is that the oak zone in the government of Kazan has a very scanty extent, squeezed in as it is between the coniferous forest district in the north and the steppe region in the south.

For the present, however, it would not seen possible to carry through the division of the flora of continental Europe amongst the main groups mentioned above. Our knowledge of the northerly limit of the species in the north of Russia is far too defective in many cases to render such a course possible. Consequently it seems to me not to be expedient at present to attempt to distinguish between a Meridio-Boreal and a Ubiquitous group, or between a Boreal and a Subarctically Boreal group. In what follows, therefore, I shall make use of only the following main groups:

I. Meridional species: in Eastern Europe mainly distributed in the steppe regions.

II. Meridio-Boreal species: in Eastern Europe abundantly distributed both in the steppe regions and in the forest region of central (and northern) Russia.

III. Boreal species: in Eastern Europe distributed mainly in the forest region of central (and northern) Russia.

IV. Sibirian species.

As appears from the following pages, however, I have endeavoured to takc into consideration the far from uniform range of the species towards the north in Russia in the laying down of distribution-types.

According to the character of the distribution outside Eastern Europe the species of each of the first three groups may be divided between different $1 y p e s$ of distribution.

For the distinction and naming of the distribution-types I have discriminated a number of phytogeographical districts in Europe and tried to name the distribution-types as briefly as possible after the district or districts comprised in the distribution. I. have discriminated the different flora districts in agreement with Engler's system (Engler und Gilg, 1912). In certain districts of minor interest from the present point of view I have simplified the system, and in a few cases I have used areas otherwise delimited.

The flora districts from which I have thus delimited and named the types of distribution are the following:

Pontis: The South Russian steppe district and the plains of Hungary and of the northern part of the Balkan Peninsula.

Dacia: about the lower regions of the East-Carpathians and the North Balkan highlands.

Danubia: the plains of Hungary and the northern part of the Balkan Peninsula, especially Rumania.

17 Geografiska Anualer 1922. 
Sarmatia: Middle Russia, between the steppe district in the south and about the northern limit of the oak in the north; southernmost Finland, Estland, Lettland, Lithuania, and Poland; the North German plain to about the line from the West Prussian-Pomeranian border to the Harz; South East Sweden (Öland, Gotland, north-castern Småland, Falbygden, Östergötland, eastern Närike, Södermanland, southeastern Västmanland, and Uppland; about this see further later on Chapt. xii). This area corresponds to Drude's »die ostbaltische Waldregion» (Drude, for instance, 1890, p. 373 ).

Subatlantis: The North German plain west of Sarmatia, in the south to the line Harz-Luxemburg; Holland, Denmark with its islands, South-West Sweden and the lower parts of South Norway. (In his »West Baltic region» Drude also includes Belgium, and northern France down to Brittany and a large part of Great Britain, all of which Engler includes in his »Atlantic province».)

Balticum = Sarmatia + Subatlantis. (Hence not quite the same sense as Drude, I890, gives the term.)

Central Europe: Central and eastern France, Switzerland, Germany south of the Balticum, Austria, and Czechoslovakia. The higher mountain regions are excluded.

Hercynia: in the extension Drude gives it (Drude 1902).

Cassubia: the western part of Sarmatia in the East to the Dnjepr and the Valdai-hill.

South Europe: the South European Peninsulas and south-eastern France.

As has been mentioned, I have not considered it possible at the present time to lay down special types of distribution for the species which have a wide distribution in the north of Russia north of the oak-limit. Nevertheless I have provisionally laid down variants of distribution types in respect of such species as in all probability have such a distribution.

The types of distribution I have considered myself able to establish for continental species are as follows: ${ }^{1}$

I. Meridional species.

I. Pontic distribution.

a. for instance, Astragalus austriacus L., Ranunculus illyricus L. (map 1, Plate 13), Plantago tenuiflora W. \& K. (map 2, Plate 13).

b. The Danubian variant, for instance, Andropogon gryllus L., Iris arenaria IV. \& K., Astragalus exscapus L., Lactuca quercina L.

c. variants forming transition types to the Pontic-Central European and the Ponticosarmatian - Central European type, for instance, Hypericum elegans Steph. (Pontic-Hercynian variant), Silene chlorantha Elrh. (Pontic-

1 The maps $1-20$ mentioned in the following, drawn in order to exemplify the types of distribution, are to be found in Plates $13-22$ at the end of the paper. 
Cassubian variant), Adonis vernalis L. (map 3, l'late 14), and Oxytropis pilosá (L.) DC:

2. Dacian distribution: this type occupies a more isolated position in comparison with the former one, thanks to the fact that the species do not exist in steppe districts, for instance, Syringa vulgaris L., Tilia argentea Desf., Rhus cotinus L.

3. Pontic-South European distribution, for instance, Stipa capillata L. (map 4, Plate I 4 ).

4. Pontic-(South and) Central European distribution, for instance, Melica ciliata L. (= M. nebrodensis (Parl.) A. \& Gr.), Aster linosyris (L.) Bernh.; Poa bulbosa L. and Holosteum umbellatum L., which are widely spread by the agency of man.

5. Some species, occurring on salt steppes and sea shores, may be said to have a P'ontic-Subatlantic distribution, for instance, Bassia hirsuta (L.) Aschers. (map. 2, Plate 13), Atriplex pedunculatum L.

II. Meridio-boreal species.

1. Pontic-Sarmatian distribution, for instance, Asperula aperina M. B. (comp. Kupffer 1905), Campanula sibirica L. and bononiensis L., Evonymus verrucosa Scop., Geum aleppicum Jacq. (comp. Kupffer), Hieracium echioides IV. \& K.

b. The Subarctically variant, for instance, Silene tatarica (L.) Pers. (comp. Kupfer), Centaurea phrygia L. - Ranunculus cassubicus L. (map 5, Plate 15 ) might belong to this group, though it, being a wood species, is not very abundant in the steppe zone.

2. Ponticosarmatian-(South and) Central European distribution, for instance, Asperula tinctoria L. (map 6, Plate 15) which follows I: I c, Veronica spicata L. (map 7, Plate 16), Trifolium montanum L. and alpestre L., Lavatera thuringiaca L., Carex praecox Schreb. (schematic map in Sterner 1921 a. At the present time the species is also recorded from Finland; Medd. Soc. Fauna et Flora fenn., 13d 47 (I92I), p. 47). Melampyrum nemorosum L. (map 8, Plate I6) and Crepis praemorsa (L.) Tausch (map 9, Plate 17 ) resemble type III: 2 through their comparatively scant distribution in steppe districts; Anemone silvestris L. (map 10, Plate 17) forms a transition to the following variant $\mathrm{c}$ through its occurrences in Subarctic Russia. b. Some species differ in having a distribution area in lirance stretching farther west, such as, for instance, Phleum Boehmeri Wib. (map i i, Plate 18), Cynanchum vincetoxicum (L.) Pers. (map i 2, Plate I 8), Prunella grandiflora Jacq., Vicia tenuifolia Roth.

c. The Subarctically variant, for instance, Delphinium elatum L. and Geranium palustre $\mathrm{L}$. which in the Subarctic region occur only in northern 
Russia. Viola rupestris Schm. and Veronica longifolia L., which occur in almost the whole Subarctic Europe. Ranunculus polyanthemos L. and Heracleum sibiricum L., which form transition types.

3. Pontic-Baltic distribution, for instance, Ononis hircina Jacq. (= arvensis L.) (map 13, Plate 19), Sonchus palustris L.; Koeleria glauca (Schkuhr) DC. differs through isolated occurrences in western France (see Domin, 1907 p. 54, where there is a schematic map).

4. Ponticobaltic-(South and) Central European distribution, for instance, Inula britannica $\mathrm{L}$.

III. BOREAL species.

I. Sarmatian distribution, for instance, Astragalus arenarius L. (map 14, Plate 20), Cnidium venosum (Hoffm.) Koch (map I 5, Plate 20), Bupleurum aureum Fisch., Agrimonia pilosa Ledeb. (comp. Kupffer 1905), Scolochloa festucacea (Willd.) Link.; Dracocephalum Ruyschiana L. (map I6, Plate 2o) differs through its occurrence in the Alpes and through its Scandinavian distribution area. b. The Cassubian variant comprises species which differ through the fact that the species reach their eastern limit already in Central Russia, for instance, Koeleria grandis (Bess.) Domin (Domin l. c., p. 244 and map 1), Pulsatilla pratensis L. (Hayek I 904), Dianthus arenarius L. (according to Ascherson und Graebner, Bd V:2 1922, pp. 422 ff.); Gypsophila fastigiata L. (map 1 7, Plate 2I) differs through its occurrences on the Bohemian, Moravian, and Hungarian plain.

c. The Subarctically variant, e. g. Cenolophium Fischeri Koch, Ledum palustre L.

2. Sarmatian-Central European distribution. This type closely resembles type II:2, from whici it differs through the fact that the species are lacking or inconsiderably distributed on the South European steppes, for instance, Potentilla alba L., Achroanthes monophyllos (L.) Beene (map I8, Plate 2I), Chimaphila umbellata (L.) Nutt.

b. The Cassubian-Central European variant, for instance, Laserpitium latifolium L., forming a transition to a Scandinavian-Central European distribution; Omphalodes scorpioides (Haenke) Schrank.

c. The Subarctically variant, for instance, Calla palustris L., Cirsium oleraceum L., Picea abies (L.) Karsi. forms a transition type to III: 3 b.

3. Baltic-Central European distribution, for instance, Scorzonera humilis L., Selinum carvifolia L.

b. The Subarctically variant, for instance, Carex ericetorum L. and Calamagrostis arundinacea (L.) Roth (map 19, Plate 22). Pyrola chlorantha L. (map 19, Plate 22), Lathyrus vernus (L.) Bernh. (map 20, Plate 2 2), Viola mirabilis L. (map 20), Pinus silvestris L. form transition types to II:2 c. 
IV. Siberian species, for instance, Artemisia laciniata Willd. and rupestris L., Potentilla fruticosa L., Carex obtusata Liljebl.; Potentilla rupestris L., which has a rather great distribution in Central Europe.

The majority of the continental spccies of the European flora belong to the types of distribution which we call Pontic and Ponticosarmatian-Central European. These species are to a large extent xerothermous. In view of their distribution and mode of occurrence outside the limits of lastern Europe they are closely connected with the xerothermous species of Southern or Central Europe. The Pontic-South European and the Pontic-(Southern- and) Central European types evidently form a transition.

The distribution-area of the species in Europe is often characterized by a boundary line running mainly in the direction NE-SIV. In many cases the outermost localities lie on a line which runs from the north-east of Russia almost due south-west, south of the Baltic Sea, down to the south-east of France; while in other cases the boundary line makes a great westward bulge over southern Scandinavia and a more or less pointed indent in the north-west of Germany (see, for instance, Plates 17 and 18 ).

Very peculiar are the markedly isolated occurrences by which certain species are represented in the flora of South-Western Europe (see, for instance, Plate 14).

The Pontic-Baltic type of distribution reckons only a few representatives, but nevertheless merits attention. Like species belonging to this type, some species of other types of distribution have a peculiar and extensive distribution in the lowlands near the south of the Baltic - e. g. Petasites spurius (Retz.) Rchb. (mainly Pontico-sarmatian), Senecio palustris (L.) Hook. (Baltic), Scolochloa festucacea (Willd.) Link., and Cnidium venosum (Hoffm.) Koch. The species may be distributed far to the west (e. g. Carex ligerica Gay, Koeleria glauca (Schkuhr) DC., and Senecio palustris (L.) Hook., but they are absent in Central Europe.

The reason for this distribution would seem properly to be sought in dispersal conditions. As has been especially pointed out by Loew (1878), Scholz (1905) and Preuss (1912), the river valleys of North Germany, ancient or modern, with their shore-slopes of loess, marl or sand, would seem to form extremely important routes of migration in an east-west direction. It is also highly probable that species on the German Baltic coast have great possibilities of such a dispersal. According to Scholz (1. c.) and Preuss (1. c.), it is now tasily perceptible how at the present time species migrate from Russia to the north-east of Germany along the Vistula - e. g. Artemisia scoparia L., Corispermum Marschallii Ledb., and Rumex ucranicus Fisch. It is conceivable, therefore, that the species now distributed over western Balticum also have immigrated along the Vistula, and that from there they have spread further along the river valleys or the coast. - There are 
many things that indicate that several species belonging to this group are still continuing to spread - e. g. Senecio palustris, Petasites spurius and Scolochloa festucacea.

Of the continentally Boreal species a great number have a very extensive distribution in the north of Europe and in the greater part of Middle Europe. The often abundant distribution of these species in Central Europe is caused by the topography: they are found in the mountain woodlands of hilly districts. Thcy reach their westerly limits in eastern or central France and in south-eastern Belgium. It should be observed that Boreal species that occur in Great Britain also have in these districts temporary western boundaries. Engler (1879) has sought to explain this circumstance by the theory that the first-named species immigrated from the east and did not get as far as Great Britain before the English Channel broke through the land-connection which is supposed to have existed in early post-glacial times.

The Boreal species that scarcely extend beyond East Europe form a group that is comparatively few in numbers, but is interesting from several points of view.

In the first place should be noticed the Sarmatian psammophilous species. The majority of these belong to critical genera which have other species very much akin to the Sarmatian ones distributed in adjacent district such as Koeleria grandis (Bess.) Domin, several Dianthus-species, some species belonging to the Potentilla collina-group, Pulsatilla pratensis L. (Hayek's sense), probably several Festuca ovina-species. Perhaps in the Sarmatian herbaceous sand-grass heaths or pine-forest heaths (on this point see also Chapt. viii) we have special psammophilous types of vegetation, which are not yet fully differentiated as regards the species which are typical of them. This might also be connected with the fact that the Sarmatian region is not sharply divided from surrounding tracts in its climatological and orographical character.

As regards the distribution of other Sarmatian or Subarctically Sarmatian species the hypothesis may be put forward, to some extent in accordance with Engler (1. c.) that these species, unlike the species that are also distributed through Central Europe, were able, at the close of the Ice Age, to spread only from one or two refuges in the east of Eurupe, but not from any refuge west of the Alps. Here then would be found an explanation why the species are lacking in Central and Western Europe.

The two East European refuges would be the Carpathians (possibly the Eastern Alps) and the Urals.

Vierhapper (1911) has devoted a careful study of the distribution and mode of occurrence of certain species falling under this group.

Several remarks of interest about the distribution of continentally-Boreal species are to be found in a recently published work of Wangerin, treating the appearance of a montan» flora in East and West Prussia (Wangerin 1920). 
CIITTER III.

\section{The ecology of continental species and the Physiography of conti- nental regions.}

In an enquiry into the causes of the distribution of species the problem may properly be stated thus: Hon' far does the distribution depond upon the ecological ctemands of species: and how hanc other factors, and what factors, prevented species from attaining the distribution allowed by their denands:

As, of course, scarcely any species can be expected to be able to reach all suitable localities if we concern ourselves with very extensive areas, this problem can only refer to enquiries within comparatively limited regions.

An enquiry into the causes of the distribution of species, however, meets with great difficulties. The qualities of the habitat that are of importance to the ecology of species act in combination or interfere in each other's range of activity. The ecological demands of species must further be very difficult to determine Each species has naturally a certain ecological amplitude, but its occurrence in nature may be more limited than might be expected from the amplitude. In addition to the dispersal power of the species, we should here have to think of the rivalry for space with other species.

The connection between the distribution of species and the quantity of lime in the ground might probably partly be looked upon as the result of such a rivalry (see further about this later on). Probably the same bolds good with regard to the relation between the common spruce and the beech at the western limit of the former in Central Europe, as that limit pretty certainly depends to some extent on the ecological demands of the spruce, i. e. its requirements in the matter of climate. But, cultivated and sheltered by man in its rivalry against the beech, the spruce may grow up, regenerate and thrive fairly well, even far outside this limit (compare Dengler, 19 1 2. See further, for instance, IVarming, igo9, p. 7 I).

However, we know very little about the rivalry between species and the importance of the part it may play in the distribution of species. The importance of the rivalry would seem for the present to remain a highly theoretical problem. Hence we have scanty information about the source of error appertaining to an enquiry into the ecology of species, founded on their mode of occurrence.

The only way in which it is at present possible to determine the causes of the distribution of species is in the first place to determine the distribution minutely and study the mode of occurrence of species. In so doing one should try to learn to know as intimately as possible not only the climatic and edaphic conditions of the habitats, but also the regetation, the plant-community, the living environment. It is in its capacity as a member of community, and consequently subject to the laws for the organization of the community, that relations of the 
species to the climate, the nature of the soil etc. should be studied. In this way we may perhaps acquire some knowledge about the ecological amplitude of the species, such as it appears in nature under the influence of such factors as, for instance, the rivalry between species.

To explain the western limits of continental species it is necessary to know in what degree the continental geographical conditions in the climate and the nature of the soil are reflected in the ecology of the species. Our knowledge about this is, at present, very scanty. Nevertheless I have considered it proper to compile from the literature - chiefly from well-known handbooks, such as Schimper, Jost, Warming (1914) - a summary of what we have to lean upon in order to judge the conditions mentioned. It seems scarcely necessary to point out that this summary must be very incomplete and will not render possible any positive conclusions.

\section{The climate and the ecology of continental species.}

The search for a direct connection between the climate and the distribution limits of plants has been of absorbing interest to scientists ever since phytogeography first came up. For a long time people generally tried to see a rather simple causal connection here. If the distribution limit of a species - generally drawn up very roughly - ran in agreement with that of a certain value of a climatological factor, the distribution of the species was supposed to be determined by that very factor. As a rule, scientists made use of thermic factors calculated in many ways: in early days chiefly the mean temperature for the year or for a season (Humboldt and Schouw); later on the average daily maxima and minima (De Candolle, Grisebach), or the accumulated temperature ("Die Wärmesumme») of the species, i. e. the temperatures ascertained in various ways from a certain date during the season of rest (for instance, the first of January) to the coming of a certain function of the species (in the simplest cases maximum temperatures of all days above $0^{\circ}$ were added together) (Boussingault, Hoffmann; see especially Ziegler 1879) or the length of the vegetative season (Grisebach).

In recent times this mode of thinking of the connection between the climate and the distribution limits has been looked upon very critically. The objections that can be made seem to be briefly as follows:

I. The distribution-limits of species must in the first place be sufficiently well known, which has hitherto not been the case many a time.

2. The meteorological material suffers from great defects. The report from a meteorological station may differ in a high degree from the conditions in a plant locality in its immediate neighbourhood; and it should especially be no- 
ticed that the temperature of the ground is generally rather different from that of the air (see, for instance, Kraus 1911).

3. The fact that the distribution-limit coincides with a border-line of a climatological factor does not prove the existence of a causal connection betiveen the distribution-limit of a plart and that factor. Only in a few cases has it been established that the species suffers from the climate by crossing the limit. Grisebach says $(1872$, p. 98): the eastern limits of Atlantic species are "nicht bloss durch die Lage der Vegetationslinien sondern zugleich durch Untersuchungen über die Lebensbedingungen der einzelnen Arten zu erledigen».

4. The use of a daily mean temperature may in a high degree point in a wrong direction. A plant can obtain a sufficient quantity of heat at a lower mean temperature, if the daily temperature amplitude is great, than if it is small (compare De Candolle 1855, I, p. 202; Brockman-Jerosch, 1913).

5. It has been established that plants have different demands as to heat for the commencement of different manifestations of life (e. g. Schimper 1908). Hence the somehow or other calculated quantity of heat offered to the plant during a longish time before the beginning of certain manifestations of life cannot express the demands for heat of the plant in this respect. Besides, it has been found that plants are in their periodical manifestations of life to a certain degree tied by hereditary dispositions. These allow a plant to suit itself to external conditions with regard to the time for the commencement of a certain manifestation of life only within a certain boundary. (See especially the good critique of Bos 1907).

6. It is preposterous to suppose that the distribution-limit of a species should be determined by only one climatic factor. A cooperation of all factors must take place. In many cases it seems more possible and suitable to follow Koeppen (1900) in letting certain plant limits or flora limits characterize the climate than to try to distinguish in the climate the various factors that may determine the distribution of plants (compare Grisebach 1. c., p. 76 and Brockmann-Jerosch 1. c.).

7. It must be taken into consideration that in most cases a spccies has no opportunity of freely reacting against external conditions in its occurrence in nature. Species may be more or less connected with each other; and generally there is rivalry between the species in the struggle for space (compare Grisebach 1. c., p. 74).

8. There may exist purely edaphic reasons for a distribution-limit: the more a species is differentiated in its choice of habitat, the more important may this circumstance be.

The causes of the distribution-limits of species being so various and also able to work into one another in different ways, it would seem justified to question 
the suitability of establishing certain limits for the distribution of plants determined by the climate, even if they are meant to be schematic. It seems rather that, within a zone of considerable latitude, the climate may become more and more unfavourable to a species, in which case the species reaches within this zone a distribution-limit which is further determined as to its position by the climate in cooperation with several other factors. For alpine tree-limits De Candolle has in vented the term "zône contestée»; Schroeter and Fries speak about a »Kampfzone» (Fries 1913, p. 152). Hence the establishment of such a zone should theoretically be much more appropriate regarding the horizontal distribution of species.

As Brockmann-Jerosch (l. c.) has pointed out, maritime districts have great possibilities of satisfying plants with an otherwise quite different distribution. In Great Britain, for instance, we find Atlantic, Mediterranean, Arctic-alpine, and Steppe species in the vicinity of each other. On the other hand the continental climate is unfavourable and weeds out many species. Several West European species have easterly distribution-limits which have undoubtedly their chief cause in the climate. Ilex aquifolium and Ulex europaeus suffer badly from frost when grown outside their eastern limits in Middle Europe (Grisebach 1. c., p. 97). Probably the eastern limit of the beech too is climatic (Brockmann-Jerosch 1. c.).

As regards the western limits of continental species, on the other hand, a climatic character would seem very difficult to establish. On the whole, the species in their most extreme localities show no noticeable consequences of any disadvantages in the climate, and many continentally distributed species have proved able to thrive when cultivated in maritime districts. Hence continental species should have a great climatic amplitude. The reason why continentally distributed species can be distinguished should be found in other quarters, for instance, in their demands regarding the nature of the soil, in the migration history of the species or in the rivalry which they have to endure with species tied to maritime districts.

Notwithstanding all this, it may be supposed that behind other more obvious limit-forming factors there may be a certain disadvantage in the climate. It is not very palpable, yet it may, for instance, render the species inferior in the struggle for space.

What has been said here, however, is valid only about the direct connection between the climate and plants. Indirectly, of course, the climate has very great importance, above all through its influence on the nature of the soil.

Even if generally the direct influence of the climate on the distribution of continental species cannot at present be proved, it would seem appropriate to make an account of the ecological features which, because of the climate, ought 
to be found in the continental species, and which may make the species dependent on continental climatic conditions.

The characteristics of a continental climate with regard to its importance to plants are above all scanty rainfall and cloudiness and within the temperate zone, high summer temperature and low winter temperature, which has given rise to marked vegetative and resting seasons.

The scanty quantity of rainfall, or, rather, the scanty quantity of effective rainfall, occasions that xerophilous character of the vegctation which is in the first place distinctive of continental districts. The species are variously qualified for life with a scanty supply of water.

There are available far too few detailed examinations of the connection between the life functions of plants and the temperature of the vegetative season. In certain species it has becn established that their ecological »temperature optima» (Schimper) form curves rising from the germination to the ripening of the fruit (e. g. Schimper, 1. c., p. 5o). Hence the demands of plants for heat would be at their greatest during the period of fruit-ripening. Each species has its special optima for its different functions. As for continentally distributed species which, in normal conditions, live under comparatively high temperatures during their vegetative season, their optima may be supposed to be comparatively high up on the scale of temperature.

The low winter temperature involves a marked yearly resting.season. Through a great number of examinations it would seem to have been proved that such a period is necessary for perennial plants of the temperate zone. During the season of rest certain processes take place in the interior of the plant which form a vital condition for it. The necessary length of the season of rest probably depends on hereditary qualities in the constitution of the plasma. It has been found to be different in different species. This season of rest, caused by interior reasons, is strongly influenced by exterior climatic conditions. Not till a certain temperature is reached will the plasma be able to re-enter an active state, so that the season of rest is generally much prolonged. Regarding the demands for a minimum length of the season of rest with different species there are as yet too few researches. It may perhaps not be impossible that with continental species there are such demands in this respect as may be a contributive cause of their absence in maritime districts.

It has been found out that certain functions of plants have comparatively low temperature optima. The development of genital parts and other organs ecologically combined with the latter, as the calix and the corolla, are promoted by a comparatively low temperature (Jost, 1. c., p. 489). There is a great number of observations of the fact that species removed to a spot, warmer at the time of the formation of the flowers than their native places, become more or less 
sterile. The long warm autumns and mild winters in maritime districts may perhaps have an unfavourable influence on the creation of flowers in continen. tal species.

In tropical deserts the division into periods of the year is occasioned by the rainfall conditions. Even in the continental regions of the temperate zone the rainfall may cause periodicity in plants. The ineffective rainfall during the height of summer forces many species to rest. The main characteristic of the vegetation of steppes and prairies is, indeed, the great number of species that flower in spring or autumn.

In his well-known biological system Raunkiaer has given expression to an important side of the connection between the character of climate and the ecology of plants, viz. the various ways in which plants manage to survive the unfavourable period (periods) (Raunkiaer, for instance, 1907 and 1909). Raunkiaer has given "biological spectra" from certain desert districts. They are characterized by a high percentage of »therophytes». Unfortunately there are no spectra available from continental districts in the temperate zone. It is evident, however, that the vegetation on the more rigorous steppes and prairies is characterized by a high percentage of therophytes, but also a high percentage of geophytes. The geophytes are equipped for utilizing the short period of vegetation between winter and the dry height of summer.

As the vegetation in more extremely continental districts, such as steppes, pampas, deserts etc. is only developed in one layer, and consequently no species are shaded by others in any degree worth mentioning, the flora should be greatly heliophilous, composed of species demanding (or at least preferring) full light. Even in continental forest districts the ground flora would probably seem to be comparatively heliophilous because of the scanty cloudiness and sparse wood layer.

As regards the influence of the supply of light on plants the following things may be especially pointed out in this connection. The origin and development of the constituent parts of the flowers are greatly furthered by a rich supply of light (Jost, 1. c, p. 488). The demand of plants for light depends on the temperature in which they live. With sinking temperature the demand for light is increased. Light and heat may to a certain extent compensate each other. Thus, for instance, it has been found that the demand of plants for light increases with the geographical latitude and height above the sea (Wiesner, for instance, 1895, p. $704 \mathrm{ff}$, and 1907, p. 31 ; compare also Brockmann-Jerosch, I913). ${ }^{\mathrm{I}}$ The latter fact may especially be of importance to continental species.

1 The sources of error in Wiesner's method of measuring the demand for light, viz, the fact that the thermic effect of light cannot be directly measured, would not seem in this case to be able to decrease the value of the results to any appreciable extent (compare Riibel, 1912, pp. 44 and 45.) 
A sinking of the summer temperature may be imagined in a continental climate to be to a certain degree compensated by a greater supply of light. The position of the northern distribution limits of species would thus appear to be influenced even by the supply of light and so depend on the cloudiness and the measure of shade in the vegetation.

For temperate regions, thereforc, the direct influence of the continental climate un the plant world may be supposed to appear in the following biological characteristics in the plants:

(1) Xerophily;

(2) A high »ecological temperature optimum» for the regetative season;

(3) The demand for a yearly season of rest of a certain duration;

(4) The demand for a comparatively low temperature at the time of the origin of the constituent parts of the flowers;

(5) Heliophily.

\section{The nature of the continental soil and the ecology of continental species.}

The nature of the soil is intimately connected with the climate. Modern pedology distinguishes between different types of soil, above all with regard to the connection with the climate. In the first place a distinction is drawn between arid and humid types of soil, of which the former are connected with a dry climate, the latter with a damp one.

According to Ramann (1911) and Wiegner (1918), the characteristics of arid types of soil are, above all, inconsiderable weathering, the massing in the upper layers of the soil of the electrolytes formed in the weathering, and an inconsiderable proportion of humus substance, depending on the scanty vegetation.

Humid soil-types are inter alia characterized by strong weathering; a removal from the upper layers of soluble electrolytes and certain colloids: ferric oxide, aluminium oxide, silica etc.; also by a considerable massing in the uppermost layer of plant remains (»örna», Sernander, 1918), which are only slowly demolished and then appear as colloids in the condition which forms what is called vraw humus».

Between these extremities many stages may be discriminated. What are known as the semi-arid and the semi-humid soil-types are characterized by abundance of humus substance and at the same time by a good supply of electrolytes in the upper layers. Aluminium-oxide and silica remain in the upper layers, giving rise to clays. The colloidal humus substances absorb the electrolytes, during which process they are transformed into absorptively saturated humus. Through the agency of animals (earthworms) and water the humus is thoroughly mixed with sand and clay. The mixture is a neutral or alkaline, granulary soil, the "mould» 
or the »ordinary humus». This is an excellent nutritive substratum for plants: there is a good supply of nitrogen in the mould which is a very important factor (e. g. Hesselman 1917 a and b). Thanks to its granulary structure, the soil gets a great capacity of absorbing heat (compare Kraus, I9I I) and gets better drained.

From a biological point of view, this soil-type is to be sharply discriminated from the more markedly humid ones. The upper layer in these, the »raw humus layer", is in a high degree devoid of the qualities characteristic of the mould and favourable to plants.

Hence the chief characteristics of more continental soil-types are as follows: a great amount of electrolytes in the upper layers; and, when there is a vegetation cover, a topmost layer formed by granulary humus, which gives the soil a high porosity, good drainage, a high power of heat absorption, a good supply of nitrogen and so on.

The assumption would seem greatly justified that continental species are in one way or other through their ecology confined to continental soil-types. Consequently the climate should indirectly in a high degree determine the distribution of these species.

Climatic soil-types may, however, have edaphic ones subordinated to them. The latter are above all caused by the changes in the composition of the mineral soil, and in its amount of electrolytes.

In more continental districts this is of small importance, the amount of electro. lytes being always sufficient at the weak leaching to satisfy the humus substances. In more maritime districts, on the other hand, the composition of the mineral-soil may in a high degree determine the soil-type. The supply of electrolytes may be so great that, in spite of the great leaching, the humus substances can be satisfied and give the soil a granulary structure. Hence in maritime districts with a large electrolytic content in the soil there may be a comparatively continental type of soil, which should naturally be of immense importance to the distribution of continental species. ${ }^{\mathrm{I}}$

It is to a great extent in its activity as an electrolyte that lime is of such fundamental importance to the distribution of plants. The amount of lime influences in a high degree the physical structure of the soil. The easily demonstrable close connection between lime and the distribution of many species, however, has long been, and still is, one of the main problems of phytogeography. To the indirect importance of lime now mentioned, in fact, must be added its rôle as a more directly active factor, concerning which research has not yet attained any definite result. The current opinion would seem to be as follows:

1 Here also attention may be drawn to the fact that the nature of the humus-layer is, to a certain degree, dependent on the nature of the vegetative eover. 
As a nutritive substance lime is necessary to all higher plants. In order to satisfy the »nutritive demands» of plants, however, only a small percentage of lime is necessary. It may be questioned whether there are species that are really confined to a higher percentage of lime in the soil (compare, for instance, Kraus 1911 , p. 6I). The so-called calciphilous plants ("calcicoles») have in most cases proved to be confined to lime only in certain districts. When cultivated, they can thrive in soil comparatively poor in lime. On the other hand, many plants never occur in calcareous soil and have proved quite unable to grow in such soil. They are consequently calcifuge plants. Besides these, of course, there are a great number of species which do not, even in nature, show any special predilection for either type of soil.

Like other electrolytes, lime may cause harm to plants when it occurs in great quantities. A great amount of electrolytes increases the osmothic pressure in the soil fluid, and hampers or renders more difficult the absorption of water by the plants. Besides, lime has in other ways an injurious influence on plants, which is due, according to the results of the latest investigation, to the fact that the high $\mathrm{OH}$-ion concentration that accompanies a high percentage of lime, operates as a poison. (See for instance, Mevius 1921). In regard to a high percentage of lime in the soil, however, plants vary a good deal.

The calcifuge species are evidently the most delicate; the calcicoles" and the plants indifferent to lime, on the other hand, can endure a higher percentage of lime. The fact that the formers generally occur only on calcareous soil, may be explained on the ground that on such localities they are free from rivalry with other species, a rivalry which they cannot endure.

The fact that in certain districts the species are confined to calcareous soil, in others not, to a certain extent favours this hypothesis, as does also the fact that, when mans intervention keeps the rivals away, some species thrive excellently in comparatively lineless soil (provided, of course, that the physical quality of the soil is not the cause of this). Hence indifferent species should have a great power of competition as well as a great amplitude in relation to the lime. The lime plants would seem to have only the last-named quality to thank for their existence.

The continental species, above all the steppe species, in many cases occur as calcicoles outside decidedly continental districts. The steppe species should also be able to stand a high percentage of electrolytes, the steppe soil being generally characterized by a high amount of electrolytes. Hence the facts that these species may occur outside the steppe districts may to a certain extent be caused by the existence of localities whose high percentage of lime they are able to stand, but not species that are superior to them in the struggle.

In this connection it should be noted that many continental species (especially 
steppe species) are generally found only in localities that are in some respect or other developed to great extremes, for instance, through a high electrolyte percentage or a low degree of dampness in the soil. One has a right to believe that the species that prefer such habitats must be specially equipped. On the other hand, those species may occur under very different habitat conditions, and when cultivated, they prove to be but little specialized concerning the nature of the soil in the respect mentioned. At the same time it is often a characteristic of the mode of occurrence of these species that they form part of a sparse vegetation, where, because of certain extreme habitat features, the production of individuals is not great enough to occupy the whole area, and where the combination of species in the vegetation would seem to be determined less by a selection among many species during a struggle for space, than by the existence of such species as can stand the extreme type of habitat. Hence the species have no greater use for a capacity of competition and may to a certain degree be supposed to be without it. They may perhaps be looked upon as forming a pariah class in the plant world, forced back to the »worst», inhospitable localities where they are able to exist. The fact that such localities may occur edaphically even outside the steppe districts, in conjunction with the dispersal capacity of the species, may perhaps to a certain extent explain the distribution.

The connection between a continental nature of the soil and the ecology, and probably also the distribution, of continental species, would consequently seem to be capable of being thus summarized: continental species generally occur in, and seem to be confined to, soil with a high amount of electrolytes (especially of lime) and often al so with a low degree of dampness. The species may be supposed to be dependent on the physical attributes of the continental soil-type; and they are able to endure the qualities, unfavourable to other species, that often characterize this type of soil - for instance, a high amount of lime and an inconsiderable degree of dampness.

\section{A few words about continental geographical conditions and the general features in the distribution of continental species in Europe.}

The steppes of South-East Europe form the most continental type of scenery in Europe. These steppes are above all caused by the rainfall conditions. The rainfall on the steppes is, speaking absolutely, not scanty, but its distribution makes it almost ineffective.

Besides this the continental character of the climate appears in a high summer temperature and a sharp division of the year into a season (or two seasons) of rest and a vegetative season (or two vegetative seasons), and also by a low comparative dampness and a scanty cloudiness. The steppe soil is chiefly to be classed with 
the semi-arid or semi-humid types of soil (Ramann 1911, Wiegner 1918). The black earth, "chernozyom", a soil with an enormous content of mould, is characteristic of large parts of the Russian steppe.

From the South-Last European stcppe region the continentality of the climate decreases towards the north and the west. The precipitation increases, and also becomes more even, as the ground becomes wooded. The summer temperature decreases too, although it still reaches a considerable height in North-East Europe. Geographical conditions of a more continental character occur only edaphically. Because of the topograpley the precipitation and temperature conditions may become abnormal within minor areas and deviate towards continentality. This occasions more continental soil-types. Lime-districts likewise get a more or less continental soil, especially in localities where the exposure is favourable.

If we examine the isolated localities or minor distribution areas of the steppc species in Central and Western Europe, we shall easily be able to prove the close connection between the edaphic development of the soil and the climate towards continentality, on the one hand, and the distribution of steppe species on the other. In the same way local conditions of climate and soil correspond to the numerous isolated occurrences of a steppe flora far north in the East European forest region.

The north-easterly-south-westerly boundary that is characteristic of the distribution of many steppe species may be connected with the summer temperature, which sinks from the east to the west, as also with the rainfall and cloudiness, which decrease towards the south in Western Europe.

Hence there would seem to be a coincidence between at any rate the general features in the distribution of the steppe species and continental geographical conditions in Europe.

An important question to be answered is to what extent such a coincidence also exists concerning the continentally distributed species that belong to other distribution-types and other vegetation-types of a less conspicuously continental character.

It is a rather universal ecological feature in all the species here called continental, that, in their occurrence in nature, they have proved to be heliophilous. This must be looked upon as a continental feature. Towards more maritime regions, where the rainfall and the cloudiness are greater, and where the vegetation, in its quite natural state, would to a great part consist of close, umbrageous forests, the species would naturally seem to have fewer possibilities of getting their demand for light satisfied. We have seen that several of the rather few continental species of the "grove" flora biologically occupy a separate position by having their most important life functions fixed at a time when the supply of light at their stations is at its greatest. 
Several forest trees belong to the continental element. It would not seem rash to suppose that the western distribution-limits in Europe of these species are partly caused by the climate. In this connection it seems especially natural to think of the decreased season of rest, which should be able to have an unfavourable influence on the formation of wood (compare Dengler 1904 and 1912). It is natural that many species in the ground flora of these forests should within not too great areas cease to exist at the same time as the forest trees reach their boundaries (compare Höck 1895 and $\gg 1896 »)$.

A universal feature of these continental species is, further, that they are found only in soil of a more or less continental character, or in water with a comparatively great content of electrolytes ("nutritive waters»). As has already been pointed out the species may be supposed to be in most cases confined to such localities. As these naturally become more and more rare as the climate assumes a more and more maritime character, this may be one of the causes of the western distribution-limits of the species.

Even species belonging to less continental vegetation-types, such as forest communities and hydrophilous communities, may thus be supposed to be more or less dependent on continental geographical conditions, thanks to certain ecological qualities. Naturally, however, they are not dependent in the same degree as the steppe species. The sorts of localities where they are wont to occur, are much more widely represented in maritime regions than those of the steppe species. The former have also in several cases a wide and even distribution rather far out towards western Europe.

For certain continental species, numerously distributed in the forest regions of East Europe, however, their western distribution-limits are often so placed that a connection with changes in the climate and the nature of the soil in a maritime direction can hardly be discerned. The mode of occurrence of these species within their distribution-area is not, as is the case in regard to the steppe species, of the kind that suitable localities might be expected to be lacking outside the limits. It is perhaps not too bold to seek causes of the limits, regarding such species chiefly in other conditions than those mentioned. Besides, a detailed examination of the distribution-boundaries of almost all species would probably show that there are many factors to be considered in deter. mining the situation of boundaries. The cause is not a certain climatic factor, nor is it to be found solely, perhaps not at all in the climate. We must consider other causes connected with the ecology of species, in the first place the nature of the soil or causes of a totally different nature, such as causes connected with migrational history and rivalry with other species. 
CHAPTER IV.

\section{Continental features in the physiography of South Sweden.}

It would seem to be a justifiable assumption that continental species are gencrally more or less confined by their ecology to habitats of continental character and that their distribution would thus be in a measure determined.

In order to establish in detail how far this is the case, and how far other causes may determine the distribution of species, it would be best to analyse the distribution of species, and their mode of occurrence within a comparatively small area and to investigate carefully its geographical conditions: an analysis of the climatic character, especially locally, of this area and the nature of the soil within it.

It is not the purpose of the present work to make any new contributions to the knowledge of the climatic character and soil-quality of South Sweden. Facts already collected, however, will be set forth in a brief form.

\section{The degree of continentality of the South Swedish climate.}

a. Temperature conditions in South Szueden. "Es kann nicht laut genug in die Welt gerufen werden, dass die nach der allein herrschenden Methode bisher angestellten meteorologischen Beobachtungen, den gegenwärtigen Aufforderungen biologischer Studien nicht im Geringsten genugen", Middendorff wrote in 1867 in Eine Reise in den äussersten Norden und Osten Sibiriens» (IV, p. 776). Even in our own days such a statement would seem to be justified to a considerable extent.

The figures which Meteorology at present usually places at our disposal only give an outline of the general features of the temperature of the air. When, on the other hand, it is a question of finding a possible relation between the character of the vegetation and the temperature within a certain area, they hardly offer any reliable bases of discussion whatever.

For such a purpose it is the purely local climate conditions that have to be investigated. What temperature amplitudes can be established within a suitable number of special areas with regard to the differences in topography, quality of soil, vegetation cover, etc. within these areas?

Furthermore a phytogeographer is little benefited by accounts of temperature in an air-layer with which the bulk of plant species has not the slightest contact. Several investigations of late years (see especially Kraus 1911) have shown how 
much the temperature in and immediately beneath the surface of the ground may differ from that measured at a height of one metre above the ground.

Meteorological data such as those given below are not, however, without their value to a study in phytogeography like the present. A certain relation may exist between the former and the local climatic amplitudes.

The South Swedish highland do, of course, in a high degree determine the temperatures in South Sweden.

Our attention ought especially to be directed to the fact that during summer and autumn this highland has a remarkably much lower temperature than

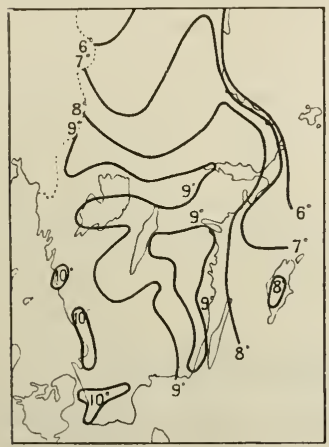

$a$

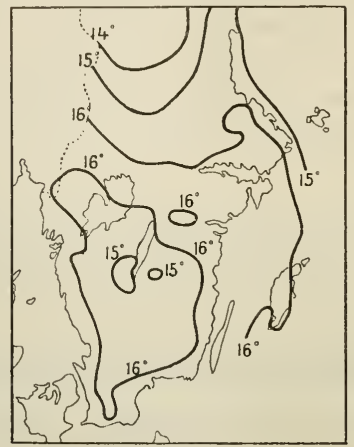

$b$

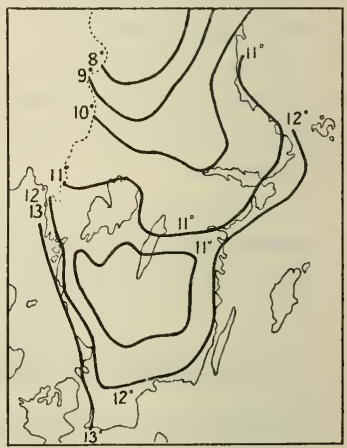

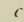

Fig. I. The mean temperature in South Sweden in Mlay (a), July (b), and September (c) (at the level of the meteorological stations), according to Hamberg Igo8.

the surrounding coast and lowland districts. Besides, the fact may be observed that the lowlands of Central Sweden are separated by isotherms from the more elevated forest region of Norrland that commences to the north thereof. Figs. I and 2 give more exact information on this subject.

As to the degree of continentality of the temperature of South Sweden a comparison with the state of things in adjacent parts of Europe yields the following results.

The July-isotherms, which as a rule are used as characteristics of summer temperature, have in northern Europe a general trend from north-east to south-west (see, for instance, Ekholm i 889.)

In the Scandinavian North the course of the isotherms is rather complicated, owing to the Baltic Sea and the Scandinavian highlands. In northernmost Russia the isotherms run close together, nearly parallel to the coast-lines of the Arctic Ocean and the White Sea. In northern Finland they are more diverse. 
The isotherm of $+16^{\circ} \mathrm{C}$., which is of special intercst in the present case, bends to the south, excluding the Baltic Sea but (as Fig. I shows) including the plain and coastal districts of South Sweden. It comprises a small area in part of south-eastern Norway, and then passes on south-westwards over south-western Jutland and the southernmost part of the North Sea, bending again to the north at the eastern coast of Great Britain, thus comprising a large part of England and southeastern Ireland. The considerable bend in the isotherm to the north over southern Scandinavia may be regarded as a climatic deviation in a continental sense.

A better expression for such divergences in temperature is given by the so-

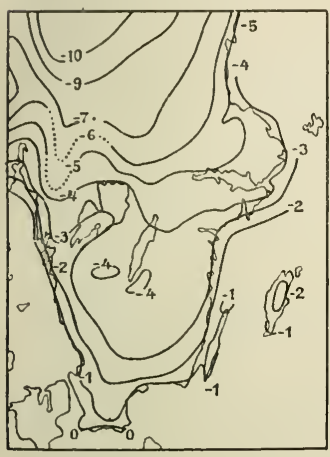

$a$

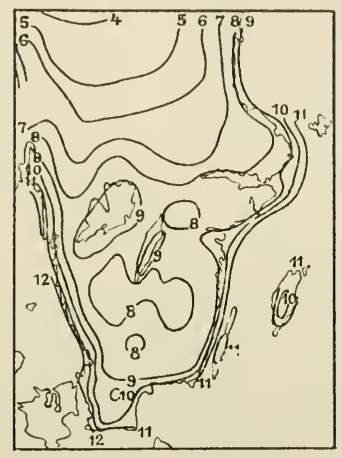

$b$

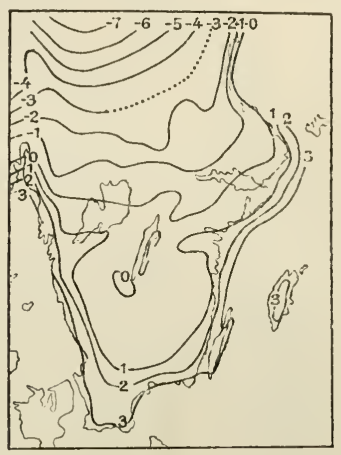

$c$

Fig. 2. The periodic daily minimum of the temperature in South Sweden in March $(a)$, September $(b)$ and November $(c)$ (at the level of the meteorological stations), after Hainberg 1914.

called isoanomals of temperature, i. e. curves of equal deviation from the average temperature corresponding to the latitude circle. Ekholm (l. c.) has published a chart of the isoanomals of temperature in July in Europe. Very large positive anomalies are shown in the northern, and especially in the north-eastern, parts of Scandinavia: $5^{\circ}$ to $6.5^{\circ} \mathrm{C}$. From here the anomalies decrease southwards. South Sweden, for instance, is intersected by the isoanomals of $+2^{\circ}$ (in the Central Swedish plain district) and $+\mathrm{I}^{\circ}$, the latter excluding south-western Sweden (from the middle of Västergötland in the north), Blekinge and parts of Öland and Gotland. This isoanomal further excludes the Norwegian west coast, Denmark (except northern Zealand) and great parts of north-western Germany.

The isoanomal of $+2^{\circ}$, on the other hand, passes through Middle Europe as far to the east as through the border regions between Russia and Germany.

It must be emphasized that in neither of these cases can there be obtained a conception of the continentality of the climate that is satisfactory from a phyto- 
geographic point of view, as atmospheric precipitations, which are of such fundamental importance to the development of the vegetation, are not taken into account.

Table 3 puts together data of temperature for South Sweden and some places in different parts of Middle and South-Eastern Europe (after Hann 1908.)

Table 3. Temperature reports for places in Middle Europe, South-East Europe and South Sweden (at the level of the sea), according to Hann and Hamberg.

\begin{tabular}{|c|c|c|c|c|c|c|c|c|c|}
\hline \multirow[b]{3}{*}{ Liverpool.. } & \multicolumn{3}{|c|}{$\begin{array}{l}\text { Mean temperature } \\
\text { (C) }\end{array}$} & \multirow{2}{*}{ 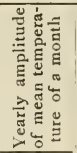 } & & \multicolumn{3}{|c|}{$\begin{array}{l}\text { Mean temperature } \\
\text { (C) }\end{array}$} & \multirow{2}{*}{ 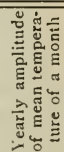 } \\
\hline & March & July & $\begin{array}{c}\text { No- } \\
\text { vember }\end{array}$ & & & March & July & $\begin{array}{c}\text { No. } \\
\text { vember }\end{array}$ & \\
\hline & $5 \cdot 4$ & $15 \cdot 4$ & 6.8 & I I. 3 & Kazan .... & -6.9 & 19.7 & -3.8 & $33 \cdot 5$ \\
\hline Cambridge & $5 \cdot 3$ & 16.4 & 5.9 & $13 \cdot 3$ & Kamyshin & $-4 \cdot 3$ & $24 \cdot \mathrm{I}$ & $-1 . x$ & $35 \cdot 7$ \\
\hline Paris & 6.2 & I8.6 & 6.0 & I6.I & Debreczin & 3.6 & 21.6 & $3 \cdot 4$ & 25.4 \\
\hline Groningen & $3 \cdot 5$ & 16.5 & $4 \cdot 3$ & 157 & & & & & \\
\hline Frankfort.. & 4.8 & 19.3 & $4 \cdot 3$ & 19.3 & Lund $\ldots . .$. & 0.9 & 16.4 & $3 \cdot 4$ & 17.2 \\
\hline Hanover .. & $3 \cdot 1$ & $17 \cdot 3$ & 3.6 & 16.9 & Gothenburg & 0.7 & 16.8 & 3.6 & $17 \cdot 7$ \\
\hline Erfurt ... & 2.9 & $17 \cdot 7$ & 3.2 & 18.4 & Strömstad... & -0.6 & 17.0 & 2.2 & 19.2 \\
\hline Göttingen... & 3.0 & $17 \cdot 4$ & 3.5 & 17.5 & Växiö ...... & -0.8 & 16.2 & I. 8 & 18.9 \\
\hline Stettin ....... & 2.2 & 18.4 & 3.2 & I9.I & Skara ... & -1.3 & 15.8 & I.3 & 18.9 \\
\hline Berlin & 2.8 & I8. I & 3.4 & 18.5 & Västerås & -2.2 & 16.9 & 0.6 & $21 . x$ \\
\hline Posen & 1.8 & 18.6 & 2.7 & 20.1 & Kalmar...... & 0.1 & 16.9 & $3 \cdot 4$ & I 8.1 \\
\hline Warsaw & 0.5 & 18.8 & I.6 & 22.2 & Linköping & -0.7 & $17 \cdot x$ & 1.8 & 19.7 \\
\hline Kiev...... & -0.7 & 19.2 & 1.2 & 25.4 & Upsala ...... & -2.7 & 16.2 & 0.2 & 20.9 \\
\hline Moscow ... & -4.8 & IS.9 & -2.4 & 29.9 & Visby . & -0.1 & 16.2 & $3 \cdot 7$ & 16.7 \\
\hline
\end{tabular}

Besides this, the duration of the vegctative season is very important for the character of the vegetation within a region. The calculation hereof with suitable

\section{Table 4. The length of the vegetative season for different places in South Sweden.}

\begin{tabular}{|c|c|}
\hline Lund & 285 \\
\hline Gothenburg & 295 \\
\hline Strömstad & 250 \\
\hline Växiö ........ & 250 \\
\hline Jönköping & 245 \\
\hline Skara ...... & 240 \\
\hline
\end{tabular}

\begin{tabular}{|c|c|}
\hline Linköping & 245 \\
\hline Västerås. & 230 \\
\hline Nyköping & 235 \\
\hline Upsala & 230 \\
\hline Kalmar & 275 \\
\hline Visby . & $2 \mathrm{So}$ \\
\hline
\end{tabular}


exactitude naturally involves great difficulties. Values of a certain usability may be obtained by calculating the number of days during which the mean temperature exceeds $0^{\circ}$ Centigracle. On the basis of the mean-temperatures for pentades published by Hamberg (1908) I have computed the values given in Table 4, which may be left to speak for itself.

b. Atmospheric precipitations and Cloudiness. Precipitations exercise a great influence on the distribution of plant species, above all by their effect on the quality of soil, the heat of the soil and its physical and chemical structure.

When we try to find a relation between the distribution of atmospheric precipitations and of species, the meteorological data can give us a safer basis of discussion than in the matter of the distribution of temperature. Fig. 3 shows, according to Hamberg (19I1), the distribution of rainfall in South Sweden during the summer half-year (May-October). Among the general features the following might be specially emphasized:

The importance of topography to the distribution of rainfall is conspicuous in the considerable outward bulge to the east of the isohyetals over the South Swedish highland, over Tiveden and Kolmairden.

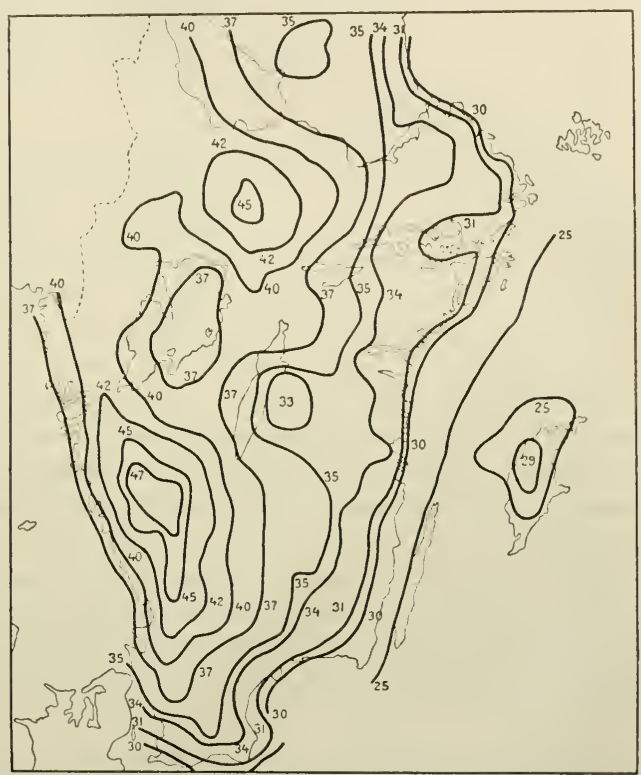

Fig. 3. The average rainfall in South Sweden during the summer half-year (May-October), after Hamberg 1911 .

The western slope of the South Swedish highland has the largest rainfall within this region, and the south-eastern coast regions - situated as they are in "rain shadow» -- have the smallest amount. The large flattish districts, especially the Mälar and Östgöta plain, show small amounts of rainfall.

The consequence of the small coast rainfall, however, is, as far as plants are concerned, counterbalanced by a smaller saturation-deficit of the air, which depresses the intensity of transpiration.

The precipitations during the winter half-year (November-April) are naturally 
also of importance to the vegetation. These precipitations show in some respects a different distribution from that of the summer half-year. Even now, however, the western slope of the South Swedish highland presents the highest amounts and the regions to the east of it the lowest.

When precipitations are to be estimated with regard to their importance to the vegetation, it is necessary to take into consideration not only their amount but also their distribution in time.

In the work of Hamberg just mentioned (p. 46) there are accounts for South Sweden of the average number of yearly periods of precipitations of five days' length or more. The differences between various parts of South Sweden prove to be quite insignificant.

A comparison with other parts of Europe shows that with regard to precipitations, and especially as to their annual distribution, South Sweden holds an intermediate position between Continental and Atlantic Europe (cf. Hamberg 191 I, pp. I5, $18 \mathrm{ff}$.) A characteristic of the East European precipitation conditions is the fact that the height of summer gets the bulk of the precipitations. July shows the highest amounts of rainfall. Western Europe, on the other hand, has its maximum of precipitations in the autumn or the winter. In South Sweden the maximum of precipitations falls in August. An exception from these rules is formed only by the Östgöta-plain (Linköping), possibly the central part of the Mälar-plain (Västerås), and the neighbourhood of Kalmar Sound (Kalmar), which regions show a slight maximum in July, and finally Strömstad, which has its maximum in October.

But while in south-eastern Sweden the August maximum differs only slightly from that of July -- but considerably from that of September and October it is just the contrary in south-western Sweden. Here we find in several places amounts of rainfall in October which come very near to those of the maximum in August.

As to the distribution of precipitations throughout the year there is thus a considerable difference between south-eastern and south-western Sweden, and a remarkable coincidence between the state of things in south-eastern Sweden and those of the continental Europe.

Table 5 shows the amount of the yearly average of precipitation within different parts of South Sweden according to Hamberg (l. c.) and in some places in Central and South-East Europe according to Hann (l. c.). The coincidence between the Kalmar district and the Russian stations is striking.

When the amounts of rainfall given above are estimated with regard to their importance in phytogeography, they suffer of course from one source of error.

The rainfall which is measured in a rain-gauge can only to a certain extent affect plants. We must take into consideration the fact that a great part of it 
Table 5. The yearly average precipitation for certain parts of Middle Europe and Southern Russia as well as for places in South Sweden (after Hann and Hamberg).

\begin{tabular}{|c|c|c|c|c|}
\hline 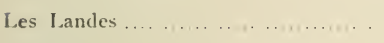 & I $14 \mathrm{~cm}$. & (iothenburg & 79 & $\mathrm{~cm}$. \\
\hline P'oitiers.. & 66 & Halmstad & 72 & , \\
\hline P'aris . & 50 & Lund & 60 & a \\
\hline The Vosges Mountains & 154 & L'ricehamn & $7 \mathrm{~S}$ & : \\
\hline The Ilarz (Brocken-summit). & 170 & Västerâs.... & $4 \mathrm{~S}$ & , \\
\hline Kolmar..... & 49 & Upsala & 54 & 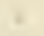 \\
\hline Bernburg. & 48 & Skara ... & 55 & , \\
\hline I'renzlau & 46 & linköping & $5^{2}$ & \\
\hline Posen ... & 49 & Växiö ........ & $5^{8}$ & trat \\
\hline Kiev....... & 53 & ,Nyköping & 56 & \\
\hline Kursk & 43 & Västervik & 52 & 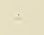 \\
\hline liessarabia & 47 & Kalmar ... & 39 & , \\
\hline Kazan ..... & 39 & Visby ....... & 49 & \\
\hline ()dessa .......... & to & Karlshamn & $5 !$ & . \\
\hline Astrachan & -15 & & & \\
\hline
\end{tabular}

evaporates directly from the surface or is collected and is carried away by the watercourses. The evaporation depends inter alia on the temperature, cloudiness, humidity, and motion of the air as well as on the properties of the soil, and consequently, varies a good deal. Nevertheless this is probably not the case to such an extent that the meteorological data become useless as relative measures.

In connection with precipitation it is appropriate to mention Cloudiness. This is of importance to the plants owing to its effect on evaporation and the supply of light. Hamberg (1909) has published data on "Cloudiness and sunshine on the Scandinavian Peninsulas.

Naturally enough these data present certain coincidences with the distribution of precipitation. The western slope of the South Swedish highland thus shows the highest values of cloudiness in South Sweden. They decrease rapidly towards the Baltic. For Öland and Gotland, therefore, the values are very low.

A comparison between the cloudiness in other parts of Europe gives Table 6 (according to Hann 1. c. and Schoenrock I895).

A summary of the above statements about the climate of South Sweden assumes the following shape:

1. Between the upland regions and the plains and coast regions surrounding them considerable differences prevail with regard to temperature as well as to precipitations and cloudiness. The contrast is specially striking between the western parts of the South Swedish highland and the south-eastern coast regions. 
Table 6. The mean cloudiness during the summer half=year (May-Septem= ber) for South Sweden and parts of Russia (according to Hamberg 1909 and Schoenrock r895), Paris and Vienna (according to Hann I, p. 66).

\begin{tabular}{|c|c|c|}
\hline Paris ....... & $5 \cdot x$ & Vänersborg \\
\hline Vienna ........... & 4.8 & 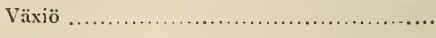 \\
\hline Central Russia. & 5.0 & Nyköping ................................. \\
\hline South Russia .. & $4 \cdot x$ & Kalmar .............................. \\
\hline West Turkestan & 1.7 & Karlshamn $\ldots$. \\
\hline Upsala ........... & $5 \cdot 5$ & Gothenburg .................... \\
\hline Västerås . . & 5.6 & Varberg........... \\
\hline L inköping ... & $5 \cdot 7$ & Lund ........................... \\
\hline
\end{tabular}

2. South Sweden is, especially as far as the summer temperature is concerned, distinctly divided on the north from the forest region of Norrland.

3. A comparison between the climatic conditions of South Sweden and adjacent parts of Europe shows clearly that South Sweden has the character of a transition area from Continental to Atlantic Europe. With regard to amount and annual distribution of precipitation south-eastern Sweden has a distinctly continental character.

\section{The nature of the soil in South Sweden.}

The nature of the soil in South Sweden has not yet been subjected to any systematic investigation. Sporadic information about it has been supplied by Andersson und Hesselman (1910), Hesselman (1911 and 1917 a and b), Tamm (1920 and 192I). About different kinds of soil and their chemical composition there are numerous reports in the publications of the Geological Survey of Sweden; here the surveys of Lindström and Törnebohm (Lindström I898; Törnebohm I90I) may be especially mentioned. For a detailed examination of the phytogeographical importance of the nature of the soil there is a very great need of comprehensive investigations.

As regards the connection of the soil with the climate the South Swedish soil-types are classed with the humid ones. Hence the water current in the ground is descending; the soluble salts and colloids disengaged in the weathering are carried away from the upper layers; the soil acquires a "podsol» type and the colloidal humus substances occur chiefly in sol condition, forming a more or less developed layer of raw humus.

The humid character of the soil, however, is of different strength in different parts of South Sweden - a fact which, if we consider only the influence of the 
climate, is especially connected with the precipitation. (To express this more accurately, the connection is to be looked for in the relation between precipitation and evaporation, and as the latter is primarily determined by the temperature, also in a relation between the quantity of precipitations and the temperature). According to Tamm (1920, p. 227), the podsolization is very weak in the neighbour hood of Kalmar, but very strong in the south-west of Sweden. The »brown soil», a less humid soil-type characterized by the facts that soluble salts are carried away, while the colloidal compounds are only in a minor degree carried away from the upper layers, and which are characteristic of the deciduous forest region in Central Europe, has also a great distribution in South Sweden (Hesselman, 1907 a, p. 399; Tamm, 1921). This type of soil is formed under the influence of a humid, but more temperate climate.

Of greater importance from the present point of view, however, are the edafic soil-types. In a climate such as that of South Sweden, which does not run to great extremity the percentage of lime contained in the weathering material and the water in the soil, and also topography, will in a high degree determine the formation of the soil.

It has already been pointed out how the supply of lime influences the nature of the soil. In South Sweden, the percentage of lime being sufficiently great, we find mould soils.

Topography is of a very great importance to the nature of the soil in climatic transition-districts. The chemical and physical changes in the soil are greatly dependent on the soil-temperature. It is natural, therefore, that a southerly exposed hillside should have a soil-type different from a level area or a northerly exposed hillside, especially if it is not shaded. Kraus's well known investigations in Central Germany (Kraus 1911), have shown how, in such cases, the temperature of the soil may reach a very considerable number of degrees, and how the nature of the soil assumes a completely continental stamp. Hesselman (1910) has pointed out that the close contact of the upper layers with oxygeneos groundwater promotes on the slopes the creation of forest types that produce a humus cover of such a character as can counteract the process of podsolization. Tamm (1920), who has made extensive examinations of soil-types in North Sweden, repeatedly points out the contrasts between the nature of the soil of hillsides and plateaus. In marked slopes there is often no podsolization (p. 131); and again a quite normal podsolization can only be expected on level terraces, or plateaus, or gently sloping hillsides (p. I33).

In judging the nature of the soil, we must thus to a great extent take into consideration the lime-percentage in the weathering constituents of the soil and the topography.

Soils rich in lime may consist of "soil produced in situ» by weathering on calca- 


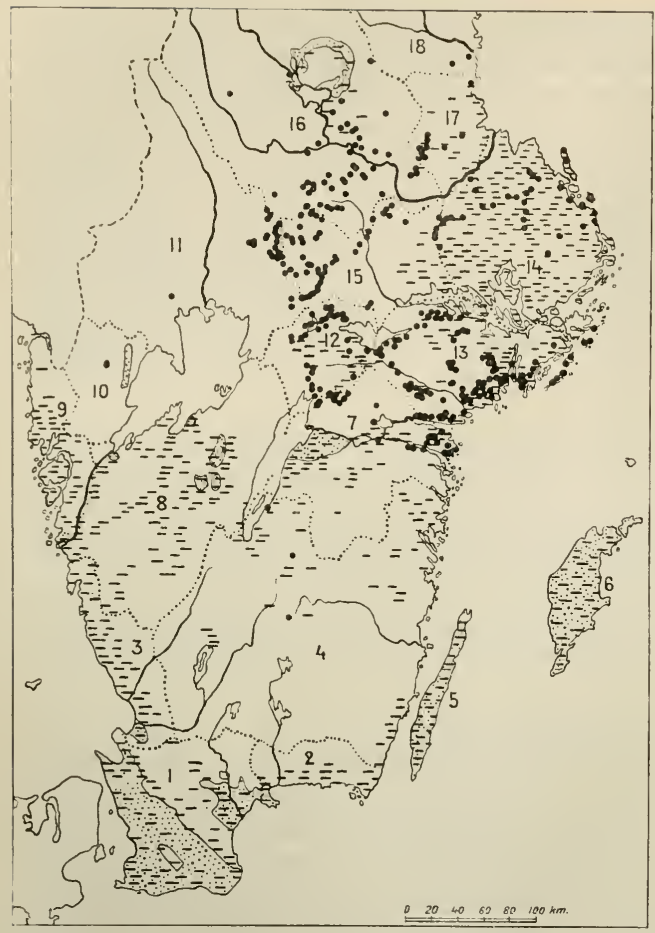

Fig. 4. The distribution of calcareous rocks and soil in South Sweden (after Flach, Juhlin-Dannfeldt, Sundbärg 1909). • : occurrences of Archaean limestone-rocks; the fine dotted areas mark the post-Archaean calcareous rocks (Silurian limestones, chalk or calcareous slates); the areas marked with short lines indicate the distribution of calcareous deposits with a lime percentage above 2.5 (clay, moraine, os-gravel). The figures indicate the provinces as follows: 1, Skåne; 2, Blekinge; 3 , Halland; 4, Småland; 5, Öland; 6, Gotland; 7, Östergötland; 8, Västergötland; 9, Bohuslän; IO, Dalsland; I I, Värmland; I2, Närike; I3, Södermanland; I4, Uppland; I 5, Västmanland; I6, Dalarna; I 7, Gästrikland; 18, Hälsingland. reous rocks or of deposits which have plenty of lime, thanks to their mineralogical character orbybeing traversed by water rich in lime.

Of calcareous rocks there are in the first place the limestones and the strongly calcareous slates, with a lime percentage of from $20-30 \%$ up to $90 \%$.

Even greenstones of various kinds (hyperites, gabbros, diorites etc.) are generally comparatively calcareous, though rather varying in their percentage of lime; the percentage of lime is said to reach Io. Fig. 4 shows the distribution of calcareous rocks and soil in South Sweden.

To this some short notes will be given, chiefly after Lindström, 1898.

Skane. Throughout almost the whole province the ground is formed of a strongly calcareous moraine or marl, $2 \mathrm{c}-30 \%$ of lime. A northern border-line can be laid down for the limerich district: From the chalk region of north-eastern Skåne to the west in the parishes of Åkarp, Vankiva and Farstorp (in the neighbourhood of Hässleholm), where it takes a bend southwards to the neigbourhood of Ringsjö and thence north-westwards somewhere along the Rönne river.

Blekinge. The lime in the striped clay (Swed. $\gg$ varvig lera»), which is wide spread in the lower parts of the province, has a rather low percentage, the average being $5.7 \%$.

Smailand. The striped clay on the coast of the Sound of Kalmar from the borders 
of Blekinge to Pataholm, reaches a mean percentage of only 5.6. In its scattered areas further north, as in the parishes of Tuma and Kristdala and in the country to the west and north of Västervik, the lime-percentage is also rather inconsiderable, $5-6 \%$.

ïland and Golland. 'The soil is, of course, almost everywhere strongly calcareous.

Ilalland. The considerable parts of the province that fall below the uppermost Late-Glacial marine limit, contain thick layers of marl. On the whole, their lime percentage decreases from north to south. Its mean values are $8.6-6 \%$, but marl with a considerably higher lime-percentage is often met with: in the interior parts of the Viska Fjord of former days, for instance, $12-14 \%$. It should be pointed out that these marl-layers are, as a rule, covered by a two feet deep clay, poor in lime.

l'ästergölland. In the districts south and south-west of the Silurian lime regions (Falbygden) there are moraine deposits (gravel mixed with clay) with a comparatively high percentage of lime $(15-16 \%)$. In the valleys of the rivers Viskan and Ätran there are icelake deposits with a pretty high percentage of lime, decreasing towards the south (8$9 \%$ in the neighbourhood of Ulricehamn, but $4-5 \%$ at Sienljunga; round Borås $7-15 \%)$. The large parts of Västergötland that fall below the uppermost marine limit are covered by marine clay with a weak lime-percentage; on the great plain south of Jake Vänern the lime-percentage seldom exceeds $2-3$.

Bohuslän. As in Halland, the marine marl is covered by less calcareous clay. The lime-percentage decreases from south to north $(5-7 \%$ in the south, but almost limeless clay north of Fjällbacka). - Shell deposits with a high lime-percentage are widespread.

Dalsland. Calcareous clays are lacking within this province. The calcareous slates in the north-eastern part, however, are of great importance.

Ostergötland. Besides in the Silurian lime district (the Omberg-Roxen-Motala region), there are very calcareous types of soil on the plain south of it (moraine with an average of $17.5 \%$, os-material with $16.4 \%$ of lime). The plain is bordered on the south by the Archaean rock of Holaveden, which, however, comprises scattered occurrences of a comparatively calcareous moraine or os-gravel. On the eastern parts of the plain, the country round linköping, the only calcareous soil-type is glacial clay, which contains an average of only $5-6.5 \%$.

Södermanland. In the country round Stockholm the lime-percentage in the clays is S-10\%; along Lake Mälar and in middlemost Södertörn 4-6\%; further south and west it continually decreases.

Närike. In a few minor areas there are remains of Silurian clay- and alumslates and some limestone. The lime-percentage in the moraine is rather low; the average about $5 \%$. Striped clay occurs sporadically, but only at a great depth and with an inconsiderable lime-percentage.

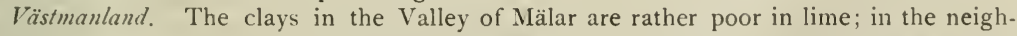
bourhood of Sala, $8-10 \%$, in the south-eastern part of the province, only $4-6 \%$; and to the west it decreases still more. West of the country about Tillberga there is 110 clay marl.

Uppland. In the north-east the lime-percentage in the moraine and the clay is even at small depths very considerable, generally $20-30 \%$. From here it decreases towards the south and south-west. About Upsala it attains an average of $12-20 \%$, but towards the east about Norrtälje it keeps between 8 and ro \%. In the southern part of the province the lime-percentage is pretty constantly $10-12$. 
Gästrikland. Silurian limestone occurs on Limön, outside Gävle. On the coast up to a level with Ockelbo in the north there is clay marl.

Dalame. In aring-like region round Lake Siljan there is Silurian limestone, which in places nearly reaches the surface (especially in the parishes of Boda, Orsa, Rättvik, Ore, and on Sollerön). Within the Boda valley and in the valley from Ore towards Orsa in this district the marl has a high percentage of lime ( $15-17 \%$ ). Moraine clay and moraine gravel with an average lime percentage of 4 is also found in the Archaean rock district south-east of Lake Siljan (in the parishes of Leksand, Al and Bjursås).

Yärmland. The clays on the shores of Lake Vänern are poor in lime.

In this survey the greenstones have not been mentioned. Yet they may locally be of great importance. Concerning their distribution the zone of hyperite occurrences in western Sweden may be mentioned. It stretches all through central Värmland, through Västergötland and western Småland down to northern Skåne. In Småland, however, hyperite occurrences are scarce. (Compare Hård av Segerstad 1920, Ringius 1888, and Tamm 1921).

In large parts of the plain of South Sweden there are consequently more or less strongly calcareous types of soil. - From a phytogeographical point of view, - as has been said above - the importance of these lies not so much in the fact that they contain rich quantities of »nutritive salts» as in the influence of the latter on the chemical changes in the soil and its development from a physical point of view. It is here, however, that the lack of investigations stands out most clearly.

In accordance with the comparatively plenteous precipitations and scanty evaporation there would seem to be a downward water-current in the ground in almost the whole of South Sweden. Hence more or less soluble salts are carried away from the upper layers. If this transference is active enough, and if no new quantities of salts are supplied, the upper layers ought sooner or later to be leached. For this reason it is conceivable that the upper layers may be very poor in electrolytes, while the latter are plenteous in deeper layers. It is then not so much the mere occurrence of a calcareous type of soil that should be examined, as just the nature of the upper layer, where the plants are generally rooted.

We have no detailed knowledge of how far there is such a washing out of the soil in South Sweden. In the accounts of the clay districts of the West Coast published by the Geological Survey of Sweden it is said that, on the calcareous clay, there rests a layer of limeless clay to a depth of one or two feet. This layer is interpreted as a layer of striped clay which has been washed out. (See the descriptions appended to the Halmstad" and "Varberg» mapsheets.)

Andersson und Hesselman (1910) ascribe to the washing out a very great importance with regard to the nature of the soil in the arable land. They say: 
》Diese Auswaschung ist in grossen Gebieten so bedeutend, dass die Ackererde auch in ausgeprägten Kalkgebieten so kalkarm geworden ist, dass die Ertrags fähigkeit westntlich dadurch herabgesetzt worden ist. Man hat dem nunmehr endgiltig durch Mergelung des Bodens abgeholfen, was in der Weise geschehen ist, dass man sich in den unteren, noch kalkhaltigen Moränen und Tonschichten heruntergegraben hat».

For Norrland (Jämtland) Hesselman (1917 a) and Tamm (1914 and 1920) have proved such a considerable washing out of the upper layers on a level surface that a decided podsolization may arise in strongly calcareous soil.

It appears from what has been said that in the parts of South Sweden where precipitations are plenteous, there is probably a rather great washing out of the upper layers going on. We cannot expect localities suitable for the species in question to exist in western Sweden in the same high degree as the more calcareous types of soil above mentioned. Thanks to the latter, however, localitics of this kind may arise, even if they arise more or less edaphically, namely on hillsides. Often the calcareous ground-water reaches to the surface or comes near it on such hillsides and causes different changes in the soil with a more or less decided mould-profile as the result. Owing to the more powerful exposure alone more favourable conditions should exist on the hillsides.

In a summary of the data enumerated above regarding the nature of the soil of such localities in South Sweden where continental species are found, the following points must be emphasized:

I. The humid climate of South Siveden is not developed to extremes. The chemical composition of the weathering soil and the topography may thus in a high degree influence the nature of the soil.

2. Soil-types of a nature evidently suitable for continental species are in the first place found in connection with the occurrences of calcareous rocks, especially on the moraines formed by the latter (Öland, Gotland, Skåne, Östergötland, Västergötland, Närike, Uppland).

3. Marine sediments (clays) with a more or less great amount of lime are widely distributed in plains that fall below the uppermost marine limit. However, their importance would seem to be highly decreased by the fact that they are often situated fairly deep down, and also by the fact that a pretty considerable washing out of the upper layers has probably taken place in western Sweden, where precipitations are abundant. - Above the uppermost marine limit there are occurrences of comparatively limerich ice-lake clay, especially round the south end of Lake Vättern.

4. The importance of topography with regard to the nature of the soil rests in the fact that, on hillsides, a ground water containing electrolytes may penetrate to the surface and influence the formation of the soil, also in the fact that, 
thanks to the higher temperature of the soil, chemical processes more favourable for the creation of the soil-types in question take place on southerly exposed hillsides.

\section{Chapter V.}

\section{The history of the South Swedish flora with regard to its importance for the present distribution of continental species.}

Modern phytogeographical science is not justified in assuming the same disparaging attitude as did Grisebach towards geological causes in the distribution of species. There are nowadays many important facts known concerning the history of the flora and in many questions historical phytogeography can build on an altogether inductive basis.

This is especially the fact with regard to the researches into the evolutionary history of Scandinavian vegetation. The geographical evolution of Scandinavia since the Glacial Period, as being from special reasons comparatively easily accessible to research, has been explained to a greater extent than that of any other district. By this means we have got fixed starting-points for an investigation of the post-glacial immigration history of the flora.

Vet even in this respect many problems remain unsolved. The great results of the keen research work are in many cases subject to various interpretations and have given rise to various opinions, even on questions of fundamental importance.

A general account of the history of the South Swedish flora does not seem necessary for our present purpose. In this chapter that history will be treated only in so far as it is of importance for the explanation of the present distribution of the species in question.

A detailed account of the history of the South Swedish vegetation, with regard to its continental features, has been given by Sernander (1908). See also the following works: Sernander 1894, Andersson 1896 and 1906, Samuelsson 1910.]

The present distribution of species may reflect the history of the flora in chiefly two ways:

1. The immigration-routes of species to a district may more or less determine the present distribution; this implies that the species have not yet had time, or owing to external hindrances (for instance, topographical ones) have not been able, to utilize fully their possibility of occurring within the district.

2. The species have relic occurrences, i. e. now isolated occurrences, forming remains of a formerly wider and more even distribution, which was rendered possible through conditions more favourable to the species. 
IVith a few exceptions, the immigration of the South Swedish flora took place from the districts south or east of the Baltic Sea. Can different routes of immigration be fixed? And do they in any case determine the present distribution?

In his important work "Bidrag till den Skandinaviska Vegetationens historia" F. W. C. Areschoug $(1866)$ has called attention to the fact that among the South, South-East or East European species in the South Swedish flora many are missing in Denmark, and a large number of them even in Skane, although localities suitable for them can hardly be lacking in those regions. Following Forbes's investigations into the history of the British flora and those of Sven Nilsson into the history of the South Swedish fauna, Areschoug points out that this fact would be fully explained if it could be proved that continuous land connections formerly existed between South-Eastern Sweden and the south or eastern coast of the Baltic. In that case distinct routes of immigration would have existed to South-Eastern Sweden, thanks to which fact South-Western Scandinavia (Skåne and Denmark) may have failed to acquire certain of the species that exclusively used those routes. - Areschoug also points out that some species with a purely easterly distribution outside Scandinavia are to be found only in Central Sweden and that they must have immigrated straight from the east and cannot have been able to take possession of the whole of South Sweden.

Grounds for the assumption of such land connections may be obtained in recent quarternary geological investigations. Munthe points out that the height above the sea-level of the southern shore of the Baltic formerly was much higher than now, and he considers that, like Skane and the Danish Islands, Öland and Gotland had next to land connections with the southern shore of the Baltic (Munthe "Igroa", p. 34; 》1910 b»; cf., however, also Antevs 1922). These more or less hypothetical land-bridges have been brought forward in the discussions of later times about phytogeographical or zoogeographical problems (for instance, Schulz 1904 and Hofsten 1919; from the latter work it is evident that there are rather strong zoogeographical reasons for the acceptance of land-bridges). It would not seem necessary, however, to demand any land-bridges in order to find the explanation of the distribution of the plant-species mentioned. Attention should be paid to the fact that the plants have a very important vehicle in the marine drift. Sernander has shown the remarkable nature, quantitatively and qualitatively, of the composition of the Baltic drift (Sernander I894, p. Ii i ; 90 I b, e. g. pp. I $34 \mathrm{ff}$. and $140 \mathrm{ff}$.). In any case we may safely leave it to the future to find out in what manner this immigration may have taken place.

Of greater importance from the present point of view it would be to find out in what way the immigration routes of species may determine the present distri. bution, and how far the distribution of species on the opposite side of the Baltic coincides with a possible immigration from the east or south-east to South Sweden.

19 Geografiska Annaler 1922. 
As to the former question, it should be pointed out that a large sheet of land where suitable localities for a certain species are missing or are very rare, and which consequently has to this species the character of a desert, must form a very important hindrance to dispersal. To certain species that have immigrated to South-Eastern Sweden the South Swedish highland may be supposed to form such a hindrance. In the following examination of the distribution of continental species in South Sweden this point of view should thus be considered: To what extent can the South Swedish highland have been the cause of the absence from South-Western Sweden of certain species occurring in South-Eastern Sweden? In complete analogy with this the question may also be put: whether species that have immigrated into South-Western Sweden have been prevented from reaching the south-eastern parts?

A great number of Areschoug's species are confined to Öland and Gotland. There they have their most northerly or north-westerly outliers in their whole European area. These occurrences may be looked upon as caused by the exceptionally favourable habitat-conditions in these islands and by the presumption of suitable localities for them being missing in other parts of South Scandinavia (cf. Areschoug 1. c., p. 72 ). For these as well as for the more widely distributed species, especially such as have a great extension in Central Sweden, however, it seems a priori not impossible that the reason to their distribution to some extent may be found in the immigration routes.

These. immigration routes of species to South Sweden, however, must be dependent on their distribution on the other side of the Baltic. The species, observed by Areschoug, have an easterly or south-easterly distribution in these regions. As to these species it may be necessary to assume an immigration to South Sweden on an easterly or south-easterly route and it may be conceivable in some cases that the South Swedish highland has made a hindrance to the dispersal into the south-western parts of the district.

Of greater interest in the judgment of the importance of such an immigration route it may be to make an investigation in this direction: Are there species occurring only in the south east of Sweden which are distributed far to the west in North Germany? Why have these species in such a case had greater possibilities to reach the south-east of Sweden than the south-western part of it? And: In what degree have species belonging to different vegetation types (steppe species, wood species etc.) made use of different immigration routes?

Later on, in chapter ix, we will have an opportunity to enter somewhat on these subjects. However, in this paper I can only in certain respects hint at the interesting problems that the study of Areschoug places before us. A more intimate investigation, being obliged to take into consideration the flora in its entirety, space does not permit. 
The distribution of a species may be determined by historical reasons even so far that its isolated occurrences within a district are remains of a formerly existing. wider and more even distribution. The species has been able to hold on only in rare, specially qualified localities, where the habitat conditions have remained favourable to it, while they have been changed in other parts of the district, thereby causing the species to disappear.

The isolated occurrences of a species may, however, have yet another reason. The species may never have had any wider distribution in the district than the isolated occurrences of the present day. These may be the first ones in an immigration now in progress; or they may correspond, nowadays as in times past, to the only localities suitable to the species. They are in any case the result of a dispersal from afar which may have taken place quite recently.

In most cases it would seem very difficult to determine the nature of the isolated occurrences. The capacity of the species for dispersal from afar should of course be examined, but it is often difficult to ascertain with certainty the presence or absence of such capacity, for in this case a rare mere chance may be supposed to be sufficient. In the history of the flora, however, we have another starting-point. If, on another basis, it can be proved that the flora as a whole must have been subjected to corresponding general changes, it is of course more probable that the isolated occurrences are real relics.

It is characteristic of many species which are markedly continental in their distribution that their distribution-area gets broken up into small areas that become more and more isolated and diminished towards the western limit of the species. In South Scandinavia there are several examples of such isolated occurrences that are the furthest outposts towards the west or north-west of the species. These occurrences have long been regarded as relics from an ancient wider and more equal distribution. What reasons are there for such an opinion?

It must be regarded as proved that, during the Quarternary era, Middle Europe passed through one or more periods with a climate of a more continental character than the present one. That this is the case with South Scandinavia is beyond doubt. With regard to the number and date of those periods, as well as the degree of continentality of the climate, however, there are different opinions. It does not seem necessary to give an account of these differences here. In the sequel I shall accept the theory which seems to me the one at present most generally accepted by quarternary geologists, namely that expounded by Sernander and von Post.

According to this theory, Sweden has had two such climatic periods: the Boreal Period and the Sub-boreal Period. The latter is placed at about 3 ooo or $2500-500$ B. C. See further Sernander, e. g. 1908, 1910, 1916; von Post 1920 (in this work the continentality of the Boreal Period is restricted to hold good 
chiefly only for South-Eastern Sweden; compare Andersson, for instance, I 906 and 1910$)$.

In the vegetation xerothermous species occupied a more prominent position than at present. It is of especially great importance that the nature of the soil must have been quite different to what it is now. In such a dry and hot climate the soil must have been of a continental character even in many localities of another character than those in which, nowadays too, special edaphic conditions may give rise to a more or less continental type of soil. The continental species which are strongly tied to more or less continental soil-types should then have had considerably increased possibilities to extend their areas at the same time as the greater warmth of the summers must have directly influenced their thriving.

It is thus established that isolated occurrences of xerothermous continental species in South Sweden may be explained by the fact that there formerly have existed other climatic conditions more favourable to those species.

Further, in chapter ix, I will a little more in detail treat the relation between some isolated plant occurrences and the history of the South Scandinavian flora.

\section{Chapter VI.}

\section{Survey of the continental element in the South Swedish flora.}

From table I (p. 230) it is evident that the South Swedish flora is closely connected with the flora of the central part of the Middle European plain. Of the species of the South Swedish flora $90 \%$ are found in Brandenburg and West Prussia; 85,84 and $83 \%$ are in common with Silesia, northern France and Livonia. For Kazan, Moscow and South-East England the percentage of species in common is, on the other hand, 62,66 and $73 \%$. Taken on an average $80 \%$ of the species of the South Swedish flora are in common with that of one of the other special districts, a very high figure, inferior only to the one shown by the Livonian flora, which is $82 \%$.

If, on the other hand, we examine how large a part the species, in common with South Sweden, form of the flora in each of the other special districts, we arrive at the highest percentage, 91 , for Livonia, then at 81 and 80 for West Prussia and Brandenburg respectively, the lowest percentages being those of SouthEast England and Northern France with 71 each and Moscow with 72. The average is here $77 \%$. If we compare this with the average for the other special districts, we shall find the South Swedish flora occupies an intermediate position; four special districts have a higher average, viz. Brandenburg 86, West Prussia 85. Silesia 84, and Northern France 79; five have a lower average, viz. Westphalia 76, Livonia and Sout-East England 72 each, Moscow 69, and Kazan 6r. 
Hence the South Swedish flora does not in any way break the uniformity in the flora of the Middle European plain. The northerly, Subarctic species that might perhaps be expected to give it a more isolated position is a very little marked element in the flora. The differences between the South Swedish flora and that of the North German districts depend in a higher degree on the fact that certain North German species are missing in South Sweden, than on the fact that the South Swedish flora has some species of its own.

With regard to these facts it may perhaps be questioned whether it is suitable to class South Sweden (Skăne with Öland and Gotland excepted) with the Subarctic zone, as is done in the flora systems of Engler, Rübel, and other authors. It would seem more natural to let the boundary between the Subarctic zone and the Middle European one ( Central European» in Rübel) coincide with the northern limit of the oak or the boundary between the Central Swedish plain and the Norrland coniferous forestland. - If we assume with Drude (1890) a »Baltic region» comprising the Middle European plain, the whole of South Sweden up to the limit of the oak in the north should naturally (as is also the case in Drude) be classed with this region.

The intermediate position of the South Swedish flora in this Baltic flora district appears from the above statements. However, the flora attaches itself most closely to the special districts in the western part of the Sarmatian district (Drude's »East Baltic»), West Prussia, Brandenburg and Livonia.

I estimate the number of continental species in the South Swedish flora at about 115 , corresponding to about $12 \%$ of the total number of species that are real natives. Yet some of these continental species approach other types of distribution. The statements given in Table $I$ (p. 230) of the number of continental species in other Middle European special districts may be supplemented by the statement that the Danish flora counts about 70 and the Norwegian flora about 55 continental species, corresponding to 8 and $5 \%$ respectively of the total number of species in these districts. It must be noted, however, that 5 of the Danish species occur only in Bornholm, and that a considerable part of the Norwegian species is formed by Subarctic-Boreal species.

In Table 2 (p. 234) are given some accounts about the mode of occurrence of the continental species in South Sweder. It may be remarked that while the South Swedish flora has about 42 steppe species, the Danish flora comprises 28 and the Norwegian flora only 14. On the other hand, Norway has got all the continental coniferous forest species of South Sweden and all its continental species of mesophytic thin broad-leaved forests except one. 
How are the South Swedish continental species divided between the established general distribution types (p. 238)? In many cases the classing of a species with a certain distribution type is rather difficult, because the distribution of species often forms a transition between two types. Calculation has given the following results (the figures within brackets give the maximum number of species):

Meridional:

Pontic: 7 (9). - Out of these there are to refer to the

Danubian variant: I (2), Lactuca quercina and (Inula ensifolia) - to the

Variants of transition-types: 4 (6).

Pontic-(South and) Central European: 8 (10).

Pontic--Subatlantic: 2.

Meridio-Boreal:

Pontic-Sarmatian: 4 (6).

Ponticosarmatian-Central European: 26 (38).

Pontic-Baltic: 3 (4).

Ponticobaltic-Central European: 2 (4).

Boreal:

Sarmatian: 12 (14). (The Cassubian are included.)

[Cassubian: 5 (6).]

Sarmatian-Central European: 16 (26).

Baltic-Central European: 4 (ro).

Siberian: 4 (5).

Concerning the distribution of the continental species in South Sweden we may here, without entering into a close examination, state that it varies largely. A considerable number of species, 18, are spread over practically the whole district and do not reach their limits until further west, while on the other hand a great number of other species are limited to Öland and Gotland (18) or Skåne (4). If we look at the extension of the distribution area towards the north in Sweden, we shall find a somewhat greater coincidence, in so far as only a couple of species reach far enough north of the Central Swedish plain.

Without the aid of a close examination a connection between the distribution and mode of occurrence in South Sweden may also be stated. Species belonging to steppe-like vegetation (xerophilous herb and grass communities) have generally a less comprehensive and easterly or south-easterly distribution, whereas the species of the coniferous and broad-leaved forests are more evenly distributed.

A list is given in Appendix I of continental species in the South Swedish flora besides information about the chief features of the general distribution of species in Europe: the boundaries of the species in Russia and Central, Western, or NorthWestern Europe. The species are here arranged in groups according to their 
mode of occurrence in Eastern Europe, as far as this has been ascertained with the help of accessible literature. A list of the literature used for this purpose will be given in connection with the more detailed treatment of the separate groups of species. A list of the literature used for fixing the distribution area of species is given in Appendix I.

With several continental species of South Sweden I have tried to map down the European distribution, the main object being to exemplify the types of distribution, described above (Plate 13-22). In drawing these maps I have followed the principle of showing the western limits of the species as fully as possible and give a schematic account of the rest of the area. The dots on the maps indicate the westernmost (and northernmost) occurrences of a species, and short lines mark the distribution areas of the species inside the western limits. Regions in which the occurrence of a species is very uncertain are fine-dotted.

Naturally the maps cannot satisfy great demands as to exactitude. The enormously extensive literature is not so easily accessible. In many cases it would further seem impossible to get rid of the probably not infrequently mistaken statements given in the literature. One reservation should especially be made concerning the representation on the maps of the distribution of species in Russia. What the maps in the first place are meant to show, however, is the most important characteristics of the distribution-type, and on that point they are probably fairly accurate.

In treating the distribution of species within such wide areas as the whole of Europe, one may easily commit the error of treating as a unit two or more proximal species. For the mapwork I have therefore tried to choose the species with discrimination as great as possible.

Another question of great importance is: what is to be done with collective species in discussions about the nature of the limits of the areas? Can collective species be treated as units, or are elementary species to be treated as equal to so-called "good species"? To enter into a discussion of the theoretical problems here met with is not permitted by the space. I will only point out that I have followed modern monographs on critical groups of species, and with regard to their general distribution and mode of occurrence I have treated the South Swedish types as elementary species. Yet I consider the distribution conditions of such species should not be placed on the same base as so-called "good species", when the investigation concerns such wide areas as the whole of Europe, for the limits of the elementary species are probably often of a different nature than those of the "good species». In studies concerning the distribution of species within such small areas as South Sweden, on the other hand, elementary species may in the present case be treated in the same way as "good species». 
Quite in the definition of the continental element in the European flora (p. 229), it was pointed out that the said element does not by any means form any sharply defined part; numerous species form even series of transition to other elements of distribution. In investigations of the South Swedish flora the separate position of the continental element is even less prominent. With regard to both their mode of occurring and their distribution, continental species often may coincide with species with a different general distribution.

Hence the distinguishing of the continental species in the South Swedish flora would often seem rather artificial. It would seem particularly unnatural to separate the Pontic steppe species possessing advanced outposts in South Sweden, from the South or Central European xerothermous species that occur there in a very similar way. South or Central European species of this type are, for instance: Anacamptis pyramidalis (Öland and Gotland, in dry meadows), Anthericum liliago (on the sandfields of eastern Skåne, in Blekinge [one locality], on the Alvar of Öland), Fumana vulgaris (Öland and Gotland on the Alvar), Globularia vulgaris (Öland and Gotland on the Alvar), Helianthemum »canum Baumg.» and oelandicum (on the Alvar of Öland), Orchis ustulata (dry meadows of Öland and Gotland, in Skåne, Blekinge [and in the Stockholm coastal skerries?]) and militaris (like the former, but not in the Stockholm archipelago), Thalictrum majus (Gotland and the coastal skerries of Östergötland), Viola alba (Öland at Borgholm in dry shrubberies), Lathyrus sphaericus (Skåne: Kullen and in one locality in S. Bohuslän).

The ecology of similar species may, of course, coincide with that of the steppe species, just as there are in several tracts steppe-like geographical conditions in South and Central Europe. An examination of the distribution of the South and Central European xerothermous species in South Sweden must thus give about the same result as an examination of those of the steppe species.

The limitation of the number of species treated in this study (such a limitation was necessary for practical reasons also), however, is in full agreement with the problem of this investigation, viz. what is the mode of occurring and distribution in South Sweden of the South Swedish species that are widely spread in continental Eastern Europe? In other words, the enquiry does not concern species of a certain ecological character, of which moreover we can know only very little, but species with certain common character in the matter of their general distribution, to which, in many cases at least, an ecological feature may be added, but at the same time also other features that are important from a chorological point of view, for instance the history of the distribution of the species. 


\section{CHAPTER VII.}

\section{Methods and Principles for the enquiry into the distribution of con- tinental species in South Sweden.}

An indispensable condition for a close discussion of the distribution of species is a thorough knowledge of their distribution itself. The first object of this examination has consequently been to acquire the greatest possible material in the way of data as to localities for the species in question.

My material has been acquired in the following way:

I. From the literature. Space does not permit me to give a list of the works consulted; but such a list will be given in a special part of this thesis, which is now in preparation. I have tried, as far as possible, to utilize also the comparatively considerable material that is to be obtained from manuscripts, letters accounts of travels etc. As will easily be understood, the examination of these takes a very great amount of time, and consequently I have not been able to use all possibilities in this respect.

2. From the herbaria of the greater museums: Upsala, Botanical Museum and Phytobiological Institution; Stockholm, State Museum of Natural history. These three I have myself examined. Lund, Botanical Museum, from which the localities have kindly been listed for me by the Conservator O. R. Holmberg. Add to this some minor herbaria belonging to public schools or private persons, which I have been able to utilize chiefly thanks to the kind assistance of other persons.

3. Through observations of other persons not hitherto published in the ways above mentioned. I have obtained a very great part of my material through other persons giving me information about their observations. If I had not in this way received considerable help in the collection of the material, it would have been impossible to carry out this investigation within a comparatively reasonable time. I am greatly indebted to those who have helped me in this for the ready courtesy they have always shown to me.

4. Through my oun obscrvations. During the last four surnmers I have made a number of journeys in south-eastern Sweden. These journeys, however, have been planned not only to study the distribution but also, and in certain cases chiefly, to study the habitat conditions of certain species in already well-known stations. The following districts have been visited. In 1918: eastern Skåne, western Blekinge, the Emå valley in Småland (from Vetlanda to Målilla). In 1919: eastern Småland (from Misterhult and the neighbourhood of Säfsjö in the north to the border of Blekinge in the south), northern Blekinge (the parishes of Sillhöfda, Öljehult, Backaryd, and Ronneby), Falbygden in Västergötland, and the neighbourhood of Mjölby in Östergötland. In 1920: eastern Småland: the dis- 
trict between the rivers Alsterån and Emån from the parishes of Ramkvilla and South Solberga in the west to those of Målilla, Fågelfors and Bäckebo in the east; the parishes of Tuna and Misterhult; the Misterhult-Västervik coastal skerries; and northern Tjust from Dalhem-Lofta and East Ed in the south; south-eastern Östergötland (south and east of the lines S:t Annae-East RydVärna-Grebo, and easternmost Kättilstad) and the neighbourhood of Omberg; Falbygden; Södermanland (the neighbourhood of Nyköping and the country round Lake Båven); Västmanland (Kolbäck and Sala); and Gästrikland (the neighbourhood of Gävle). In I921: Småland (the neighbourhood to the east and south-east of Säfsjö and the westerly parishes of southern Tjust); Östergötland (the Stångå valley, the neighbourhood of Kisa and the border-lands towards Tjust); Södermanland (Rekarne and the central part of the province from Malmköping towards Trosa). - Besides the above, I have also made less thorough journeys in western Småland, on the Västgöta plain and in South Halland.

In each of these years I made a number of excursions in Uppland, especially in the neighbourhood of Upsala. Besides, comprehensive phytogeographical studies in Öland have to some extent been used for this treatise. In the summer of 19 I 7 I visited Gotland and examined certain plant-communities of a continental type.

The material used by me certainly very nearly contains all that is at present known about the distribution of the species here treated. Parts of South Sweden being still imperfectly known as to their flora, there are certain gaps in the material. The more important of these are parts of Småland, especially the district to the north of the upper Emå valley, between Vimmerby and Eksjö.

An important question is how far the material may be deemed accurate. The possibility of errors in one statement or an other can hardly be denied. False statements have been laid bare as well in literature as in the herbaria of our museums. I have found it necessary to treat the material from these sources criticcally as far as possible, and I have omitted or specially marked the statements I have found doubtful.

It is naturally of special importance to know in what degree the information given to me by other persons is reliable. In most cases the competence of the informants would seem to exclude any suspicion of errors in the statements. Further, the information in question is often the result of researches made with special regard to the species required by me and thus not given from memory. The reliability of the material would also seem to be increased by easily observed and not critical species being chosen for the inquiries. Besides, it is clear that, ever since the material reached a certain extent, I also got fairly great possibilities of directly judging the reliability of the statements. For instance, my knowledge of the habitat conditions of the species rendered me capable of 
judging the degree of probability of the occurrence of each separate species in a certain district.

Even if one or other statement should prove erroneous, nothing will probably have to be abandoned in the conclusions and the discussions, as far as they are based on floristic material.

It would have been very desirable to publish the material in extenso here. Space and expense have prevented this. The material is so extensive that this treatise would be more than trebled in scope if the material were thus added. All the statements have been accurately indexed, and a complete, suitably worded list will be deposited and made accessible at some public institution. I further hope to be able soon to publish at least the essential part of the material.

\section{The maps.}

The decidedly best way of making use of the material is to make it the base of distribution maps. I have made such maps for a great number of the species here treated. The method used is founded on the principle that the material should appear directly on the map; the total distribution of a species will be shown by the marking of the occurrences on the map. In analogy with what has been the case in certain earlier phytogeographical works, of which that of Andersson och Birger (IgI2) should be mentioned in the first place, I have marked the occurrences with round dots of suitable size. With such a method the distribution of species will appear in a completely exact and very clear manner, as far as the material suffices. However, the application of this method makes very great demands on the completeness of the material and hence offers great difficulties. To prove the more or less common occurrence of a species within a district solely by means of dots must meet with considerable difficulties, as, naturally, statements of occurrence in such cases are only to be obtained in a comparatively small degree. For the maps published in this work, however, I have such a complete material that in the most cases a satisfactory view of the distribution might be obtained through the distribution of the dots.

The size of the dots has been determined by a compromise between the demands that the map should be readily comprehensible and that it should be accurate. If the dots are small, there must be dense occurrences to make the map comprenhensible; if they are big, we shall miss valuable details in the distribution. - A number of somewhat doubtful localities have been given on the maps and indicated by rings.

Three types of maps have been used. A more detailed one of South Sweden, one of Scandinavia and one of Fennoscandia and Denmark. Besides, as has 
already been mentioned, attempts have been made to map the whole European distribution of certain species.

The occurrence material for the distribution of the species in Norway, Denmark and Finland has for the most part been obtained from the literature. Regarding Norway, the statements from the litterature have been supplemented by information obtained from the collections of the Christiania and Bergen Museums, as well as by unpublished observations by Mr. Ove Dahl, Conservator of the Museum, and Mr. Rolf Nordhagen, Ph. D. Concerning a few »critical» species I have myself gone through the collections which have kindly been lent to me. On the whole, however, I have to thank Professor Jens Holmboe of Bergen and Doctor Nordhagen of Christiania for these statements. - As to the distribution in Finland, Professor $\mathrm{Hj}$. Hjelt has shown me the kindness to let me make use of the material of as yet unpublished parts of »Conspectus Florae Fennicae». Docent W. Brenner, Helsingfors, has listed the localities of Ranunculus polyanthemos in the herbarium of the Helsingfors Museum. Even on the South Swedish maps occurrences in the neighbouring countries have been marked as far as the map has allowed of this. Consequently it has been possible to include Åland, regarding the flora of which a rich material of statements is accessible thanks to Palmgren (1915). The distribution there is of great importance to complete the picture of the East Swedish archipelagic distribution. - Distribution-maps have also been made for a few species that cannot be called continental according to the previously laid down principles. It is important to know the distribution of these species, as this in a high degree facilitates the comprehension of the distribution of certain continental species.

It is my hope that the distribution of the species will be adequately exhibited in the distribution maps. A verbal account of the distribution of each separate species, which would demand much space, will, I hope, be unnecessary. Consequently the distribution of the species will be discussed below chiefly from certain rather general points of view. These may be summed up thus: the general distribution and mode of occurrence of the species in Europe will be examined; the distribution in South Sweden will be treated in relation to the mode of occurrence of the species, to the geographical conditions (climate, soil conditions, topography, influence of human intervention) and, as far as possible, to the immigration history and biology of disseminating. An important object is to arrive at some certainty with regard to the causes of the distribution limits. Fixed results on this point can hardly be expected, because, as has already several times been pointed out, our knowledge of the ecology and immigration history of the species is much too scanty 


\section{CHAPTEK VIII.}

\section{The Mode of Occurrence of Steppe Species in South Sweden.}

In the list of continental species belonging to the flora of South Sweden in Appendix I the species are arranged according to those types of vegetation in which they seem to occur normally in South-Eastern or Eastern Europe. The distinguishing of the types of steppe vegetation is made according to Rübel (1914). The mode of occurrence of species I have studied in many papers on the South Russian vegetation (see the list of literature at the end of the work). For this purpose I have, however, especially made use of the reports in Korshinsky's excellent work on the flora of Eastern Russia (Korshinsky I898).

The following remarks should be added with regard to the mode of occurrence of the species in Eastern Europe:

I. Meadow steppes have many species in common with xerophilous scrubs or forests, as "steppe woods", dry wood edges, scrubs or woods on dry hillsides etc. Among Swedish species the following are in this work with hesitation classed as steppe species: Crepis praemorsa, Fragaria viridis, Polygala comosa, Prunella grandiflora, Ranunculus polyanthemos, Seseli libanotis, Trifolium montanum, and Tiola mpestris; see, for instance, Korshinsky (1. c. pp. 16, 102, 143, 175, 262, and 337), Alechin (1909 and 1910), Krassnov (1894), Paczoski (1904), Novopokrovskij (1906), Sidorov (1897), Keller (1903), Naumov (1902) etc.

Concerning Crepis praemorsa, Ranunculus polyanthemos and Seseli libanotis, the fact that they are not so distinctively steppe species is conspicuous in their distribution and mode of occurrence in the rest of Europe. In the highlands of Central Europe they have a rich »montan» distribution, but they are comparatively rare on the North German plain (see Plate I 7 ; cf. Wangerin 1920).

2. Allium montanum, which has often been confused with A. acutangulum Schrad., occurs in Central Europe, where the distribution is well known, on dry hillsides (it belongs to the »pontische Hügelformationen» of north-eastern Germany, Preuss I 9 I 2, Scholz 1905, etc.) or on rocks (e. g. Drude I885, p. I04).

It is quoted by Ascherson and Graebner from Southern Russia and by Schmalhausen (1886) from almost all governments in South-Western Russia, where it is said to be found in sandy or stony places. Korshinsky (1. c. p. 420) says: »in decliviis apricis calcareis vel arenosis.» (Obs. cf. p. 396.) According to Paczosky (1899) it occurs in Volhynia and Kiev in forests on sandy soil together with Calluna vulgaris! Whether the species is a steppe plant must be considered uncertain. Probably it grows chiefly on cliffs.

3. Melica ciliata is generally a cliff plant, yet it belongs to the pure steppe vegetation in South Russia (for instance, Borovikov 1909, Novopokrovsky 1906). 
4. Tiola pumila has in several parts of its area of distribution been distinguished only in late years, and consequently some uncertainty may be inherent in the reports about it. In South Russia it seems to occur chiefly on the steppes. Korshinsky (1. c. p. 53) says: in steppis stipaceis, decliviis apricis (imprimis calcareis) stepposis necnon in pratis stepposis». Litvinov (1886) quotes $»$ V. pratensis M. K.» from the government of Tambov, and reports that it there grows principally in "steppelike places» on the "chernozyom». These accounts are confirmed by the specialist in Violae, Becker, who in his monograph on the European Violae species (Becker IgIO) quotes V. pumila from the Russian steppes, and who in a paper (Becker 1916) gives observations of his own on this subject.

5. Isatis tinctoria is at least in some parts an important distinctive plant in the Stipa steppe. It was formerly grown over great parts of Middle Europe, and it is impossible to fix its spontaneous distribution outside the steppes. It may be that it is spontaneous on the Baltic coast of South Sweden and that its occurrence here is possibly analogous to that of Silene viscosa (see later on chapter ix).

6. The mode of occurrence of the Siberian species is often difficult to make out. Carex obtusata, according to Korshinsky (1. c. p. 437), occurs only on rocks in its East European localities in the Urals (gov. of Perm and Orenburg); in its inconsiderable localities in Central Germany it seems to form part of herbaceous sand-grass heaths or dry meadows on hillsides (Drude 1902, p. 416 and Ascherson in Verh. d. botan. Vereins d. Provinz Brandenburg, Bd. 39, pp. xLii ff.).

Halophytic Steppe Species. A separate position is occupied by the species which are peculiar to the halophytic steppe: Bassia hirsuta, Plantago tenuiflora, Atriplex pedunculatum, and Artemisia rupestris and laciniata. Outside the steppes these species exist principally on the seashore or in other places where the soil is rich in salt.

Bassia hirsuta has its few localities in Europe, except in Southern Russia, exclusively on sea shores (Plate 13).

Atriplex pedunculatum, besides having a fairly wide distribution on the shores of the southern Baltic Sea and the North Sea, has also some localities in saltish places in Central Germany (e. g. Drude 1902, p. 39).

Artemisia mestris, which has its principal distribution in Siberia, occurs in two localities in Central Germany in saltish places (1. c. pp. 387 ff.), but on Öland and Gotland, where it has a wide distribution on the pavement of the "Alvar», it is often found in a heath- or steppe-like vegetation in shallow soil, which during the winter half-year is rich in water and shows decided signs of a heav- 
ing up of the ground by the freezing of the water. The species can, however, though rather seldom, form part of a halophytic vegetation on the shore. At Södvik in the parish of Persnäs on Öland I have observed Artemisia rupestris on the sea-shore, growing together with Artemisia maritima, Juncus Gerardi, and Suaeda maritima (comp. K. Johansson 1897, p. I I 5 ).

Plantago temiiflora (Plate 13) has only one definitely known occurrence outside the South Russian and Hungarian steppes, namely Öland. It is distributed all over that island on the Alvar-pavement. In spring, when the species has its vegetative season, its stations are damp. The soil is a very thin crust (only a few cm. thick) of mouldy, strongly calcareous "alvarmo» on the limestone pavement. The ground is already dried up by Midsummer. The composition of the vegetation may be illustrated by the analyses in Table 7, Appendix II.

Artemisia laciniata IVilld. Korshinsky (1. c. p. 219 ) says about the mode of occurrence of this species in Siberia: "Non solum in salsis, sed etiam in rupibus et in pratis silvaticis vel inundatis occurrit.» Besides those on Öland, this species has only three occurrences in Europe. In Lower Austria it is found at Lassee and there it occurs, according to Beck (1890), »auf feuchtem, salzhaltigem, lettigem und sandigem Boden» (p. 32). In Germany the species occurs, together with A. rupestris, in two saltish places in Saxony and Thuringia. On Öland it belongs to dry meadows (see the analyses in Table I, Appendix II), a mode of occurrence which corresponds to »in rupibus et in pratis silvaticis».

The way in which Artemisia rupestris and Plantago tenuiflora occur outside the steppes is worthy of special notice. The species show themselves to be independent of any large amount of salt in the soil. The characteristic feature of their sccurrence on Öland and Gotland is the extreme development of the habitat in another respect. The ground is strongly calcareous and nearly dried up during a considerable part of the vegetative season. No doubt these two species have, like certain other species in the peculiar Alvar-flora, a high osmothic pressure (Falck 1913). Thanks to this inter alia they are able to stand such extreme habitats. Species of the Stipa Steppe, the Sand Steppe, and the Meadow Steppe. The steppe species which form part of the South Swedish flora have in many cases a large distribution in the forest region of Central and Northern Russia. They appear here partly on cliffs, partly in a xerophilous herb and grass vegetation which attaches itself either to the meadow steppe or otherwise more or less to the sandsteppe.

The meadow-steppe-like vegetation is found on southerly exposed slopes, especially such ones with calcareous soil (Korshinsky: »declivia aprica argillosa vel calcarea») in the whole of the forest region. The sand-steppe-like vegetation seems to occur especially in tracts with a scanty rainfall in Middle Russia, chiefly as ground vegetation in thin pine forests. 
The stock of species belonging to the steppe flora decreases naturally farther to the north. Nevertheless steppe species are still to be found not far from the coast of the Arctic Ocean. Pohle (1903, p. 93) has described from an area south of the Kania Peninsula xerothermous hillside communities, surprisingly rich in species and including many steppe species; and from the lower Lena in Siberia Cajander (1906 a) mentions as growing on calcareous hillsides a vegetation rich in species which comprises several in common with the southern Siberian steppe vegetation.

The xerophilous herb and grass communities in other parts of Middle Europe which contain steppe species attach themselves more or less to the steppe communities. As outposts of real East European Stipa-associations might be considered a vegetation rich in Stipa pennata or S. capillata and a great number of steppe herbs, which are found in a few scattered, minor districts: north-eastern Germany on the Vistula (in southern West Prussia and north-eastern Posen; description in Scholz 1905, pp. 168 ff., and Preuss 1912, pp. 460 ff.), in Central Germany (south-east of Harz; Drude 1902), and above all in Bohemia, Moravia and Lower Austria (Hayek 1914, Podpera 1904, Laus 1910, Beck 1890 and others).

Plant communities in which steppe species are found outside the steppes may generally be divided into two types of xerophilous herbaceous vegetation. One of these belongs to the vegetation which is often called the "Trift-formation", "Triftgrasfuren», or »Grasige Triften», for instance, by Drude 1890, 1896, 1902 etc. and by Hayek 1914. Diels (1918) calls it "xerophorbium», Warming (1909) "waste herbage»; Brockmann-Jerosch and Rübel (I912) call it »Hartwiesen», "Duriprata». The second type corresponds to the sand-steppe vegetation and is shortly to be characterized as herbaccous sand-grass heaths ("Sandgrasfluren" Drude, Hayek a. o.).

The composition of the "Trift-formation» in Middle Europe varies to a great extent, according to the geographical position and the nature of the soil. In the central parts of Middle Europe, where it is abundantly distributed and often has a flora rich in species, it may, according to Drude, be characterized thus: a xerophilous fairly closed vegetation of low grasses and a very abundant herb flora. The grasses do not here form a cover as they do in the meadow; but the separate individuals are scattered about and the place between them is more or less taken up by the numerous herbs. The grasses ("Triftgräser» Drude, "hillside-grasses», Swed. "backgräs») consist principally of Festucae ovinae, F. rubra, Avenae (in the first place A. pratensis), Bromus inermis and erectus, Brachypodium pinnatum, Koeleria "cristata", Phleum Boehmeri, and Sesleria coerulea. The herbs are almost exclusively perennial (Drude I896, p. 344 ; 1902, pp. 174 ff.).

It is found on slopes exposed to the sun or on rocky ground with only a thin layer of loose soil. Within the region of the inland ice in the central and eastern 
parts of the North German plain there are specially suitable localities on the slopes of marly, sandy, or gravelly moraine hillocks and alongside the "Strom-» or »Urstromtäler» traversing glacio-fluvial deposits or loess formations (e. g. Loew 1879, Scholz 1905, Preuss 1912). In Central and South Germany the \Trift -formations are preferably housed on rocky grounds. They form inter alia part of the regetation which popular speech here calls "Heide» ("Garchinger Heide» near Munich, Sendtner 1854, pp. 447 ff.; "Wachauer Heide» in Lower Austria, Kerner 1863; Gradmann Iyoo, I, pp. 113 ff.; Drude I902, pp. 159 ff.). In the east of Central Europe the flora shows a very great likeness to that of the meadow steppe, for instance, "Die podolische Trift-formation» in Hayek (1914, pp. $286 \mathrm{ff}$.) and the so-called "Pontische Huigelformation» rich in steppe species (Preuss 1909 and 1912, Scholz 1905, Graebner 1901, Drude, e. g. 1902, etc.).

In southern parts of Central Europe a Mediterranean weft in the flora becomes more and more prominent; see, for instance, Kerner's and Beck's descriptions of the flora in the valleys of the Eastern Alps (Kerner 1888, Beck 》1907») and the corresponding descriptions of Jaccard (1895) and Briquet (1898) from the Western Alps.

In Western Europe the "Trift》-formation becomes rarer and more feebly developed and its existence is more dependent on the mineralogical composition of the soil. In south-eastern England, however, there is still to be found a fairly rich » Trift»-flora in which even a few steppe species can be met with. (Tansley 1911, pp. 95, 158, 175.)

The second type of the herb communities outside Eastern Europe corresponds to the sand-steppe. These communities are characterized by grasses (Sand-grasses) which form tufts or have long creeping rhizomes, and of a fairly rich herb flora composed partly of perennial herbs which often have widely ramified shoots, partly by annual and biennial species. The principal grasses are Festucae ovinae and F. rubra, Corynephorus canescens, Koeleria-species, Phleum-species (Ph. Boehmeri), and certain Carices, such as C. arenaria, ligerica, praecox Schreb., and ericetorum [Drude 1896, pp. 346 ff.; 1902 e. g. pp. 450 ff.; Warming 1909, pp. 265 ff.; Scholz 1905; Hayek 1.c., e.g. pp. I 28, 276; Graebner I 901 ("Heidekrautlose Sandfelder», "Grasheide", partly)]. They differ from the sand-steppe in respect of the composition of the phanerogamous flora and through the fact that the plant cover is more closed, largely owing to the abundant occurrence of shrub lichens (Cladoniae, Cetrariae).

This psammophilous vegetation may be referred to the "grass heaths» but occupies a position apart on account of their floristic composition. Stress may be laid upon the important part the sand-grasses play and the abundance of the herb flora.

It would seem to be confined to sandy areas in districts with comparatively 20 Geografiska Annaler 1922. 
continental climates. In maritime districts it is replaced by grass heaths poor in herbs and dwarf-shrub heaths. In Northern Europe it is almost entirely absent. There the sandy areas are occupied by pine forests, rich in lichens and dwarfshrubs. Hence it is chiefly between the sand-steppes of South-Eastern Europe, the pine-forests of Northern Europe and the heaths of Western Europe that this psammophilous vegetation is distributed. It reaches its richest development in Sarmatian regions. Hence I will call it Sarmatian sand-grass heath.

We often find this or a similar sand-grass heath forming the ground vegetation in thin pine forests on sandy soil. In Middle Russia, especially in the zone of the "Transition Steppe", this vegetation type seems to have a wide distribution (e. g. Flerov 1902, e. g. pp. 229, 245, 255; 1910, e. g. the plant lists 459, 562, and 762; Sukaczev 1902 p. 159, Taliev 1896, 1904, Tanfiljev 1894).

According to Drude (1902), Pax (1915), Jännike (1889), Scholz (1905), Graebner (1901) sandy areas in the eastern and southern parts of the North German plain are to a great extent occupied by herbaceous sand-grass heaths. To the west and near the coast they are replaced by grass heaths poor in herbs, Aira flexuosaand Nardus stricta-associations and ericaceous heaths (cf. Graebner 1. c., pp. 147 and 217 , and Preuss 1912). In the west they seem to reach as far as the region around the lower Elbe (Graebner 1. c., Drude 1. c., p. 450).

This vegetation-type is represented in the vegetation of South Sweden, about which further particulars will be given beiow. To judge from statements in Hayek (1914) and Laus (1910), it seems to have a great distribution in northern Galicia, in Moravia and in Bohemia. In Eastern Balticum it is principally represented as ground-vegetation in a thin pine-forest (cf. Lehmann 1895, p. 64 and Meinshausen 1878 , p. xii). In Poland it is widely distributed (Pax 1918).

I have not been able to decide whether these herbaceous sand-grass heaths are also found in western Europe. Some species of the Sarmatian sand-grass heaths have localities in these parts, especially in the sandy areas in Central France on the middle Loire (Veronica spicata, Phleum Boehmeri, Carex praecox Schreb. and ligerica, Koeleria glauca, and Peucedanum oreoselium.; cf. Sterner I 92 I a, p. 213).

Besides the types of plant communities just mentioned, the pure colony vegetation on rocky cliffs, steep sandy or clayey slopes, and rocky pavements becomes an important place of resort for steppe species. In North Germany, steep slopes exposed to the south in the "Strom- or Urstrom-Täler» are very rich in steppe species (Loew 1879, Preuss 1912, Scholz 1905). According to Drude (1902), the colony vegetation on rocky pavements and rocky cliffs in Central Germany houses many steppe species among its rich herb flora. The outposts of the steppe species to the west would in many cases seem to consist exactly of such localities. 
The South Swedish plant communities containing steppe species belong partly to the "Trift»-formation, partly to the grass heaths. They are characterized inter alia by their great number of herbs; and with regard to them great use may be made of the name of "herb-hillsides", Sweed. "örtbackar» (Hult 1885, p. 218 ; Sernander, for instance, 1900, pp. 29-34).

They are in part closely connected with the most steppe-like communities outside South-East Europe, viz. the above-mentioned "Pontische Hiigelformation» and the Sarmatian sand-grass heaths. With these, however, the South Swedish types usually have little to do. These last lack a considerable number of species; and, in accordance with the more boreal climate conditions of South Sweden, they also deviate through the fact that shrub-lichens form a bottom layer to a much greater extent.

In this very short account of the South Swedish xerophilous herbaceous grass communities that I take leave to give here, only a few types will be distinguished.

In the first instance I start from the degree of the xerophilous character of the vegetation, as that appears in the floristic composition. An important feature of the more xerophilous types - besides the differences in the composition of the phanerogamous flora - is the existence of a bottom layer formed of shrub-lichens (Cetrariae, Cladinae, Cladoniae) and certain mosses (Barbula ruralis, Grimmia canescens and ericoides, Thuidium abietinum etc.). ${ }^{1}$ The more mesophilous type lacks shrub-lichens, and other mosses form its bottom-layer (Hylocomium parietinum and proliferum, Hypnum lutescens, sericeum and plumosum, Thuidium tamariscifolium and recognitum etc.). I shall call the first-named xerophilous type "grass heaths», the latter $\gg d r y$ meadous».

Within these main types we can then distinguish subordinate types with regard to the continental character of the flora.

In the lime districts of South-Eastern Sweden, especially on the calcareous plateaus of Öland and Gotland, there is herbaceous grass-land where South-Eastern and South European species play a very conspicuous part as regards both the number of indivicluals and the number of species. These communities are very closely connected with the above-mentioned »Pontische Hiigelformation». Even in parts of the Archaean rock district in South-Eastern Sweden, where there is little precipitation, locally similar communities may be found.

On wide sandy areas in South-Eastern Sweden, especialiy eastern Skåne, there are herbaceous sand-grass heaths with many species of a great distribution in Pontis or Sarmatia. They must be ranged together with the above-mentioned Sarmatian sand-grass heaths.

Both these types seem to be characteristic of Engler's Sarmatian province and to be chiefly distributed within the latter, so I propose to call them Sarmatian.

${ }^{1}$ On steeper slopes a cover of lichens or mosses is lacking. 
In great parts of South Sweden, above all in the districts where precipitation is plenteous and lime scarce, dry meadows and grass heaths are much less developed than in the cases indicated above. They play a much smaller part in the vegetation. They occur on unshaded hillsides, especially sandy ones exposed towards the south, on oses, moraine hillocks etc. Their existence in these localities, however, is in a high degree caused by the transformation of the natural vegetation brought about by human activity. In most cases the forest would throw shade over the surface of the ground if it were not kept away by the hand of man. As the composition of the flora is greatly dependent on the degree of human influence, and as, besides, the surfaces at the disposal of the communities are often quite inconsiderable, the communities must vary greatly in their composition. The flora has many species fewer than the types mentioned before. South-East European or South European species are lacking, or are very rare. Outside South Sweden these communities would seem to exist chiefly in Engler's Subatlantic province. Hence they may here be styled Subatlantic.

Between the types thus distinguished there are naturally no sharp boundaries. Yet the Sarmatian sand-grass heath occupies a more isolated position.

According to these principles I divide the xerophilous herbaceous grass communities of South Sweden into the following five types:

\section{Dry meadows.}

a. Sarmatian dry meadous contain many South-Eastern European or SouthCentral European species, none of which, however, seems to occur constantly. The following species may be mentioned as more pervading characteristic species: Filipendula hexapetala, Fragaria viridis, Galium verum, Helianthemum chamaecistus, Hieracium pilosella, Medicago falcata, Plantago lanceolata, Potentilla Tabernaemontani, Avena pratensis, Briza media, Festuca ovina, Phleum Boehmeri, Poa angustifolia, and Hypnum lutescens and sericeum. (See Table I, Appendix II).

This type is most developed in Öland and Gotland but is also found on the South Swedish mainland where there is little precipitation, especially in the lime districts.

b. Subatlantic dry meadorvs. According to analyses, distributed all over SouthEastern Sweden from Blekinge up to Gestrikland, the following species within this area are characteristic of the vegetation type:

Achillea millefolium, Campanula rotundifolia, Galium verum, Helianthemum chamaecistus, Hieracium pilosella, Pimpinella saxifraga, Plantago lanceolata, Stellaria graminea, Agrostis tenuis, Festuca ovina, Luzula campestris, and Hylocomium parietinum. (See Table I, Appendix II.) 
II. Grass heaths.

a. Sarmatian sand-grass heaths. Characteristic species are: Thymus serpyllum, Pulsatilla pratensis, Artemisia campestris, Dianthus deltoides, Galium verum, Hieracium pilosella, Sedum acre, Carex arenaria, Corynephorus canescens, Festuca sabulosa (Ands.) Lindb. fil., Koeleria glauca, l'hleum Bochmeri, Viola rupestris, Barbula ruralis, Cetraria aculeata and islandica, Cladina silvatica, Cladonia rangiformis. For Skåne we have to add: Astragalus arenarius, Dianthus arenarius, Anthericum liliago and ramosum, and Helichrysum arenarium; for Öland Carex ligerica and obtusata. (See Table 3. Appendix II.)

These communities have a scanty distribution in South Sweden: Skåne, Blekinge on Lister and the Torhamn peninsula, and on Öland and Gotland. They are most highly developed in eastern Skåne.

b. Sarmatian hillside-grass heaths - like the dry meadows - contain several South European and South-Eastern European species (see the analyses in Table 2, Appendix II). The following may be picked out as more pervading characteristic species:

Thymus serpyllum, Artemisia campestris, Filipendula hexapetala, Galium verum, Hieracium pilosella, Plantago lanceolata, Potentilla Tabernaemontani, Sedum acre, Avena pratensis, Festuca ovina, Hypnum lutescens, Thuidium abietinum, Cetraria islandica, and Cladonia rangiformis. For Öland we have to add Helianthemum oelandicum.

This type would seem to be somewhat more confined to Öland and Gotland than type Ia. The analyses from Västergötland and Östergötland in Table 2 have only with great hesitation been ranged with the grass heaths.

c. Subatlantic grass heaths, generally on sandy soil. On sand-fields they may occupy small areas, where for one reason or another Calluna does not form the vegetation cover. Thus, for instance, on old dunes ("graa Klit", Warming). In South-Eastern Sweden, where the type merges into the Sarmatian grass heaths, it occurs principally on sandy hillsides. According to analyses distributed over the whole district from Blekinge in the south to Västmanland and Gestrikland in the north, it is in this district characterized by the following species:

Achillea millefolium, Campanula rotundifolia, Galium verum, Helianthemum chamaecistus, Hieracium pilosella, Pimpinella saxifraga, Plantago lanceolata, Potentilla argentea, (Scleranthus perennis), Sedum acre, Thymus serpyllum, Trifolium arvense, Viscaria vulgaris, Agrostis tenuis, Carex ericetorum and caryophyllea, Festuca ovina, Luzula campestris, Poa angu- 
stifolia, Polytrichum juniperinum, Thuidium abietinum, Cetraria islandica, Cladina silvatica, Cladonia rangiformis, and Peltigera canina. (See Table 2, Appendix II.)

Of steppe species that may occur in the Subatlantic types in SouthEastern Sweden, we notice Potentilla arenaria (Blekinge and Småland), Phleum Boehmeri (especially Östergötland and Uppland), and Trifolium montanum.

For a close study of the mode of occurrence of steppe species in South Sweden a fairly considerable material of vegetation analyses has been collected. Tables $\mathrm{I}-3$, Appendix II, contain extracts from this material. The scope of the present work does not allow of the publication of the whole material.

It is important to point out that these vegetation-analyses are not meant to examplify the established types in their typical composition; the analyses have been carried out only to show how steppe specics occur in South Swedish vegetation. I have tried, however, to arrange the analyses according to the above grouping of the vegetation-types, though in many cases they form transition types.

Nor are the analyses suited to form bases for a description of plant associations according to modern principles. It is true that the experimental areas have always been distinctly limited, but the size of the areas used has varied a great deal, because some analyses were carried out several years ago (I9I6 and 1917).

My analyses partly concern great areas with homogeneous vegetation, which have been fully analysed, by means of a great number of smaller squares of a certain size ( 1 or $4 \mathrm{~m}^{2}$ ) and placed in a certain unit, partly similar smaller squares chosen sporadically one by one in different places in a similar, homogeneous vegetation. The great majority of these isolated smaller areas also are of one or four square metres.

The first-named analyses are denoted in the tables by Latin figures. In these columns the number of squares in which a species is found, are given with percentage figures (the individual frequency of the species). With Latin figures (or the sign of $X$ ) are in these columns given also the coefficients of the average area which is covered by a species, the $\gg$ Arcalprozent» or the degree of covering of the species». The degree of covering is judged according to the Hult-Sernander scale of five degrees. (About the principle of this method see Du Rietz I921, pp. $224 \mathrm{ff}$.) This five-degree scale, however, has been enlarged with the sign of $X$, which signifies that a species occurs quite slightly, only in one or two individuals, and with one degree between I and II, marked I + , and one between II and III, marked II +. - The statements about the coveringdegree of species in these analyses always refer to experimental areas of one square metre.

By means of experiments I have found that, with regard to these vegetation types, a good idea of the character of the vegetation is generally obtained with experimental areas of four square metres. If the experimental areas are made larger, the increase in the number of species becomes so inconsiderable that the said size ought from $a$ practical point of view to be the one most suitable for the object in question. On the other hand, I do not wish to maintain the opinion that this area should be the minimum area of the association (the \$Minimiareal.: „das kleinste Areal, auf welchem die Assoziation ihre definitive Anzahl Konstanten erreichts, Du Rietz, Fries, Osvald und Tengvall 1920, p. 35; Du Rietz 1921 , p. 146). Even with an experimental area of one square metre, 
however, a good result may be gained in so far as the number of species, added at the increase of the experimental areas to four square metres, is rather inconsiderable. I have to a great extent availed myself of the size of one square metre, above all because wider areas with a uniform vegetation have in many cases not been procurable.

By analysing experimental areas of the size of one square metre or four square metres I consider I have gained sufficient knowledge of the character of the vegetation to clear up the mode of occurrence of steppe species.

The vegetation analyses given in the tables offer certain information about the mode of occurrence of steppe species in South Sweden. It appears from them that certain species chiefly belong to the dry meadows, others to the grass heaths. In virtue of numerous observations and examinations outside these analyses, especially regarding the Öland vegetation, I consider myself able to divide the steppe species according to their mode of occurrence in the said respect in the following manner. Chiefly in dry meadows there occur: Adonis vernalis, Anemone silvestris, Artemisia laciniata, Aster linosyris, Centaurea jacea, Crepis praemorsa, Fragaria viridis, Medicago falcata (common on Öland in a transition type and may also be found there on grass heaths; cf. Tables I and 2), Ranunculus polyanthemos, Polygala comosa, Prunella grandiflora, Senecio integrifolius (according to its occurrence Skåne: Ivetofta), Seseli libanotis, and Trifolium montanum.

With the flora of the grass heaths are to be classed: Allium montanum (according to its occurrence Skåne: Espet; in localities in Dalsland it would generally seem to be a pure cliff plant), Pulsatilla patens (according to its occurrences »File hed» and Follingbo: Skrubbshage on Gotland, K. Johansson 19r2, pp. 24 ff.; in the locality of Lojsta: Tonnklint on Gotland, it occurs in the transition zone between a sparse herbaceous pine forest and a steppe-like herb vegetation on a limestone rock. See Sernander 1894, p. 83; K. Johansson 1. c. pp. 27 ff.), Ar. temisia campestris, Carex obtusata, Helichrysum arenarium, Koeleria glauca, Medicago minima [according to its occurrence Öland: Borgholm. About the nıde of occurrence in the few localities in eastern Skåne Areschoug says (1889): „Occurs rarely on dry, sandy hillsides"; hence it even here probably belongs to a grass heath], Potentilla arenaria and rupestris (often a pure cliff plant), Stipa pennata (see the analyses of Vartofta in Table 2 and Sernander 1908, pp. 54 and 62. This grass heath, however, closely resembles the dry meadows), Viola rupestris (in Central and Northern Sweden also in dry meadows). - Phleum Boehmeri and Veronica spicata occur on the Alvar of Öland and probably also of Gotland often in dry meadows. They would, however, occur chiefly in grass heaths. Oxytropis pilosa forms part on the locality at Heda: Norrö (analysed in Table 2) as at the neighbouring Högby: Skogsjö in Östergötland in a transition type. At Lummelunda on Gotland it occurs in a sparse vegetation on a sandy sea- 
shore, where there are next to no mosses and lichens, but the flora nearly coincides with that of the grass heaths.

Certain steppe species in South Sweden belong neither to dry meadows nor to grass heaths. Concerning the mode of occurrence of these species the following brief observations may be made: -

Carex ligerica, Holosteum umbellatum, Peucedanum oreoselinum, Poa bulbosa, and Ranunculus illyricus occur chiefly in localities, where, thanks to human intervention, the vegetation is sparse and more or less like a colony vegetation, such as fallow fields on sand, roadsides, earth roofs etc. According to Areschoug (I889), Peucedanum occurs in its distribution area in Skåne on »dry, gravelly pasturelands». The natural occurrence of these species in southernmost Sweden, especially on Öland, is on steep southerly slopes or rocky pavement with a thin vegetation. The phanerogamous flora of these localities closely resembles that of certain grass heaths (see further Sterner 192I).

Silene viscosa, a decided steppe plant in its chief distribution, has a very remarkable distribution area on the shores of South-Eastern Sweden, Southern Denmark, and Southern Finland, the only one outside the steppes. It occurs here on rocky islets, skerries etc., frequently in places rich in guano, where it is able to grow, probably because it is free from the struggle for space with stronger species.

If the likewise decided steppe plant Isatis tinctoria is to be looked upon as spontaneous in South Sweden, its occurrence is to be placed side by side with that of Silene viscosa, but it occurs chiefly on sandy or gravelly sea-shores.

Concerning the species now mentioned, their mode of occurrence in South Sweden coincides rather well with their rich distribution on the South European steppes (compare above p. 28I).

Viola pumila has on Öland and Gotland, as generally outside Pontis, a mode of occurrence that does not correspond to its character of steppe plant. On the Alvar it occurs in damp places - damp at least during periods of precipitation and especially in spring - partly in crevices in the limestone together with hydrophilous or mesophilous plants, partly in rather hydrophilous meadows where the main part of the vegetation is formed of Sesleria coerulea, Carex panicea, glauca and Hornschuchiana. However, I once saw the species on the Alvar of Öland occur in a strongly xerophilous vegetation, Helianthemum oelandicumCetraria islandica - heath (compare above p. 282).

Melica ciliata in South-Eastern Sweden belongs to the sparse colony-like vegetation on precipitous cliffs and rocky ground, as is generally the case outside the steppes.

Concerning the mode of occurrence of the steppe species in South Sweden, it appears from what has been said that it generally agrees well with the occurrence of the species in the steppe vegetation. Species belonging to the strongly xero- 
philous Stipa or the sand steppes in Pontic regions, are in South Sweden chiefly found in more xerophilous herbaceous communities, in grass heaths or in a sparse, more or less colony-like vegetation, attached to them, and the species of the Pontic meadow steppe belong chiefly to the less xerophilous, closed dry meadows.

Sarmatian psammophilous species. It would seem most suitable to mention in this connection also the species which, not occurring in South-Eastern European steppe districts, have a great distribution in the Sarmatian province, where they belong to the above-mentioned herbaceous sand-grass heaths. As a matter of fact, these species completely resemble certain sandsteppe species with regard to their mode of occurrence in South Sweden.

The species in question are Astragalus arenarius, Dianthus arenarius, Gypsoplita fastigiata, Pulsatzlla pratensis, and, probably Potcntilla leucopolitana P. J. Müll. Of these species the three first mentioned belong in South Sweden solely or chiefly to the Sarmatian sand-grass heaths (see the analyses from Skane in Table 3; cf. Samuelsson 1910, p. 35, and Sterner 1921, p. 202). Gypsophila forms an exception, in so far as on Öland and Gotland it forms part of the above-mentioned lichen heaths on the Alvar. Pulsatilla pratensis occurs in Småland, Östergötland, Södermanland, and Uppland in dry meadows or hillsides-grass heaths. Potentilla leucopolitana occurs on Öland, where it is rather common, chiefly on roadsides, sandy fallow fields etc. Its natural habitats are dry meadows (or, rarely, herb or grass heaths) on sandy soil.

It should be pointed out that Festuca sabulosa (Ands.) Lindb. fil., which is an important leading species in south-eastern Swedish sand-grass heaths, is as yet very imperfectly known as to its distribution outside the limits of Scandinavia. It seems to me to be a foregone conclusion that its distribution is similar to that of the said Sarmatian species.

In this connection a few words also may be mentioned about another trait of character in the mode of occurrence of steppe species outside the steppe districts.

The dispersal of steppe species is in a high degree favoured by the activity of man. In this way many artificial habitats suitable for steppe species have been created.

In the arable districts of Central Russia a considerable number of steppe species occur as weeds or as colonists. In Central Europe and South Scandinavia steppe species together with Oriental and Mediterranean species form the principal part of the more xerothermic Anthropochores. South Swedish species of this kind may be exemplified as follows: Anchusa officinalis, Anthemis tinctoria, Centaurea scabiosa, 
and Senecio vernalis, which are weeds or colonists; Salvia pratensis and Lavatera thuringiaca which are probably fugitives from cultivation (cf. Sernander 1908, pp. $224 \mathrm{ff}$.).

Regarding their mode of occurring in South Sweden certain steppe species hold a position the distinct characterisation of which is difficult. The species chiefly occur as anthropochores but, besides, they also may have localities similar to those of real natives. Some of these species will here briefly be mentioned.

Draba nemorosa is distributed over the whole of East Europe, as a real native in the steppes, dry hillsides etc. and as an anthropochore. Its distribution in Sweden is treated by Sernander (I908, p. 223) and Frödin (1917, p. 334), who has made a distribution map. In the east of Central Sweden the species has a number of localities, a few of which are herbaceous hillsides (as in the neighbourhood of Upsala), the main part, however, more decidedly artificial habitats of different kinds, where the species appears as a colonist.

Melampyrum arvense. As a weed-plant it is distributed over the whole of Central Europe, being observed as a casual even in South-Eastern England. In South Sweden it is distributed over the coast-districts, especially in the South-East Swedish flat regions. It is often observed in herbaceous hillsides but is also often met with as a weed-plant. According to the statements in taxonomic works this mode of occurring might have been its principal one in former days. This is also indicated by its Swedish name »Pukvete», (cf. Sernander 1. c., p. 226).

Malva alcea is widely distributed in South-Eastern and Central Europe as a real native occurring chiefly in the "Trift formation». As a certainly introduced plant it also occurs in Western Europe. In South Sweden it is widely distributed, in most cases doubtless as a fugitive from cultivation. In South-Eastern Sweden, especially on Öland and Gotland it is rather common in dry meadows, on roadsides, balks, and hillsides, and, perhaps, it might be a native in this region.

Lepidium latifolium is widely distributed in the steppe-districts in Central and Western Asia and in South Russia, especially in salt-steppes (cf. N. Busch in Flora Sibirica, 1913). In South Sweden it occurs on the Baltic coast partly at the ports as an introduced plant (probably by ballast); partly on the sea-shore far from ports, where it appears as a real native. Perhaps, we have here about the same state of things as in the case of Silene viscosa and Isatis tinctoria (see later on pp. $324 \mathrm{ff}$.).

The occurrence and distribution in South Sweden of the above mentioned species are, of course, of some importance in the judging of the continental character of the South Swedish vegetation. They give us an evidence of climatic conditions favourable to xerothermic plants, existing in the district. 
CHAPTER IX.

\section{Distribution of Steppe Species and Sarmatian Psammophilous Species in South Sweden.}

As has already been pointed out, the scope of this work does not permit me to enter into any detailed account of the distribution of species or any exhaustive discussion of the numerous and interesting problems thus brought for ward. As to the distribution I have only to refer to the maps and the statements given in Appendix I. In what follows I must confine myself to treating the distribution from the points of view that seem to me to be, generally speaking, most fundamental. Hence I shall examine how far certain ecological features, which, to judge from the general distribution and mode of occurrence, may be characteristic of the species, are reflected in the principal traits of the South Swedish distribution: i. e. the heliophily of the species and their demands with regard to the nature of the soil and climatic conditions. At the same time, however, I shall try to prove the influence of two other important factors, viz. the change in the natural vegetation of South Sweden by human interference and the inmigration history of the species.

\section{The possibilities of occurrence of the species in South Sweden if the vegetation were unaffected by human interference.}

The great demand of steppe plants for light must be looked upon as a specially important ecological feature. Numerous examples show that the occurrence of the steppe species may be primarily dependent on the supply of habitats where this demand can be satisfied.

In the Boreal forest zone, where, except in sporadic spots, a shady woodlayer ought to cover the whole ground, this ecological character should in a high degree determine the distribution of the species. But in extensive districts the hand of man has removed or thinned the forests and thus created numerous localities for a heliophilous ground flora. It has thus in a high degree been able to change the natural distribution of the heliophilous species.

An endeavour to imagine the South Swedish vegetation brought back to its natural state and to establish the possibilities of occurrence of steppe species in such a vegetation - such an endeavour would be of great importance for the explanation of the character of the South Swedish flora. In certain cases a similar investigation may also be of great importance for the explanation of the 
present distribution of species, viz. through the fact that the wider dispersal the species have attained thanks to human action has originated in natural occurrences.

An examination of the possibilities of occurrence of the steppe species in a South Swedish vegetation unaffected by human interference naturally meets with great difficulties.

Inter alia we must take into consideration that the species may have a fairly great amplitude in relation to their habitats, and appear in a vegetation that is not their normal place of abode. The above grouping of what are here treated as steppe species was based on the normal mode of occurrence. If we now especially attend to the importance for the present distribution of species, that the former occurrence of fully natural, suitable localities may have had, it is of great consequence to notice the capacity of several species to hold on to a locality in what is for them a normally strange vegetation, even if they lead a pining life. Through their organization the species may survive vegetatively. In South Sweden the steppe species if they ever had similar occurrences there - have generally been highly favoured by human activity and procured considerably increased possibilities of distribution. Yet there are examples of cases of the said kind. Some observations may be given:

Among the peculiar plant occurrences that characterize the upper Emå valley in north-eastern Smaland there are a few occurrences of the Arctic-Alpine Oxytropis campestris. They generally are located on slopes towards the river which are southerly exposed and are made up of fine gravel (see table 2, Appendix II). At Klövdala, in the parish of Järeda, I found (7. VIII. 1918) an individual of the species in a dense pine forest, where it grew in a completely closed ground vegetation of Arctostaphylos uva ursi, Calluna vulgaris, Dicranum majus, and Hylocomium parietinum. It was not flowering, but had a pod from the preceding year.

The great Högsby ridge, which runs through eastern Småland from the country round Gränna down to the Straits of Kalmar at Pataholm, is, in the western part of the parish of Fagelfors, spread out into a large, partly hilly gravel plain. On southerly exposed slopes in the vicinity there is a very rich herbaceous flora. The level gravel-plain is occupied by a closed pine forest with a ground vegetation of chiefly mealberry and cowberry. A close examination of an experimental area of $\mathrm{I} \mathrm{m}^{2}$ showed that in this cover there were inter alia a few sterile individuals of Potentilla arenaria and Viola rupestris and one flowering, but dwarfed individual of Ranunculus polyanthemos (16. VII. 1920).

It seems to me that importance must be attached to the capacity of certain steppe species to retain by vegetative propagation an occurrence that does not completely correspond to the ecological demands of the species. It might be conceived that they vegetatively hold on to a locality during a longish time, until, for some reason, the habitat changes its nature and becomes better able 
to satisfy the demands of the species. (In the present case we may think of windfalls.) In that case they may flower, bear fruit, increase in number of individuals, and perhaps also spread to other suitable localities. (Cf. Preuss 1912, p. 459.) Another, fact rendering difficult a juclging of the natural possibilities of occurring of steppe species is that such possibilities may bave arisen at the same time as, or after, man began to transform the original vegetation. In the last but one period of the post-glacial epoch, the sub-boreal period, when the xerothermous and heliophilous species were particularly favoured, and immigrated or spread, there already existed in large parts of the country a farming and cattle breeding population. In certain cases, therefore, it is difficult to decide how far the distribution of the steppe species is to be ascribed to the advance of civilization or to the original nature of the district. It will appear from the following account that this is in a high degree the case in the South Swedish lowlands.

A possibility of judging to some extent the character of the South Swedish vegetation unaffected by the activity of man can be attained by studies of the vegetation in other parts of the Eurasiatic Boreal forest zone, where civilization has not yet left its stamp on it to any great extent.

In north-eastern Russia there would seem to be, or to have been a few decades ago, extensive areas where the vegetation can, or could, justly be looked upon as quite natural. In one of his excellent works on the East Russian vegetation Korshinsky has thoroughly treated the occurrence of the steppe species in the forest region north of the steppes (Korshinsky 1886, Review pp. $268 \mathrm{ff}$.; 1888, Review pp. 255 ff.; I 89 I).

This author asserts that the distribution of the steppe species is not dependent on the climate. It is determined by the distribution of the forest. Where, for some reason, trees will not grow, steppe vegetation appears. The strong decrease in the steppe flora towards the north is not in the first place due to an alleged direct unsuitability of the climate to the species, but to the fact that the forest torms a shady cover, thanks to which latter fact localities for steppe species become scarce and inconsiderable in extension. Steppe species are found on: s. B. siidliche Kalkabhänge, Sandboden, Abstiirzen und Felsen». The high degree of warmth of the ground is mentioned as an important reason for the inability of the forest to shut out the steppe-flora in such localities.

If for sthe steppe floras we substitute "a xerophilous and heliophilous herbaceous hillside flora", what has been said would also seem to hold good for the South Swedish vegetation, untouched by civilization. Hence the plant communities where steppe species may be found, should be looked for on rocky opavements", in sandy areas and on steep southerly exposed slopes or precipices, especially with calcareous soil. The slopes may be so steep that a strongly shading forest layer is excluded; or, by their situation close to a country where 
no forest can grow (a lake surface, a large watercourse or a fen), they may be sufficiently exposed.

This herbaceous hillside flora would seem to be richest and to have its greatest distribution on the rocky pavements of Öland and Gotland. The inconsiderable thickness of the soil in conjunction with the scanty precipitation does not here allow of the existence of a shading forest layer. In the comparatively large sandy areas in the precipitationless regions in the most south-easterly part of Sweden, especially in the vicinity of the seashore, herbaceous sand-grass heaths ought to have their natural place of abode. Among suitable exposed hillsides, the calcareous slopes in parts of Västergötland (especially Falbygden), Östergötland (the western part of the plain), and Skane (at least the northeastern part) would in the first place seem to be taken into consideration. Thick moraines, oses and hilly tracts here form dry, steep slopes, where a more closed and shading forest layer may be supposed to be excluded without the intervention of man. With regard to Västergötland minor "Alvar-pavement» areas may also be added. In sundry places in other parts of South Sweden there are steep slopes of noses》 in the ground vegetation of which xerophilous and heliophilous species may probably exist without human interference, especially if the slope faces an unwooded country. Lastly we have to consider southerly exposed hillsides on shores and rocky escarpments.

The steppe flora has a remarkably great number of representatives in the xerophilous herb-grass communities that are thickly spread on Öland and Gotland on rock-pavement or as sand-field vegetation.

Of the South Swedish steppe species only the following are lacking on Öland: Allium montanum, Inula ensifolia, Oxytropis pilosa, Potentilla rupestris, Pulsatilla patens, Senecio integrifolius, Silene viscosa (which has, however, been observed on the island once in the past), and Stipa pennata.

On Gotland the following are missing: Allium montanum, Artemisia laciniata, Bassia hirsuta, Carex ligerica and obtusata, Inula ensifolia (note, however, the occurrence on Gotland of I. vrabelyiana Kern., a hybridogenous transition type between I. ensifolia and salicina. Cf. Lindman, "Botaniska Notiser» 1910, pp. 3 I ff.), Koeleria glauca (found on Gotska Sandön by Sernander 1893, cf. K. Johansson I9ro), Peucedanum oreoselinum, Plantago tenuiflora, Potentilla rupestris, Ranunculus illyricus, Senecio integrifolius, Silene viscosa (seen once on Stora Karlsö; Sernander I894, p. 92), and Stipa pennata.

Falbygden in Västergötland is known of old for its peculiar flora, which is to a great part caused by the occurrences of steppe species. An account of the geographical conditions of Falbygden and of the unique flora on its numerous 
moraine hillocks and ridges has been given by Sernander (1908). The following steppe species are to be found there: Artemisia campestris (Plate 5), Asperula tinctoria (Plate 5 and 15), Centaurea jacea (? spontaneous), Crepis praemorsa (p. 315), Fragaria viridis, Phleum Boehmeri (Plate 5), Polygala comosa (p. 316), Potentilla rupestris (p. 326), Prunella grandiflora (Plate 6), Ranunculus polyanthemos (p. 319), Seseli libanotis (p. 334), Stipa pennata (cf. Appendix I), Trifolium montanum (p. 30I), Veronica spicata (p. 310), and Viola rupestris (p. 319).

Here we may call attention to the two decidedly continental wood-hillside species Dracocephalum Ruyschiana (Plate 4) and Pulmonaria angustifolia (Plate 4) which have in Falbygden their richest occurrences in South Sweden. The flora of Västergötland comprises two more steppe species, Allium montanum, which has a minor occurrence at Alingsås (Plate 6), and Inula ensifolia on the limestone pavement at Österplana on Kinnekulle (cf. Appendix I).

The occurrences of the steppe species in Östergötland are something like those in Falbygden. The steep and well-exposed slopes of Omberg and of the calcareous moraine hillocks and oses on the Silurian plan immediately to the east of Omberg form suitable localities.

The neighbourhood of Omberg contains the following steppe species: Artemisia campestris (Plate 5), Asperula tinctoria (Plate 5), Centaurea jacea (? spontaneous), Crepis praemorsa (p. $315)$, Fragaria viridis, Melica ciliata(Plate 10), Oxytropis pilosa (Fig. 5), Phleum Boehmeri (Plate 5), Polygala comosa (p. 316), Potentilla arenaria (Plate 3 ; cf. Appendix I), Ranunculus polyanthemos (p. 319 ), Seseli libanotis (p. 334), Trifolium montanum (p. 301 ), Veronica spicata (p. 310), and Viola rupestris (p. 3 I9).

Here attention must be called to the remarkable occurrences in this district of species such as the continental Vicia pisiformis (Plate 12) and Cotoneaster melanocarpa (Plate 12).

A great number of the steppe species are included in the flora of $\mathrm{Sk}$ an $\mathrm{e}$. Their generally extensive distribution in the province is naturally in the first

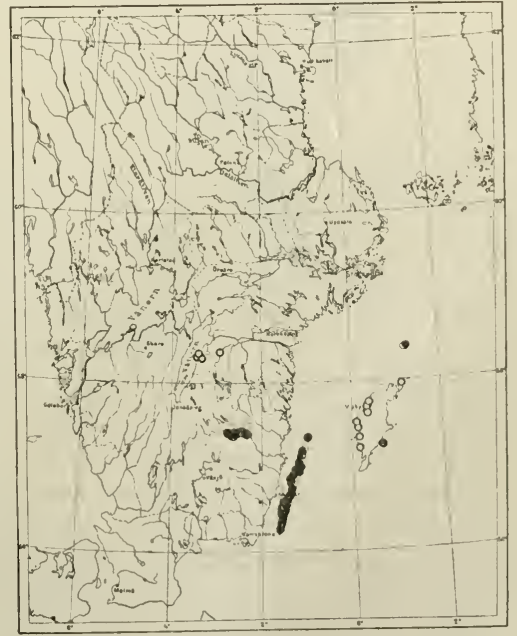

Fig. 5. The distribution of Oxytropis pilosa and the Arctic-Alpine Oxytropis campestris in Sweden. $\mathrm{O}$ : occurrences of $\mathrm{O}$. pilosa $\mathrm{O}$ : occurrences of $\mathrm{O}$. campestris. 
place to be ascribed to human influences together with the high lime percentage in the soil.

Of conceivable, natural localities the sand-fields, occupied by a continental vegetation type, especially those on the eastern coast of Skane, should be mentioned first. At the present time a spontaneous pine-forest would, primarily owing to climatic reasons, seem to be excluded on these localities (cf. Sernander 1902, pp. $46_{4}$ ff.; Hemberg 1904, pp. I 22 ff.).

The Calluna heath, a dangerous rival of the sand-grass heath, is in the sandy areas of eastern Skåne at the present time strongly discouraged by the climate. The sand is probably too dry and too much heated during summer and too much exposed to the wind on the shores. Calluna plays quite a subordinate part in the sand-field vegetation and appears in thinly growing carpets like dwarfed shrubs. On Öland and Gotland and in North-Eastern Germany (Graebner 19or; Preuss 1912, p. 79) the case is similar.

As has been mentioned before, the herbaceous sand-grass heaths contain several steppe species. The following ones are to be found in Skåne: Allium montanum (Plate 6), Artemisia campestris (Plate 5), Carex obtusata (only one locality, at Åhus), Helichrysum arenarium (Plate 5), Holosteum umbellatum, Koeleria glauca, Medicago falcata and minima, Peucedanum oreoselinum, Phleum Boehmeri (Plate 5), Poa bulbosa, Veronica spicata (p. 3 I o), and Viola rupestris (p. 319).

The sand-grass heaths of eastern Skåne are characterized by certain species belonging to the Sarmatian distribution type: Pulsatilla pratensis (p. 333), Astragalus arenarius (Plate 19), Dianthus arenarius, and Gypsophila fastigiata (Plate 21 ).

Among other possibilities of occurrence for steppe species in the natural vegetation of Skåne, calcareous hillsides should be considered. In the rich herbaceous flora on the chalk hillsides of north-eastern Skane there are some especially remarkable occurrences of steppe species, such as the former occurrence of Asperula tinctoria at Uddarp (Plate 5; cf. Appendix II); Polygala comosa (p. 316), Senecio integrifolius (Plate 6), Ranunculus polyanthemos (p. 319), and Crepis praemorsa (p. 315), have here some of their comparatively few occurrences in Skåne. - Here it may also be pointed out that the continental wooded slope species Laserpitium latifolium (Plate 7 ), which has a remarkably scanty distribution in Skåne, has most of its occurrences in the north eastern part.

Besides the species just now mentioned, the flora of Skåne contains the following steppe species: Centaurea jacea, Fragaria viridis, and Seseli libanotis (p. 334).

It is remarkable that a number of species with a very extensive distribution in the eastern parts of Central Sweden have quite an inconsiderable distribution in Skåne: Crepis praemorsa, Ranunculus polyanthemos, Polygala comosa, and 
Seseli libanotis. Trifolium montanum is absent in the whole of eastern Skane, a fact that can hardly depend on any lack of suitable localities (cf. p. 3:5).

Os-slopes in Smaland. It is a characteristic feature of the distribution of most steppc species in South Sweden that they are absent, or very scarce in the so-called South Swedish highland. The more widely distributed species enclose this district, for instance, Artemisia campestris (Plate 5), or embrace it from the east in a curve, more or less open towards the west, for instance, Trifolium montanum (Fig. 6). The absence of suitable localities to such an extent would seem to be primarily connected with the nature of the soil and the topography. By far the larger, south-western part of the s South Swedish highland» in reality consists of a plateau. ("The Archaean rock plateau of Småland „, De Geer 1913; cf. Ahlmann 1920), which is hardly cultivable and for the most part occupied by forests or, especially in its western part, extensive moors and ericaceous heaths. (Cf. Fig. 8, p. 312). In north-eastern Småland, with adjacent parts of Östergötland and Västergötland, where the terrain is often broken the climate and the nature of the soil form considerable obstacles toxerothermous species.

An examination of the occurrences of steppe species within the district shows that they are generally situated on the oses.

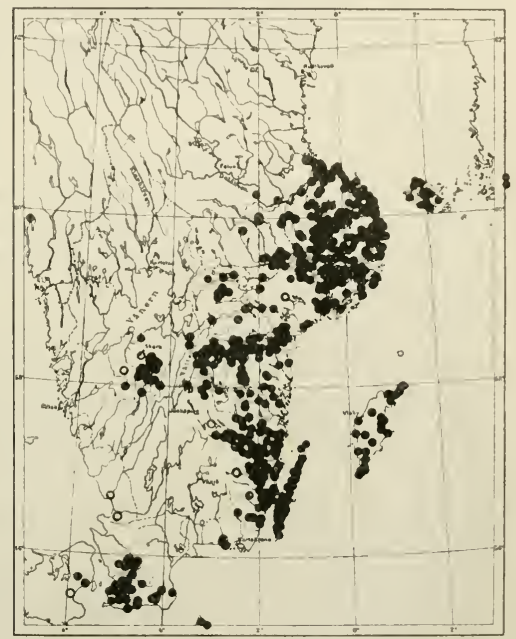

Fig. 6. The whole distribution of Trifolium montanum in Scandinavia and Denmark.

(O: uncertain occurrences; cf. p. 401).

The eastern half of Småland is traversed by a great number of oses, emanating from the central parts and stretching down to the coast in a south-easterly or southerly direction (see Plate 3). On the plain along the Straits of Kalmar the ridges are very conspicuous. They run close to one another and are generally powerfully formed. They have here a decisive influence on the contour of the countryside and the geography of the settlement. In the interior of Smăland there are only a small number of oses, and with a couple of exceptions they consist of quite inconsiderable isolated sand or gravel hillocks.

2 I Geografiska Auraler 1022. 
The largest os in eastern Smaland is the so-called »Högsby is ». This can be followed from the country about Gränna down to the Straits of Kalmar at Pataholm. In the upper Ema valley from the neighbourhood of Vetlanda to Målilla, it partly fills the valley, and the Emå river has carved its way down through the sand and gravel deposits, giving rise to southerly exposed slopes on its northern bank. From the parish of Virserum down to the coast the os is generally sharply formed with a high ridge.

Several oses run from central Småland in a due southerly direction down to the coast of Blekinge. The most important of these oses begins at Lake Örken on the border between the counties of Kronoberg and Jönköping. It is here for a short distance powerfully formed (note the manor name of "Braås»), but afterwards it is inconsiderable down to southernmost Smaland, from where it follows the valley of the Ronneby river and sometimes reaches a considerable magnitude.

The oses are of great consequence with regard to the flora of eastern Smaland. There are not a few species that have their occurrences within the district solely on them. On the dry and warm southern slopes, composed of sand or fine gravel, there are very suitable localities for xerothermous heliophilous species.

To a great extent, however, this is possible only in consequence of human action. The os regetation probably belongs to the sections that were first exposed to human influences. The oses have formed an important route of communication, ever since there has been anything of the kind, and the first colonization evidently took place on or at them. Certain os sections, however, would, even without the help of human intervention, have been able to form a place of abode for the said species.

The natural vegetation on the os slopes seems to be coniferous forests. On the steeper, more southerly exposed slopes there is a sparse pine forest with a ground vegetation of chiefly mealberry and cowberry. In such places there is often no cover of mosses or lichens. Nor is the surface of the ground covered by the fallen needles; they seem to be to a great extent washed away by heavy showers.

On the above mentioned »Braås» at Drettinge in the parish of Dädesjö I have (14. VII. 1920) noticed on the slope a vegetation such as I imagine that an os vegetation must have been in its original state. The os is here very substantial. Its height above the surface of the drained Lake Drettingen seems to amount to about 25 metres. The degree of inclination of the slopes is great, about $20^{\circ}$. The soil of the ground surface consists of small gravel. The ridge runs from NNI to SSE. The eastern slope is occupied by Hylocomium-coniferous-forest. On the western siope the forest had been cut down quite recently (in the preceding winter?). It had consisted of comparatively sparse Scotch pines and a few 
common spruces, and between them there had been juniper shrubs, some birches, Rosa villosa, and Pteridium. The ground vegetation consisted partly of carpets of mealberry, here and there broken and replaced by a thin herb vegetation. An analysis of an experimental area of $1 \mathrm{~m}^{2}$ in such a vegetation gave the following result:

Shrubs: Juniperus communis (one shrub $3,5 \mathrm{~m}$. high, slender), Rosa villosa (one shrub $0,75 \mathrm{~m}$. high).

Indershrubs: Arctostaphylos uva ursi I, Vaccinium vitis idaea I.

Herbs: Achillea millefolium $\times$, Antennaria dioec $a \times$, Arenaria serpyllifolia $\times$, Campanula rotundifolia I, Fragaria vesca $x$, Hieracium pilosella I, Hypericum montanum $x$, Knautia arvensis $x$, Pimpinella saxifraga $x$, Potentilla arenaria I, Trifolium medium $x$, Veronica chamaedrys $x$, Vicia cracca $x$, Viola rupestris $x$.

Grasses: Agrostis tenuis 1, Carex ericetorum I, Festuca ovina I, P'oa angustifolia $\times$. Mosses and lichens: Bryum sp. I, Barbula sp. I, Cladonia pyxidata $\times$.

As regards the herb flora we have here a quite normal eastern Småland herbaceous hillside.

The os slope faced downwards towards a wooded country, but the os was so high that the forest below could not in any degree worth mentioning contribute to the shading of the ground. This os section is situated in a fairly desolate country. It had on one side Lake Drettingen, one kilometre broad, on the other wide woodlands and moorlands. The occasional timber-cutting on the os slopes has furthered the heliophilous ground vegetation, but would not seem to have been of very much greater importance to it than the thinning of the forest through windfalls. Windfalls ought to take place easily as it is difficult for the trees to gain a secure roothold on the steep gravel slope.

A fact that speaks strongly in favour of the oses playing a great part for the occurrence of steppe species in eastern Småland, even in a quite natural vegetation, is that the steppe species often occur in a large number on or near os sections where a sufficiently exposed southerly slope may be conceived to have always existed: where the os is high and steep, as at Drettinge, or faces unwooded country. A couple of examples of the composition of the flora in such cases will be given.

A couple of miles north of Drettinge »Braåsen» runs along the western shore of Lake Örken. It projects some distance into the lake, forming a promontory. On the north-east, therefore, it is here surrounded by the wide surface of the lake and on the south-west by a piece of swampy ground, forming a creek in the lakc. Braås would seem to be botanically famous thanks to several rarities in its flora. On the os grow the following species inter alia: Brachypodium pinnatum, Cotoneaster melanocarpa (? really spontaneous), Crepis praemorsa (which is a rarity in Småland), Hypericum montanum, Potentilla arenaria, Pulmonaria angustifolia, and Thesium alpinum. 
Tab. 7. Herbaceous vegetation on a southerly exposed os-slope at Ramsebo in the parish of Virserum in Småland. 16 VII 1920. The experimental areas (1-4) have each the size $1 \mathrm{~m}^{2}$. Declination about 15 .

(As to the sense of the table-figures see p. 290.)

\begin{tabular}{|c|c|c|c|c|c|c|c|c|c|}
\hline & 1 & 2 & 3 & 4 & & $\mathbf{I}$ & 2 & 3 & 4 \\
\hline Dwarf-lignoses (tree-seedlings'. & & & & & Potentilla Tabernaemontani & $\mathrm{II}+$ & $x$ & - & -1 \\
\hline Arctostaphylos uva ursi & I & IV & $\mathrm{V}$ & III & Primula veris $\ldots \ldots \ldots \ldots \ldots$ & - & I & - & - \\
\hline I'opulus tremula $\ldots . \ldots . .$. & - & $x$ & - & I & Pulmonaria angustifolia......... & - & I & I & I \\
\hline Thymus serpyllum ..... & $x$ & I & $x$ & - & Pulsatilla (vulgaris or pratensis)... & I & I & I & I \\
\hline & & & & & Silene nutans $\ldots \ldots \ldots . .$. & - & $x$ & - & - \\
\hline Herbs. & & & & & Trifolium medium .. & - & - & $\times$ & - \\
\hline Achillea millefolium .......... & - & $x$ & $\times$ & I & " montanum & I & I & I & I \\
\hline Alchemilla pubescens ..... & - & - & $x$ & - & Veronica officinalis ...... & - & - & - & I \\
\hline Arenaria serpyllifolia $\quad . . .$. & $\times$ & - & 一 & - & Vicia cassubica $\ldots \ldots . .$. & - & - & I & - \\
\hline Astragalus glycyphyllus....... & - & 1 & - & - & Viscaria vulgaris ......... & $x$ & 一 & - & $\times$ \\
\hline Campanula persicifolia ...... & -1 & -1 & - & $x$ & & & & & \\
\hline , rotundifolia $\ldots \ldots \ldots \ldots$ & - & - & $x$ & $x$ & Grasses. & & & & \\
\hline Chrysanthemum leucanthemum ... & - & $\times$ & - & - & Agrostis tenuis & I & I & I & It+ \\
\hline Fragaria vesca $\ldots \ldots \ldots \ldots \ldots \ldots$ & - & $x$ & - & $\times$ & Briza media...... & - & 一 & $x$ & I \\
\hline Galium verum $\ldots \ldots \ldots \ldots \ldots$ & - & - & $x$ & I & Carex caryophyllea.... & - & - & I & - \\
\hline Hieracium cymosum (coll. & - & - & $x$ & - & $\gg$ ericetorum..... & I & I & I & $\mathrm{I}+$ \\
\hline$\$ \quad$ pilosella ......... & $\times$ & I & I & $x$ & Festuca ovina ..... & I & I & I & I \\
\hline , umbellatum ......... & - & - & - & $x$ & Luzula campestris & - & - & $x$ & $\times$ \\
\hline \$ vulgatum (coll. ...... & - & $x$ & - & - & Melica nutans ......... & 一 & - & I & I \\
\hline Hypericum perforatum ........ & $x$ & $\times$ & - & - & Phleum Boehmeri ... & $x$ & 一 & $\times$ & $x$ \\
\hline Laserpitium latifolium ...... & - & - & - & I & Poa angustifolia ....... & 一 & - & $x$ & - \\
\hline Lathyrus heterophyllus....... & - & - & -1 & $I+$ & Sieglingia decumbens..... & - & - & 一 & I \\
\hline$» \quad$ montanus $\ldots . . .$. & - & I & I & I & & & & & \\
\hline$\$ \quad$ niger $\ldots . . . .$. & - & - & - & I & Mosses. & & & & \\
\hline Pimpinella saxifraga ..... & - & $x$ & $x$ & - & Hylocomium proliferum. & - & - & - & $x$ \\
\hline Plantago lanceolata ....... & 一 & $x$ & $x$ & - & & & & & \\
\hline Polygala vulgaris $\ldots . .$. & - & - & - & $x$ & Lichens. & & & & \\
\hline Potentilla arenaria............. & I & - & I & - & Cetraria islandica & I & - & - & - \\
\hline . $\quad$ leucopolitana..... & I & 一 & - & - & Cladina silvatica ........ & I & - & 一 & - \\
\hline rupestris $\ldots \ldots$ & II & I & $\mathrm{I}+1$ & $1-1$ & Cladonia rangiformis. & $\mathrm{I}+$ & -1 & $1-1$ & - \\
\hline
\end{tabular}

The os-slopes are occupied by a park-like birch-wood. The vegetation has naturally been for centuries more or less influenced by human action, but the plant occurrences mentioned above are in all probability originally quite natural. 
Only the frequency of the species would be changed if human influences passed off.

When the aforementioned large Högsby os comes down from the hilly country of Östra härad on to the plain of the county of Kalmar in the southern part of the parishes of Virserum and Fangelfors and becomes more continuous, it spreads out and forms an extended gravel-field. In the latter are embedded a large number of smaller os-cavities, forming little more or less filled-up lake-basins. Here there are in several places rather steep southerly slopes, facing the cavities. Such a southerly slope just to the east of the village of Ramsebo in the parish of Virserum I have examined closely (16. VII. 1920). The slope was covered with sparsely growing young pines, birches and oaks. The ground vegetation consisted chiefly of mealberry scrub, forming thick carpets and solitary herbs and grasses. Here and thcre Arctostaphylos was absent or formed a less complete covering and gave room for a herbaceous hillside vegetation. The experimental areas in Table 7 may give some idea of the composition of the vegetation. Besides the species belonging to those experimental areas the following were noted down from the slope: Arabis thaliana, Calamintha acinos, Centaurea jacea, Clinopodium vulgare, Dianthus deltoides, Draba verna, Helianthemum chamaecistus Herniaria glabra, Jasione montana, Galium verum, Lotus corniculatus, Polygonatum odoratum, Potentilla argentea, Scleranthus perennis, Sedum acre, and Thesium alpinum.

Here, of course, the vegetation has been influenced by human action. A highroad passes along above the slope, separated from it only by a fence, and the forest has, of course, been cut every now and then. The influence of grazing cattle, on the other hand, would seem to be inconsiderable, as neither the slope itself nor the swampy ground that begins immediately below it, have any particular attraction to cattle. I should like to regard the occurrence of the species enumerated on the slope as chiefly original. The species were able to exist here, even before the hand of man interfered, thanks to the exposed position.

It has been mentioned above that southerly exposed sand or gravel slopes run along the Emå River in the valley between Målilla and Vetlanda. The slopes facing the course of the river are well exposed. In column ix of Table 2 , Appendix Il a detailed analysis has been given of the vegetation on such a slope. The Emå valley is well known through a number of peculiar plant occurrences: Dracocephalum Ruyschiana (Plate I 3 and 4), which formerly, at any rate, existed at Vetlanda and at Germunderyd in Alsheda, Brachypodium pinnatum (Alsheda), Oxytropis campestris (p. 299 and Plate 3), Potentilla arenaria (Plate 3 and 6), leucopolitana (Målilla) and rupestris (p. 326), Pulmonaria angustifolia (Plate 3 and 4), Pulsatilla pratensis (Plate 3 and p. 333). In most cases these occurrences are found to exist on the southerly exposed slopes facing the river. 
Among other os sections remarkable for their flora there may be mentioned: the os at Högsby, which on one side descends abruptly into the broad valley, formerly occupied by a lake; the os inside Skäggenäs in the parish of Ryssby on the Straits of Kalmar (here grow Artemisia campestris, Centaurea jacea, Myosotis micrantha, Poa bulbosa, Potentilla arenaria, leucopolitana and Tabernaemontani, Scleranthus perennis, Sedum album and rupestre, Thymus serpyllum, and Trifolium montanum). At Skogsjö in Östergötland (a few kilometres north of Mjölby) there is an os-cavity in the large, thick Skänninge-os, forming a smallish lake. A low but marked ridge stretches from the north and south shores out into the lake, almost dividing it into two parts. On the more northerly of the two promontories thus formed, the south-western slope is occupied by a sparse pine forest with a thicket layer and a ground vegetation of a sparse dry meadow. In the latter the following plants form part: Astragalus glycyphyllus, Avena pratensis, Carex montana, Oxytropis pilosa, Potentilla Tabernaemontani, and Scabiosa columbaria.

The above statements will have shown that os-slopes may, even in a quite natural vegetation, play a fairly important part in the distribution of the steppe species in eastern Småland.

In the existing vegetation, which has been influenced by human action, the importance of the os for the distribution of species is very great. The distribution of a great number of species within the district is entirely determined by the oses. That the occurrences of Veronica spicata are to a great extent located on the oses would seem to appear even from the map in fig. 7, p. 3 I o. The dots also mark certain large stretches of oses.

A still more striking example is the distribution of Potentilla arenaria in southeastern Småland.

Potentilla arenaria is an important constituent of the Stipa steppe. In Europe it has a strongly South-East European distribution, a Pontic-Sarmatian distribution, which, however, resembles a Pontic-Hercynian one. Its South Scandinavian distribution appears from the maps in the Plates 3 and 6 . The distribution is rather unique with regard to the strong concentration of occurrences in southeastern Småland. A closer examination of these occurrences shows that they are to a great extent located on the oses.

Plate 3, map 2 shows the distribution in eastern Småland of the oses and a few rare species: Pulsatilla pratensis, Dracocephalum Ruyschiana, Oxytropis campestris, Phleum Bochmeri, Pulmonaria angustifolia, and Veronica spicata. That there is an intimate relation between the distribution of the species and the oses would seem to appear clearly.

The following steppe species have their occurrences in eastern Småland more or less solely located on the oses: Artemisia campestris (Plate 5), (Carex erice- 
torum,) Crepis praemorsa, Phleum Boehmeri (Plate 5), Potentilla arenaria, leucopolitana (with several newly discovered occurrences) and rupestris (p. 326), Trifolium montanum (p. 3or), Veronica spicata (p. 3Io), and Viola rupestris (p. 319 ). Add to these the continental wooded-hillsicle species: Dracoceplalum Ruyschiana and l'ulmonaria angustifolia; and the following species, not continental, yet re. markable witlı regard to their distribution: Hypericum montanum (p. 346), Lathyrus heterophyllus (Plate 4), Oxytropis campestris, Potentilla Tabernaemontani, Scleranthus perennis, Thesium alpinum (l'late 4), and Thymus serpyllum.

In this connection must be mentioned the importance of the oses in eastern Smaland for the migratory history of many xerothermous and heliophilous species in South Sweden. The inmigration and first dispersal of such species should to a great extent be assigned to a period with a dry and warm climate (the Boreal and Sub-boreal period). In this case the southerly exposed slopes might have formed suitable immigration routes to a much greater extent than would be the case in a natural vegetation with the present climate. Thanks to them the species have been able to make their way into or through the South Swedish highland, which must, as to the rest, have been like a desert to them. And by this route they may perhaps have reached other parts of South Sweden. The Högsby os should be especially noted. I should like to put forward the question whether this os may not have formed a link across South Sweden from Öland-Gotland and south-eastern Småland to Lake Vättern and Falbygden in Västergötland. The very peculiar distribution-type of a few species points to the existence of such a link and to the determination by it of the distribution of the species. The species are distributed in the eastern part of the province of Jönköping, especially in and about the Emå valley and in parts of Västergötland, especially Falbygden. In the country to the south-east of the southern end of Lake Vättern there may be occurrences that to some extent connect these centres of distribution. Such is the distribution of Dracocephalum Ruyschiana (Plate 4) and Potentilla rupestris (p. 326) and, though not so decidedly, Pulmonaria angustifolia (Plate 4). Even the easterly Central European Lathyrus heterophyllus (Plate 4) and Thesium alpinum (Plate 4) may be ranged with this group. The absence or scanty distribution of these species in Östergötland is especially remarkable. As to the direction of the migration we can hardly draw any justifiable conclusions from the present distribution. The two firstnamed at least may be supposed to have passed from Västergötland to Småland. The wide distribution of Dracocephalum in South-Eastern Norway and the species being lacking on Öland and Gotland may justify such a supposition about this species.

In western Smaland the glacio-fluvial deposits are not, as a rule, developed into ridges. They are placed in old crosion valleys, partly filling them. But if 
a water course has made its way through them, there are slopes composed of sand and fine gravel even here. I have no detailed knowledge of the composition of the vegetation on these slopes. But steppe species are almost totally absent. Only Artemisia campestris (Plate 5) (it is perhaps uncertain whether this is quite spontaneous here), Veronica spicata (p. 310 ), and Ranunculus polyanthemos (p. 319) (according to a report from Phil. kand. Hård av Segerstad) have a few occurrences here. The marked absence of steppe species would seem to be caused chiefly by the climate as will be proved later on.

The oses are naturally of great importance for the distribution of steppe species in other parts of South Sweden than eastern Småland. The sole occurrences in Blekinge of Phleum Boehmeri (Plate 5) and Trifolium montanum (p. 301) are at Ronneby, where there are numerous os slopes. The numerous oses in the plains of Östergötland and the provinces around Lake Mälar harbour in present time many occurrences of steppe species and probably steppe species might have some possibilities of occurring on them in a fully original vegetation, too.

The great importance of the oses for the distribution of the steppe species rests on the facts that on the southerly slopes the species can have their demands for light satisfied, and that the dry and warm sand or gravel soil satisfies their demands in the matter of the nature of the soil. Naturally slopes of other kinds may be of the same importance if they satisfy the said demand.

Slopes of rock hills, however, are generally less dry than the ones of the oses. Because the rock-ground does not let the water through, the forest on them becomes denser and more shading, and hence the ground vegetation comes to be formed of less heliophilous and xerophilous species. The southerly slopes will be occupied by wooded hillsides, less sparse and xerophilous and more shaded than the vegetation on the os slopes.

The flora of these wooded slopes is of great interest in the estimation of the continental element in the vegetation. For several species form part of it that have otherwise a great distribution in Eastern Europe, where they belong to the dry, sparse woods that form oases on the steppes or form the transition between these and the forest region proper. The distribution of these species will, however, be treated further on (Chapter $\mathrm{x}$ ). Here it will only be pointed out that some of the species treated as steppe species may in South Sweden form part of similar, wooded slopes and have a distribution which is in certain districts connected with the distribution of broken country, viz. Crepis praemorsa (p. 3i5) and Ranunculus polyanthemos (p. 319) and, in a smaller degree, Fragaria viridis and Trifolium montanum (p. 301). The distribution in Småland of the two firstnamed species to a certain extent reflects the main features of the topography (cf. later on pp. 342 ff.). 
Rocky Escarpments. The natural occurrences of steppe species in the Archaean rock districts of South Sweden might be supposed to have been made possible also through southerly exposed precipitous cliffs. The great supply of light and heat, as well as the absence of species more fit for competition, make these cliffs favourable to steppe species. Great parts of the South Swedish Archaean rock country are much broken and rich in southerly exposed rocky escarpments. This is especially the case in north-eastern Småland, Östergötland and Södermanland, western Västergötland, northern Halland, and northern and central Dalsland. (See p. 343.)

Nevertheless the escarpments are not so important as might be expected for the distribution of steppe species. Only the distribution of a few species is determined by the occurrence of rocky escarpments. Probably the reason is partly that the rock.ground is unsuitable for many species; partly that most steppe species in South Sweden occur as calciphilous species and may thus not thrive on the non-calcareous Archaean rock-ground; and lastly that the cliffs are gencrally so strongly isolated that species furnished with less effective power of dispersal cannot utilize all suitable localities. Later on, in treating another group of species (Chapter $\mathrm{x}$ ), I shall have an opportunity of giving a more detailed account of the importance of the rocky escarpments for the distribution of species in South Sweden.

The steppe species that occur to a greater extent on those localities are only Allium montanum (Plate 6), Potentilla rupestris (p. 326), Melica ciliata (Plate ro), Veronica spicata (Fig. 7), and Artemisia campestris (Plate 5). As regards Veronica spicata, it has the greater part of its occurrences in Östergötland, Tjust and Södermanland on rocky escarpments.

Poa bulbosa besides appearing on sand-fields and rock-pavements in eastern Skåne and Öland and Gotland, has a small number of probably spontaneous occurrences on cliffs in the coast regions of Småland, Östergötland and southern Södermanland, and in this respect it coincides with Melica ciliata.

On the great arable flat regions of South Sweden, especially in the Mälardistrict, there are smaller uncultivated areas scattered about, which partly form rocky hillocks. The hollows and crevices in the ground of these hillocks being filled up by deposits of clay, sand or gravel there are in these places many suitable localities for a herbaceous hillside vegetation. To a great extent, however, these are rendered possible by the cutting down of a shading woodlayer. A natural occurrence of steppe species in the localities mentioned is not to be excluded; however, it is impossible to judge in what degree this may be the case. The abundant distribution of many steppe species in these regions will be treated later on (pp. 314 ff.). 


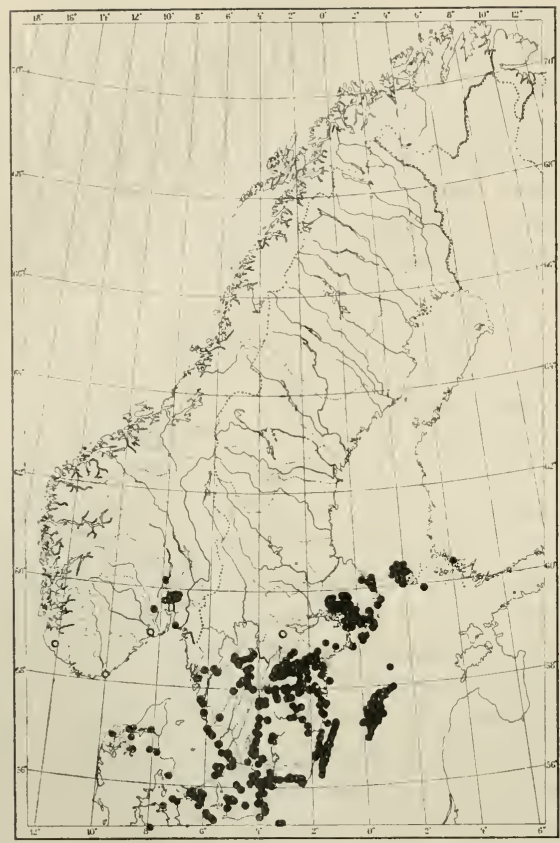

Fig. 7. The distribution of Veronica spicata in the Scandinavian North.

O: uncertain occurrences; cf. Plate 16.

Sea-shore hillsides. In view of the high demands for light on the part of steppe species, hillsides on the sea-shores, sloping down towards the water, ought to offer the species fairly good habitats in a natural vegetation. In the sskärgaird» (coastal skerries) of South Sweden, therefore, there should be numerous occurences of steppe species. This, however, is by no means the case. On the contrary, the absence or inconsiderable occurrence of the steppe flora on coasts is an almost universal feature of the distribution of species in South Sweden. An important cause of this seems to be the fact that suitable localities for most species are lacking, thanks to the nature of the ground in the rocky archipelagoes, especially if the rocks are non-calcareous, as for instance in the skärgaird of Tjust. Perhaps, too, the climate may be of a certain importance. The steppe species are generally strongly thermophilous, and such should especially be the case in South Sweden, where they are generally quite close to their northern or north-western limits. In the exterior part of the south-eastern coast of Sweden the temperatures are much less continental than some distance further inland. As it to some extent is shown by the isotherm maps on p. 256 the coasts have during spring and early summer a lower monthly average than the interior ${ }^{\mathrm{I}}$. If the average of the daily maximum temperature is considered, the difference naturally grows still greater. The remarkably scanty precipitation on the south-eastern coast of Sweden that might be supposed to favour steppe species is counterbalanced by the lower saturation deficit in the dampness of the air.

1 It should be observed, however, that, during the height of summer and in autumn, the daily mean temperature and the average minimum temperature are higher on the coast than in the interior. 
While steppe species are thus able to utilize only to a very small extent the localities on the sea-shores that have abundance of light, continental species, belonging to other groups have had greater possibilities of doing so. In treating the distribution of these species we shall have an opportunity of showing the enormous importance the skargardar have and have had for the distribution of plant species in South Sweden (Chapter x).

Of the few steppe species found on the sunny cliffs and hillsides on the shores, Silene viscosa should first be called to mind. Its peculiar distribution in the South-Eastern Swedish archipelagoes (p. 325), shows what an unexpectedly great amplitude in relation to external factors the steppe species may have, and how easy it may sometimes be to imagine the distribution of a species in a high degree determined by its capacity of dispersal and the absence of competition with other species.

Artemisia campestris has a fairly wide distribution on sandy sea-shores. Its northernmost spontaneous occurrences in Sweden, in north eastern Uppland, are situated on shores.

Hence the occurrence-possibilities of steppe species that we may expect in a South Swedish vegetation untouched by the hand of man, are rather inconsiderable. We should expect to find steppe species in the larger lime districts, cspecially on the rocky pavements of Öland and Gotland, and in the rainless districts on one or other in some way especially favoured, hardly shaded hillside, as the oses especially in eastern Smaland. The quite different distribution of many steppe species in South Sweden is in the first place to bc ascribed to the influence of human activity.

\section{The Distribution of the species and Arable Land in South Sweden.}

The remodelling activity of civilization on the natural vegetation appears most in the cutting down or thinning of the forests and in the transformation of the woodland into plough-fields or pasture land.

Among the changes in the flora that take place in consequence of such an influence of civilization it should above all be noticed that forest species disappear or become scarcer, new species immigrate, such as weed-species, and certain species that had in a natural vegetation only minor sporadic localities at their disposal may get increased possibilities of distribution owing to the fact that human intervention creates new localities for them and facilitates their spread.

In South Sweden there are sharp contrasts between two different types of natural scenery. Extensive forest and mountain districts contrast with large, 


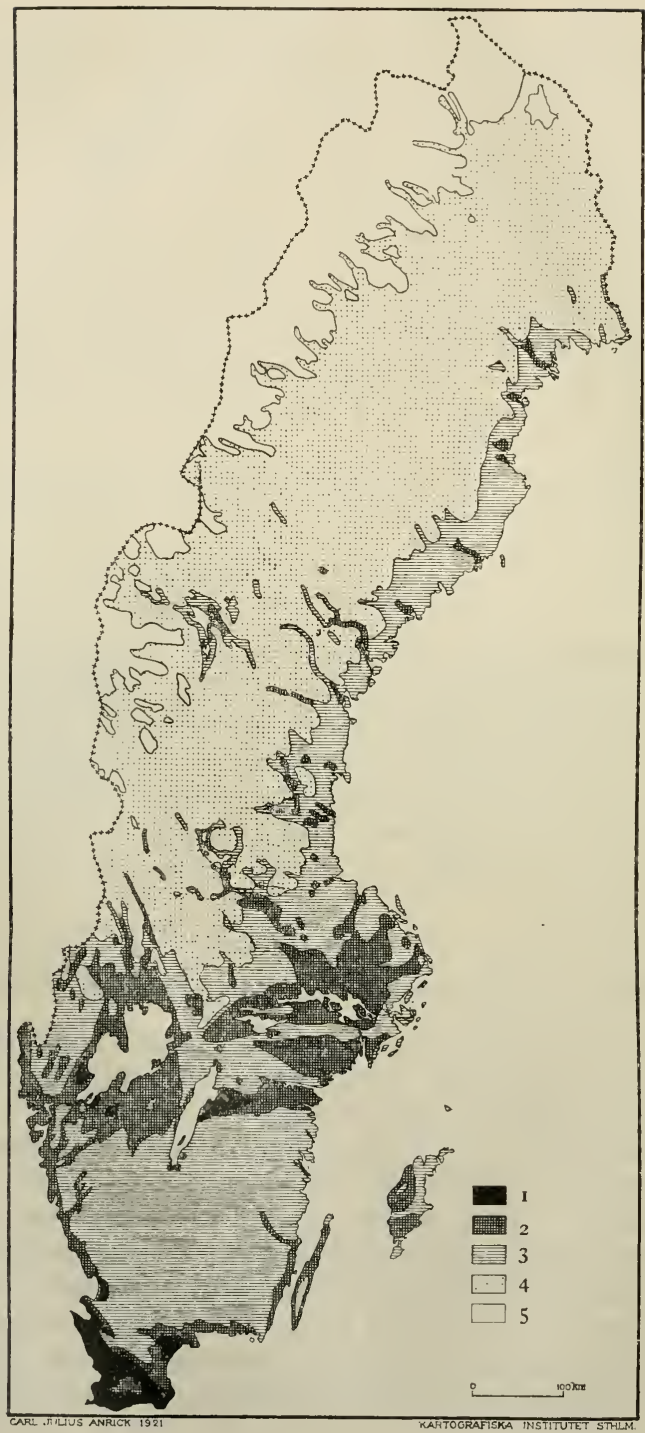

Fig. 8. The distribution of the arable land area in Sweden.

After Anrick 1921. The Geological Survey of Sweden has kindly placed the stereotype at my disposal. 1. Purely agricultural districts; 2 . Districts with preponderating arable land; 3 . Districts with sparse arable land; 4. Districts deficient in arable land; 5. Alpine districts. 
woodless or poorly wooded arable lands. The South Swedish highland that forms a broad zone almost across South Sweden separates the Skåne - SouthHalland arable plain from the large Central Swedish plains which are in their turn separated from one another by minor wooded mountain districts: Kolmairden between Östergötland and the vale of Mälar, Tiveden between the latter and the plain of Västergötland (see fig. 8).

These main features in the character of the landscape clearly reappear in the distribution of plant species in South Sweden. Many southerly xerophilous and heliophilous species are limited to the plains, whereas northerly or Central European "montan"-subalpine elements have their occurrences in the forest districts.

A species, whose nccurrence is in the highest degree characteristic of the arable fields of South Sweden is Avena pratensis.

It is an important feature of the type of scenery of the South Swedish arable plains that the cultivated fields are here and there broken by uncultivated spots marked by mounds of moraine or of Archaean rock, rising like islets out of the "clay sea", or by oses running bandlike across the plain (cf. Sernander » 190 I a", p. 108$)$.

In these uncultivated spots, as on balks, waysides etc., the vegetation is formed of more or less xerophilous herbaceous hillsides (Swed. »örtbackar»), in which Avena pratensis is such an important constituent that its distribution in South Sweden nearly corresponds to that of the large arable areas (cf. the vegetation analyses in Tables I and 2, Appendix II. See the map on Fig. 9; this map is incomplete concerning southern Skåne, the coast district of Halland, western Västergötland, and, probably, some parts of southern Värmland, especially the peninsula Vaiset). It is interesting that such details in the distribution of the arable land districts as the occurrences in certain river valleys and near certain lakes in Småland, are corresponded to by Avena occurrences. The distribution in Norway shows the same good agreement with the distribution of arable districts. Arable fields of some importance are found in the country round the Christiania-Fjord and the valleys just to the north of it, in south-westernmost Norway on Jäderen and in the neighbourhood of Trondhjem, where Avena also occurs.

The character of the South Scandinavian distribution of Avena pratensis also appears clearly if the distribution-map of that species is compared with the map showing the distribution of Pulsatilla vernalis, which is tied to the heath-like forest communities in sterile sandy or gravelly soil. (See figures 9 and 10).

Hence, in the distribution of Avena pratensis we have a picture of the maximum distribution of the rich herbaceous hillside flora of South Sueden.

On these herbaceous hillsides a great number of the steppe species of the South Swedish flora have their most numerous abodes. We find a remarkably 


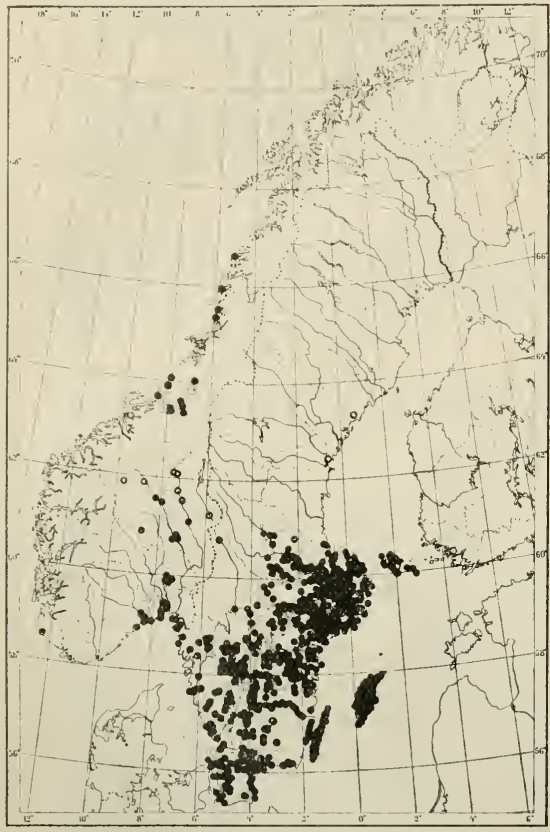

Fig. 9. The distribution of Avena pratensis in Scandinavia and Finland.

0 : accidental occurrences.

In Denmark the species occurs chiefly in the north-eastern part of Jutland and on the Islands.

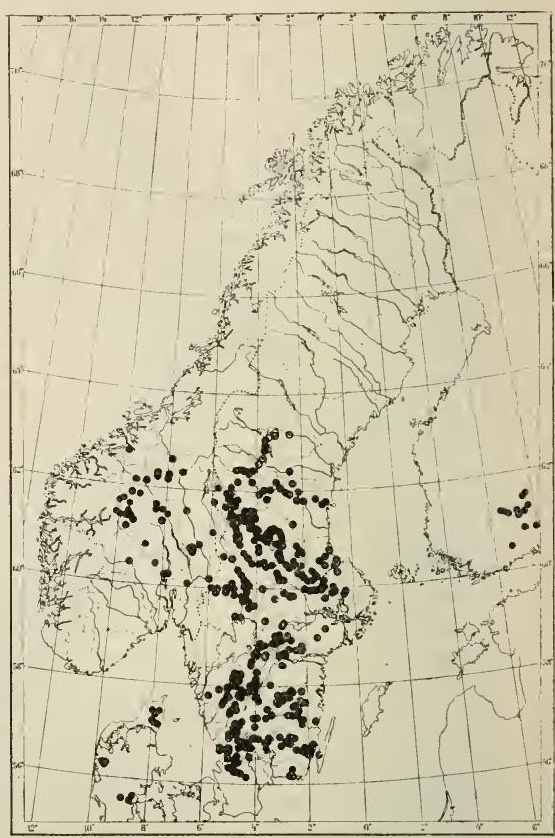

Fig. Io. The distribution of Pulsatilla vernalis in Scan dinavia, Denmark and western Finland.

$O$ : uncertain occurrences.

powerful massing of occurrences of many species in the eastern parts of Central Sweden: on the plains of Uppland, Southern Västmanland, north-eastern Närike, northern Södermanland, and also in Östergötland. The steppe species are especially well represented in the herbaceous hillside flora of Uppland (see Sernander j 908).

The northern and north-western distribution limits in South Sweden, which will be further treated below, with regard to the majority of the steppe species coincide with the north-north-westerly boundaries of the Central Swedish plains.

The following steppe species are remarkable with regard to their distribution on the plains in the South Swedish mainland: Artemisia campestris (Plate 5), Asperula tinctoria (Plate 5), Crepis praemorsa (Fig. I I), Phleum Boehmeri (Plate 5), Polygala comosa (Fig. 12), [Pulsatilla pratensis (p. 333)], Ranunculus polyan- 
themos (p. 319), Seseli libanotis (p. 334), Trifolium montanum(p. 301 ), and Viola rupestris (p. 319), and the following for which no distribution maps have been drawn up: Centaurea jacea (it might be questioned whether it is spontaneous in other places than Skåne, Falbygden and the Omberg district), Fragaria viridis (richly distributed on the Central Swedish plains, especially in Uppland, Västergötland and Östergötland), Medicago falcata (universally distributed in Skåne, south-western Uppland, and especially on the Upsala plain. However, it may perhaps be questioned, whether it is spontaneous in the latter case. In the other arable districts its occurrence is surely not spontaneous).

Regarding this distribution on the arable plains of certain species a pretty remarkable fact may be noticed: The plains in the eastern part of Central Sweden seem to be more rich in occurrences of steppe species than the ones of southernmost Sweden. Three species, Asperula tinctoria, Polygala comosa, and Seseli libanotis, are rather lacking in southernmost Sweden, whilst other species as Ranunculus polyanthemos, Trifolium montanum, and Viola rupestris are less distributed in the last mentioned region than in Central Sweden.

Attention may also here be paid to the fact that Crepis praemorsa and Ranunculus polyanthemos, widely distributed in the herbaceous hill. sides on the Central Swedish plains, have many occurrences in the South Swedish hill districts, north-eastern Småland and southern Östergötland, Kolmården, western Västmanland, and southernmost Dalarna. This fact coincides very well with the species not being distinct steppe species and with their wide distribution in the Central European highlands.

The cause of the numerous occurrences of the steppe species on the arable plains, as has been mentioned, in the first place rests on

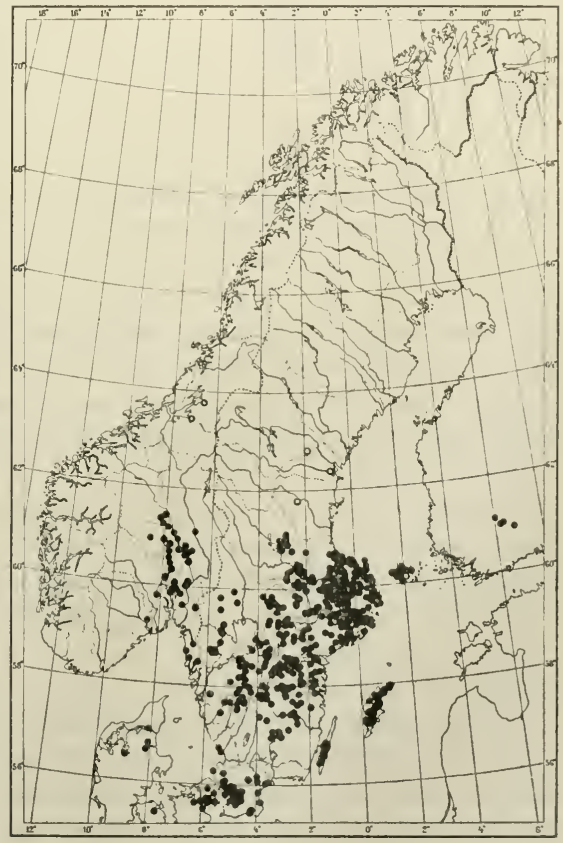

Fig. 11. The whole distribution of Crepis praemorsa in the Scandinavian North.

O: uncertain occurrences; cf. Plate 17. 


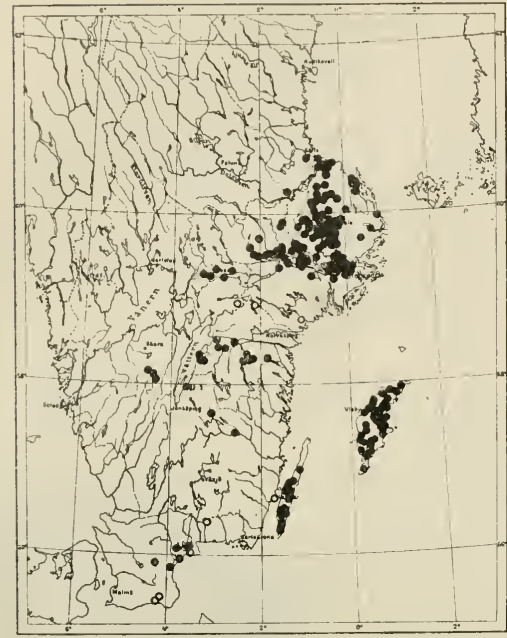

Fig. 12. The whole distribution of Polygala comosa in the Scandinavian North.

O: uncertain occurrences; cf. p. 400.

the fact that on the arable plains the species have at their disposal numerous dry and unshaded localities. Concerning certain features of their distribution on the plains, however, there are other causes as well. One is the higher lime percentage of the soil in certain districts (see fig. 4, p. 264). We find the steppe flora most numerously represented in places where the soil has a high lime percentage: Skåne, Uppland, parts of Västergötland and of Östergötland. In Västergötland the importance of the lime percentage in the soil is very striking: the occurrences of steppe species are located in the more calcareous districts, especially Falbygden, but they are missing on the wide plain to the west of Falbygden where the clay and the moraine are comparatively poor in lime. (See further later on p. $32 \mathrm{I}$.)

We should also take into consideration the fact that the climate on the plains may favour steppe species. It appears from the tables and isothermal and isohyetal maps on pages $256-259$ that certain plain districts, especially in Uppland and Östergötland, have a higher temperature and a lower precipitation in summer than the surrounding woodland and hill districts.

It may further be noticed that, in accordance with their steppe distribution, many species are adapted to an open flat country in their dispersal equipment. Their seeds or dispersal units of other kinds are equipped for a dispersal by wind and consequently they can move widely about above the woodless, flat plains (cf. Sernander I $901 \mathrm{~b}$ ). Moreover the human activity directly facilitates the distribution in various ways.

Finally great importance must be attached to historical causes. Sernander (1908, p. $219 \mathrm{ff}$.) has pointed out that the rich herbaceous hillside flora on the hillocks and os slopes of the Upsala arable plain may partly be a relic from the time when the plain had just risen out of the sea. For this upheaval of the land took place, for the most part, during the Sub-boreal period when the climate was favourable for the distribution of xerothermous species. The first tlora in the localities mentioned must have been rich in such species. 
The investigations made of late years into the history of the settlement of this district have shown that, when the clay fields rose out of the sea, there existed a farming and cattle-breeding population that immediately and in a fairly. high degree availed itself of the new fertile areas. Hence the ground has probably never been to any very great extent occupied by forest. Ever since the land came into existence, there have been wood-edges and unshaded hillsides (cf. Högbom 1912; Ekholm 1915). The casc would seem to be similar in the arable areas in other parts of Uppland, on the Mälar plain of Västmanland (Olsson 1917), and probably also on the lowly situated plains in north-western Södermanland.

In other regions too a connection may be conceived to exist between the rich occurrence of steppe species and the history of settlement. The fertile plains in Skåne and in the Silurian districts in Västergötland and Östergötland are very old farming settlements. Falbygden was a centre of the rich farming culture of the passage-grave period. It is perhaps not impossible that, ever since the Subboreal period there have been pasture lands and cultivated fields here, surrounding the oses and the moraine hillocks and preventing a strong shading of the hillsides.

As to Central Europe a close connection has been established between the situation of older centres of settlement and the distribution of steppe-like districts (especially loess districts). The first settlers are supposed to have sought out these districts because there were natural pasture lands there. The settlement took place during a continental period, when the vegetation in these districts was steppe-like. Thanks to grazing and farming, the forest has ever since been prevented from spreading (Gradmann 1900, I, 355 ff.; 1901, pp. 36 I ff., and 435 ff., and 1906, pp. 305 ff.; Hoops 1905, p. 90; Schalow 1922; cf. Vidal de la Blache 1903 , pp. 31 ff.) A. M. Hansen ( 1904 ) has sought to show, for Norway, a very interesting connection between the distribution of certain xerothermous and heliophilous plant species (the Origamum formation») and the oldest s IndoGermanic» colonization. The first resident population, according to this writer sought out the natural woodless places that contain localities suitable for the recently mentioned species.

The parts of South Sweden mentioned have great qualifications for harbouring a xerophilous and heliophilous flora, thanks to the high lime-percentage of the soil and the great number of suitable hillsides. It may be supposed that the hillsides were occupicd by a fully natural, steppe-like flora when, during the Subboreal period, the climate was more continental than now; this flora has been preserved, thanks to human interference, though the climate has become rather unfavourable.

(As has been said before (p. 298), however, steppe-species would seem to 22 Geografiska Annaler 1022. 
have been able to hold on to one or other locality in these parts even without human intervention. In any explanation of the rich occurrence of steppe-species in the districts mentioned, both these circumstances should be taken into consideration.)

\section{The Distribution Boundaries of the species in South Sweden.}

In most cases the steppe species of the South Swedish flora reach definitive distribution limits within the borders of South Sweden. In the sequel I shall try to explain the latter with the help of what has been said above about the mode of occurrence of species and the geographical conditions of South Sweden.

For all but one of the species the northern limit of their European distribution passes through South Sweden or in some cases through the southernmost section of Norrland.

The species that has a considerable distribution in Norrland too is Viola rupestris (Fig. I3).

This species has a number of occurrences in northernmost Scandinavia, in Sweden at Torne Träsk, which are, in fact, the westernmost occurrences of the great distribution of this species in northern Finland and Russia. In Medelpad and Jämtland runs the limit of the South Scandinavian distribution. Viola rupestris occurs in southern Norrland, above all on sandy slopes in the river valleys, but it also belongs to the flora of southerly hill slopes (Swed. "sydlutor» Andersson och Birger 1912, p. 93).

Some other steppe species stretch into southern Norrland with a small number of occurrences. Foremost amongst them should be mentioned Ranunculus polyanthemos (Fig. 14) and Crepis praemorsa (p. 315).

The wide distribution towards the north of these two species may be connected with their rich mountainous distribution in Central Europe and their less decided character of steppe species (cf. above pp. 281 and 315).

The species have numerous occurrences in southern Dalarne. They reach their northern limit with a cluster of occurrences in the Silurian district of Lake Siljan.

From the coast district of southern Norrland there are only very uncertain locality-reports concerning Crepis praemorsa. Ranunculus polyanthemos, on the other hand, has numerous quite positive occurrences there. Its northernmost occurrence is in the parish of Nordingrå in Ångermanland (H. W. Arnell). (Its locality in Jämtland, reported by Olsson 1894 , must be judged very uncertain.)

The distribution of Ranunculus polyanthemos in the districts named might be put in connection with local occurrences of calcareous soil, Archaean lime (cf. Grevillius 1894), shell-gravel banks (cf. Halden 1917 and 1920) or marl occur- 


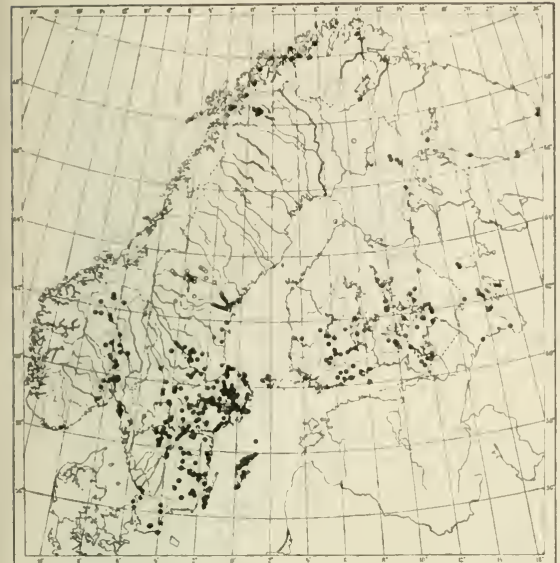

Fig. 13. The distribution of Viola rupestris in the Scandinavian North.

: uncertain occurrences.

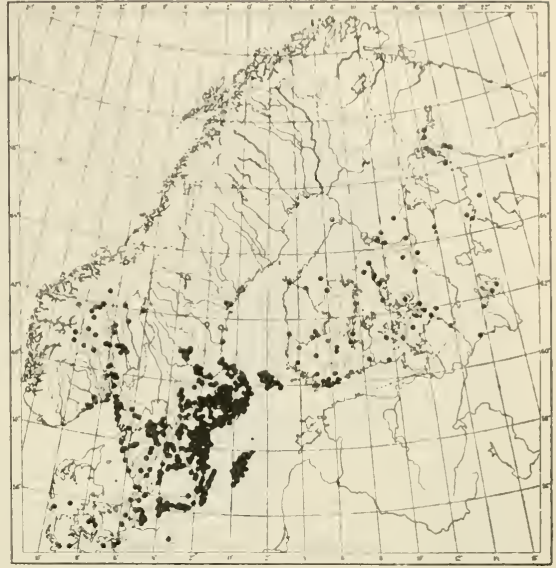

Fig. 14. The distribution of Ranunculus polyanthemos in the Scandinavian North. O: uncertain occurrences.

rences. It agrees well with the occurrence of the species in north-eastern Finland; From a rich distribution in large parts of South Finland (»In Fennia australi et media plerumque satis frequenter», Hjelt) it stretches eastwards, with isolated occurrences high up in the north; it reaches the Kola Peninsula, and further east it is found on the River Pinega inside the Kania Peninsula (Pohle 1913). The localities consist of southerly hill slopes with calcareous soil.

We have here an example of the not uncommon circumstance that species which are southern in the western parts of the Scandinavian North have a northern limit that rises strongly towards the east. This has recently been pointed out by Samuelsson concerning several hydrophytes that are southerly in Sweden and looked upon as comparatively heat-loving and exacting as regards nutrition (Samuelsson 1920, p. 37). Samuelsson considers that the explanation should be sought in the wide distribution of lakes rich in nutrition in the said districts.

Attention must also be paid, however, to the temperature conditions, especially concerning Ranunculus polyanthemos.

The distribution of the species in question towards the north in Finland and Russia is due, of course, to the occurrence of calcareous soils and "Eutrophian Lake types» in these districts, for the species are in their whole distribution tied to soil or water that is comparatively rich in nutrition. But the rise of the northern limit 
towards the east may also be judged dependent on the temperature conditions in summer, which are very favourable in the east. The $16^{\circ} \mathrm{C}$. July isotherm which comprises large parts of South Sweden (see Fig. I, p. 256), travels through Finland in a north-easterly direction not unlike the distribution limit of Ranunculus polyanthemos. The general temperature conditions in northern Finland during this season, schematically expressed in the position of the July isotherm, are consequently hardly more disadvantageous than those of the same kind in Central Sweden, i. e. the richest part of the distribution area of the species in the Scandinavian North. It might be said, also, that, on account of the favourable temperature conditions, the species has been able to utilize the suitable localities, suitable as to the nature of the soil, that exist in northern Finland.

The distribution areas of several other species belonging to the flora of the South Swedish herbaceous hillsides, often forming important elements in it, stretch along the coast to central Norrland and even reach some distance into the interior, especially on the Jämtland Silurian district. Of herbaceous hillside species with such a distribution we may mention Galium verum, Calamintha acinos (distribution map in Andersson och Birger I91 2, p. 347), Arabis hirsuta (1. c. p. 339), Saxifraga granulata, Pimpinella saxifraga, and Viscaria vulgaris. We have here the northernmost outposts of the Baltic herbaceous hillside flora.

Many South Swedish steppe species reach their northern limits on the Central Swedish plains.

With regard to some species the limit in the eastern part of Central Sweden pretty faithfully follows the northern limits of the arable land, for instance Artemisia campestris (Plate 5), Phleum Boehmeri (Plate 5), Polygala comosa (p. 316), and Seseli libanotis (p. 334).

It should be noted that even species of the South Swedish herbaceous hillside flora with a different general distribution in Europe have a similar northern limit in Central Sweden, for instance the Western European Pulsatilla vulgaris (Fig. I5) and the general Middle European Helianthemum chamaecistus (Fig. 16).

This northern limit would thus seem to be put in connection with the mode of occurrence of species and the topography of the district. It is also of great importance, however, that, thanks to the high lime percentage of the soil and to the favourable climatic conditions, the Central Swedish plain districts offer the species better conditions than the higher, hilly coniferous forest districts in the north. It should be noted that a great number of South Swedish species with a wholly different mode of occurrence have their northern limit in these parts, for instance, Inula salicina (Plate 7), Serratula tinctoria, Pulmonaria obscura (Plate II), Selinum carvifolia (Plate 7), Chimaphila umbellata (Plate 12). 


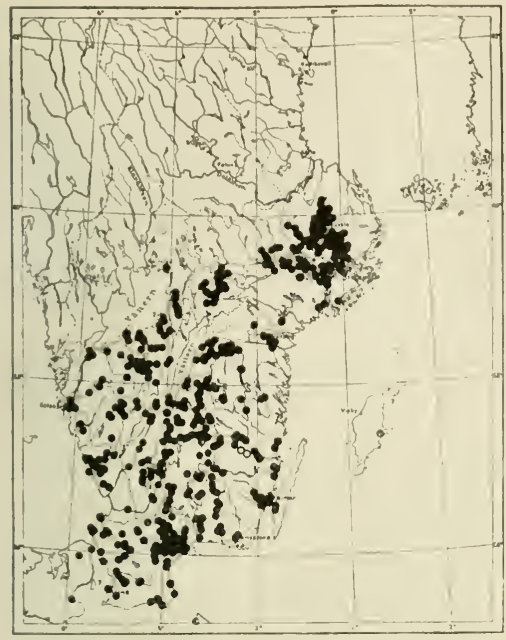

Fig. 15. The distribution of Pulsatilla vulgaris in Scandinavia (West-European).

O: occurrences, which, perhaps, should be referred to P. pratensis.

The species does not exist in Finland. In Denmark it occurs in most north-easterly Zealand, north-western Fyen and in a great part of central and eastern Jutland.

[The occurrence of var. gothlandica K. Joh. on Gotland is marked.]

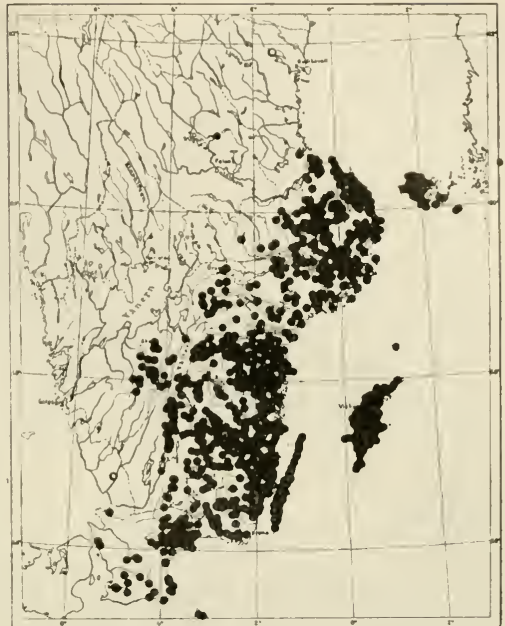

Fig. I6. The distribution of Helianthemum chamaecistus Mill. (coll.) in Scandinavia.

Except a few occurrences in Skåne, Blekinge, and southern Småland, which refer to $H$. hirsutum Thuill.) Mérat, the map may, also, hold good of H. nummularium (L.) Dun.

$O$ : uncertain occurrences.

The species is distributed in southernmost Finland and in Denmark on the Islands and in eastern Jutland.

While the limits of certain species in the central parts of Västergötland make a bend in a southerly or south-easterly direction, forming a westerly distribution limit through Småland, it continues in what is for the most part a westerly direction concerning other species. Consequently these last species have a minor number of occurrences in southern Värmland, Dalsland, and in Bohuslän. In north-westernmost Sweden the limits take a more northerly direction, cross the Swedish-Norwegian frontier and surround a larger or smaller section of SouthEastern Norway: Artemisia campestris (Plate 5), Crepis praemorsa (p. 315), Ranunculus polyanthemos (p. 319), Veronica spicata (p. 310), and Viola rupestris (p. 319).

The occurrence of these species in Dalsland and Bohuslän may be looked upon as being due to the broken country with calcareous soil in central Dals- 
land, to the arable area in southern Dalsland and to occurrences of shell banks on the coast of Bohuslän.

Disregarding Inula ensifolia and Stipa pennata, which in Västergötland have only very inconsiderable and isolated occurrences - the most north-westerly ones of their European distribution - the following species reach in this region the north-westerly limits of their European distribution: Asperula tinctoria (Plate 5), Phleum Boehmeri (Plate 5), Polygala comosa (p. 316), Prunella grandiflora (Plate 6), Seseli libanotis (p. 334), and Trifolium montanum (p. 301). Except Polygala and Prunella, these species, however, have one or a few isolated occurrences farther in the west in the neighbourhood of Christiania.

The great contrasts in the nature of the soil in Västergötland appear in very sharp distribution boundaries. It might be questioned whether such sharp differences in the character of the vegetation and the flora as occur in this district can be found anywhere else in South Sweden. The species in question are confined to the calcareous districts. Immediately to the west of Falbygden the barren plain called "Svältorna" pushes in a wedge of land towards the north, to a great extent occupied by pine-planted heaths on sand and large moor-land, and beyond a large arable plain comes in, whose moraine and clay are, at least in the upper layers poor in lime.

Even the species that do not reach their westerly limits in South Sweden but show their continental character by an incomparably richer distribution in the eastern parts, have the westerly limit of this richer part of the distribution area in the calcareous districts. The species are richly distributed in Falbyden and the neighbourhood of Kinnekulle but are missing or very scarce further west, for instance Viola rupestris (p. 319), Crepis praemorsa (p. 315), Veronica spicata (p. 310 ).

The fact that a very great number of species show an irregular distribution in Småland has long been subject to the attention of scientists (E. Fries "1825"; Wahlenberg 1833, pp. XL ff.; Scheutz I 857 and 1861; Hård af Segerstad 1912). The most prominent features of the flora of Småland are that southerly, "nutrition-exacting", xerothermous species are confined to, or have their chief distribution in the eastern part of the province, while westerly or northerly, less exacting species are preferably or only found in the south-western part. Scheutz has pointed out that a great number of species do not reach far inside the Baltic coast, and that a likewise considerable number of species reach their western limits in the central part of the province (the country about Växiö). A closer study of the distribution of the species in Smalland and their causes offers much of interest. As a similar investigation is being carried out by another student, I can here only treat this problem summarily and with regard to a few species.

As has been pointed out before. Småland is to a great extent uninhabitable by the South Swedish steppe species. An account has been given on pp. $301 \mathrm{ff}$. 
of the generally sporadic localities the species have here at their disposal. Their suitable localities are usually to be found in the north-eastern part of the provincc. The occurrences of a majority of species reach their definite or occasional western limits in South Sweden in this district. The limit, broadly speaking, then runs from central Västergötland in a more or less straight south-easterly direction down towards the coast district on the Straits of Kalmar. Concerning some species the limit then bends towards the west and passes through Blekinge (where, however, many species are missing and others are very scarce) and Skåne and then, concerning a few specics, assumes a northerly direction and embraces the plain of southern Halland. Hence the boundary forms a curve round the South Swedish highland, more or less open towards the west. [For instance Trifolium montanum (p. 301), Phleum Boehmeri (P'late 5), Polygala comosa (p. 316), and Crepis praemorsa (p. 315)].

The position of the distribution boundary in Småland can be put into connection with the topography, viz. the oses and the broken country. A number of species have their sole occurrences in Smalland on southerly exposed os slopes or hillsides in the eastern part of the country of Jönköping, especially in Östra härad (see above p. 307). There is, however, another factor, the influence of which appears not so conspicuous in the distribution of the species here treated in their more specialized mode of occurrence, but which is, none the less, very important, viz. the presipitation conditions.

The account of these conditions given above ( $p$. 259) shows them to vary greatly in different parts of the district. There is a very decided contrast between the eastern (especially the north-eastern) parts and the western parts. Considering the intimate relation between the nature of the soil and the quantity of precipitation, we must allot to this relation a very great importance with regard to the nature of the vegetation in a district like Smaland, where the weathering soil material is to a great extent poor in electrolytes.

Add to this the fact that in large parts the country is level. The Archaean rock-plateau of Småland comprises the greater, south-western part of the province. (See the map on p. 343.) In this part the drainage is weak, and lakes and moor lands occupy considerable areas.

An excellent example of the connection between the precipitation conditions and the configuration of the country on one side, and the nature of the vegetation on the other is formed by the contrast between Östra härad in the county of Jönköping and Uppvidinge härad to the south of it. The broken Archaean rock country of Östra härad, where there is a comparatively scanty precipitation, with its smiling scenery and its flora, rich in southerly and continental species - the level moraine plateau of the Vidinge wastes, where precipitation is more plenteous, filled with meagre coniferous forests and large moor lands with 
an immensely barren nature and with several occurrences of northerly (for instance Betula nana) and Atlantic species (for instance Erica tetralix).

To these factors making a hindrance to the occurring of steppe species in Småland there are to be added considerable disadvantages in the temperature conditions. As may distinctly appear from the accounts given above on pp. 256 and 257, the coast regions and lowlands around the South Swedish highland have a considerably more genial climate than the latter.

With regard to the steppe species now being treated, the causes of the South Swedish distribution-limits are thus to be sought in the following phenomena:

I. The distribution of the arable land;

2. The distribution of calcareous soils, which, especially in Västergötland, causes very sharply defined boundaries.

3. The occurrences of well-developed os-slopes and broken country in north-eastern Småland.

4. The strongly varying precipitation conditions, especially the contrast between the north-eastern and the south-western parts of the South Swedish highland.

The less directly displayed influence of irregularities in the temperature conditions should also be ascribed a certain importance.

With regard to the distribution-limits of the remaining steppe species, whose South Swedish distribution is not restricted to a small number of occurrences, the following may be said:

A few species have a pretty remarkable distribution area along the coast of Sonth-Eastern Sweden. Melica ciliata (Plate 10; in the interior part of the coast, chiefly on limestone) [Poa bulbosa (often a colonist)], and Isatis tinctoria and Silene viscosa, which are sea-shore plants. - This distribution type will be treated later on in connection with similar ones of other continental species (Chapter x).

Regarding Silene viscosa, however, a few words will here be mentioned.

The peculiar character of its habitats on the Baltic sea-shores has been above (p. 292) slightly treated. Not less peculiar is, however, its area of distribution in this region, the only one outside the steppe districts (Fig. 17). It may conceivably be that the islets and skerries hardly exposed and often strongly nitrophilous in their soil, form suitable habitats, the species in them getting rid of the struggle for space with other species. Another cause of the distribution area might be found in the climatic conditions, the scanty precipitation (it must, however, be observed that this factor is to a great extent counterbalanced by the lower saturation deficit in the dampness of the air) and the high temperature during the latter part of the summer. The most important factor, however, seems to 


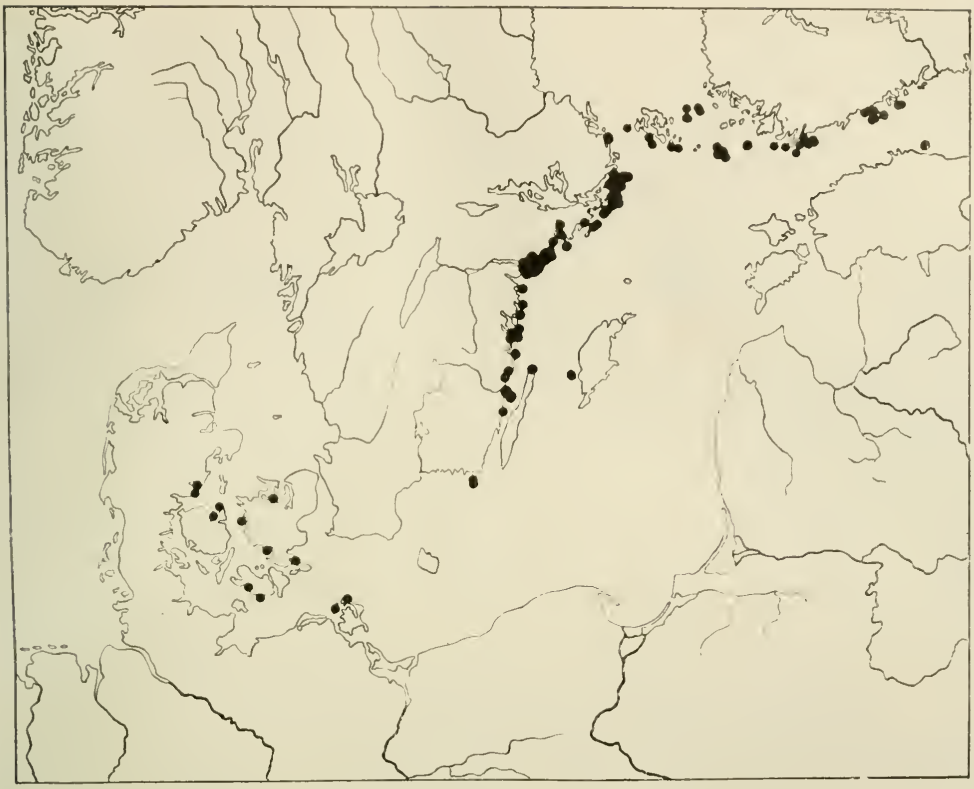

Fig. I7. The distribution of Silene viscosa on the Baltic shores.

me to occur in another quarter, viz. in the mode of dispersal of the species. As Sernander (Igor b, p. 403) has pointed out, the waves may be an effective vehicle and, perhaps, also the water-currents are to be counted in. To this, probably, may be added a dispersal of the seeds by birds; the striking agreement of the distribution area with migratory bird-routes can hardly be an accident. The frequency of the species in its localities being very changeable (often the species is a real accident) the dispersal must be, in any case, a very effective one, but in the same time, strongly restricted to certain regions.

The distribution of Isatis tinctoria on the Baltic shores, where it may be a real native (cf. Hjelt, „Conspectus» Vol. iii, Pars ii, p. 390), shows a noteworthy coincidence with that of Silene viscosa: it is rather abundantly spread on the seashores of South-East Sweden and South-West Finland but has only a few occurrences in other shores (cf. later on p. 372).

The Swedish distribution-area of Potentilla rupestris (Fig. I8), the peculiarity of which has already been mentioned (p. 307), is strongly isolated. Its nearest 


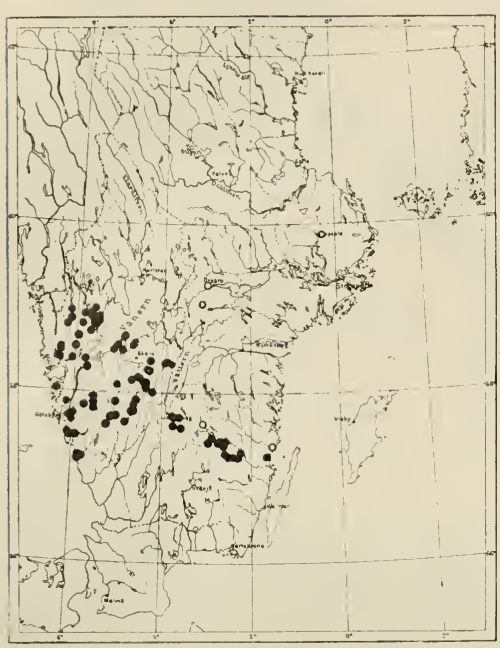

Fig. 18. The distribution of Potentilla rupestris in the Scandinavian North.

$O$ : localities in which the species is a colonist or fugitive from cultivation.

occurrences outside Scandinavia are in north-eastern Germany, where the species belongs to the »Pontische Hugel-formation» and reaches its western limit so far east as the Oder. The present area of distribution in South Sweden can hardly be explained with reference to the influence of geographical factors. The numerous occurrences in Bohuslän, the country round Gothenburg and northern Halland show that the habitat amplitude must be rather great and cannot be supposed to form a hindrance to a continued distribution. Evidence in favour of this view is to be found in the fact that the species has been observed as a colonist or as a plant fugitive from cultivation in other parts of the country, for instance in two localities in Närike and one in Uppland (Vaksala). In Östra härad in Småland I have several times noted the species spread at roadsides. The present shape of the distribution will probably have to be viewed as not permanent. The species is now undergoing a process of spreading from some older occurrences, which may possibly be relics and which can in the first instance be ranged with Falbygden and Östra härad [cf. the distribution of Dracocephalum Ruyschiana (Plate 4), Pulmonaria angustifolia (Plate 4), and Lathyrus heterophyllus (Plate 4)]; and this process is greatly assisted by human activity directly as a vehicle and indirectly by creation of suitable localities.

The peculiar distribution of Potentilla arenaria (Plate 3 and 6) in eastern Småland and Blekinge would seem to some extent to be explained in a similar manner. The species is much spread on the oses, but just outside the present boundary there, probably are localities of value equal to those inside. ${ }^{\text {I Thanks }}$ to human intervention (the species is to a great extent spread along the roadsides, the seeds probably accompanying the road gravel), the species is being spread from the few natural localities it may have had in the district; and the

1 The os in the valley of the rivulet $\gg$ Brusan" (between the upper Emå-valley and the Östergötlandboundary) is not fully investigated. Certainly the species occurs on the os slopes all the way between Hultsfred and Eksjö. 
present distribution is thus, probably not its maximum distribution under the present geographical conditions.

Of the species confined to southernmost Swedcn (Skåne, in certain cases also Blekinge, Öland and Gotland) those belonging to psammophilous vegetation should above all be noted: Helichrysum arenarium (Plate 3), Holostcum umbellatum (on Öland also on the rock-pavements of the Alvar), Koeleria glauca, Medicago minima (the occurrence on Öland at Borgholm, however, being on "pavement»), and Poa bulbosa (on Öland and Gotland also on the "pavement"). To these may properly be added the Sarmatian species, Astragalus arenarius (1'late 19), Dianthus arenarius, and Gypsophila fastigiata (I'late 2I).

The scanty distribution of these spccies in South Sweden is primarily, of course, to be ascribed to the distribution of large sandy districts (or limestone pavements). However, the first-named species are in their whole European distribution more southerly than the steppe species that are also widely distributed in Central Sweden, and should be assumed to be more heat-loving than the latter. The Sarmatian species, on the other hand, reach far north in Eastern Europe, which is already testified by the peculiar occurrence of Gypsophila on sandy fields in Dalarna.

\section{Isolated Occurrences of the species in South Scandinavia.}

With the treatment of these last-named species we have come to the feature that is so conspicuous in the distribution of many steppe species, i. e. the isolatcd position of the westerly occurrences.

A comparison, with regard to the distribution in Central Europe, between steppe species and continental species with another mode of occurrence, for instance forest species, shows that this feature is particularly characteristic of the distribution of the steppe species. The others have generally a more or less continuous distribution even to the extreme limit (see, for instance, Plate 15 and 16). The reason is naturally in the first place that, in accordance with the strongly specialized ecological demands of the steppe species localities suitable for these species get more scarce the farther we get from the steppes.

It is curious, however, that the species have been able to reach all these strongly isolated localities, and that this capacity is common to a great number of species with a rather different means of dispersal. Another remarkable circumstance is the fact that these steppe species with isolated outposts in Central or Western Europe consist almost solely of perennial species which are also often able to propagate vegetatively, while the steppe species include comparatively numerous annual hapaxanthous plants.

These remarkable circumstances agree well with the current opinion about the 
explanation of the distribution of the steppe species: the isolated occurrences should be looked upon as relics from an earlier and more even distribution. Our knowledge of the post-glacial history of the country lends support to such an opinion (see e. g. the summaries in the work of 》Deutsche Geologische Gesellschaft» I9Io and Hausrath I9I1). During the periods with more continental climatic conditions the species have had occurrences that have more or less closely connected the present isolated ones ${ }^{\mathrm{I}}$.

Even if isolated occurrences of steppe species generally find their real explanation in this circumstance, we must not leave out of consideration the fact that, thanks to a long-distance dispersal (even nowadays) certain species have been able to reach isolated suitable localities.

Samuelsson (I910, pp. $480 \mathrm{ff}$.) holds that the peculiar isolated occurrences of Gypsophila fastigiata in Fennoscandia should be explained as the result of a long-distance dispersal. Another example of this, which may be of interest in the sequel, is the occurrence on Rügen of Mulgedium tataricum, which is hitherto scarcely found outside the steppes, a fact explained by several scientists on the hypothesis that it has been brought thither in one of the great invasions of sandgrouse in the middle of the Igth century. (Preuss, "Berichte d. Deutsch. Botan. Gesellsch.», Bd. 27, 1909; Leick, »Mitteil. d. naturw. Vereins für Neuvorpommern und Rügen», Jahrg. 48, 1921).

It would seem to be expedient not to imagine the power of long-distance dispersal of species to be too narrowly limited. As has already been pointed out, even very rare opportunities may be of great importance.

In South Sweden there are number of interesting isolated occurrences of steppe species. Most of these are found on Öland and Gotland, where of course favourable conditions are offered to these species. There are also remarkable isolated occurrences in Östergötland in the country round Omberg (Oxytropis pilosa), in Falbygden (Stipa pennata), at Kinnekulle (Inula ensifolia), and in Skåne (for instance, Senecio integrifolius, Allium montanum, Asperula tinctoria, and Carex obtusata).

Many steppe species have their remotest North-West European occurrences on Öland or Gotland: Adonis vernalis (Plate 14), Anemone silvestris (Plate 17), Aster linosyris, Carex ligerica, Pulsatilla patens (note the occurrences in central Norrland, in the parishes of Resele, Liden and Ramsele in Angermanland), and Viola pumila; the strongly isolated occurrences on Öland and Gotland of the Siberian species: Artemisia laciniata and rupestris and Carex obtusata, and the occurrences of the Pontic species: Bassia hirsuta (Plate 13), Plantago tenuiflora

\footnotetext{
1 Under these favourable climatic conditions the species may also be supposed to have had greater power of distribution through a better fructification.
} 
(Plate 13), and Ranunculus illyricus (Plate 13) are very peculiar. Here it may also be observed that many South or Central European species have isolated occurrences on Öland and Gotland (cf. above p. 276).

The occurrences on Öland and Gotland are attached to isolated minor distribution areas in North-Eastern and Central Germany, which, like those of Öland, rest on ecological conditions that are exceptionally favourable to the species.

True, the flora of Öland and Gotland lacks a number of species found in the North German centres of occurrence of steppe species (e. g., Stipa pennata and capillata, Aster amellus, Scorzonera purpurea, Campanula sibirica and bononiensis etc.); but it must be considered remarkable that the Baltic has not been better able to prevent the species from reaching Öland and Gotland. It must be pointed out, however, that on the other hand Öland and Gotland lack steppe species that have a wide and even distribution in North Germany (Trifolium alpestre, Thesium ebracteatum, Eryngium campestre, Dianthus carthusianorum etc.)].

The species here called "Siberian» are especially characteristic of the flora of Öland and Gotland. (Add to the just mentioned species Potentilla fruticosa, belonging chiefly to a vegetation type, which will be treated later on in Chapter $\mathrm{x}$.) Their occurrences on these islands are the only important ones outside the Siberian and North American distribution-areas. They may be explained as being caused by an immigration from localities in Central Europe, which in their turn should be looked upon as relics from a wider European distribution during some pre-glacial or inter-glacial epoch. During the continental periods of the postglacial epoch they must have had a wider distribution than at present; and thus we can more easily imagine their immigration to Öland and Gotland. - The occurrence of these Siberian species on Öland and Gotland, as in their other isolated European localities, is of very great interest from several points of view; and thus there should be much to add here, but space does not permit it.

Of the remaining isolated occurrences of steppe species on Öland, the occurrence of Plantago tenuiflora is probably the most striking one (Plate 13).

Its appearance on the Alvar of Öland would seem to be the only one outside the Pontic steppes. It is so much the more remarkable, as the plant in its dispersal is wholly dependent on its fructification. It can easily be observed that the frequency of the species varies a great deal during different years, and that this is connected with the state of the weather, but in spite of this the species has been able to spread over almost the whole of the island. Hence we have here another example of the great climatic amplitude of steppe species.

But if Plantago tenuiflora thrives so well on Öland in the present climate, it may be questioned whether its immigration thither must be placed in some continental period, during which an immigration step by step into Öland would ex hypothesi take place, thanks to now vanished occurrences in Central Europe. 
Concerning this question we must admit the difficulty of explaining why the species should have become extinct in these Central European occurrences. The occurrence of the species on Öland should perhaps rather be taken as a result of a long-distance dispersal through birds.

From South-Eastern Europe there are migratory bird-routes to the Southern Baltic (Palmén 1876; Duncker 1905; Lucanus I922). For certain gull species, especially Larus ridibundus, which breeds in great numbers in swamps on the Alvar of Öland, there are migratory routes from the Hungarian plain to the Southern Baltic (see, for instance, Lucanus 1. c., pp. $31 \mathrm{ff}$.). The birds would generally seem to make the passage from South-Eastern Europe to the Southern Baltic in a very short time (one day or so) without any pause. It seems to me quite conceivable that the birds then, occasionally, bring with them such little seeds as are here spoken of. As Plantago tenuiflora grows in Hungary in places that are damp in spring, the edges of small bodies of water, lakes etc., (Kerner, Österreich. botan. Zeitschr. 1875, Prodan 1915 and 1916), where also many migratory birds have their whereabouts, I consider it by no means unlikely that the immigration of the species to Öland has taken place in this way.

A similar explanation seems to me to be most likely regarding the former occurrence of Bassia hirsuta on Öland (at Ottenby). Its immigration would, however, seem to have taken another route than that of Plantago. The species has a fairly considerable number of occurrences in Southern Denmark and on the German and Dutch coasts of the North Sea. Outside South Russia it occurs, besides, in a few places in the Mediterranean region, inter alia on the French coast of the Mediterranean (Plate I 3 ).

An important migratory bird-route runs from the south of the North Sea across the Southern Baltic, where it turns off to the north east or the north at the southern end of Öland. Enormous masses of birds pause on or at the southern end of Öland. Bassia might be supposed to have reached its locality on Öland from the occurrences on shores of the North Sea through these birds.

The birds get to the south of the North Sea across the Western Mediterranean, the French Mediterranean district and the valleys of the Rhone and the Rhine, and on the French coast of the Mediterranean Bassia has, as has been mentioned, one of its Mediterranean areas of occurrence.

In this connection attention should once more be paid to the peculiar distribution area of Silene viscosa along the south-eastern coasts of Sweden and the southern coasts of Finland, where very important migratory bird-routes pass along (p. 325). In this case also an immigration through birds from the Hungarian plain or the South Russian steppes seems to me to be conceivable.

To give any very great value to these hypotheses of dispersal by migratory birds, of course, more evidence than has here been produced is wanted. Among 
other things it must be proved that seeds capable of germination exist at the time when the birds are supposed to spread them.

The occurrence of Ramunculus illyricus on Öland is of a quite different nature to those of Plantago tenuiflora and Bassia.

It is not rare in the central and especially in the southern part of the island. Its mode of occurrence there has been treated above (p. 292). The frequency of the species varies a good deal with different years; and the variations are clearly connected with the question how far the state of the weather is favourable to a xerothermous, heliophilous plant. The flowering seems to vary very much. In certain summers flowering individuals are very scarce, while on the other hand sterile individuals may give a silver gray hue to wide areas through their leaves. The fructification seems often to fail (cf. Erikson $\mathrm{r} 898$ ).

In relation to Plantago tenuiflora there is here the important difference that the plant has a capacity of regenerating vegetatively in a very effective manner. Each old individual developes germ-buds at the end of subterranean runners, and in the next vegetative season each germ-bud gives rise to a new individual. Thanks to the vegetative regeneration, therefore, Ranunculus illyricus is able to survive even years unfavourable to flowering and fructification.

With regard to such a species, therefore, we have not far to look for the relic theory.

Several species with remarkably isolated occurrences in South Sweden are equipped to survive long and also to some extent to propagate in the vegetation. Adonis vernalis has a considerably powerful subterranean system, from which a great number of vegetative-floral sprouts rise during every vegetative season. As the subterranean stock of the older individuals gradually branches off, new individuals are created. The case would seem to be similar concerning Stipa pennata, Oxytropis campestris and pilosa, Pulsatilla patens and pratensis (cf. Johansson 19I2), Anemone silvestris, and Asperula tinctoria. The view that these species are remains of an ancient, more xerothermous flora should find a certain support in this feature of the organization of species.

Here the Pontic-South and Central European Poa bulbosa may be called to mind. Along the coast of south-eastern Siveden it has a branch of distribution, projecting strongly towards the north from its Central European distribution area. This branch might be connected with the capacity of the species of vegetative propagation. In South Sweden it is extremely rare as non-viviparous.

As has before been cursorily mentioned, some steppe species which reach their north-western distribution-limits in south-eastern Sweden have one or more isolated occurrences farther west, viz. in south-eastern Norway, in the country 
about Christiania and in various places in Denmark, especially north-eastern Jutland and north-eastern Zealand. These isolated occurrences are worth special attention. They would nowadays generally seem to be interpreted as relics of an ancient, more continuous distribution area. With regard to certain occurrences in Jutland that belong to these species, Warming has, among others made himself spokesman of a similar opinion (1904, p. 78).

In the neighbourhood of Christiania the following steppe species have isolated occurrences: Asperula tinctoria at Östensö (Plate I 7 ), Phleum Boehmeri: in many localities (Plate 5), Pulsatilla pratensis (Fig. 19), Seseli libanotis (p. 334), Trifolium montanum (p. 301), and Allium montanum (Plate 6).

In north-eastern Jutland there are, inter alia: Asperula tinctoria (formerly at Aalborg), Crepis praemorsa, Eryngium campestre, Medicago falcata, Prunella grandiflora (Plate 6), Senecio integrifolius (Plate 6), and Trifolium alpestre (Plate 6), to which may be added Anthericum liliago (Central European distribution). On Zealand there are somewhat isolated occurrences of Potentilla arenaria, Pulmonaria angustifolia, Prunella grandiflora, and Thesium ebracteatum.

The occurrences in question correspond to very favourable ecological conditions in the isolated localities. The soil is strongly calcareous, and the temperature-conditions in the neighbourhood of Christiania differ greatly in favour of xerothermous species. Hence it is not so remarkable that these steppe species are able to thrive in the localities, but the strong isolation makes the occurrences peculiar.

Concerning many steppe species with a comparatively wide distribution in Southern Scandinavia a division of the distribution area into two branches, an easterly and a westerly one, forms one of the chief features. The eastern branch comprises Sweden to the east (and north) of the South Swedish highland; the western one is formed by occurrences in Skane, on the Danish Islands, Jutland and, if you like, in the neighbourhood of Christiania, to which may be added for some species one or another locality in South Sweden to the west of the South Swedish highland (Plate 6). The distribution branches of some species are sharply defined, as in the cases of Phleum Boehmeri (Plate 5), Crepis praemorsa (p. 315), and Pulsatilla pratensis (Fig. 19), [cf. also Cynanchum vincetoxicum (Plate 18), Melampyrum nemorosum (Plate 16), Cnidium venosum (Plate 20) etc.]; in other instances the western branch is much weaker, as in the cases of Asperula tinctoria (Plate I5), Trifolium montanum (p. 30r), Potentilla arenaria (Plate 6), and Seseli libanotis (p. 334).

The reason for this division of the South Scandinavian distribution area is naturally in the first place the fact that only the plains on both sides of the South Swedish highland furnish localities suitable for the steppe species; the eastern branch, forming a more continuous piece of land and being poor in precipi- 
tation is naturally more favourable than the western one, dismembered as the latter is by the sea.

If the said isolated occurrences of steppe species are relics of a more continuous distribution, they ought to be relics of a more powerfully developed western branch of the Scandinavian distribution area.

As the North German plain should have been able, with a more continental climate, to offer favourable conditions to a steppe flora, its continuation towards the north-west, which the Danish Islands and the peninsula of Jutland may be said to form, should at the same time have been much more suitable for steppe species than at present. Apart from the climatic conditions, this should have been the case during an earlier postglacial period, for the soil must have been better in these parts, before it was leached by the precipitation.

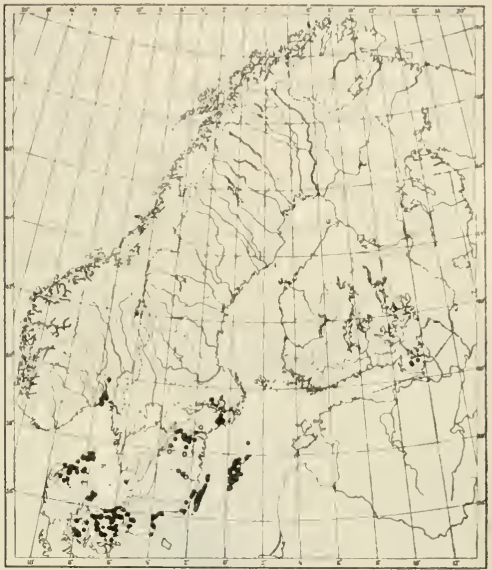

Fig. 19. The distribution of Pulsatilla pratensis (L.) Mill. in the Scandinavian North.

As to Denmark the map refers to $P$. spratensis (L.) Mill, , in Hayek's sence + P. snigricans Störck". Cf. p. 402 in Appendix I and Ostenfeld 1911 , pp. $252 \mathrm{ff}$.

$O$ : uncertain occurrences.

Hence it seems to me to be fairly probable that these isolated occurrences of steppe species should form remains of a more continuous western branch of distribution that the species once had in Western Scandinavia.

In connection with this there might be brought forward the possibility of certain peculiar occurrences of species in Västergötland having arisen as part of a similar westerly branch of distribution: Prunella grandiflora (Plate 6), (which has a locality in north of Jutland and one, but somewhat uncertain, on Zealand), Allium montanum (Plate 6), Stipa pennata, Dracocephalum Ruyschiana (Plate 4), and Potentilla rupestris (p. 326).

\section{The two branches in the South=Scandinavian distribution.}

The division mentioned of the Scandinavian distribution-area into two branches is also of interest from another point of view. It has been pointed out that the reason of the division is that the South Swedish highland isolates from each other two plains with localities suitable to the species in question. In some cases, however,

23 Geografiska Annaler 1922. 
the two distribution branches are marked also through the absence or very scanty distribution of the species in southernmost Sweden (Skåne): Seseli libanotis (Fig. 20) is almost totally missing in southernmost Sweden, but it has many localities in Southern Denmark, though it does not occur there further east than on the western coast of Zealand. The case is similar, though less conspicuous, regarding Asperula tinctoria (Plate 5), Potentilla arenaria (Plate 6), and Prunella grandiflora (Plate 6).

The two branches of distribution also mark two immigration routes to Scandinavia, for usually the only localities suitable to the species were along these

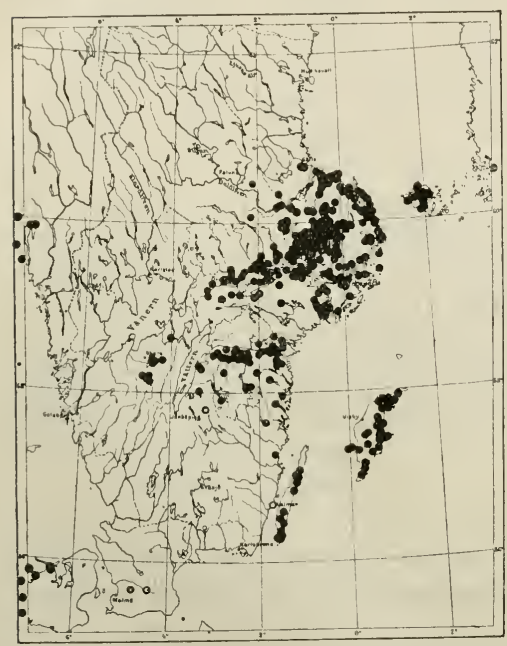

Fig. 20. The distribution of Seseli libanotis in Scandinavia and Finland.

$O$ : uncertain occurrences.

In Denmark the species has a number of occurrences also on Fyen, Lolland, and Samsö, and in Schleswig. routes. Regarding the recently mentioned species this immigration must have been split up into two routes already before the southwesternmost part of Sweden was reached. This may have been the case with the immigration of several other species too, but as these are widely spread in southernmost Sweden (Skåne), the original immigration routes cannot now stand out distinctly.

Hence in the distribution of the species in question we should have examples of the fact that the immigration route determines the present distribution: in Skåne, which was situated off the immigration routes, the species did not spread to any extent worth mentioning in spite of the probable supply of suitable localities. In this connection it may be observed that some steppe species, which have only the westerly distribution branch, are more or less spread in Denmark but are absent in Skåne, Trifolium alpestre (Plate 6), Thesium ebracteatum, and Eryngium campestre.

A number of species are lacking in Denmark but are spread in south eastern Sweden, and have consequently only availed themselves of the easterly immigration route. Besides species with a more inconsiderable distribution in southeastern Sweden (for instance, Oxytropis pilosa, not to mention the species confined to Öland and Gotland), Polygala comosa (p. 316) and Viola rupestris (p. 319), should be pointed out. They have only a small number of occurrences in Skåne but are, especially, Viola, widely distributed in south-eastern Sweden. Several 
continental species belonging to other vegetation types have a similar distribution, Geranium bohemicum (Plate 12), Ledum palustre, Achroanthes monophyllos (Plate 21), Scutellaria hastifolia (Plate 10). To these might be added many noncontinental species, especially certain calciphilous species, as e. g. Carex ornithopoda, Corydalis pumila and Draba muralis (Plate 8).

The species might be supposed to have immigrated by an easterly route to south-eastern Sweden and, for some reason or other, not to have attained its full distribution towards the west (cf. Chapter xi).

That several cliff-plants spread in south-eastern Sweden are absent in southwestern Scandinavia is natural, as suitable localities are there almost wholly lacking for similar species (for instance, Melica ciliata (Plate 1o) and Sedum album (p. 357).

Perhaps, in some cases, the cause of these peculiarities in the South Scandinavian distribution are to be ascribed to the South Swedish highland, making, of course, a hindrance to the interchange of species between central and southernmost Sweden.

To what extent does the distribution on the other side of the Baltic correspond to the division of the species between the distribution-branches mentioned? We find the remarkable circumstance that several species of the westerly route are missing in a considerable part of north-western Germany. Some species have their westernmost occurrences in the coast districts of northern Germany as far to the east as the country round Stettin: Asperula tinctoria (Plate 15), Crepis praemorsa, which has, however, an occurrence on Rügen too (Plate 17), Potentilla arenaria (Plate 6), Prunella grandiflora, Pulsatilla pratensis (in Hayek's sense), and Senecio integrifolius (Plate 6). The continental Pulmonaria angustifolia, belonging to another vegetation type, shows the same peculiarities in its distribution. In order to make out the immigration of these species into Western Scandinavia it is, however, not necessary to conceive a former distribution farther in the west in North Germany. A direct immigration across the sea from the neighbourhood of Stettin into Western Scandinavia may be as possible as a similar one from North-Eastern Germany into South-Eastern Sweden.

How are the steppe species that are confined to the eastern distributionbranch, spread on the other side of the Baltic? With a couple of exceptions, these species are confined to the eastern part of the North German plain. Polygala comosa and Carex ligerica form the exccptions: they reach their western limits in the east of Hanover. (Of the other continental species, just mentioned, which are lacking in western Scandinavia Scutellaria hastifolia has a remarkably wide distribution in North Germany. It reaches its western limit not until the lower Weser; cf. Chapter xi).

Here it should be remembered that some steppe species with a wide distri- 
bution in North Germany are totally missing in Scandinavia, such as Dianthus carthusianorum, Carex praecox, and Astragalus cicer.

\section{Summary.}

1. The occurrences of the steppe species in South Sweden are situated in the eastern part of that area, or are strongly concentrated there. They are found mainly in the calcareous districts, on the great arable areas, on sandy fields, and on the slopes of the os-ridges.

2. The region in South Sweden within which the distribution of the steppe species more or less completely falls can be defined thus: in the north the boundary runs from the lower part of the Dalälven in an approximately southwestern direction across the plains of Västmanland and Närke to the central part of Västergötland, where it turns off in a south-easterly direction and passes through Småland down towards the Kalmar district. From here the boundary runs westward, enclosing parts of Blekinge and Skane, though it should be observed that several species distributed in the eastern part of Central Sweden are altogether absent or rare in Skåne and Blekinge.

3. The present distribution of the steppe species in South Sweden seems, as a rule - so far as we can form an opinion at present on such questions to be determined by the present geographical conditions of the region, its climate, the nature of its soil and topography, in connection with the capacity of the species to spread themselves.

4. In some cases we are compelled to have recourse to another mode of explanation - the species have occurrences that are relics of a distribution which was wider in former days and which was made possible by more favourable geographical conditions.

5. The distribution of the species throughout Scandinavia and Denmark may be said to be divided into two branches - an eastern one and a western one, parted by the South Swedish highland. Many species have the western branch marked by only a few isolated occurrences, which are probably mere relics, while other species lack this branch altogether. But there are also some species that have no eastern branch.

6. The distribution of the species on the other side of the Baltic is usually in accordance with the Scandinavian distribution: species restricted to the east of South Sweden reach their western limit in the east of North Germany, while species that are found in western Scandinavia and Denmark also have a distinctly more westerly limit of distribution in North Germany. Nevertheless it is to be noted that there are exceptions to this: one or two species that are 
distributed only in the east of South Sweden have a westerly limit of distribution in the west of North Germany, while some species that have in Denmark and western Scandinavia a westerly limit of distribution have a comparatively easterly limit in North Germany. At the same time it must be pointed out that several species distributed far to the west in North Germany are altogether lacking in the east of South Sweden, while some of these species have occurrences in Denmark and the west of Scandinavia.

\section{CílApter X.}

\section{Species belonging to the thin foliferous forests of Eastern Europe.}

\section{Their Mode of Occurrence.}

The thin foliferous forests that are here in question correspond to two types of vegetation in the scheme on p. 233, namely the xerophilous thin foliferous forest (»steppe forests», dry wooded slopes, brushwood slopes etc.), and secondly the mesophilous thin forests formed of trees which do not throw so much shade. I have combined the types here in order to economize space, and also because several species belonging to different types exhibit similar conditions of distribution in South Sweden.

We have now passed over to types of vegetation which have their proper domicile in the Middle European flora district, and which contribute to characterize that district. In accordance with this fact we shall find that the flora that distinguishes the types of vegetation has a tolerably uniform composition throughout the whole of Middle Europe. But the fact that there are better conditions for the species falling under this head in continental regions than in maritime ones is shown by the greater number of species in the flora of the first-named regions.

We find both the types of forest that are now in question abundantly represented in the vegetation of Central Russia.

The xerophilous thin foliferous forest is closely connected with the meadow steppe in the matter of the composition of the flora. There is a connecting link in the steppe forests".

These consist of low-growing, thin coppices which appear here and there on the steppes where the conditions of the ground are suitable, as near watercourses or on mounds where the salt in the soil has been leached to a considerable depth (cf. Tanfiljev 1894 and 1906 etc.). As regards the composition of the flora, I can here give only a few slight indications and refer to other publications: e. $g$. Chirjaev 1907, e. g. pp. 350, 35I, 362, and 367 ; and 1910 , e. g. pp. 350 and 362 [government of Kharkov]; Keller 1903, e. g. pp. I1, 23 [government of Saratov]; 
Novopokrovsky 1914 [The Territory of the Don Kossacks]; Sidorov I897, pp. $5 \mathrm{ff}$. [Ekaterinuslav]; Tanfiljev I894, pp. 146 ff. [Voronezh]; Taliev 1902 and 1904 etc.

These coppices seem, as a rule, to have a mosaic vegetation formed of groups of trees or shrubs with patches of meadow steppe between. The most important tree is the oak, while amongst the shrubs may be noticed Prunus spinosa and fruticosa, Evonymus verrucosa, Acer campestre and tataricum etc. Of the abundant herbs in the flora may be mentioned Agrimonia eupatoria, Clinopodium vulgare, Cynanchum vincetoxicum, Geranium sanguineum, and Origanum vulgare, which often recur in lists of species.

In Central Russia we find similar forest types on slopes and escarpments with a southerly exposure on dry ground. Copious lists of species illustrating the composition of the flora may be found, for instance, in the following works: Flerov 1902 and 1910 (e.g. lists 34, 66, 68, 494, 648); Murashkinsky 1906; Korshinsky 1888 and I891; Gordjagin 1889 (e. g. pp. 46 ff.); Smirnov 1903.

In Central Europe this type of forest would seem to have its best representative in thin oak forests on fairly dry ground and in certain brush communities, for instance, in Hayek I914, 》Eichenniederwälder» (pp. I23, I24), 》Sommergrüne Buschhölze» (p. I 26); Drude 1 8g6, "Lichte Hain- (und Vorholz) formation» (p. 3 I 2), 1902 (e. g. pp. I 84 ff., 439); Domin 1906 ("Lichte xerophile Haine und Gebüsche», pp. $32 \mathrm{ff}$.). In the ground flora, of course, some of the species have disappeared, and others have been added, but the resemblances must be regarded as considerable. In the south of England there are oak forests and brush communities on calcareous ground which may perhaps be regarded as representatives of this type (Tansley 1911, p. 153; Moss 1913, pp. 79, 99).

The mesophilous foliferous forest type with which we are here dealing seems to play a prominent part in the vegetation of Middle Russia. Especially does this appear to be the case in the eastern parts of the region. It would seem pos. sible to connect this fact with the circumstance that the foliferous forest formed of trees throwing a strong shade (»lunden», »the grove») retires rapidly, a fact which in its turn probably has its foremost cause in the increasingly continental character of the district.

The trees composing these forests are chiefly birch, aspen, and oak, but not infrequently there are also pines. The shrub layer, which is often but little developed, includes such plants as Evonymus verrucosa, Prunus padus, and Rhamnus frangula. The ground vegetation can be characterized as rich in herbs. Among the species that are most frequently included in the lists of species may be mentioned Calamagrostis arundinacea and Melica nutans, Melampyrum nemorosum and pratense, Geranium silvaticum, Convallaria majalis, Fragaria vesca, Solidago virgaurea, Pteridium aquilinum, Trifolium medium, Polygonatum odoratum, Potentilla erecta, Rubus saxatilis, and red and blue whortleberries. See too Fleror 
1902 (e.g. pp. 73, 79, 114,286 ); I9 10 (lists 47, 1 28, 172, 192 etc.); Korshinsky 1888 (e.g. pp. 104, 105); 189 I etc.

To what extent these communities have been created by human intervention it is impossible for me to determine. But it would seem to be quite certain that there cxist communities of this kind that are entirely natural.

In Central Europe this type of regetation is scarcely likely to be found in its genuine form. It seems there to be replaced by more shaded types of forests, especially the beech forest. We may regard as corresponding to it certain mountain forests of birch and aspen, and certain forests in which the oak is the dominant tree. In the former, however, the ground flora seems to be poorer in herbs and richer in undershrubs; and in the latter there have appeared a number of species belonging to Central or Western Europe. The following references can be given: Hayek 1. c., „Gemischte Laubwälder» (p. 89, in part), » Birkenwälder» (p. 90), „Der süddeutsche Eichenwald» (p. 104), „Der ostböhmische Eichenwald» (p. 123 ); Drude 1896, »Vorholzformation» (p. 312), »Baltisch-hercynischer (Nadelund) Laubwald» (p. 3 I4); Drude 1902, "Gemischte Laublıölzer und Buschgehölze», „Untere hercynische Laub- (und Nadel-Meng-) wälder» (pp. 135 ff.); Domin 1. c., „Lichte, mässig feuchte bis halbxerophile Haine» (p. 31). In England the type of vegetation here in view would seem to have something corresponding to it in certain oak forests in which there is no undergrowth of hazel throwing a deep shade (Tansley 1. c., e. g. pp. I 23 ff.).

In the south of Sweden forest types of this kind are widely distributed and play a prominent part in the vegetation. They are of several different kinds, sometimes produced by human intervention, and sometimes quite natural.

The pre-condition for their existence as natural is a broken topography. It is the slopes with a southerly exposure and the natural forest edges on shores which would seem to be, in the main, their natural abode.

Through the transforming activity of man on the primeval forest this type of forest has to a large extent been replaced by a forest vegetation with a sparse stock of trees. Through cutting, pasture and haymaking coniferous forests have had to give way over large areas to light birch and aspen forests ("hagar»); and the closed shady foliferous forest ("lunden») has passed into a park-like mosaic vegetation called "lövängcn», composed of small "groves» separated by meadows.

Space does not permit me to say anything, except with the very greatest brevity, as to the composition of these types of forest and their occurrence in South Sweden. (See Hult 1885; Sernander 1892, pp. 32 ff.; 1900; "Igor a»; »I920 b»; 1922, p. 35; Hesselman 1904; 1905 etc).

Nearest to the dry, thin, steppe forests of Russia come one or two peculiar types of forest on Öland and Gotland. They occupy an intermediate position between the vegetation of the Alvar and the closed forest. They appear where 
the layer of soil on the limestone pavement is not sufficiently thick and moist to permit closed forests to arise. On Öland they consist of low foliferous forests, mainly composed of hazel and with sporadic low trees, such as oak, ash and Sorbus suecica. Between the hazel thickets the ground is covered by meadows rich in herbs, greatly reminding one of certain Alvar meadows. On Gotland the pine is the dominant tree (cf. Hesselman 1908, pp. $83 \mathrm{ff}$.). These types of vegetation would seem to show great resemblances in composition to those in corresponding localities in Central Europe. Special mention may be made of their wealth of orchids.

On hill slopes with a southerly exposure and with a nutritive soil there are found throughout South Sweden forest types which we can call »oak slopes» or "grove slopes» (Swed. »ckbackar» and »lundbackar»). They are most fully developed, and occur in the greatest abundance, in the south-east of Sweden, especially in calcareous districts. In these forest types we have something that corresponds exactly to the thinner oak forests of Central Europe. Many of the species distinctive of South Sweden are distributed throughout the oak-forest zone of Middle Europe: e. g., Agrimonia eupatoria. Clinopodium vulgare, Geranium sanguineum, Lathyrus niger, Melampyrum cristatum, Origanum vulgare, Serratula tinctoria. Here too we find many species which have a continental distribution.

The flora of these forest slopes have many representatives in the conglomeration of species from wholly different plant communities, which forms the flora on tree-clad rocky slopes with a southerly exposure. Here they meet with representatives of cliff vegetation proper, of the flora of herbaceous slopes, the flora of coniferous forests, ploughland weeds etc. As so far scarcely any analyses of this vegetation have been published with regard to South Sweden, I have considered it proper to give some such analyses from different districts in the south-east of Sweden (See table 4, Appendix II; cf. Erdtman 1922).

These lists of species may be of interest from several points of view. In this place I shall only call attention to a peculiarity with regard to the dispersal biology of the species, which is of some consequence for its bearing on an argument in the sequel. The flora includes what is assuredly an unexpectedly small number of species which are especially equipped for wind dispersal. It should further be observed that the species which have such equipment occur abundantly in other types of vegetation in the surrounding district, in coniferous forests or on ploughlands. An exception to this, however, is provided by Cynanchum vincetoxicum. This is all the more peculiar because the equipment of the species for wind dispersal ought to be extremely effective - namely a winged, flattened, light seed provided with a powerful pappus. As will be shown below, this circumstance may be connected with the peculiar distribution of the species in South Sweden. 
The forest and mountain districts of South Sweden, and also large parts of the low-lying forest tracts of Central Sweden, usually lack the climatic and edaphic conditions for the above mentioned oak and grove slopes. The thin foliferous forests which we can here think of as a natural vegetation are of quite a different character. On suitable slopes, and also in the natural forest-edges, we should here meet with comparatively thin mixed forests, in which birch and aspen were the dominant kinds of trees. Owing to human intervention, these types of forest have obtained an immensely increased distribution, and, next to the coniferous forests they are the most important types of forest in South Sweden. In Swedish they are called »hagar» [which seems to correspond to one of the dialect meanings of the English word "hag"].

It is in the east of Sweden, that a type of forest which falls under this head, a mixed birch forest rich in Calamagrostis arundinacea, finds its main distribution. Its ground vegetation is formed of mesophilous and comparatively heliophilous grasses and herbs. The general distribution of this type of forest in Middle Europe is clearly continental; and besides Calamagrostis itself it has several species of continental distribution (Campanula cervicaria, Laserpitium latifolium, Melampyrum nemorosum, Ranunculus polyanthemos, Selinum carvifolia); see Plate 22. It is of interest to note that the commonest mesophilous thinned foliferous forest in Central Russia seens to have as its distinctive species Calamagrostis arundinacea and Melampyrum memorosum.

In the north-eastern parts of the South Swedish highlands this type of vegetation appears pretty generally on slofes with a southerly exposure. In the less elevated parts of Östergötland, in Södermanland, in Uppland, and also in parts of Västmanland and the south of Gästrikland I have seen this type of vegetation abundantly distributed, with a mode of occurrence which strikes me as possibly being its natural mode. It is met with on the edges of coniferous forests which occupy regions with Archaean rock or moraine rich in boulders, and which outside these regions are replaced by clayey ground, marshes or lakes. In a forest district in Uppland situated 2-4 miles (Swed.) north-west of Upsala, in the parishes of Vänge, Skogs-Tibble, Järlåsa, Junkil, Bälinge, and Vittinge, where, as far as one can judge, the vegetation may still show much of its natural character, there is a district which is especially worthy of study. Large areas of marsh ground, which are now for the most part drained and cultivated, and some small lake basins alternate with Archaean rock tracts or low boulderous moraine tracts covered with coniferous forests. The old shore-zones are occupied by foliferous forests or mixed forests, in the ground vegetation of which the leading part is played by Calamagrostis arundinacea.

In Table 5, Appendix II there are given a number of analyses (Columns I and $\mathrm{I}-8)$ of foliferous forests rich in Calamagrostis arundinacea from different 
parts of south eastern Sweden. They should be able to throw a certain amount of light on the composition of that type of forest.

One of the most characteristic plant-communities of the South Swedish highland is the meadons or forest-meadonvs rich in Arnica montana. In this respect the South Swedish highland suggests comparison with the mountain tracts of Central Europe that are poor in lime and rich in precipitation (see, for instance, Drude 1902, pp. 137, 140, 217, 24I). These Arnica-communities are common in the western parts of the highlands. Further east they appear less abundantly, and they are extremely rare on the coast along the Straits of Kalmar.

Their flora, which is poor in species, consists, as a rule, of species that are ubiquitous in the forest tracts of Middle Europe, or of West European species; but in the east of Smalland they may sometimes be richer in species, and in such cases may contain one or other continental species, of which examples are provided in the analyses 9 and 10 , Table 5, Appendix II.

\section{The Distribution of the species.}

From what has already been said it will be seen that the continental species that are to be treated here are extremely dependent on the topography in regard to their natural possibilities of occurrence. The natural region of distribution of the species ought to be located in districts with broken terrain where slopes and rocky escarpments facing south and shore belts are occupied by more or less thin forest associations. Thus it is the requirements of the plants for light which should chiefly determine their natural distribution.

Another ecological character that appears in this way seems to be high requirements with regard to the nature of the soil. The species appear in their entire distribution area only on spots with more or less mould-like humus and soil rich in electrolites. Thus their natural distribution would to some extent be determined by the precipitation conditions and the nutritive (lime) content of the weathered material in the soil.

In contrast to what is the case with the steppe species, the actual distribution of the species in our days is also chiefly determined by these factors. The bringing of new areas into existence by means of cultivation is not of such salient influence with regard to them as with regard to the steppe species.

Species closely akin to the steppe species. For a number of specics certain characteristics appear again which are found in the distribution of the steppe species. Naturally these features show closer resemblance the more a species approaches the steppe species in its mode of occurrence. A transition between the two groups of species is formed by the previously treated Crepis praemorsa and Ranunculus polyanthemos, which are marked by an abundant distribution in 


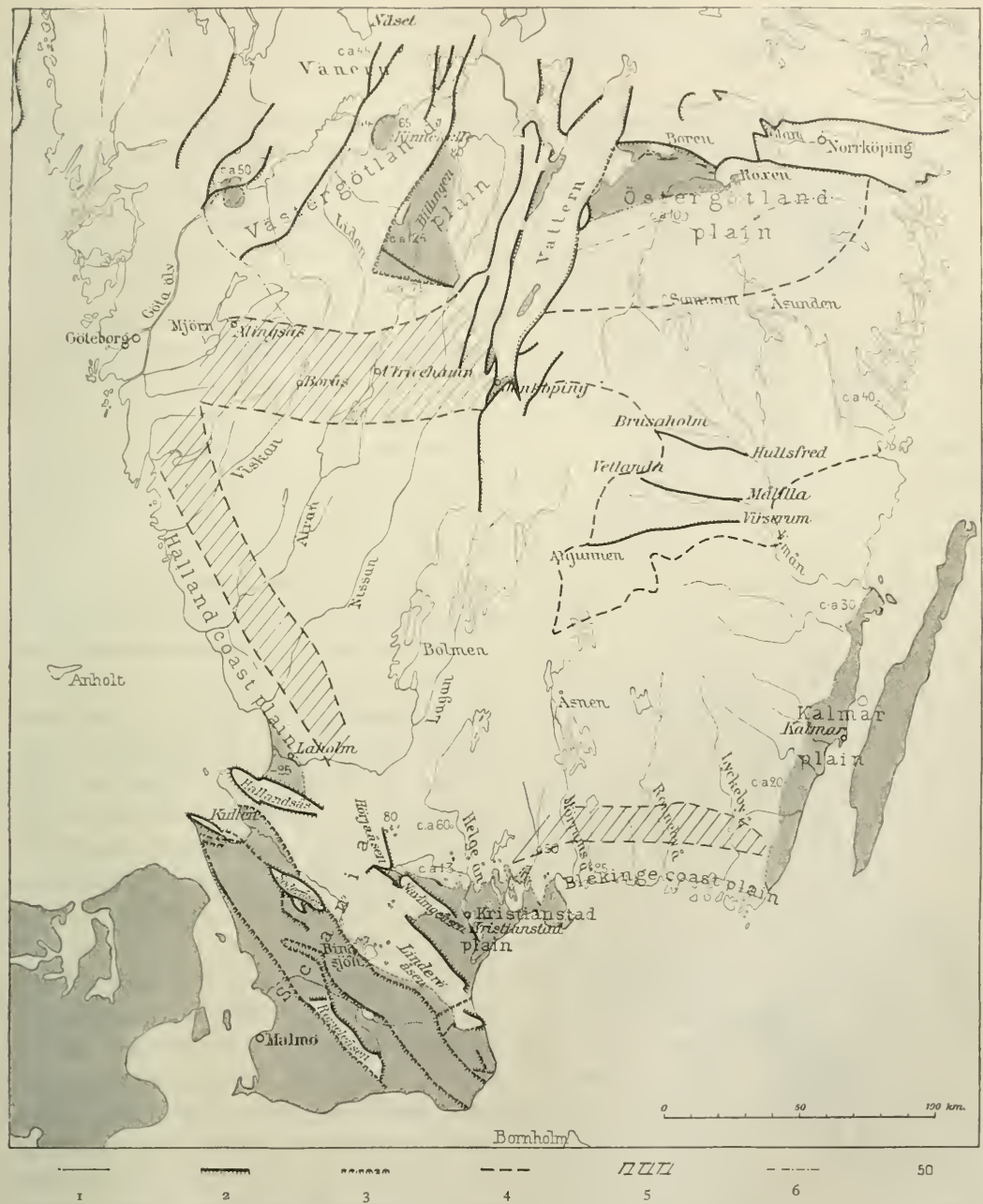

Fig. 21. Geomorphological Sketch-map of the South Swedish highland and the surrounding plains (after Ahlmann 1920. The stereotype has kindly been placed at my disposal by the editor of , Geografiska Annalern.) - 1: land contours, lakes and rivers; 2 : fault escarpments; 3 : faults not actualized in the topography; 4 : limit of broken topographic areas. [Further in the west from Vetlanda and further in the south of Virserum there are smaller and less hilly tracts; cf. the distribution map of Hypericum montanum, fig. 25]; 5: broken marginal zones; 6: limit of the Västergötland and Östergötland plains. The dotted areas show post-Archaean ground. 
the flatter regions of Central Sweden and a Smaland-distribution which is limited or concentrated to the broken regions in the north-east. (See Figs on pp. 315 and 319.)

Some other species previously mentioned Dracocephalum Ruyschiana (Plate 4), and Pulmonaria angustifolia (Plate 4), as well as Ajuga genevensis are also connected with certain steppe species as regards both mode of occurrence and distribution in South Sweden. For all these species we have statements as to their occurrence in meadow-steppe regions (e. g. in the Streletz-and the Kasatz-steppes in the government of Kursk, according to Alechin, 1909 and 1910), but in that case they most frequently belong to scrubs or forest oases in the steppe region. [Cf. Korshinsky's (1898) information as to the way in which the species appear in the east of Russia]. In the south of Sweden the species appear both in dry meadows and in dry hilly thickets (see Sernander 1908, pp. 54 ff., 6 I ff., and the analyses of vegetation on p. 304). The distribution of the species in southern Scandinavia, which is in many cases interesting, has already been mentioned (see pp. $306 \mathrm{ff}$. and the distribution maps on Plates 3 and 4, and Appendix I.)

Some species more or less typical of thin dry forest associations. - In the first place I will briefly treat two species distributed in almost the whole of Middle Europe. A species which is characteristic of dry wooded hillsides throughout

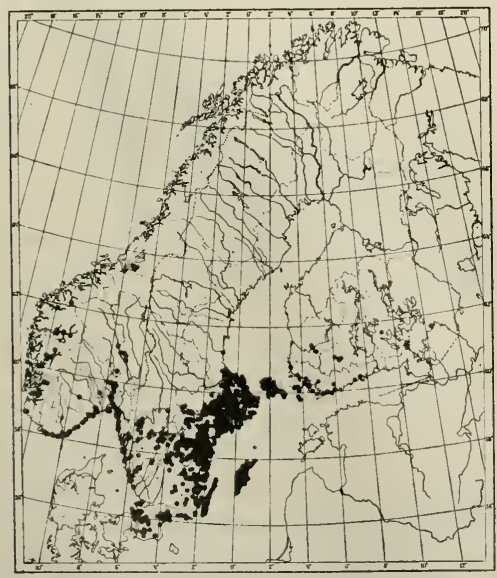

Fig. 22. The distribution of Agrimonia eupatoria in Scandinavia and Finland.

In Denmark the species is abundantly spread over almost the whole country.
Middle Europe is Agrimonia eupatoria. Its distribution in Fennoscandia is shown in the annexed map (Fig. 22). This distribution would seem to correspond very closely to the maximum distribution of species with a similar mode of occurrence. Thanks to its effective equipment for spreading itself, of course, Agrimonia has a great capacity for reaching suitable localities.

This species is found nearly all over the south of Sweden, but considerably more abundantly in the eastern than in the western parts. In Småland its greatest distribution is on the coast and in the north-eastern interior of the province. The species is very richly represented in the plains of Central Sweden. In addition to a number of natural occurrences, it has also, thanks to its capacity for spreading itself, been able to acquire a 
number of localities produced by cultivation (roadsides, fieldsides, and baulks etc.). Like many other species falling under this head, Agrimonia has a northern limit of distribution that coincides closely with the transition from the Central Swedish plain into the Norrland forest region. Attention should also be directed to the wide distribution of the species in the coastal skerries of South-East Sweden and in the broken mainland that lie behind those skerries.

In passing we must point out its distribution in Norway. With its isolated occurrences in the inner parts of the fjords of western Norway Agrimonia appears as a representative of Blytt's » Boreal elements (Blytt, e.g. 1876 and 1893) and of Hansen's »Origanum formation» (Hansen, 1904 a and b; see above p. 317).

Geranium sanguineum (Fig. 23) is another species which is pretty general in Middle Europe. In the south of Sweden it especially belongs to the flora of rocky escarpments, but it may also form a part of the same dry forest hill-

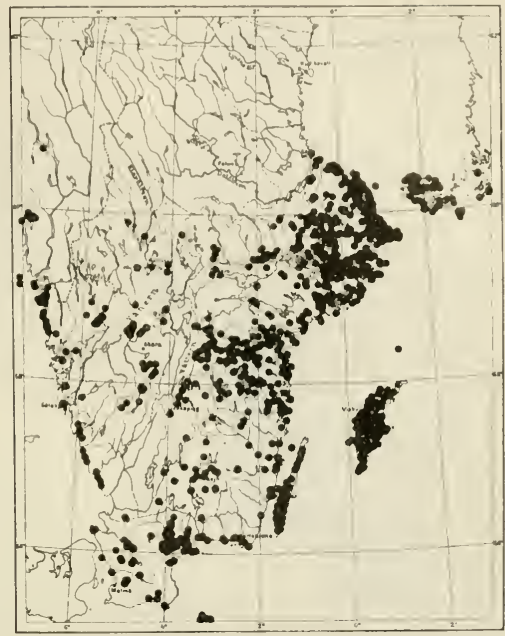

Fig. 23. The Swedish distribution area of Gera nium sanguineum.

In Norway the species is pretty abundantly spread over the south-eastern district (in the north to Toten) and on the southern and western coast to Söndfjord ; in Denmark it is not rare in northern Jutland, on northern Zealand and on Bornholm; besides it is found on Falster, Lolland, Fyen, and in Slesvig. In Finland it has also a few occurrences in the south-western mainland. side as Agrimonia (see table 4, Appen-

dix II). Geranium sanguineum is found almost throughout the south of SivedenIn the west, especially in the west of Smaland, it resembles Agrimonia in oc. curring less abundantly than in the east. But it is not rare on the rocky coast of the north of Halland and Bohuslän. It is less favoured by civilization in its distribution than is Agrimonia. Thus it is not so common as the latter plant on the plains of Central Sweden. Its distribution in the south of Sweden may serve as an example of the maximum distribution of species belonging to this group which have shown comparatively little power of making use of the help of civilization. - For this species too attention must be drawn to its wide distribution in the coastal skerries and on the broken mainland behind. Inland occurrences are especially to be found in cliffs and on the sloping edges of lakes and watercourses. 


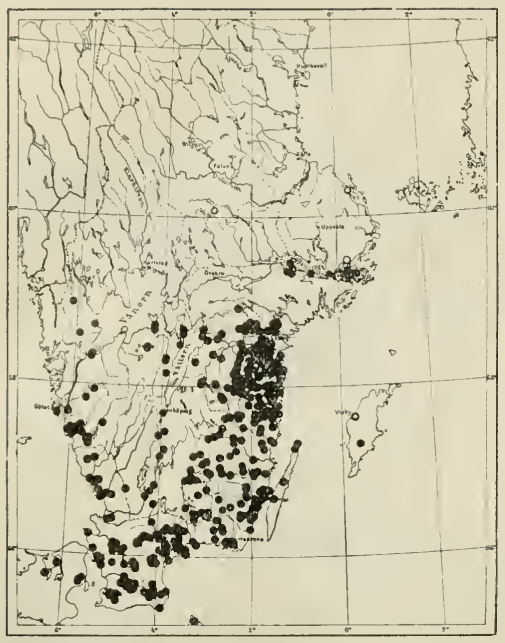

Fig. 24. The Swedish distribution area of Vicia cassubica.

O: uncertain or accidental occurrences.

In Norway the species has a few localities on the southern coast (Bamle, Lyngör-Christiansand); it is not found in Finland; in Denmark it occurs also in north-eastern Jutland, in Slesvig (Midsunde), on Fyen, and on Bornholm.

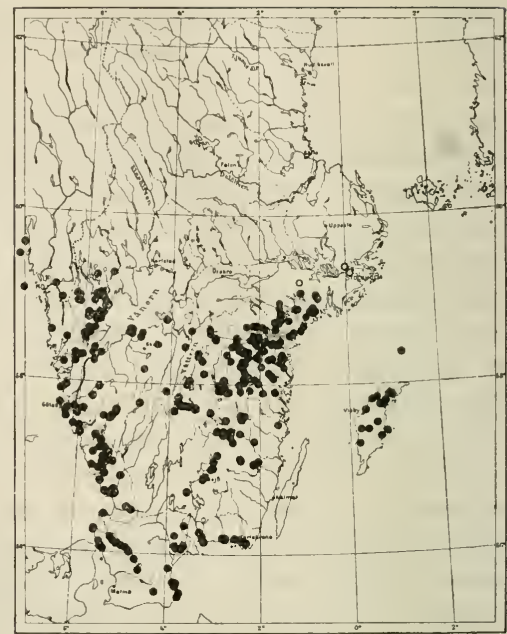

Fig. 25. The distribution of Hypericum montanum in Sweden (a West European species).

$\bigcirc$ : uncertain occurrences.

The species is pretty abundantly spread in southern and western Norway to Lofoten in the north; in Denmark it occurs rarely on the islands, except Falster and Lolland, and in Jutland; it is not found in Finland.

A type which is divergent in several respects is represented by the continental species Vicia cassubica (Fig. 24).

In certain districts of the mainland of South Sweden this species is one of the commonest in the flora that is especially distinctive of rocky escarpments and dry wooded hills.

The species has evidently a great capacity for spreading itself in limited areas. It is probably spread by birds, e. g. gallinaceous birds, which gather the peas in their crops. Conservator Kjell Kolthoff of Upsala has had the kindness to inform me that one can imagine a very effective dispersal by the seizure of gallinaceous birds with peas in their crops by birds of prey, which like to seek out a place from which they have a good view and where they can enjoy their booty undisturbed, such as rocky cliffs and open wooded slopes. The content of the crop will thus be emptied in such places. 
This species has a not inconsiderable power of turning to account suitable localities created by civilization. Thus, it is rather often met with on roadsides, railway-beds, in gravel-pits etc.

As appears from the map, the distribution is very different from that of the two species mentioned above. I should especially like to direct attention to the curious leap made by the species from Kolmairden to the southern shore of Lake Malar, where it has some few occurrences, the only ones in the Mälar district. Cf. the distribution of the IVest European Hypericum montanum (Fig. 25)].

Attention may also be drawn to the fact that the species is almost completely lacking on Öland and Gotland. Vicia silvatica, also a species characteristic of wooded hillsides in South Sweden, shows the same peculiarity in its distribution.

Vicia cassubica exhibits a close agreement with the preceding species in a frequent number of occurrences in the broken coast regions of Östergötland and northern Småland. In Norway the species has a remarkable distribution. It occurs in the escarpments on the southern coast (Lyngör-Christiansand), but is lacking in the Christiania district.

In connection with this species may be mentioned two other continental species which are far rarer in the south of Sweden, but which nevertheless have certain main features of distribution in common with Vicia cassubica: Cotoneaster melanocarpa (Plate 12), whose general distribution in Europe is very peculiar owing to a great bulge towards the west over southern Scandinavia from the distribution area of Siberia and Eastern Europe, and Vicia pisiformis, which has a few occurences scattered over Central Sweden and the south-eastern Norway, which are very much isolated from the also very much scattered occurrences found in the Sarmatian-Central European distribution area. (Plate I2).

Some species belonging to mesophilous thin forest associations. These species are principally met with in the luxuriant vegetation, often rich in species, which forms the edge of the wood in the shore belts of marshes, lakes and watercourses in tracts with comparatively nutritious soil. To a great extent, of course, they have obtained increased dispersal through human agency and are often found in hayfields. Many of them can also be met with on dry wooded slopes.

Here may be mentioned in the first place Calamagrostis arundinacea. The species has a wide distribution in South Scandinavia, but shows, nevertheless, an evidently continental character. In South Sweden it is spread much more in the north-eastern forest districts than in the south-western ones (Plate 22). - A similar South-Scandinavian distribution has Thalictrum simplex.

A species falling under this heading which also is very widely distributed in the south of Sweden is Selinum carvifolia (Plate 7). Outside Sweden this species is found over the whole of the mainland of Europe, with the exception of a small 
area in the north-west. In the south of Sweden it proves to be to a very large extent limited to low-lying land; in Central Sweden it is abundantly distributed on the low-lying plains round the great lakes, while it is very rare in the SouthSwedish highland. To judge by my own observations, the species occurs very often in Östergötland, Södermanland and Uppland in the broad-leaf forests which have been described above as being rich in Calamagrostis arundinacea.

Campanula cervicaria (Plate I1). In a number of localities in the north east of Småland, in the south-east of Östergötland and Södermanland and Uppland (Jumkil and Järlåsa!) I have seen this species occur in wood meadows rich in Calamagrostis arundinacea. According to information kindly given to me by the late Mr. Herman Fröding, the clever taxonomist, the species is to be met with in Värmland especially in the edges of woods or thickets on hay-fields by the side of lakes and watercourses (see too Skårman, Svensk Botan. Tidskr. 1912, p. 400 and 1914 , p. 368). To judge by the position of the occurrences on the map this seems also to be its usual mode of occurrence in Central Sweden and southern Norrland. According to Andersson and Birger (I91 2, p. 95), it also appears on southward-facing hills in Värmland. In the south of Sweden the species would seem often to appear in slopes covered with groves or oaks. On Öland this is its normal mode of occurrence.

The distribution of this species differs from that of the species previously mentioned in the fact that it comprises a large part of the forest region of southern Norrland, and in the fact that in South Sweden it would seem to be considerable more abundant in wooded hill districts (the north-east of Småland and the south of Östergötland, Kolmården, Tiveden etc.) than on plains and in coastal districts. It should be pointed out that this species is restricted to the northiastern and more broken districts in Smaland. In this respect the species shows accordance with certain species previously mentioned, especially Ranunculus polyanthemos (p. 319) and Agrimonia eupatoria (p. 344).

To this group of species may be referred Campanula persicifolia and Scorzonera humilis, which are common, or all but common, in almost the whole of South Sweden. The first-named, however, is lacking, or rare, in a rather large area in the south-west of Smaland. Towards the north this species pushes its way along the coastal region of Norrland as far up as Angermanland, and is found even in Jämtland, while Scorzonera, on the other hand, reaches its northern limit so far south as the Gävle district, the south of Dalarne and the south of Värmland. - In Middle Europe the species are very widely distributed, but they are totally absent from Great Britain and in an area on the mainland of North-West Europe.

Inula salicina (Plate 7), which is also found throughout almost the whole of Middle Europe, is widely distributed in South Sweden. The distribution differs 
in some respects from that of the above-mentioned types. The species especially belongs to the flora of hills covered with oaks or groves but it may also appear in meadows, especially in high-lying shore-meadows, and sometimes too in dry meadows (see table I, Appendix II). It seems to be somewhat more exacting with regard to the nutritive nature of the soil than the preceding species. More remarkable, from the viewpoint of distribution, is the peculiarity that the species is all but totally lacking even in the coastal districts of Småland and Östergötland. In this respect it agrees with a large number of "calciphilous» species. A small number of occurrences right through central Småland form a peculiar kind of connecting link. - The comparatively wide distribution of this species on the west coast would seem to have its primary cause in marl and shell-bank occurrences.

The species which have just been treated have not shown, or at least not shown to any great extent, any easterly distribution in the south of Sweden. But to the types of vegetation here in question there belong a number of species which are lacking in the south-west of Sweden. A hint of this type of distribution is to be found in the circumstance, which has been pointed out with regard to some species already treated, that the distribution is considerable more abundant in the south-east than in the south-west of Sweden [Ranunculus polyanthemos (p. 319), Crepis praemorsa (p. 315), Agrimonia eupatoria (p. 344), Geranium sanguineum (p. 345), and Vicia cassubica (p. 346)].

Another transitional type is supplied, as is shown by the map on Plate 7 , by Melampyrum cristatum. This is very characteristic of the flora on hillsides covered with oaks or groves in the south-east of Sweden. With regard to its general distribution the species agrees pretty closely with Geranium sanguineum but it is somewhat less widely distributed in the west of Europe.

Laserpitium latifolium (Plate 7), which is also characteristic of the richer hillsides covered with oaks or groves in the south-east of Sweden, has a greatly restricted and purely easterly distribution in the south of Sweden. The species makes its way into Västergötland only in a small number of localities. From there the limit runs in a southerly direction through the centre of Småland and the east of Skane. It is worthy of especial notice, therefore, that Skåne falls almost entirely outside the limit. Throughout the whole of north-eastern Småland, from about the line Kalmar-Vetlanda-Jönköping, Laserpitium is pretty abundant. The few occurrences south of the line just mentioned fall in smaller areas with undulating terrain.

This remarkable distribution limit of Laserpitium may to some extent be de- 
pendent on the precipitation conditions and the topography. In Småland at least these causes must be of great importance. It seems to me, however, not impossible that the spreading of the species in South Sweden is not yet finished. The peculiar, isolated occurrences on the southern coast of Norway and the total absence of the species in the neighbourhood of Christiania and in northern Jutland, may also be irregularities in the distribution, that might hint at an as yet unfinished spreading (cf. above Vicia cassubica).

The decidedly continental Melampyrum nemorosum (see Plate 10) is in the south-east of Sweden, as in large parts of the east of Middle Europe, a species highly characteristic of more or less thin rather mesophilous foliferous forests of different kinds. In lists of species from Central Russia it is one of those which most frequently recur. Its area of distribution in Sweden, as appears from Plate 8. even lies somewhat more to the east than that of Laserpitium. Nevertheless it comprises the west of Skåne and from there forms a distinct West-Scandinavian extension through Zealand and the north-east of Jutland.

The distribution of Melampyrum nemorosum in the south-east of Sweden is of great interest.

In certain skerries on the south-east cuast of Sweden Melampyrum nemorosum is pretty common. The gaps in the distribution would seem to be partly explicable by the fact that suitable localities are lacking, or at any rate are rare, in certain districts, e. g. amongst the rocky skerries of northern Småland.

On the mainland the species appears more or less abundantly in some districts within the skerries. In the most south-easterly part of Smalland, south of Kalmar, for instance, where there are no skerries, this species is entirely absent. [Cf. Agrimonia eupatoria (p. 344) and Geranium sanguineum (p. 345)].

Occurrences on the mainland are usually found on the banks of watercourses, lakes or marshlands. From the coast of Blekinge the species stretches up through the river valleys into the south of Småland, where it has a number of occurrences near some lakes.

In Östergötland, Södermanland, and also, though not so distinctly, in Uppland, the occurrences that lie furthest inland are isolated from the more abundant distribution on the coast. In Södermanland Melampyrum is abundant along the coast. Apart from this it is lacking in the province, in spite of the great number of lake-shores except in the extreme west. In Östergötland we find a similar state of things. Here the distribution is peculiar for another reason too. Within the most westerly occurrences, and at a higher altitude above sea-level than they have, there are numerous localities which seem to be quite suitable, but of which the species has made no use.

In Uppland, from which province very copious material has been very kindly placed at my disposal by Mr. Erik Almquist, Phil. Mag., I have been able to 
study the distribution in great detail (Plate 8). Over and above a very abundant distribution in the skerries and on the coast, the species has a large number of occurrences in the south-eastern portion of the province. In most cases these occurrences are found on shores. In certain districts, especially round Upsala, the species appears on slopes occupying the border zone between moraine hillocks and the cultivated clay-fields lying at their foot. In connection with what has been said above (p. 317 ) as to the abundant distribution of certain steppe species on the Upsala plain, the explanation of this state of things would seem to be found in the fact that wood-edges have existed here ever since the land came into existence. At the time when the moraine hillocks formed islets and skerries in a coastal archipelago, Melampyrum grew in wood edges on the shores; and - even after a continuous land surface emerged, the species has been able to retain these occurrences owing to the fact that the clay areas have never been occupied by forests in consequence of the intervention of man.

West of the Upsala plain, Melampyrum has a smaller and somewhat isolated distribution area, which falls within the above-mentioned (p. 34I) moraine and marsh ground region in the parishes of Jumkil, Järlăsa, Skogs-Tibble etc. In these parts we can still study the mode in which the species naturally occurs: it occurs abundantly in Calamagrostis-forests on the banks of (former) marshes or lakes (see the analyses of vegetation in table 5 , Appendix II). - The cause of the gap in the distribution between this region of occurrence and the occurrences down on the shores of Lake Mälar to the south and on the plain of Upsala to the east would seem partly to be found in the rarity of lakes and marshlands in the intermediate region. Another cause is perhaps to be found in the fact that this region lies higher than the plain of Upsala and that its coming into existence in the form of a continuous land-surface happened at a time when the population of Uppland was still mainly engaged in fishing and had no reason for preventing the forest from overrunning the entire surface of the land (Cf. Högbom 1912; Eriksson 1913; and Ekholm 1915). Space does not permit of a more detailed treatment of the interesting connection, here only hinted at, between the present distribution of species in Uppland and the geographical development of the land.

The distribution of Melampyrum nemorosum in Sweden, therefore, is in many respects peculiar and is widely different from that of the species previously treated. It would be particularly interesting to attempt to determine the causes why the area of distribution is restricted to coastal districts. Why has not this species, like the species with which it most abundantly occurs in its localities on the east coast, been able to spread itself further over the country?

The distribution of Cynanchum vincetoxicum in the south of Siveden. "The Cynanclum problem». Several of the above-mentioned peculiarities in the matter 


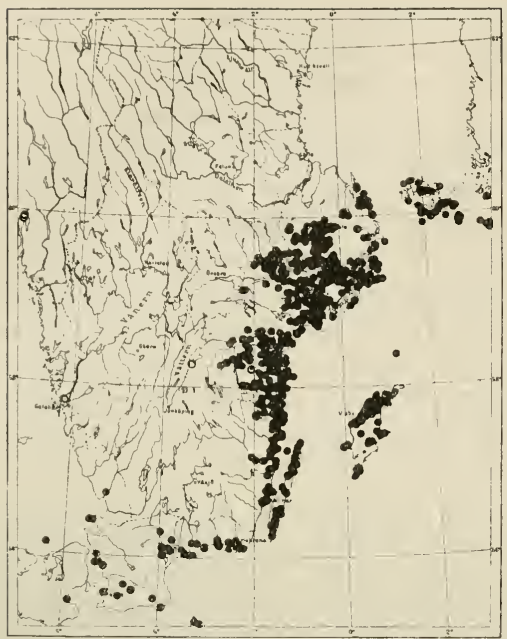

Fig. 26. The distribution of Cynanchum vincetoxicum in Scandinavia and Finland.

0 : uncertain occurrences. Cf. Plate i8.

In Denmark the species has a few occurrences also on Fyen and is found in one locality in north-eastern Jutland.

of distribution are shared by Melampyrum nemorosum with other species. In particular, its distribution exhibits several points of agreement with that of Cynanchum vincetoxicum.

I have submitted the distribution of Cynanchum in the south of Sweden to an extremely searching examination. But as this examination is not yet completed, only a brief report can be inserted here.

Cynanchum has an extensive distribution in Middle Europe (Plate I8). In Russia it also occurs abundantly in the steppe region. Nevertheless it does not appear to belong to the true steppe, but to the steppe-forest oases (»non est planta vera stepposa», Korshinsky I898, p. 289). In Central Russia, as also in Central Europe, it grows especially in rocky escarpments and on rocky flat ground. In the south of Sweden this is the most usual way in which the species occurs (see analyses in table 4, Appendix II). In the coastal skerries, and in certain mainland districts lying only a very little above the sea, it may also be met with in dry wooded slopes, especially on stony ground.

As. compared with the distribution of Melampyrum, that of Cynanchum differs by being quite continuous along the east coast, so far as the skerries extend, and by the fact that the species is lacking in the interior of Blekinge and in the south of Småland. In the greater part of south-eastern Sweden, however, the situation of its distribution limit up-country very largely coincides with the limit of Melampyrum.

In order to obtain, if possible, some clear idea as to the causes of this distribution-limit up-country, I have first and foremost sought to determine the distribution in detail.

As Cynanchum in the interior of the country occurs all but exclusively in rocky escarpments or cliffs, it is only natural to seek a connection between the distribution of the species and that of the localities mentioned. It appears that the absence of the species in the south-west of Södermanland has its principal 
cause in the fact that suitable localities are rather lacking. To some extent the same would seem to be the case also with the distribution in Uppland and Västmanland. However, for the first-named province, at least, there might hold good the same connection between the distribution of this species and the geographical development of the land that has been pointed out with regard to Melampyrum nemorosum. In the districts whcre, owing to the influence of cultivation, forests have never been able to occupy a land-surface, therefore, Cynanchum would seem to have retained, to a very large extent, its skerry occurrences. It must also be noticed that Cynanchum has its occurrences situated on such levels that they must have come into existence during the Sub-boreal period, during which the spreading of this xerothermous species must have been favoured (Cf. above p. 316$)$.

In Östergötland the distribution of Cynanchum shows no accordance with the distribution of suitable localities. Further inland than the species reaches in that province, especially near the lakes in the Stangä-valley, there is an abundance of suitable escarpments, many of which nourish an unusually abundant flora.

A close scrutiny of the distribution of Cynanchum in this last named district is of great interest (See Plate 9).

From its abundant distribution in the coastal district of Tjust (the northern part of the Kalmar county), which the map shows in its entirety only for one or two minor areas, Cynanchum has long rows of occurrences up into the country. Here it follows the sharply-defined valleys which are characteristic of that region. Along such a valley the species passes in one place even into Östergötland, passing the boundary in the parishes of Dalhem and Oppeby. In the eastern part of the latter parish, on the shores of Lake Björken, there have been at the disposal of the species excellent rocky escarpments in an unbroken sequence into the lake-basins of the Stangå valley. In this, as has been mentioned, the species might have been expected to make its way in great abundance. Nevertheless it is only to the eastern part of Lake Asunden that Cynanchum has reached. In view of the fact that Cynanchum has an extremely good dispersalequipment - flattened, winged seed provided with a powerful pappus - it is extremely curious that the species has not made its appearance in the numerous other suitable localities.

Other peculiarities in the general behaviour of the species in the south of Sweden seem to me to show that dispersal by means of seed does not take place to any great extent.

In the first place I have never been able to find the species in suitable localities more or less recently created by human intervention, such as rockblastings by the side of roads or railways, or dry, excavated, wooded hillsides; and in the second place the exceptional position pointed out above on p. 340 
which Cynanchum takes in the matter of dispersal in the flora of rocky escarpments, seems to me to be remarkable from this point of view.

In order to obtain some definite knowledge with regard to the dispersal of the species by means of the seed, comprehensive researches were set on foot in the latter part of last summer as regards the formation of fruit and seed. These researches must, of course, be continued for some years in order to yield satisfactory evidence. The results so far are as follows: -

In the interior part of southern Tjust and in the south-east of Östergötland I found that the formation of fruit was quite insignificant. In most localities I sought in vain for anything of the kind, while the numerous flower-stalks that remained bore witness to an abundant blossoming. In Södermanland and Uppland the formation of fruit varied greatly. As a rule it may be said that on open localities, especially high rocky escarpments, there was little or no formation of fruit; on localities in a more sheltered position, as on the low rocky humps in ploughlands or moraine hillocks, on the other hand, the formation of fruit could be regarded as fairly good. The richest formation of fruit had taken place in localities which lay in the neighbourhood of barns or adjacent to roads with a heavy traffic.

These circumstances are in good accordance with the account of the pollination biology of Cynanchum which is to be obtained in the textbooks (e. g. Kirchner I9I1, pp. 216 ff.). The Cynanchum flower can be pollinated only by certain large flies which have strength enough to tear away the pollinia and carry them off (Anthomyia, Pyrellia, Sarcophaga, Onesia, and Tachina). These flies naturally thrive less well on rocky cliffs exposed to the wind than on lowlying shore-slopes and hillocks; and the flies would appear in greatest numbers in the neighbourhood of barns and highroads.

The occurrences of Cynanchum in the interior of the country, especially those lying high above sea-level, are chiefly found in rocky cliffs. That the dispersal of the species further inland is so insignificant, therefore, is probably explained by the pollination biology of the plant and the nature of the localities.

These researches have also comprised the formation of seed. This last varied greatly, and the material before me does not supply a safe basis for a judgement as to the causes of this fact. To a very great extent the seeds were destroyed by insects (according to information kindly given me by Professor Ivar Trägårdh, probably by a fly, Ortalis connexa), or else they had for some other unknown cause come to nought, killed in an early stage, shrunken and empty. Possibly sometimes shortage of water may be a cause why the seeds do not develop. In most cases, however, the plant as to the rest showed no traces of suffering from drought. - Geisenheyner (1904), who has studied the biology of Cynanchum in Brandenburg, has, as to that area, too, reported a feeble formation of fruit, a 
fact that he would explain by the scanty supply of water. However, if the species not suffering from drought has formed fruit, the formation of seeds is not good; he says: Meist sind aber ihre Samen sehr dünn und scheinen mir nicht keimfähig» (pp. 87 ff.).

Another circumstance which should be pointed out is that the seeds, as a rule, seem to ripen so late in the autumn that they may be injured by frost.

These investigations into the formation of fruit by Cynanchum thus seem to show that any continuance of the inland dispersal of the species from its occurrences in rocky cliffs is impossible, or at least extremely insignificant.

But in that case the question immediately presents itself: how has Cynanchum been able to attain its present occurrences furthest in the interior of the country? This brings us to a very remarkable peculiarity in the distribution in the southeast of Sweden, which is common to several species.

With regard to certain species mentioned above, emphasis has been laid on the abundant distribution in the skerries and in certain undulating districts on the mainland lying immediately within those skerries. These mainland areas all fall considerably below the highest marine limit, and thus have not become part of the mainland until a comparatively late stage in the post-glacial upheaval of the Swedish land. Their broken terrain shows that during certain phases in the upheaval of the land they formed skerries of about the same kind as the present ones. Consequently it is very natural to assume that the species in question were abundantly distributed in those skerries also. When the skerries became a continuous mainland, over which woods spread their shady covering, the species lost a large number of the occurrences they had on the shore slopes, but they were able to maintain their position on escarpments and cliffs and on the shores of inland lakes in those regions.

As regards Cynanchum, of course, it might be conceived that there might be a spreading outwards, from low shore-slopes fairly well protected from the wind to similar spots, as they from time to time emerged from the sea; while a spreading inland to suitable rocky escarpments could in any case take place on a smaller scale, and that a continued spreading in this last- named direction, from escarpment to escarpment, would be impossible in case the complicated pollination biology of the species rendered impossible the formation of fruit in such localities.

As regards Cynanchum vincetoxicum, the occurrences that lie furthest inland and highest above sea-level would in that case be the oldest habitats of the species in these regions. If this is really the case, the internal distribution-limit ought to coincide approximately with some former coast-line. As is shown by Plate 9 , this is the case in Östergötland and Småland. Apart from some minor divergences, which mark valleys penetrating furthest into the country, the occur- 
rences which lie most inland and highest above sea-level fall about at the level which corresponds to the situation of the shore about the time of the maximum extension of the Ancylus Lake.

If we summarize what has been said about the distribution-conditions of Cynanchum vincetoxicum in the south-east of Sweden, we get the following: -

In Småland and Östergötland the occurrences situated furthest up-country would be the oldest habitats of the species in those districts, and be survivals from the distribution on the coast which existed at the time of the maximum extension of the Ancylus Lake. Outwards from these oldest occurrences the species spread itself abundantly as suitable new localities came into existence with the gradual rising of the land, but, owing to the nature of the localities, in conjunction with the pollination biology of the species, it did not spread inwards over the mainland. In Södermanland and Uppland, which for the most part became land considerably later, the spread of the species inland seems to be determined by the distribution of suitable escarpments and perhaps, so far as Uppland is concerned, by certain human action on the vegetation and the geographical development of the land.

The fact that the xerothermic Cynanchum immigrated into the south-east of Sweden about the time of the maximum extension of the Ancylus Lake - that is to say, during what Sernander calls the Boreal period - thus stands in agreement with previously expressed views concerning the history of the immigration of Swedish flora; see, for instance, Sernander 1894, p. 8 I (cf. 1908, p. 2 19!); G. Andersson 1896, p. 41; Sundelin 1917, p. 285; 1919; v. Post 1920; Sandegren 1920; etc.

As has already been hinted, however, a number of species exhibit similar distribution in the south-east of Sweden. These species are entirely dissinilar to Cynanchum in many respects with regard to their biology and ecology.

I have already given an account of the distribution of Melampyrum nemorosum. Its present most inland occurrences might be regarded as remains of the original distribution along the coast; but its inland limit is still unexplained.

Sedum album, distributed in Central Europe and Scandinavia, shows great resemblances to Cynanchum with regard to its distribution in the east of Sweden. But its Scandinavian distribution is in other respects very unlike that of Cynanchum. It has an abundant and extensive distribution-area in the north-west of South Sweden and in the south of Norway, an area which is connected with its habitats in south-eastern Sweden by certain sporadic occurrences on the shores of the lakes in Central Sweden. The biology and ecology of this species would also seem in several respects to be unlike that of Cynanchum. The continental, but in Middle Europe widely distributed Scutellaria hastifolia (Plate ro) - which ought to be included amongst the flora of shore-meadows, which Sernander calls 
sepilitorals - has an abundant distribution on the eastern coast of South Sweden. It has also a number of inland occurrences - sometimes rather isolated which are, it is true, situated fairly near to the coast and on somewhat lower levels than those of Cynanchum, but may nevertheless give reason for associating the species from our present point of view (cf. Sernander 1920 a).

The xerothermic species Melica ciliata (Plate 8) and Draba muralis (Plate 8) the latter of which is mainly Central European - which are so unlike one another with regard to their dispersal biology, have distribution areas in the southeast of Sweden which agree in the main along the east coast. As compared with that of Cynanchum, their distribution differs through the fewness of the occurrences and, as regards Draba, by the existence of some occurrences near Lake Vättern and in Västergötland; but nevertheless the resemblances are striking. These two species are naturally connected with Poa bulbosa (see above p. 331).

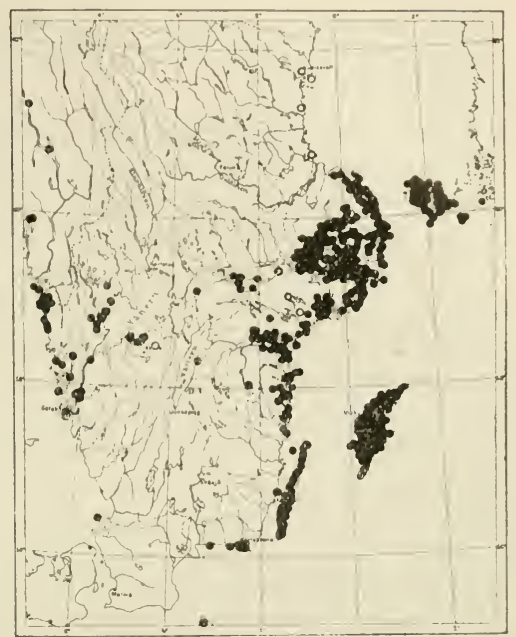

Fig. 27. The distribution of Sedum album in Sweden, Denmark and Finland.

0 : probably non-spontaneous occurrences.

In Norway the species is pretty abundantly distributed in the south-eastern part and occurs rarely on the southern and western coasts, in the north to the fjord of Trondhjem.

Allium schoenoprasum, which in Germany is found on the banks of rivers, has in the skerries of south-eastern Sweden a rich distribution. Unlike Cynanchum, it has practically no inland occurrences. The history of its distribution in the region, however, might be conceived to be the same, with the exception that the species has not retained its older shore-occurrences. Tanacetum inulgare, which is abundantly represented in the east of Europe in regions subject to fluvial flooding, is very widely distributed in the skerries on the south-eastern coast of Sweden, where it grows in shore thickets. The species has long been cultivated, and it is not impossible that its distribution along the coast is purely secondary. But the opposite is equally possible; and in that case its distribution would be closely connected with that of the preceding species. The same is the case with regard to Asparagus officinalis, which is very abundantly represented in Eastern and Central Europe, where it is especially met with in shorethickets near lakes and watercourses. 
We have thus before us a problem in plant geography which is of truely considerable range, and assuredly we ought to ascribe to this problem a considerable rôle in the floristic plant geography of South Sweden. In fact, we might reasonably speak of a "Cynanclum problem» in that region.

The problem is, as will be seen, complicated, and probably its solution will assume different shapes for different species. The only proper course of procedure in this matter would seem to be to subject the distribution, biology, and ecology of each separate species to careful examination. Until that has been achieved the problem as a whole should be left open.

Even now, however, it may be suitable to propose a working-hypothesis as follows: Probably, there can be found a connection between the present distribution of certain species and the post-glacial upheaval of the land in the southeast of Sweden, in the sense that species which in other respects have a distribution which is by no means tied to the shore of the sea, immigrated on to a former coast and from there were able to extend only over the newly arising skerries, but at the same time were able in certain cases to maintain some of their occurrences on the former shores.

In order to throw still further light on this peculiar distribution, the following points may be mentioned.

One must not leave out of sight the fact that climatological conditions may be contributary causes with regard to certain species. The coasts of the south-east of Sweden have a higher temperature in the late summer and autumn than their hinterlands. In this connection, however, it must be noticed that the information of the meteorological stations is not of much use as evidence when it is a question of species whose ecology is in many respects dissimilar. The same objection can be made against another climatological factor which in the case before us may be regarded as important, namely the fact that the precipitation greatly decreases towards the east in the coast districts. For such species as Melica ciliata, Poa bulbosa, and Draba muralis these factors might well be thought to be of importance.

Sernander has repeatedly paid attention to the relation between the distribution of species and the post-glacial upheavel of land in South Sweden. Already in his work of 1894 he has connected the distribution of certain species on Gotland with the height above the sea-level of their occurrences and as has been mentioned above on p. 316 he has in his paper of 1908 from the same point of view treated the history of the flora on the Upsala plain.

Sundelin (1917 and 1919) has carried out comprehensive investigations into the quarternary geology of the east of Östergötland and Småland. In so doing, he has made interesting observations as to the fossil distribution of certain waterplants. Trapa natans, Ceratophyllum demersum, and Najas flexilis had in former 
days a comparatively abundant distribution in these districts. The species begin to appear in the layers of marine sediments that were formed approximately during the maximum extension of the Ancylus Lake. In the bays and lagoons of brackish water which were formed in the process of land-upheaval after that time they have also been found, but at lower levels they begin to disappear. Thus, the species during a certain perind of time moved outwards from their first localities as the coast-line was pushed outwards in consequence of the upheaval of the land.

In the regions where the land has been elevated on the mainland of South Sweden there are a number of occurrences of halophilous species, which for that matter also grow on our sea-shores (as regards Uppland, see Sernander 1905). A description of an Uppland locality (Skensta salt spring at Torstuna) with a number of such species has been given by Sernander (1920 a, pp. $330 \mathrm{ff}$.). An examination of the ground water at this spot showed that the salinity was quite insignificant. Sernander considers that the seashore plants here are survivals from a time when the locality lay on the seashore. As a rule, the species have followed the seashore as it pushed its way outwards, but in some few localities they have for some reason held their own.

In Finland a number of species have their main distribution on the southern coasts, but at the same time a number of isolated habitats in or near lakes. Lindberg (e. g., Svensk Bot. Tidskr., 1915, p. 467) has tried to explain these inland occurrences as relics from the lie of the coast of the Ancylus Lake.

In this connection should be mentioned the theory put forward by Selander (1914) as to another connection between the post-glacial land-upheavel of the south-east of Sweden and the distribution of certain species. In the Stockholm skerries the species which Selander (in part erroneously) has cited as southern or south-easterly xerothermic species would not have had the capacity to spread to such islands, islets and skerries as fall below a certain altitude above sea-level, namely the altitude corresponding to the position of the shore-line at the close of the dry and warm Sub-boreal period. The thenry may have a certain suggestive value, but the material of investigation on which Selander's account rests is quite inadequate (see, for Romell's criticism, Romell 1915).

Something must be very briefly said about one or two species which are rare in the south of Sweden. Vicia tenuifolia, a characteristic species of the scrubsteppe ("steppae fruticosae», Korshinsky 1898) in South Russia, probably, in South Sweden is most abundant on Öland, where it occurs in scrubs, most frequently, however, as a weed-plant, especially in barley-fields. ITiola elatior is found fairly frequently in the southern and central parts of Öland, where it has its favourite 
haunt in the above-mentioned "Alvar forests, a mode of occurrence which would seem fully to correspond to that in Eastern Europe (»in fruticetis stepposis, in decliviis apricis (imprimis calcareis) stepposis vel silvosis», Korshinsky 1898, p. 53). Lactuca quercina and Rosa Fundzillii Bess. appear in steep places on the limestone cliffs in Lilla Karlsö on the west coast of Gotland, to a very great extent isolated from their area of distribution in Central Europe (Cf. Sernander 1894 , p. 84 ).

Here also may be mentioned the Siberian species Potentilla fruticosa. In Siberia and North America, where it is widely distributed, it seems to belong to different types of vegetation. Chiefly, however, it seems to occur on shores of rivers forming scrubs between the wood and the more hydrophilous vegetation, or it appears on rocky ground in crevices and on ledges often forming a dwarf-shrub layer in thin forests. (See e. g. Printz 1921, p. 281; Marmajanova I882, p. 77; Harshberger 1921).

In South Sweden it is common on southern Öland and has a few localities on north-eastern Gotland. On Öland it occurs chiefly on the Alvar forming peculiar scrub-associations, thin or closed according to the thickness of the soil on the limestone rock. A couple of analyses in table 6, Appendix II may in some degree show the composition of this vegetation. (Cf. Johansson 1908.)

Finally, something must be said about three species which hold a special position owing to the fact that they are greatly spread by the hand of man and perhaps do not belong to the spontaneous flora of South Sweden.

Heracleum sibiricum. This is distributed over practically the whole of Scandinavia. In the south-west of Sweden, however, it is rare, and in the west of Norway it is altogether lacking; in both these regions, on the other hand, the south-west European H. sphondylium L. (= branca ursina All.) is distributed. In Scandinavia H. sibiricum is most widely spread in the eastern part of Central Sweden.

Lusula pallescens (Wg.) Bess. and Trifolium spadiceum have a similar distribution. (As regards Luzula this statement is made on the strength of courteous information from Docent Samuelsson, to whose memoir on the subject, which will appear shortly, I must refer). Luzula, however, is less widely distributed in the south-west of Sweden than Heracleum, and Trifolium spadiceum is lacking altogether in a large south-westerly part of the district.

These species, coming probably straight from the east, have immigrated to Central Sweden and there attained a wide distribution. But they are rare or are lacking in the south-west of Sweden, and seem thus not to have reached South Sweden by a south-westerly route. Yet the species are widely distributed far to the west in North Germany and also have occurrences in Southern Denmark. 
Thanks to human intervention, these species are in the act of spreading over Scandinavia and have evidently not yet attained their full distribution there. Probably the South Swedish highlands form a substantial obstacle for them.

The following pages will show that a similar state of things can be established with regard to several other continental species. (Cf. pp. 335 ff., 365.)

\section{Summary.}

1. The South Swedish continental species which belong to the plant com munities of thin, xerophilous or mesophilous foliferous forests of the east of Europe have in the south of Siveden a mode of occurrence which is in complete agreement with that in the east of Europe. - They appear on oak and grove slopes, thicket slopes, rocky escarpments, and in forest-communities rich in Calamagrostis arundinacea.

2. Many species are widely distributed in South Sweden and are found both in the eastern and the western parts, a fact which stands in agreement with an extensive general distribution in Europe. The majority of these species, however, have their centre of gravity in the south of Sweden in the eastern part of the country, especially in the skerries and their immediate hinterlands on the mainland. In Småland some species have their distribution only or chiefly in the north-eastern part. The distribution of the species would seem to be determined by the distribution of broken country and by the precipitation and soil conditions.

3. A number of species are restricted to the south-east of Sweden. Amongst these those are of special interest which exclusively, or all but exclusively, occur in the skerries and in certain parts of the regions lying immediately behind the skerries. As to these species the following working-hypothesis may be proposed. The distribution-limits of these species, which lie at different distances from the coast and at different heights above sea-level for different species, may be interpreted as remains of the first distribution of the species along the coast. From these oldest occurrences the species have spread outzeards, to the new suitable localities which have come into existence with the continued upheaval of the land. On the other hand they have not been able, or have been able only to a very slight extent, to spread inland over the old mainland. The causes for this are not known, except, possibly, for Cynanchum vincetoxicum.

In Södermanland, and to a large extent also in Uppland, the distribution of Cynanchum seems to be determined by the supply of suitable localities (rocky escarpments). In Östergötland and Småland this is not the case. Possibly the 
cause of the incapacity of Cynanchum to spread further inland is to be sought in its apparently extremely defective formation of fruit, which may have its cause in the pollination biology of the species and the windy character of the rock cliffs.

The inland distribution limit of Cynanchum and, although not quite so clearly, Melampyrum nemorosum coincides fairly well with the position of the coast-line at the maximum extension of the Ancylus Lake. In that case, therefore, the species would have their first distribution on the coast of south-eastern Sweden at the time of that maximum extension.

\section{Chapter XI.}

\section{The other continental species in the flora of South Sweden.}

The remaining continental species belong to types of vegetation which are of a less strikingly continental character. Their distribution conditions are, accordingly, unlike those of the species previously treated in several respects and do not offer the same interest as they do from our present point of view.

For this reason, and also because of the very restricted space at my disposal, these species will be treated with the utmost brevity.

With regard to those species that may reasonably be assumed to be less bound by climatological and soil conditions of a character other than those which are found in the south of Sweden, it is of special interest to investigate to what extent they have distribution limits and to what extent those limits differ from those of the steppe and wooded hillside species, and what may be the causes of those differences.

\section{Species of the Flood Meadows.}

In the immense forest areas of middle and northern Russia the vegetation presents excessively little variety. What to some extent breaks the great monotony of the forests and marshes is the vegetation of the river banks. Where the rivers have cut their way downwards, and steep or sloping banks with a suitable exposure have come into existence, there are possibilities for xerothermous species to exist; but where, on the other hand, the bed of the river is wide and the banks are flat, there have been formed - at least in part with the help of man - flood meadows having their own flora, which is especially rich in herbs. 
Accordingly, in descriptions of the vegetation of these regions the vegetation of the river-banks takes a prominent place. The following works, amongst many others, may be cited: Cajander 1908; liedtshenko 1897; Flerov 1902 (e. g. pp. 54, 58, 203-205, 26I-263, 274, 281) and 1910 . This substantial work on the vegetation along the river Oka contains a large number of lists of species from riverside meadows and some photographs of them, which give a good idea of the wealth of herbs found in the meadows, e. g. Plates 6, 22 and 26]; Komarov 1896; Kuznecov 1888 and 1901; Pohle 1903.

In the south of Russia the differences of level of water in the rivers are considerably greater $(2-3$ meters in the middle Volga). If the shores are flattish, therefore, the regions liable to floods are very extensive. During a great part of the year, however, they are very dry, and consequently the vegetation has a highly xerophilous character: it is steppe-like and has many species in common with the steppes. Thus the flora of the flood-regions in South Russia is of a different character from those in the centre and north of Russia. See, for instance, Busch 1888; Kuznecov 190I; Paczoski 1890 (pp. 74 ff.), 1904; Savenkov 1910 ; Korshinsky 1888; Krassnov 1887, 1889; Taliev and Vojnovsky 1902.

Lists of species from the flood-meadows of middle Russia do not contain very many species which are foreign to Central Europe and the south of Scandinavia. We meet with species that are purely East European ones, it is true, but the bulk of them are well known to us. It is, roughly speaking, the species of our own luxuriant cultivated meadows with their wealth of herbs that we meet again. It may specially be pointed out that such important constituents of our cultivated meadows as Alopecurus pratensis, Festuca pratensis and Phleum pratense form very important elements in these flood-meadows.

It is quite natural that the flood-meadow species with a continental distribution that belong to the flora of South Sweden should be highly favoured by, and dependent on, human intervention.

Many species which in South Sweden have undoubtedly been introduced and spread more widely by the hand of man grow more or less commonly in the flood-meadows of central Russia, where some of them at least probably have a natural abode, such as Bromus inermis, Bunias orientalis, Campanula patula, Cichorium intybus, Euphorbia virgata, Geranium pratense, Melandrium album, Melilotus albus, Polygonum bistorta, Symphytum officinale.

Ononis arvensis is a species belonging to this group which has mainly to thank human intervention for its great distribution in the south of Scandinavia, but which perhaps may also have spontaneous occurrences there. Here I am thinking chiefly of Öland and Gotland (Plate I9). In the east of Europe this species has its main distribution in the steppe regions, where it principally belongs to the flora of the flood-meadows. 
Some few species are to be regarded as natural elements in the flora of South Sweden: Cnidium venosum, Dianthus superbus, Inula britannica, Scutellaria hastifolia, and Veronica longifolia. These are found in natural wet meadows on river banks; Cnidium, Scutellaria and Veronica also on the seashore. To these must be added Petasites spurius, which in the south of Scandinavia, as in Russia, belongs to the colony-like vegetation of sandy banks and shores.

The distribution of the species exhibits one or two remarkable features which must here be briefly pointed out.

Some species push out somewhat from a distribution region in the east of Europe westwards over the Baltic flora region, while they are as good as entirely absent from Central Europe. Such species are Cnidium venosum (Plate 20), Ononis arvensis and Petasites spurius. Species with a mode of occurrence like those named have evidently great possibilites of spreading from the east over the Baltic lowlands (cf. pp. 242 and $37 \mathrm{I}$ ).

Dianthus superbus has a distribution which possesses a certain amount of interest. A great distribution area which comprises the whole of Eastern and Central Europe extends into the Scandinavian Peninsula only, in the south, across Denmark into Skåne and into southern Halland, and, in the north, across to the north of Finland into the extreme north of Norway. In Finland the species is found only in the east and in the north. As it is widely distributed in the east of the Baltic and the north-east of Germany, however, it is remarkable that it is altogether lacking in the south-east of Sweden.

Veronica longifolia, which is similarly distributed throughout Eastern and Central Europe (and is also found all over Finland) has quite a different distribution in Scandinavia. From Denmark it extends up along the west coast of Sweden from the north-west of Skåne in the south. In the Vänern districts it is found not only on the shores of Lake Vänern, but also has occurrences on the uplands of central Värmland and the interior of Dalsland. This distribution-area in the west of Sweden is connected with a distribution-area in the south-east of Norway. In the east of Sweden the species is found on the coast from the skerries of Blekinge in the south as far as the river Torneälv, where there distribution is connected with that in Finland. On the Swedish coast, however, there are certain gaps: it should especially be noticed that the species is lacking in Smalland and on Öland and Gotland. In the extreme north of Norway, moreover, the species extends from north Finland to Alten and Inner Finmarken in the west.

Thus this species, thanks to its distribution in Finland, has been able ro reach the east coast of Central and Northern Sweden. It has also reached the coast of Blekinge, probably across the south of the Baltic. But this species also is lacking in a great part of the south-east of Sweden, in spite of its abundant distribution in the east of Balticum and the north-east of Germany. 
Scutcllaria hastifolia has a distribution which presents a quite different appearance (Plate Io). This species is widely distributed in the centre and south-west of Russia, and also in Central Europe north of the Alps; and in the east of Balticum and the north of Germany it is found on the shores of lakes and watercourses as far west as the river Weser. Noreover round the Baltic it is distributed along the south-eastern coast of Sweden but is altogether absent in the south-west of Sweden and also in Denmark.

The distribution of these three species around the Baltic would seem to show how very differently the Baltic must have influenced the dispersal of different species in the north-west of Europe (cf. above pp. 270 and 335).

As regards the distribution of the species belonging to this group, the following points may also be observed. in Scandinavia the species show no predilec tion for the areas which are markedly continental in their nature. The distribution of the species is determined by the degree to which they have been able to turn to account the influence of human intervention or the supply of suitable natural habitats, the existence of which may be only in a comparatively very small degree dependent on continental geographical conditions. There might be indications that the species have not yet attained their fullest distribution in the south of Scandinavia. Perhaps there is going on an invasion of species with this mode of occurrence.

\section{Species found in Coniferous Forests.}

By coniferous forests is here meant Scotch pine- and Common spruce-forests rich in mosses or undershrubs.

The small number of species which can be counted as distinctive of this type of vegetation are very widely distributed over Boreal Europe. In Western Europe most of these species are also distributed outside the limits of the pine and the spruce.

The distribution of the pine and the spruce in Scandinavia may be studied in a copious literature, to which, for lack of space, I must here confine myself to referring: Andersson 1896; Gloersen 1885; Hemberg 1904; Hesselman och Schotte 1906; Sernander 1902 and 1909; Sylvén 1916.

The continental species of South Sweden which can rightly be named here are only two in number - Chimaphila umbellata and Pyrola chlorantha.

The first-named is remarkable because of its southerly and distinctly easterly distribution in Scandinavia (Plate 12). Moreover attention must be drawn to the marked concentration of occurrences to low-lying tracts of Central Sweden. The distribution approximates to the type which may be said to have the form of a

25 Gengrafiska Annaler 1922. 
triangle with the apex in the south-east of Norway and the base in the east of Sweden.

The distribution of Pyrola chlorantha accords tolerably well with that of the pine (Plate 22).

Although, of course, it cannot be regarded as a genuine coniferous forest plant as regards mode of occurrence, mention may perhaps also be made here of Geranium bohemicum. Its distribution in Scandinavia excellently illustrates the triangular type mentioned above (Plate 12). It appears in Sweden not only in places where there has been a forest fire, near charcoal-kilns and the like, but also »in ruderatis». The main distribution of the species would seem to lie in the western part of Middle Russia, although even there it would appear to have merely sporadic occurrences. (See, for instance, Paczoski 1897, I, p. I 35 and Petunnikov I896, I, p. I I 2).

\section{Grove species.}

As has already been pointed out, I bring together under the name of "groves" (Swed. »lundar») close mesophilous forests of broad-leaved trees casting a heavy shade.

We find the "grove» most fully developed in Western and Central Europe, where it culminates in the beech forest. Of other Central European types of forest that should probably also be brought under this heading may be mentioned those described by Drude (e. g. I 896) as »Auenwälder», „Gemischte Laubholzformationen der Niederung und Hügelregion», and amongst those mentioned by Hayek (1914), the following: 》Gemischte Laubwälder» (p. 89), »Auenwälder» (pp. 91, I 24, 146, 272), 》Der herzynische Bergmischwald» (p. 91), Laubmischwälder (pp. 143, 269), and $\gg$ Die podolische Eichenwald» (p. 280).

Outside the easterly limit of the beech in the east of Europe the "grove» becomes more infrequent and more weakly developed. The principal obstacles in the way of its extension eastwards are probably the growing continentality of the clinate and the unfavourable conditions of the surface of the land. In the Moscow district true "grove" vegetation appears to be encountered only on shaded slopes, as in the river valleys (see, for instance, Flerov I910, species lists $27,32,65,163,431,434$, and 435). The bulk of the broad-leaf forests here consists of the above-mentioned thin birch, oak, or aspen forest. As far east as the Government of Kazan, according to Korshinsky (r 888), there can be distinguished a shady type of foliferous forest. But many of the characteristic species of the Central European "grove» have reached their easterly limit to the west of this. In the distribution-region thus sketched, as has been pointed out above (p. 234), the "grove» has a highly varying composition. Many species that are distinctive of the "grove» in Eastern and Central Europe are altogether lacking 
in Western Europe; and on the other hand many species in the Western European "grove" have a distinctly westerly distribution.

The westerly limit of the first-named species runs, as a rule, through the west of Germany or the north and east of France (see p. 234). Amongst these species may be observed both a few trees and shrubs - Acer platanoides, Llmus foliacea Gilib. and laevis Pallas, and Lonicera xylosteum - and many specics in the ground vegetation, such as Anemone hepatica and ranunculoides (which are physiognomically very prominent), Pulmonaria officinalis (both the more southerly officinalis vera and the north-easterly obscura Du Mort.), Corydalis cava, intermedia, pumila, and solida, Gagea minima and spathacea, Viola mirabilis, and Lathyrus vernus.

The "grove" vegetation of South Sweden belongs, in the main, to the East- and Central European type. It is closely connected with the "Laubmischwälder» of Central Europe.

As regards the distribution of the continental "grove» species in South Sweden, I shall here only mention briefly one or two circumstances.

Some species are very extensively distributed in Scandinavia, as throughout the north of Europe: Acer platanoides, Gagea minima, Lathyrus vernus, Lonicera xylosteum, and Viola mirabilis. The continental character of the distribution does not appear clearly until somewhat far towards the south, inasmuch as the species are lacking in the whole or in a great part of Western Europe. The distribution of these species in the south of Sweden does not diverge from the type of distribution which is generally characteristic of "grove» plants in that region, that is to say the species are absent or are rare in the South Swedish highland. For many species the area of distribution is more or less completely divided into a southern one (Skåne and Blekinge) and a northern one, which two are joined in the east by occurrences on Öland and Gotland and, in the case of some species, by sporadic occurrences in the east of Småland. These types of distribution reflect of course, the possibilities of occurrence that exist in South Sweden for "grove» vegetation.

A species which is of a more southerly continental character in its general distribution but shows this type of distribution in South Sweden is Bromus Benekeni (Lge.) Syme, the distribution of which in the Scandinavian countries has been mapped by Samuelsson 1922 a, p. 5 r.

Poa remota Forselles diverges from the above-named species by its more north-easterly distribution. In Scandinavia its main distribution lies in the southeast of Norway, in the south of Norrland, and in the east of Central Sweden. Further towards the south in Sweden it has only a small number of scattered occurrences. The species may be said to form a transition to a group of sgrove» species that are limited to the Subarctic zone (sensu Engler), where they are en- 
countered in shady moist broad-leaved forests (Swed. »lunddälder»), such as Glyceria lithuanica Lindm. (= G. remota Fr., Poa lithuanica Gorski) and Cinna pendula Trin.

Pulmonaria obscura exhibits a different distribution (Plate i1). Owing to its limit of distribution towards the north-west in Central Sweden, it agrees with the distribution of many of the previously mentioned continental species. It should be observed that Pulmonaria is lacking in Norway.

Anemone ranunculoides has a similar distribution in South Sweden. Nevertheless it is more southerly and rarer in Central Sweden than Pulmonaria. In Scandinavia as a whole, Anemone has quite a different distribution from Pulmonaria. It is widely distributed in Norway, and also occurs sparingly in Jämtland and Medelpad (see too Appendix I, p. 408).

Ranunculus cassubicus shows a peculiar distribution of another kind (Plate 15). From its abundant distribution on the other side of the Baltic, the species has immigrated, evidently from Finland and Åland, to the east of Central Sweden, chiefly to Uppland. But it is difficult to explain the extremely peculiar occurrence of the species in one or two neighbouring localities in the north of Småland. There are several continental species which have probably reached Sweden from the east by the same route (some such species have been mentioned above on p. 360; cf. plate I 2). Almost without exception, however, these species have attained a much more extensive distribution in Central Sweden: in most cases, in fact, they have occurrences so far to the west as the south-east of Norway. One of the reasons why Ranunculus cassubicus forms an exception in this respect is perhaps to be sought in the fact that it easily forms hybrids with Ranunculus auricomus. These hybrids are fertile, it is true, but as the latter species is so much more abundantly represented in the localities and their surroundings, the result must be that Ranunculus cassubicus disappears sooner or later (cf. Sterner 1921 b, p. 132). In accordance with this circumstance, there occur in Uppland, Västmanland and the south-east of Dalarne, outside the distribution-area proper of Ranunculus cassubicus, a number of occurrences of transitional forms to Ranunculus auricomus. In fact, that is the state of things along the whole of the western limit of Ranunculus cassubicus in east-central Europe.

Some species are distributed in Scandinavia only to the south of the South Swedish highland: Corydalis cava, Thalictrum aquilegiifolium, Ulmus foliacea Gilib., and Ulmus laevis Pallas. Of these species Thalictrum and Ulmus laevis go very much more to the north in Russia, while Ulmus foliacea, on the other hand, is more southerly there.

The continental "grove» species of South Sweden form quite an insignificant part of the abundant species of the "groves flora. With one or two exceptions the species are distributed either over large parts of South Sweden or only in 
the extreme south of Sweden. In both cases their distribution agrees with that of non-continental "grove» species.

A remarkable exception is formed by Ranunculus cassubicus, the restriction of whose distribution to the east of Central Sweden may possibly have its explanation in the migrational history of the species.

Mainly restricted to the south-east of Sweden are Anemone ranunculoides and Pulmonaria obscura. I leave undecided the question whether the cause of this is the ecology of the species or their migrational history.

Thus we see that the distribution of the continental "grove» species in South Sweden scarcely exhibits any of the dissimilarities which might be connected with a continental-maritime formation.

\section{Marsh species.}

Marsh associations cannot be definitely defined: they pass without a perceptible boundary on the one side into the meadow associations and on the other side into the water-plant associations. What I here mean by marsh associations may be held to correspond to Warming's helophytous associations. Thus reed associations fall under this heading.

A distinctive feature of marsh associations is that they have a very similar composition in large areas. This, of course, stands in connection with the fact that the compositional factors which are of most consequence for the species that fall under this head are found under geographical conditions which vary very much in other respects.

In order to show in some detail to what extent the composition of the marsh associations varies in Middle Europe I have made the following calculations. Of the 174 or so marsh.plants found in the Government of Kazan, $90 \%$ occur in Silesia, $87 \%$ in South Sweden, and $83 \%$ in England, while of the 200 or so marsh-plants of South Sweden there are $80 \%$ in the Government of Kazan, $93 \%$ in Silesia, and $91 \%$ in England. By way of comparison it may be mentioned that of about 190 species belonging to the xerophilous grass associations of the Government of Kazan, $55 \%$ are found in Silesia, $39 \%$ in South Sweden and $25 \%$ in England, while of the 195 or so species belonging to this category in South Sweden there are $53 \%$ in the Government of Kazan, $83 \%$ in Silesia, and $67 \%$ in England.

As regards the marsh associations in Middle Russia, they seem, as a rule, to be more abundant in herbs than they are in Scandinavia. [See, for instance, Flerov 1910, lists of species $54,137,528,608,755,835,858$; Savenkov 1910; Kuznecov 1901; Krishevsky 1912, pp. 322, 324 (Kherson); Naumov 1903, pp. 
58 ff. (Kharkov); Taliev and Vojnovsky 1903, pp. 193, 194 (Samara); Sukascev I 903 , pp. 327 ff. (Kursk); Korshinsky I 888 (East Russia)].

The continental marsh-plants that are found in South Sweden are remarkably rare there, as a rule, and occupy a peculiar position owing to their mode of occurrence. Many of them do not form part of a closed and stable marshvegetation but of a sparse, more or less colony-like and temporary vegetation on shores, or in localities more or less recently created by human intervention, such as turf-cuttings, ditches, areas of new soil that have come into existence through the lowering of the level of lakes and the like.

Bidens radiatus and Scirpus radicans are good examples of this. They have been observed in a number of localities of the last-named kind in Central Sweden, to which they might have spread quite recently and over great distances (see Sernander I901, p. 404; I9II, pp. 278 ff.). Senecio palustris seems in Skåne to have some marsh occurrences, but as a rule it appears in about the same fashion. - Cardamine parviflora, which has a number of sporadic occurrences in Central Sweden, grows in sparse vegetation on sandy shores. - Carex vulpina would seem to grow, possibly with some exceptions, in places which have been called into existence by the hand of man - ditches, ponds etc. (cf. Samuelsson 1922 b). - In this way Arabis Gerardi occurs, rarely, on Gotland.

Geranium palustre and Cirsium oleraceum in general have natural marsh-like places of growth (forest swamps). This is certainly the case with Scolochloa festucacea (the shores of lakes and banks of rivers), Viola uliginosa (forest swamps and shores), Euphorbia palustris (marshes and sea-shores), and Achroanthes monophyllos (chalky marshes). To these may be added Sonchus palustris, which grew wild in former days in a locality in the extreme west of Blekinge, probably in a reed association (cf. Wahlstedt in "Botaniska Notiser» 191 1, pp. 17, 18). These species, however, have a rather insignificant distribution, or a very small number of occurrences, in South Sweden. Apart from a few localities, probably relics, near Lake Mälar, Alopecurus ventricosus grows in South Sweden only on sea-shores.

The remaining species, Calla palustris, holds a peculiar position. It is abundantly spread in the forest districts of South Sweden, and the places where it grows are quite natural forest swamps.

These species are very different from one another in the matter of distribution.

Cirsium oleraceum, Euphorbia palustris and Geranium palustre are found in the whole of Central Europe, Euphorbia even in large parts of Western Europe. These species occur in the north-west of Germany: Euphorbia and Cirsium in the west to about the Lower Weser, Geranium only as far west as Hanover. They may be said to have a west-Scandinavian distribution branch running out from there. Geranium and Cirsium are spread over parts of Denmark and Skåne and in southern Halland and have some occurrences further in the north in 
western Sweden and in south eastcrn Norway (Cirsium; cf. p. 41 1). Euphorbia, on the other hand, is lacking in Denmark, and is not found on the west coast of Sweden until the north of Halland and Bohuslän, and moreover it has an area of distribution in the south-east of Norway. In these districts it most often grows on sea-shores. Perhaps we may imagine a direct dispersal to these parts by sea-currents from the southern coasts of the North Sea. Unlike the other, Euphorbia has also an eastern distribution branch, comprising Öland and Gotland. There it grows in marshes, mostly on peat soil.

Some species have a peculiar general distribution. From Middle Russia they extend far towards the west across North Germany, but further to the south they reach their western limit much earlier or are entirely lacking; such are Bidens radiatus, Cardamine parviflora, Scolochloa festucacea, and Senecio palustris. Sonchus palustris has a similar distribution. It is abundant in the north-west of Germany, and in Holland and Belgium, and it also has a few occurrences in the southeast of England, while in France it is to be seen only in some few scattered places. We have already had an opportunity of noticing this type of distribution (see p. 364).

Several species have their occurrences in South Sweden situated on the Central Swedish lowlands. They may have a few occurrences scattered right across the lowlands, e. g. Bidens radiatus, Cardamine parviflora, and Scirpus radicans - or they may be restricted to the eastern parts, such as Scolochloa festucacea (the Motala River and some lakes through which that river flows in Östergötland). As all these species are found in North Germany (though there, as generally in its distribution, Bidens is highly sporadic), it is remarkable that the species are altogether lacking in the extreme south of Sweden. If we imagine that the immigration of these species into Central Sweden took place direct from the east, we should observe that Bidens and Scirpus have their nearest occurrences in this direction situated so far away as the extreme east of Finland or in Estland and Lettland, while Cardamine, as well as Scolochloa, on the other hand are, distributed over almost the whole of the extreme south of Finland. For the first-named species, therefore, a long-distance dispersal must have taken place.

Achroanthes monophyllos is distributed in a similar way in Sweden (see Plate 21). Its distribution-area in Central Scandinavia forms a continuation of its distribution-area in Finland and the east of Balticum. Along North Germany this species does not reach further west than Rügen and Usedom.

Carex vulpina and Viola uliginosa have a distribution in South Sweden which is well worthy of attention. Both these species are distinctly restricted to the south-east of Sweden. The distribution of Carex vulpina bears a great general resemblance to that of Melampyrum nemorosum (Plate 10; see Samuelson 1922 b, 
where there is a map showing its distribution). Viola, it is true, has but few occurrences, but the general form of the distribution is much the same.

Alopecurus ventricosus, as has been mentioned, occurs in South Sweden on sea-shores. The distribution in the Scandinavian lands is peculiar and worth a detailed account. The Scandinavian distribution of the species may be said to consist of two parts, one northerly and one southerly. The former comprises the coast of the Arctic Ocean (to the west as far as Senjen in Tromsö Amt in Norway) and inland behind this stretch of coast, mainly the Russian and Finnish Lappmarks. To this part of the distribution-area also belong one or two occurrences at Haparanda and Torneå. The southerly area comprises the coasts of the South Baltic: the south-western coast of Finland from Satakunta (southern Österbotten: Vasa?) in the north to Fredrikshamn in the east, the coast of Estland and Lettland (from Kandel on the Gulf of Finland to Libau in the south, mainly on the islands; Kupffer 1906); the eastern coasts of South Sweden from Öregrund down to the east of Skåne, and the coast of Germany, where however it is known only from Hither Pomerania behind Rügen and at Danzig. To these must be added one or two occurrences in Denmark, one in the south of Zealand and one on Falster. Besides this the species has been observed on the west coast of Sweden in Bohuslän (two localities), and at one locality in the south-east of Norway near Larvik.

What I would especially wish to call attention to in this place is the fairly close accordance which is to be found between the southerly part of this distribution-area and the distribution of Silene viscosa on the Baltic (see p. 325). It would seem to be indisputable that the explanation of this lies in the fact that the dispersal of the two species in the southern Baltic district goes on in a similar manner. Neither species may have reached its full distribution in the region; and the fact that they so nearly agree with one another points to vehicles of dispersal which work in about the same limited field.

We have thus found that the few marsh-plants of South Sweden that can be regarded as continental ones largely consist of species with a peculiar mode of occurrence, and that with some exceptions they are rare in the region and play a very insignificant part in the vegetation. Several species, owing to their capacity for long-distance dispersal, have settled down, probably quite recently, on localities brought into existence by the hand of man, where they appear as colonists, often as ephemeral ones. Species which are part of a more stabilized vegetation, and which probably spread more step by step, have a very insignificant distribution in South Sweden. - We have also found that, with some exceptions (Carex vulpina and, possibly Viola uliginosa), these continental species in their South Swedish distribution do not reflect the formation of the region in a continental-maritime respect. 


\section{Water=plants.}

In my definition of water-plant associations I follow Warming (1909, pp. 149 ff.). As regards the composition of the water-plant associations in Russia I desire to give the following references to the literature of the subject. Flerov Igio (e. g. the lists 279, 309, 570, 615, 726, 766, 769), Borovikov 1906 (the Donetz), Korshinsky 1888, Krishevsky 1912 (Kherson), Naumov 1903 (Kharkov), Saljessky I 900 (Orel), Sidorov 1897 (Ekaterinoslavl), Sukaczev 1903 (Kursk).

The species falling under this head possess, as a rule, very extensive distribution-areas. Many are rare, with their occurrences scattered over vast areas. With regard to the distribution of the species in Middle Europe, however, it seems as if no inconsiderable number of species had a more or less maritime distribution, while the continental flora includes only some few representatives.

Thus while of about 75 water plants in South Sweden only $58 \%$ are found in the Government of Kazan and $70 \%$ in Silesia and England, out of the 37 species or so in the Government of Kazan, 36 are included in the flora of Silesia, 34 in that of South Sweden, and 32 in that of England. To some extent perhaps this has its cause in the fact that species may have been overlooked in the somewhat imperfectly known flora of Russia.

Perhaps, however, in this circumstance we may see an illustration of the pronouncement of Brockmann-Jerosch cited above on p. 246 , namely that the climate can to only a very slight extent be the direct cause of the absence of continental species in maritime districts. That this is the case may stand out very distinctly with regard to water-plants, for obviously they have very good dispersal-power, as a rule, and their requirements with regard to nature of the ground (water) can be satisfied to a far higher degree than those of land-plants irrespective of a continental or a maritime development of the climate.

As regards the continental species of this group in the south of Sweden I have not much to say, especially as a monograph on the distribution conditions of water-plants in Sweden is in process of elaboration by another writer.

Of the few species which can come into question here, of course, Trapa natans immediately attracts attention. But as the distribution of the species as a fossil falls outside the scope of the present memoir, and as moreover there has recently been published an exhaustive account of the species (Malmström 1920, where the distribution map is to be noticed), 1 have nothing to say in this place.

Elatine triandra Schkuhr is another waterplant which may probably be treated, with more or less certainty, as a continental species. The species, however, is probably not yet sufficiently well known as regards its general distribution; it may have been overlooked in many regions, especially in Russia (cf. Appendix I). It 
belongs to the phanerogamous "Micro-flora» of shores, which is of great interest, not least in the matter of the distribution conditions of the species. The distribution of Elatine exemplifies a type that we have previously encountered on several occasions, inasmuch as the majority of its occurrences fall within the Central Swedish lowlands; but the species is also found in the extreme south of Sweden, and stretches far towards the north in the coast-region of Norrland.

\section{Moor species.}

The plant associations which have been brought together under this heading are characterized by the abundance of Sphagna. In other respects they may be of widely different kinds - grass-sedge associations, shrub associations, or forest associations.

These types of vegetation in Europe are chiefly distributed in the Boreal coniferous forest zone. Here they form some of the most important types of vegetation.

In the north of Russia Sphagnum associations occupy immense areas (Middendorff I867; Pohle 1903). What causes their appearance in these regions would seem to be the large amount of moisture in the ground (caused by, among other things, the small amount of evaporation), a weak drainage system owing to the flatness of the surface, and soil poor in nutrition.

The Sphagnum associations have a great distribution towards the south. According to Tanfiljev 1890 , its boundary coincides approximately with the northern limit of the black earth; but still further to the south there are scattered occurrences, edaphically caused by moist leached sandy soil and bad drainage.

The North-East European Sphagnum associations have a floristic character which differs from those of the north-west of Europe. Several species which are important constituents of Sphagnum mosses of the Subatlantic and the Northatlantic flora-provinces are altogether lacking in the north-east of Europe, while on the other hand one or two species falling under this group are confined to the north-east of Europe. Of these last-named species the most important is Ledum palustre.

This species seems to be highly characteristic of the Sphagnum associations of Middle Russia, as it is found in practically all lists of species dealing with such associations. [Flerov 1910, e. g. lists 262, 566, 774, 805; Kossinsky 1913, p. I I (Kostroma); Saljessky 1900, p. 169 (Orel); Kultschitskaja and Endaurova I906, p. 43 (Ryazan); Korshinsky I 888 (Eastern Russia); Michajlovskij I 903 (Chernigov) etc.] 
Attention should be drawn in passing to the remarkable fact that Ledum appears as a cliff-plant in the south-east of Central Europe (Drude 1902, p. 480).

The distribution limit of Ledum towards the west is of great interest. In the Scandinavian Peninsula it is distributed practically all over Sweden, while in Norway it is found only in the extreme north (in Finnmarken and Tromsö Amt to Reisen) and very far to the south-east, with some few occurrences near the Swedish border. In view of its distribution in the north of Scandinavia, Heintze 1909, and Fries 1913 have maintained that Ledum ought to be regarded as a species immigrating from the east. In South Sweden the species occurs far more abundantly in the eastern and central parts than in the south-western part. [A detailed investigation of its distribution is now being carried out by another writer.] In the north of Germany Ledum has a westerly limit which shows a great resemblance to the westerly limit of many steppe species (see Appendix I, p. 4I4, and Graebner 190I, the map).

What determines the limit of Ledum in the Baltic flora region it is difficult to decide. It may be climatic factors, but also a competition with westerly species, chiefly Erica tetralix. A detailed investigation of the mode of occurrence and distribution of the species might perhaps give an answer.

\section{Summary.}

The species treated in this chapter might, with regard to their distribution in South Sweden, be divided into three groups. The first comprises species with a distribution over practically the whole of South Sweden; and the distribution corresponds more or less closely to the distribution of types of vegetation. To this group belong the majority of the forest species here treated and, of the others, Calla palustris and, though to a smaller degree, Ledum palustre. The second group comprises species with only one or two or a somewhat larger number of very much scattered occurrences. The distribution of these species seems to correspond very slightly to the possibilities of occurrence in the region. Under this group, above all, fall the marsh species and some of the species of the flood-meadows. The third group consists of species which have a more or less restricted distribution, a distribution that does not at all correspond to the distribution of types of vegetation. This, however, comprises regions of a geographical character which are to some degree of a special nature, e. g. the extreme south of Sweden, the south-east of Sweden, and can therefore be imagined to correspond approximately to the occurrence-possibilities of the species in South Sweden, e. g. Corydalis cava, Ulmus foliacea and laevis, Carex vulpina, Ononis arvensis, and Inula britannica. 
The species of the first group, which thus do not reach their distributionlimits within the borders of South Sweden, generally show the unevenness in their distribution by occurring more abundantly in the eastern than in the western part. The primary cause of this is to be found in the nature of the soil. Probably, too, the climate is of some importance, both directly and indirectly.

The species can be accounted continental owing to their distribution in Central and Western Europe. They are abundantly represented in Central Europe and reach their westerly limits in the western parts of that region. [Ledum forms an exception.] The reasons for these limits are not easy to find; probably the climate is an important factor. We may content ourselves with the knowledge that the factors that come into play here have not brought about any westerly limits in South Sweden.

The species of the second group scarcely show any uniform features in their distribution. Only this can be maintained, namely that their infrequent occurrences are situated in the coast regions or the flat regions of Central Sweden. The distribution of these species displays no connection with the continental formation of the land.

As has already been pointed out, several of these species show in their general distribution the peculiarity that, outside East Europe, they are to be found only or chiefly in the Baltic lowlands. Several of the species are peculiar owing to the rareness of their occurrences throughout their distribution outside East Europe. It even seems as if such a sporadic appearance also characterizes the East European distribution of, for instance, Arabis Gerardi, Bidens radiatus, Cardamine parviflora, Scirpus radicans, and Viola uliginosa; but of course these species may have been largely overlooked there.

The species we have treated in this chapter, are, in the main shade-plants or marsh-plants: they may be said, to some extent, to be the opposite ecologically of the light-loving or dryness-loving steppe species. Consequently we cannot except that their distribution should show a continental character to the same degree as the steppe species. In accordance with this fact also they form a comparatively insignificant part of the total stock of species in the corresponding type of vegetation. Thus we have now found that the distribution of the species in South Sweden only slightly reflects the formation of the region in a continentalmaritime respect. There are only one or two species which within the region show distribution limits that can be connected with geographical conditions of a continental type. 


\section{CinAPTER XII.}

\section{Conclusions about the Position of the South Swedish Flora.}

One object of the enquiry that is now concluded has been to make some contribution towards the establishment in some detail of the position of the flora of South Sweden in the floristic region of Middle Europe. As the enquiry affects only some of the species of the South Swedish flora, it cannot, of course, lead to any final result in this respect. I should like to summarize the hints that it has given:

Engler, in his flora system, divides the lowlands of Middle Europe, Balticum or the Baltic Region, into two provinces - an easterly one, the Sarmatian, and a westerly one, the Subatlantic province. The boundary between them is placed somewhere about the central part of North Germany. Of South Sweden only the most southerly part is included - a south-westerly part, Skåne, which is brought under the Subatlantic province, and a south-easterly part, Öland and Gotland, which are brought under the Sarmatian province. The remaining and larger part of South Sweden is assigned to a sub-province which he calls 》Scandinavia», in the Subarctic district ( Gebiet»).

Drude (1890) also distinguishes in Balticum two regions: „Die Ost- und Westbaltische Waldregion.» $\mathrm{He}$ does not say in any detail where the boundary between them is to be placed. But the whole of South Sweden, as far as the limit of the oak, falls under Drude's Baltic flora districts and seems to be accounted part of the East Baltic region.

A division of Sweden in accordance with Engler's principles would a priori scarcely seem to be the most natural one. The most important change in the Swedish flora we should more probably expect to find in Central Sweden and the extreme south of Norrland, that is to say in the neighbourhood of the northerly limit of the oak. A closer investigation also shows plainly that the flora in these districts undergoes a distinctly greater change than the transition from the extreme south of Sweden to Central Sweden. Of the Swedish species that are found in North Germany about 90 species do not extend, or extend only to an insignificant extent, north of Skåne, Blekinge, southern Halland, Öland, and Gotland, while about 300 species are found in the rest of South Sweden but are altogether lacking in Norrland (cf. pp. 272 and 273).

Thus it would seem to be most expedient to follow Drude in letting the limits of the Baltic region include the whole of South Sweden.

Manifest though it is that the Baltic region ought to be divided into an easterly and a westerly province, it is no less difficult to determine where the boundary 
between these provinces in North Germany is to run. The change in the climate from a definitely continental to a definitely maritime character proceeds very slowly, and in the broad transitional zone edaphic factors play a great part in the character of the vegetation and the flora: the continental and the Atlantic elements get abundant opportunities of penetrating into each other's distribution-areas.

The enquiry which has here been carried out has shown that in South Sweden there prevails, with regard to the distribution of the continental species, a sharp contrast between an easterly and a westerly part. The cause of this is the topography and, in conjunction therewith, the climate and the distribution of calcareous soil.

As has been pointed out above, the eastern part is bounded by a line running from the lower part of the River Dalälven or the north of Uppland across the south-east of Västmanland and the centre of Närike to the Falköping district (or possibly Kinnekulle), and from there in a south-easterly direction down to the Kalmar district. Here one might let the boundary run on and turn off in a westerly direction enclosing Blekinge and Skåne. But whether Skåne should properly be accounted part of this south-easterly region in Sweden, is not quite certain. Many continental species are included in the flora of Skåne; and in fact that flora even includes some continental species that are lacking in the rest of South Sweden. But on the other hand the east of Central Sweden, in its turn, has many species which are lacking, or remarkably scarce, in Skăne. A close examination of the division of the continental species between Skane and the recently mentioned eastern part of South Sweden (Öland and Gotland excepted) shows that Skane has $\mathrm{i} 3$ (16) species that the other region lacks, while that region has 18 species that are not found in Skåne, and also 8 species which are much more rare in Skane than in the other region. It would therefore be by no means unjustifiable if the boundary with which we are concerned were made to exclude Skåne (consequently also Blekinge). On p. 238 above I have made use of such a boundary when the westward extension of the Sarmatian province was being determined.

Starting from the results yielded by this enquiry, one might thus bring a south-easterly part of Sweden, roughly speaking, the east of Central Sweden with the north-east of Småland, together with Öland and Gotland under the eastern province of the Baltic flora region (Sarmatia), and the south-west of Sweden under the western province of the Baltic region (Subatlantis).

As has already been pointed out, this determination of the place of the South Swedish flora in the Middle European flora districts, must be regarded simply as provisional. Above all it is necessary for a final decision that an investigation 
should be made into the distribution of the Atlantic element in South Sweden. To judge by the information on this subject which is at present available, however, it seems as if such an enquiry would lead to much the same result. The distribution in South Sweden of such Atlantic or West European species as the beech, Erica tetralix, Galium saxatile, Juncus squarrosus, and Narthecium ossifragum, seems to point to an easterly and northeasterly boundary for Subatlantic Sweden approximately coinciding with that mentioned above for Sarmatian Sweden.

\section{LITERATURE.}

\section{List of works referred to in the Text.}

Acloque, A., Flore du Nord de a France (Somme, Pas-de-Calais, Nord, Ardennes et Aisne). - Paris 1903.

AhLMAnN, Hans W:sson, Some working hypotheses as regards the Geomorphology of South Sweden. - Geografiska Annaler, Årg. II, h. 2. Stockholm 1920.

Alechin, W., - Trav. Soc. Natural. de St. Pétersbourg. Section Botan., Vol. 40 and 41. Petrograd 1909 and I910. (The Streletz- and Kasatz-steppes in the Governm. of Kursk.) [In Russian with German summaries.]

Andersson, G., Svenska växtvärldens historia. 2:dra uppl. - Stockholm i 896.

- Die Entwicklungsgeschichte der skandinavischen Flora. - Résult. scient. Congr. intern. Botan. Vienna 1905. Jena 1906.

—, Swedish climate in the Late-Quaternary period. - Die Veränderung des Klimas seit dem Maximum der letzten Eiszeit. Compte Rendu i i:e Congr. Géol. Intern. Stockholm I910. Stockholm I 9 10.

och BIRGER, S., Den norrländska florans geografiska fördelning och invandringshistoria med särskild hänsyn till dess sydskandinaviska arter. - Norrländskt handbibliotek, 5. Upsala I 9 I 2 .

— und Hesselman, H., Verbreitung, Ursprung, Eigenschaften und Anwendung der mittelschwedischen Böden. - Führer zu wissensch. Excurs. 2. agro-geol. Konferenz in Stockholm rg ro. Stockholm igro.

ANRICK, C. J., Beskrivning till Karta över Sveriges åkerareal. - Sveriges Geol. Undersökn., Ser. Ba, nr 10. Stockholm I 921 .

ANTEvs, E., Senkvartära nivåförändringar i Norden. - Geol. Fören:s i Stockholm Förhandl., Bd 43, h. 6-7. Stockholm 1922.

Areschoug, F. IV. C., Bidrag till den Skandinaviska Vegetationens Historia. - Lunds universitets årsskrift för år i 866 . Lund 1866-67.

- -, Skånes Flora. 2:dra uppl. — I und I 88 I. 
Ascherson, P. und Graebner, P., Synopsis der mitteleuropäischen Flora. - Leipzig $1896-. \quad(\$ 896 \%)$.

- Flora des Nordostdeutschen Flachlandes (ausser Ostpreussen). — Berlin I $898-99$.

Becker, W., Violae europeae. Systematische Bearbeitung der Violen Europas und seiner benachbarten Gebieten. - Dresden 19 Iо.

_-. Viola pumila Chaix, eine xerophile Pflanze des pontischen Elements. - Mitteil. Thüringer Botan. Vereins, Bd. 33. Weimar i9 6.

Beckhaus, K., Flora von Westfalen. - Münster r 893.

Beck von Mannagetta und Lerchenau, G. R., Flora von Nieder-Österreich. - Wien I $890-93 . \quad$ ( I $890 \%)$.

- - Vegetationsstudien in den Ostalpen. - Sitz. ber. math.-naturw. Kl. Akad. d. Wissensch. in Wien, Abt. I. - Part 1: Bd 116, 1907; Part 2: Bd 117, 1908; Part 3: Bd I 22, 1913.

BLytT, A., Forsög til en Theori om Invandringen av Norges Flora under vexlende regnfulde og törre Tider. - Nyt, Mag. for Naturvid., Vol. 21. Kristiania 1876.

—, Zur Geschichte der Nordeuropäischen, besonders der Norwegischen Flora. Engler's Botan. Jahrb., Bd I 7. I 893 .

Borovikov, - Zapiski novoryss, obscestva estestvojspyt., Vol. 33. Odessa I909. [The Terr. of the Don Kossa ${ }_{c}$ ks.]

Bos, H., Zur Kritik der Lehre von den thermischen Vegetations-Konstanten auch in Bezug auf Winterruhe und Belaubungstrieb der Pflanzen. - Verhandl. Botan. Vereins Prov. Brandenburg, Bd. 48. Berlin 1907.

BRiquet, J., Les colonies végétales xérothermiques des Alpes limanniennes. - Bull. Murithienne soc. valaisienne d. scienc. natur., 27-28. Aigle $1898-99$. (》1 898 ). Brockmann-Jerosch, H., Der Einfluss des Klimacharakters auf die Verbreitung der Pflanzen und Pflanzengesellschaften. - Engler's Botan. Jahrb., Bd. 49, Beiblatt 109. I9I3.

und RüBEL, E., Die Einteilung der Pflanzengesellschaften nach ökologisch-physiognomischen Gesichtspunkten. - Leipzig г 9 I 2.

Busch, N., Papaveraceae and Cruciferae in "Flora Sibiriae et Orientis extremi a Museo Bot. Acad. Imp. Scient. Petropolit, edita». [Nrs 24 and 25; Vipysk 1.] Petrograd I9I3.

Cajander, A. K., Die Vegetation des Urwaldes am Lena-Thale. - Acta Soc. scient. Fenn., Tom. 32. Helsingfors 1906. (1906 a).

_- Beiträge zur Kenntniss der Vegetation der Alluvionen des nördlichen Eurasiens. I, Die Vegetation der Alluvionen des unteren Lena-Thales. - Ibid. (I906 b). II, Die Alluvionen des Onega-Thales, - Ibid., Tom. 33. 1908.

Chirjaev, - Trav. Soc. Natur. à l'Univers. de Kharkov, Vol. 40:2 and 43. 1907 and igio. [The Lebedin-distr. of the Governm. of Kharkov.]

De Candolle, A. P., Essai élémentaire de géographie botanique. - Dictionnaire d. scienc. natur. Paris 1829 .

De Candolle, Alphonse, Géographie botanique. - Paris 1855 .

De Geer, Sten, Beskrivning till översiktskarta över Södra Sveriges landformer. Sveriges Geol. Undersökn., Ser. Ba, nr 9. Stockholm i9i3.

DENGLER, A., Untersuchungen über die natürlichen und künstlichen Verbreitungsgebiete einiger forstlich und pflanzengeographisch wichtigen Holzarten in Nord- und Mittel 
deutschland. - I, l)e Horizontalverbreitung der Kiefer. Neudamm 1904. - II, Die Horizontalverbreitung der Fichte (Picea excelsa L.). Neudamm I912.

Dentsche Geologische Gesellschaft, Die Klimaveränderungen in 1)eutschland seit der letzten Eiszeit. - Berlin 1910.

Diels, I., Pflanzengeographie. - Samml. Göschen, $\mathrm{nr} 389.1918$.

Domis, K., Das böhmische Mittelgebirge. - Engler's Botan. Jahrb., Bd 37. I906.

—- Monographie der (rattung Koeleria. - Biblioth. Botan., Bd 14 , H. 65-66. Stuttgart 1907 .

DRUDE, O., Die Vertheilung und Zusammensetzung östlicher Pflanzengenossenschaften in der Umgebung von I)resden. - Festschr. naturw. ( iesellsch. Isis in I)resden. Dresden I $885_{5}$.

- - Handbuch der P'flanzengeographie. - Stuttgart i 890.

—- Deutschlands P'flanzengeographie. - Stuttgart I 896 .

- Der Hercynische Florenbezirk. - Engler und Drude: Die Vegetation der kirde, 6. Leipzig 1902.

Duncker, H., Wanderzug der Vögel. - Jena r 905.

De Rietz, (i. E., Zur methodologischen Grundlage der modernen Pflanzensoziologie. Dissert. Upsali. Wien 1921 .

, Fries, Th. C. E., Osvald, H. und Tengrall, T. $\Lambda$., (iesetze der Konstitution natürlicher Pflanzengesellschaften. - Vetenskapliga och praktiska undersökningar i Lappland, anordn. av Luossavaara-Kirunavaara Aktiebolag. Flora och Fauna, 7. Upsala 1920.

Екноцм, G., Studier i Upplands bebyggelsehistoria. I, Stenåldern. -- Dissert. Upsala. 1915 .

EкноLм, N., Sveriges temperaturförhållanden jämförda med det öfriga Europas. Ymer i 899, h. 3. Stockholm i 899 .

ENGler, A., Versuch einer Entwicklungsgeschichte der Pflanzenwelt, - Leipzig i 879. — und Gilg, G., Syllabus der Pflanzenfamilien. - Berlin I9 I9.

ERntmax, G.. Floristiska anteckningar från sydberg och sessiliflorieta i Nordhalland och Mark. - Botan. Notiser 1922, h. 7. Lund 1922.

Ekrıssox, J., En studie öfver Ranunculus illyricus' morfologi, biologi och anatomi. Ofversigt af Svenska Vetenskaps-Akad:s Förhandl. 1898 . Arg. 55 (p. 87). Stockholm is 898 .

ERIKsson, J. V., Studier öfver Upplands förhistoriska geologi. - Upplands Fornminnesfören:s Tidskr., Bd 29. Upsala 1913.

FALK, K., Iakttagelser öfver alfvarvegetationen på Öland, särskildt med hänsyn till alfvarväxternas osmotiska tryck. - Svensk Botan. Tidskr., Bd 7, h. +. Stockholm I 913 .

lemtshenko, - Bull. Soc. Natur. de Mouscou., N. S., Vol. I 1., i 897 . The district of the upper Pechora. In Germ. in »Allgemeine botan. Zeitschr.», Jahrg. I 898.]

Fiek, E., Flora von Schlesien. - Berlin I88I.

Flfkor, A., Flora des Gouvernements Wladimir. -- Moskva 1902 (Dissert). [Schrift. d. Naturforsch. Gesellsch. bei d. Univers, in Jurjev, N:o Io.]

—. Okskaja Flora. - Acta horti Univers. Petropolit., Tom. 27. Petrograd igro. Flach, W., Juhlin-Danxfeldi, H. och Sundb.ïrg, G., Sveriges jordbruk vid igootalets början. - Göteborg 1909.

Forbes, Eduard, On the connexion between the distribution of the existing Fauna und Flora of the British Isles, with the geological changes which have affected their 
area especially during the epoch of the northern drift. - Mem. of the Geol.

Survey of Great Britain., Vol. I. London 1846 .

Fries, EliAS, Stirpes agri Femsionensis index. - Lund 1825-1826 (»1825»).

FriEs, TH. C. E., Botanische Untersuchungen im nördlichen Schweden. - Dissert.

Upsala r9i3. [Vetenskapliga och praktiska undersökningar i Lappland anordnade

af Luossavaara-Kirunavaara Aktiebolag.]

Fróds, JoHN, Iakttagelser i Kebnekaise-områdets sydberg. - Svensk Botan. Tidskr. I 9 I 7 , Bd I I. Stockholm I917.

Geisenheyner, L., Bemerkungen zu Vincetoxicum officinale Moench. - Festschr. z.

Feier d. 70. Geburtstages des Herrn Professor Dr. Paul Ascherson. Leipzig I904.

Gloersen, A. T., Vestlands-Granen og dens Indvandrings-Veje. — Den norske Forstforen:s Aarbog for I 884 . Christiania I 885 .

Gordjagin, A., Botanisch-geographische Untersuchungen in den Kreisen Kazan und Laischew. - Trav. Soc. Natural. à l'Univers. de Kazan, T. 22:2. Kazan 1889. (In Russian.)

- Ueber die Vegetation der Kalkfelsen an FI. Tura im Gouvernement Perm. Ibid., T. $28: 2$. Kazan 1 895. (In Russian.)

Gradmanx, R., Das Pflanzenleben der schwäbischen Alb. 2. Aufl. - Tübingen 1900.

—, Das mitteleuropäische Landschaftsbild nach seiner geschichtlichen Entwicklung. Geogr. Zeitschr., Bd. 7. Leipzig 1901.

- Beziehungen zwischen Pflanzengeographie und Siedlungsgeschichte. - Ibid., Bd. I 2. Leipzig 1906.

Graebner, P., Die Heide Norddeutschlands. - Engler und Drude: Die Vegetation der Erde, 5. Leipzig I $90 \mathbf{1}$.

Grevillius, A. Y., Bidrag till kännedomen om kärlväxtvegetationen på nephelinsyenitområdet i Alnöns norra del samt på närliggande holmar i Medelpad. - Ófversigt af Svenska Vetenskaps.Akad:s förhandl. I894. Årg. 51. Stockholm I894. Grisebach, August, Über den Einfluss des Klimas auf die Begrenzung der natürlichen Floren. - Linnaea 12. 1838 .

- Ueber die Vegetationslinien des nordwestlichen Deutschlands. - Göttingen I 847 . - Die Vegetation der Erde. - Leipzig 1872. - 2. Aufl. Leipzig r884.

HALDEN, B., Om torvmossar och marina sediment inom norra Helsinglands litorinaområde. - Sveriges Geol. Undersökn:s Årsbok för år 1917. Stockholm 1917.

—,$O m$ de norrländska skalbankarnes växtgeografiska betydelse. — Svensk Botan. Tidskr. 1920, Bd 14, h. 2-3. Stockholm I920.

HAliberg, H. E., Medeltal och extremer af luftemperaturen i Sverige 1856 - 1907. Bih. t. Meteorol. Iakttag. i Sverige, Vol. 49. Uppsala 1908.

- Molnighet och solsken på den Skandinaviska lıalfön. — Ibid., Vol. 50. Uppsala 1909 .

—, Nederbörden i Sverige I860-I910. - Ibid., Vol. 52. Uppsala I9I I.

Hann, J., Handbuch der Klimatologie. - Stuttgart I 908.

HAnsen, A. M., Landnåm i Norge. En utsigt over bosætningens historie. - Kristiania 1904 ( 1904 a).

- Hvorledes har Norge faat sit plantedække? - Naturen, Bd $2 \dot{8}$. Kristiania 1904 (1904 b).

Harshberger, J. W., Phytogeographic Survey of North America. 2:d ed. - Engler und Drude: Die Vegetation der Erde, Bd 13. Leipzig 1921. 
Hauskath, H., Pflanzengeographische Wandlungen der deutschen Iandschaft. - Wissenschaft und Hypothese, I3. Dresden I 9 I I.

HAlEK, A. E., Kritische Übersicht über die Anemone-Arten aus der Section Campanaria Fndl. und Studien über ihren phylogenetischen Zusammenhang. - Festschr. z. Feier d. 70. Geburtstages des Herrn Professor 1)r. Paul Ascherson. Leipzig I904. —. Die Pflanzendecke Usterreich-Ungarns. Bd I. Wien I9I4-I9I6 (»I9I4»).

Hrer, Oswald, Beiträge zur P'llanzengeographie. I, Die Vegetationsverhältnisse des südöstlichen Theils des Kantons Glarus. - Zürich i $8_{35}$.

Hrintze, AUG., Om Ranunculus lapponicus och andra granens följdväxter i Skandinavien. - Botan. Notiser r 909 . Lund r 909 .

Hemberg, E., Tallens degenerationszoner i södra och västra Sverige. — Skogsvårdsfören:s 'Tidskr., Arg. 2, I904, h. 3-5. Stockholm 1904.

Herder, F. VoN, Die Flori des europäischen Russlands. Nach den Forschungsresultaten der letzten 40 Jahre statistisch zusammengestellt. - Engler's Botan. Jahrb., $\mathrm{Bd} \mathbf{1}+$ Leipzig $\mathbf{1} 802$.

Hesselana, H., Zur Kenntnis des Pflanzenlebens schwedischer Laubwiesen. - Botan. Centralbl., Beihefte, Bd I 7 . I 904 .

- Svenska löfängar. — Skogsvårdsfören:s Tidskr., Årg. 3. Stockholm 1905.

-, Vegetationen och skogsväxten på Gotlands hällmarker. - Ibid., Árg. 6. Stockholm I 908 .

-, Om vattnets syrehalt och dess inverkan på skogsmarkens försumpning och skogens växtlighet. - Medd. fr. Statens Skogsförsöksanstalt, h. 7. Stockholm r9io.

, Jordmånen i Sveriges skogar. - Skogsvårdsfören:s folkskrifter, n:ris $27-28$. Stockholm I9 I 1 .

- Studier över salpeterbildningen i naturliga jordmåner och dess betydelse i växtekologiskt avseende. - Medd. fr. Statens Skogsförsöksanstalt, h. I3-1 4. Stockholm I9I7. (1917 a).

—, Om våra skogsföryngringsåtgärders inverkan på salpeterbildningen i marken och dess betydelse för barrskogens föryngring. - Ibid. Stockholm 1917. (1917 b). och Sснотте, G., Granen vid sin sydvästgräns i Sverige. - Skogsvårdsfören:s Tidskr., Arg. 4, h. 9-10. Stockholm 1906.

Hildebrand, F., Die Verbreitungsmittel der Pflanzen. - Leipzig 1873.

Hielt, HJ., Conspectus Florae Fennicae. - Acta Soc. pro Fauna et Flora Fenn., Bdd 5 (1890-92), 20: I (1900-02), 30:1 (1904-06), and 41 (1915-1919). Helsingfors.

Hofsten, N. vos, Planaria alpina som glacialrelikt på Bornholm jämte några ord om landfaunans invandring till Bornholm. - Vidensk. Medd. fra Dansk naturhistor. Foren., Bd 7r. Köbenhavn i9 19.

Hooker, J. D., The Students Flora of the British Islands. 3:d ed. - London I 884. Hoops, J., Waldbäume und Kulturpflanzen im germanischen Altertum. - Strassburg 1905. Hult, R., Blekinges vegetation. Ett bidrag till växtformationernas utvecklingshistoria. - Medd. Soc. pro Fauna et Flora Fenn., h. 12. Helsingfors 1885.

Humboldt, Alexander von, De distributione geographica plantarum secundum coeli temperiem et altitudinem montium. Prolegomena. - Paris I 8 I 7 .

HARd af Segerstad, F., Södra Siındsjö sockens fanerogamer. Ett bidrag till kännedomen om de pontiska och nordatlantiska växternas gränslinjer i sydöstra Sverige. - Arkiv för Botanik, Bd I I, nr 8. Stockholm I912.

- Utkast till en flora över Värnamotrakten. Bidrag till kännedomen om grönstenarnas inflytande på växternas utbredning. Värnamo I 920. 
Höck, F., Brandenburger Buchenbegleiter. - Verhandl. d. botan. Ver. Prov. Brandenb., Bd 36. Berlin 1895 .

- Studien über die geographische Verbreitung der Waldpflanzen Brandenburgs. Ibid., Bdd 37-4I, 43, 44. I896-1900, 1902, 1903 (》 $1896 »)$.

Högвom, A. G., Studier öfver Upplands äldre bebyggelsehistoria. - Ymer I912. Stockholm I9 I 2.

Jaccard, H., Catalogue de la flore valaisienne. - Neue Denkschr. allgem. schweiz. Gesellsch. f. d. gesammten Naturwiss., Bd 34. Zürich 1895 .

Johansson, K., Hufvuddragen af Gotlands växttopografi, grundade på en kritisk behandling af dess kärlväxtflora. - Srenska Vetenskaps-Akad:s handl., N. F., Bd 29. Stockholm 1896 .

—_, Ytterligare om Potentilla fruticosa på Gotland. - Svensk Botan. Tidskr. 1908, Bd 2, h. 3. Stockholm 1908.

—_, Nyare bidrag till kännedomen om Gotlands kärlväxtflora. - Botan. Notis. I 910. Lund 1910.

—_, Bidrag till de gotländska Pulsatillornas naturhistoria. - Svensk Botan. Tidskr. I 9 I 2 , Bd 6, h. I. Stockholm I912.

Jost, L., Vorlesungen über Pflanzenphysiologie. - Jena г 9 I 3.

JÄNnıcke, A., Die Sandflora von Mainz, eine pflanzengeographische Studie. - Flora, Jahrg. 72,1889 .

KeLler, B., Aus der Steppenregion des Europäischen Russlands. Botan.geographische Forsch. im Gouvernement Ssaratow, District Sserdobsk. - Trav. Soc. Natur. à l'Univers. de Kazan, Vol. 37, Livr. 2. Kazan I 903 . [In Russian.]

Kerner, A., Das Pflanzenleben der Donauländer. - Innsbruck 1863.

- Einfluss der Winde auf die Verbreitung der Samen im Hochgebirge. - Zeitschr. Deutsch. Alpenvereins 187 I.

_- Beiträge zur Geschichte der Pflanzenwanderungen. - Oesterr. Botan. Zeitschr., Bd 29. Wien 1879 .

—- Studien über die Flora der Diluvialzeit in den östlichen Alpen. - Sitz. ber. Math.-naturw. Kl. Akad. d. Wissensch. Wien, Bd 97. 1888.

Kirchner, O., Blumen und Insekten. - Leipzig i 9 I I.

Klinggraeff, H. von, Versuch einer topographischen Flora der Provinz Westpreussen. - Schrift. Naturforsch. Gesellsch. in Danzig, N. F., Bd 5. Danzig 1881.

Koeppen, W., Versuch einer Klassifikation der Klimate, vorzugsweise nach ihren Beziehungen zur Pflanzenwelt. - Geogr. Zeitschr. 1900. Leipzig 1900.

—-, Geographische Verbreitung der Holzgewächse des europäischen Russlands. Beiträge zur Kenntnis des russischen Reiches, 3. Folge, Bdd 5 and 6. Petrograd 1888 and 1889 .

Komarov, - Trav. Soc. Natural. de St. Pétersbourg. Vol. 26, 1896. [The Governm. of Novgorod.]

Korshinsky, S., Die nördliche Grenze des Steppengebietes in dem östlichen Landstriche Russlands in Beziehung auf Boden- und Pflanzenvertheilung. I: Phytogeographischer Umriss des Kazan-schen Gouvernements. - Trar. Soc. Natural. à l'Univers. de Kazan, Yol. I 8, Livr. 5. Kazan i 888. [Rev. in Botan. Centralblatt, Bd 40, I889, pp. $254 \mathrm{ff}$. and $29 \mathrm{I} \mathrm{ff}$.]

—, Die nördliche Grenze etc., 2: Phytogeographische Untersuchungen in den Gouvernementen Simbirsk, Samara, Ufa, Perm und zum Theil Wiatka. - Ibid., Vol. 22, Livr. 6. 1891. [Rev. in Botan. Centralbl., Bd 54, 1893, Beiblatt pp. $242 \mathrm{ff}$.] 
Korshinsky, S., Tentamen Florae Rossiae orientalis. - Mém. de l'Akad. du scienc. de St. Petersbourg, 8:e Ser., Tom. 7. Petrograd i 898.

Kossinsky, - Bull. Jard. imp. de St. Pétersbourg, 'T. I3. Petrograd I9I3. [The Governm. of Kostroma.

Krassnov, A. N., Materialien zur Kenntnis der Flora der Nordgrenze der TchernosemVerbreitung. - Trav. Soc. Natural. de St. Pétersbourg, Vol. I 5, Livr. 2. Petrograd I884. Rev. in Botan. Zentralbl., Bd $3 \mathbf{I}$ ( I887), pp. $37 \mathrm{I}$ ff.]

- Untersuchungen in den Kalmüickensteppen. - Bull. Russian Geograph. Soc., Vol, 22. I 886. In Russian. Rev. in Engler's lotan. Jahrb. i 889.]

- Steppes de la Russie méridionale. - Annales de Géographie i 894.

Krads, Gregor, Boden und Klima auf kleinstem Raum. - Jena 19 I 1.

Krishevsky, - Trav. Soc. Natural. à l'Univers. de Kharkov, Vol. +5. Karkov I9I2.

[The Governm. of Kherson.

Kultshitskaja and Enduurova, - Trav. Soc. Natural. de St. Pétersbourg, Vol. 35, Livr. 3, Sect. botan. Petrograd I 906. [The Governm. of Ryazan.]

KupfFer, K. R., Verzeichnis seltener Pflanzen Liv- und Kurlands. - Sitz. ber. Naturforsch. Gesellsch. bei d. Univers. Jurjev, Bd I I. Jurjev I 895 .

- Bemerkenswerte Vegetationsgrenzen in Ost-Balticum. - Verhandl. botan. Vereins Prov. Brandenburg, Bd 46. Berlin 1905.

—, Kleine Notizen. - Korrespondenzbl. d. Naturforsch. Vereins zu Riga, Bdd 48 und 50. Riga 1905 and 1907 .

Kiznecov, N. J., Die Vegetation und die Gewässer des europäischen Russlands. Engler's Botan. Jahrb., Bd 28. I901.

I.ALs, H., Die Vegetationsverhältnisse der südmährischen Sandsteppe zwischen Bisenz und Göding und des Nachbargebietes. - Botan. Zeitung, Bd 68. r9ro.

Lehulans, ED., Flora von Polnisch-Livland mit besonderer Perücksichtigung der Florengebiete Nordwestrusslands, des Ostbalticums, der Gouvernements Pskow und St. Petersburg (Archiv f. Naturk. Liv-, Esth- und Kurlands. 2. Serie, Bd I I, Lfg. I) Jurjev I 895 . - Nachtrag (ibid. Lfg. 2). Jurjev i 896.

Lindeberg, H., [Om Finlands och dess floras utvecklingshistoria]. A lecture in the meeting I3. IV. I9 I 5 of the Botan. Sect. of the Soc. of Natural Sience Students at Upsala. Summ. in Svensk Botan. Tidskr. I9 I 5, Bd 9, h. 4, p. 467.

LiN1)MAn, C. A. M., Srensk fanerogamflora. - Stockholm I9 I 8.

LiNDströı, A., Några allmänna upplysningar till öfversigtskarta angifvande de kvartära hafsaflagringarnas område samt kalkstens- och mergelförekomsters utbredning i Sverige. - Sveriges Geol. Undersökn., Ser. Ba, nr 5. Stockholm 1898 .

Lotw, E., Uber Perioden und Wege ehemaliger Pflanzenwanderungen im norddeutschen Tieflande. - Linnaea, Bd 42. $1878-79$.

Lucanus, Fr. vox, Die Rätsel des Vogelzuges. Ihre Lösung auf experimentellem Wege durch Aeronautik, Aviatik und Vogelberingung. - Langensalza I922.

Malmströs, C., Trapa natans L. i Sverige. -- Svensk Botan. Tidskr. 1920, Bd I4, h. I. Stockholm 1920.

Marmajanova, N., - Trav. Soc. Natural. à l'Univers. de Kazan, Vol. i r, livr. 3. Kazan I882. [The flora of Minussinsk in Siberia.]

Meinshausen, K. Fr., Flora ingrica. - Petrograd i 878 .

Mevius, W., Beiträge zur Physiologie kalkfeindlicher Gewächse. - Jahrb. f. wissensch. Botanik herausgegb. von Pringsheim, Bd 60, H. 22. 1921 .

Meven, Fr. J. F., Grundriss der Pflanzengeographie. - Berlin $188_{3} 6$. 
Middendorff, A. Th. von, Reise in den äussersten Norden und Osten Sibiriens. Bd IV: Übersicht der Natur Nord- und Ost-Sibiriens. Petrograd i 867.

Michajlovskx, S., Eine Skizze der Vegetation des Kreisen Njeshin des Gouvernement Czernigov. - Schrift. d. Naturforsch. Gesellsch. bei d. Univers. in Jurjev, nr 12. Jurjev 1903. [In Russian with a German summary.]

Moss, C. E., Vegetation of the Peak district. - Cambridge 1913.

Munthe, H., Studier öfver Gottlands senkvartära historia. - Sveriges Geol. Unders., Ser. Ba, nr 4. Stockholm 1910. (1910 a).

_- Studies in the Late-Quaternary history of Southern Sweden. — Geol. Fören:s i Stockholm Förhandl., Bd 32. Stockholm 1910. (1910 b).

Murashkinskx, - Acta Horti Botan. Univers. Jurjev., T. 5 and 7. Jurjev 1904 and 1 906. [The Governm. of Nizhy-Novgorod.]

Naumor, - Trav. Soc. Natural. à l'Univers. de Kharkor, Vol. 37. Kharkov 1903. [The neighbourhood of Roublevka in the Governm. of Kharkov.]

Novopokrovskij, A., Kurze Mitteilung über eine Reise nach auf Sandböden gelegenen Forstrevieren der Donschen Kosaken. - Engler's Botan. Jahrb., Bd 50. I9I 4.

Novopokrovskij, J., Recherches phytogéographiques de la partie de sud-est du Gouvernement Stauropol et de la partie avoisinée de la province Terskaja. - Zapiski novoryss. obscestva estestrojspyt., T. 29. Odessa 1906. JIn Russian.]

Olsson, Eskil, Stenåldern i Västmanland, Dalarne och Gästrikland. - Ymer 1917. Stockholm 1917 .

Ostenfeld, C. H., Anemone- og Kobjælde-Arternes Udbredelse i Danmark. - Biologiske Arbejder tilegnede Eug. Warming paa hans 70 aars födelsedag. Köbenhavn I 9 II.

Paczoski, I., Materiaux pour servir à l'étude de la flore des steppes de la partie Sudest du Gouvernement de Chersone. - Mém. Soc. Natural. de Kiev, T. i I, Livr. 1. Kiev 1890. [In Russian.]

—, Flora Poljesje. - Trav. Soc. Natural. de St. Pétersbourg, Vol. 27,29 and 30. Fasc. 3, Sect. botan. Petrograd I897, 1899 and 1900. ( $1897 »)$. [In Russian.] —, - Zapiski novoryss. obscestva estestvojspyt., Vol. 26. Odessa 1904. [The neighbourhood of the Dnjepr in the Governm. of Taurida. In Russian.]

PalméN, J. A., Über die Zugstrassen der Vögel. - Helsingfors I 876.

Palmgren, A., Studier öfver löfängsområdena på Áland. II: Floran - Acta Soc. pro Fauna et Flora Fenn., Bd 4r. Helsingfors 1915.

PAX, FR., Schlesiens Pflanzenwelt. Eine pflanzengeographische Schilderung der Provinz. - Jena I 915.

- - Pflanzengeographie von Polen (Kongress-Polen). - Veröffentlichungen der landeskundlichen Kommission beim Kais. deutsch. Generalgouvernement Warschau, Reihe A, Bd I. Berlin I918.

Petunnikov, A., Ueber Carex gracilis Schkuhr und C. obtusata Liljebl. - Allgem. Botan. Zeitschr. Jahrg. 4. I 898.

—- Kritische Uebersicht der Moskauer Flora. Part I: Scripta botan. horti univers. Petropolit., Fasc. 13. 1896. - Part 2: Trav. Soc. Natural. de St. Pétersbourg. Vol. 30, Fasc. 3, Sect. botan., 1900. - Part 3: Ibid. Vol. 31. I90 I.

Podpera. J., Studien über die thermophile Vegetation Böhmens. - Engler's Botan. Jahrb., Bd 34. 1904 .

Pohle, R., Bericht über die Resultate zweier botanischer Forschungsreisen in Nordrussland. - Acta horti botan. Univers. Jurjev., Vol. 3, Lief. 3. Jurjev 1902. 
Poнle, R., Pflanzengeographische Studien über die Halbinsel Kanin. Theil I. - Acta horti botan. univers. Petropolit., Tom. 2r, Fasc. I. Petrograd 1903.

Post, L. vox, Postarktiska klimattyper i Södra Sverige. - Geol. Fören:s i Stockholm Förhandl., Bd 42, h. 5. Stockholm 1920.

Prfuss, H., Die Vegetationsverhältnisse des deutschen Ostseeküstes. - Schrift. d. Naturforsch. Gesellsch. in Danzig, N. F., Bd 13, H. 1-2. Danzig I9I I-I 2. (》I 9 II 》).

, Die pontischen Pflanzenbestände im Weichselgebiet. - Beiträge zur Naturdenkmalpflege herausgegb. von H. Conwentz, Bd 2, H. 4. Berlin I9I2.

, Die Pflanzendecke in den abgetretenen Gebieten der Provinzen Westpreussen und Posen. - Ibid., Bd 9, H. r. Berlin I 92 I.

Printz, H., The regetation of the Siberian-Mongolian frontiers. (The Sayansk region).

- Contribut. ad floram Asiae int. pertinentis edidit Henrik Printz, III. Trondhjem I 92 I.

Prodan, J. Die Halophytenflora des Komitates lícs-lBodrog. - Magyar Botanikai Lapok, 13. Budapest I9 15. [In Magyar.]

—, Flora des Komitates Bacs-Bodrog. - Ibid. I f. Budapest I9 I6. In Magyar.

Ramans, E., Bodenkunde. 3. Aufl. - Berlin r9 r r.

Raunki.er, C., Planterigets Livsformer og deres Betydning for Geografien. - Köbenhavn 1907 .

- Livsformernes Statistik som (irundlag for biologisk Plantegeografi. - Botan. Tidskr., Bd 29. Köbenhavn 1909.

Ringius, G. E., Vegetationen på Värmlands hyperitområden. - Öfrers. af Svenska Vetenskaps-Akads:s förhandl. I 888 , Arg. 45. Stockholm I $888-1889$. (» 888 ).

Romell, L. G., Gränser och zoner i Stockholms yttre skärgård. - Svensk Botan. Tidskr. I 9 I 5, Bd 9, h. 2. Stockholm I9 I5.

RÜBEL, E., Pflanzengeographische Monographie des Berninagebiets. - Engler's Botan. Jahrb., Bd 47. I9 I 2 .

—, Die Kalmuickensteppen bei Sarepta. - Engler's Botan. Jahrb., Bd 50. I9I4. Saljessiki, - Trav. Soc. Natural. de St. Petersbourg. Tol. 3o. Petrograd y 900. The Governm. of Orel.

Samulesson, G., Regionförskjutningar inom Dalarne. - Svensk Botan. Tidskr. I 9 Io, Bd 4, h. I. Stockholm I 9 IO.

—, De nordiska Sagittaria-arterna. - Ibid. 1920, Bd 14, h. 1. Stockholm 1920. —, Floristiska fragment, III. - Ibid. 1922, Bd 16, h. I. Upsala 1922. (1922 a). —, Floristiska fragment, IV. - Ibid. I922, Bd I6, h. 2. Upsala 1922. (1922 b). SAndegrex; R., Najas flexilis i Fennoskandia under postglacialtiden. - Srensk Botan. Tidskr. I 920, Bd I 4 , h. 2-3. Stockholm 1920.

Savenkov, Materiale zum Studium der Wasserflora des I)onets im Gourernement Charkov. - Trav. Soc. Natural. à l'Univers. de Kharkov. Yol. 43 (1909). Kharkov I 9 Io. [In Russian.]

Schalov, E., Uber die Beziehungen zwischen Pflanzenverbreitung und der ältesten menschlichen Siedelungsstätten im mittelsten Schlesien. - Engler's Botan. Jahrb., Bd 57. Beiblatt 127 . 1922 .

Schfutz, N. J., Conspectus florae smolandiae. - Dissert. Upsal. I 857.

—, Växtgeografiska anteckningar öfver östra Småland. - Ofversigt af Kongl. Svenska Vetenskaps-Akad:s förhandl. I\$61, Arg. IS, pp. 433-450. Stockholm IS62.

Schimper, A. F. IV., Pflanzen-Geographie auf physiologischer Grundlage. - Jena I 898. 
Schmalhausen, I., Flora jugozapadnoi Rossii (south-western Russia). Kiev 1886.

Schoenrock, A., Die Bewölkung des russischen Reiches. - Mém. Acad. du scienc. de St. Pétersbourg, 8:e Sér., Tom. r, nr 6. Petrograd r 895.

Scholz, Josef B., Die Pflanzengenossenschaften Westpreussens. - Schrift. d. Naturforsch. Gesellsch, in Danzig, N. F., Bd I I, H. 3. Danzig 1905.

Schouw, J. Fr., Grundtræk til en almennelig Plantegeografi. - Köbenhavn 182 r.

Schulz, A., Uber die Entwicklungsgeschichte der gegenwärtigen phanerogamen Flora und Pflanzendecke Schwedens. - Berichte d. deutsch. botan. Gesellsch., Bd 22. I 904.

Selander, S., Sydliga och sydostliga element i Stockholmstraktens flora. - Svensk Botan. Tidskr. I9I4, Bd 8, h. 3. Stockholm I 9 1 4 .

Sendtner, O., Die Vegetations-Verhältnisse Südbayerns nach den Grundsätzen der Pflanzengeographie geschildert. - München $1 \&_{54}$.

Sernander, R., Die Einwanderung der Fichte in Skandinavien. - Engler's Botan. Jahrb., Bd r 5 . Leipzig r 892 .

- , Studier öfver den gotländska vegetationens utvecklingshistoria. - Dissert. Upsala 1894 .

—, Sveriges växtvärld i nutid och forntid. — Sveriges Rike, utg. af J. F. Nyström. Stockholm I 900 .

—_, Växtvärlden. - «ppland», Bd I, h. I. Stockholm I90I. (I90 I a).

- Den skandinaviska vegetationens spridningsbiologi. Upsala I90 I. (I90 I b).

- Bidrag till den västskandinaviska vegetationens historia i relation till nivåförändringarna. - Geolog. Fören:s i Stockholm Förhandl., Bd 24. Stockholm r 902.

—, Entwurf einer Monographie der Myrmecochoren. — Svenska Vetenskaps-Akad:s Handl., Bd 4r. Upsala I 906.

- Stipa pennata i Västergötland. En studie öfver den subboreala periodens inflytande på den nordiska vegetationens utvecklingshistoria. - Svensk Botan. Tidskr. r 908 , Bd 2. Stockholm I 908 .

- De scanodaniska torfmossarnas stratigrafi. - Geol. Fören:s i Stockholm Förhandl., Bd 30. Stockholm s 909.

- Die schwedischen Torfmoore als Zeugen postglazialer Klimaschwankungen. Die Veränderung d. Klimas seit d. Max. d. letzt. Eiszeit. Comte Rendu du I I:e Congrès Géol. Intern. Stockholm i 9 Io. Stockholm 1910.

—, Scirpus radicans Schkuhr funnen i Närke. — Svensk Botan. Tidskr. rgro, Bd 4, h. 4. Stockholm 1911.

- Den nordeuropeiska vegetationens historia i relation till den geologiska och den arkeologiska utvecklingen. - In: Högbom, A. G., Sernander, R., Almgren, O., Wide, S., Montelius, O., Kronologiska öfversikter till Europas förhistoria meddelade vid en offentlig föreläsningsserie vid Uppsala Universitet höstterminen I 9 5 . Uppsala i 9 16.

—, Förna och äfja. I. - Geolog. Fören:s i Stockholm Förhandl., Bd 40. Stockholm I 9 I 8 .

—, En supralitoral havsstrandäng från äldre bronsåldern bevarad i det inre Uppland. - Svensk Botan. Tidskr. 1920, Bd 14, h. 2-3. Stockholm 1920. (1920 a).

—, Den svenska hagens historia. - Svenska landtbruksveckans 1920 förhandl. Stockholm I 920 ( I 920 b). 
[SkRnander, R.,] Närikes väitsamhällen. In: Aspling, k.., Gralén, J., Lindén, H., Närke. Hembygdsböckerna. Upsala 1922. |pp. $27 \mathrm{ff} . \mid$

Sinorov, IV., Beiträge zur Kenntnis der Flora des Jekaterinoslawschen Gouvernements. - Scripta horti botan. Univers. Petropolit., Fasc. 14, 1897. Petrograd 1897. [In Russian with a German summary.]

Skirman, J. A. O., Om några förekomster af ädla löfträd i nordligaste Värmland. — Svensk Botan. Tidskr. I9I I, Bd 5, h. 4. Stockholm I9I2.

, Bidrag till nordligaste Värmlands flora. - Ibid. I9I3, Bd 7, H. 4. Stockholm I 914 .

Suriknov, V., Pflanzengeographische Forschungen im nordöstlichen Theile des Gouvernements Ssaratov. - Trav. Soc. Natural. à l'Univers, de Kazan. T. $37: 4$. Kazan 1903. In Russian,

Sprýrin, I., - Ibid., T. 4I:3. Kazan 1907. [The Scotch fir and its acolytes in the Governm. of Pensa. In Russian.]

StrRner, R., Carex ligerica Gay. En floristisk och växtgeografisk studie. - Acta Florae Sueciae, Bd I. Stockholm 1921. (1921 a).

—, Om Geum hispidum Fr. - Svensk Botan. Tidskr. 1921, Bd I5, h. 1. Stockholm 1921. (1921 b).

Stkacsev, W., - Bull. Jardin imp. botan. de St. Pétersbourg, T. 2, Livr. 5. Petrograd 1902. TThe tlora of the Governm. of Kharkov. In Russian.

- - Trav. Soc. Natural. à l'Univers. de Kharkov. Vol. 37 (1902). Kharkov r903.

The districts of Grajvoron and Obojan in the Governm. of Kursk. In Russian.

Sundelin, U., Fornsjöstudier inom Stångåns och Svartåns vattenområden. - Sveriges Geolog. Undersökn., Ser. Ca, nr I6. Stockholm 1917.

, Über die spätquartäre Geschichte der Küistengegenden Östergötlands und Smålands. - Bull. Geolog. Instit. of Upsala, Vol. 16. Upsala r9r9.

Sylvex, N., De svenska skogsträden. I. Barrträden. - Stockholm 1916.

TAliev, V., Sur la limite des forêts et des steppes dans le district de Valki dans le Gouvernement de Charkov. - Trav. Soc. Natural. à l'Univers. de Kharkov, Vol. $36: 2$ (1901). Kharkov 1902. In Russian.

, Sur les vestiges des forêts de pins dans les steppes du Gouvernement d'Oufa. - Ibid. Vol. $38: 2$. (1903). Kharkor 1904. [In Russian.]

and Vojnovsky, S., - Ibid. Vol. 37 (I902). Kharkov 1903. The southern part of the Burguruslán-district in the Governm. of Samara. In Russian.]

ТАмм, O., Die Auslaugung von Calciumkarbonat in einigen Böden der Ragundagegend. - Geolog. Fören:s i Stockholm Förhandl., Bd 36. Stockholm 1914.

, Markstudier i det nordsvenska barrskogsområdet. - Medd. fr. Statens Skogsförsöksanstalt, H. I 7. Stockholm I 920.

- - Om berggrundens inverkan på skogsmarken. - Medd. fr. Statens Skogsförsöksanstalt, H. I8. Stockholm I $92 \mathrm{I}$.

Tanfiljev, G. I., Die Ursachen der Bildung und Verbreitung von Torfmooren in Russland. - 8. Ssjesd. Russk. Jestestr. i Wraczej. Ssekz. Agronom. I890. [Rev. in Engler's Botan. Jahrb., Bd 24, p. 68. I 898.]

- Die Waldgrenzen in Süd-Russland. - Petrograd 1894. [In Russian with a German summary.]

—, Die süidrussischen Steppen. - Résult. Scient. Congr. Intern. Botan. Vienne 1905. Jena 1906.

TANsley, A. G., Types of British Vegetation. -- Cambridge 1911. 
Thurmans, Jules, Essai de Phytostatique appliqué à la chaine du Jura et aux contrees voisines. - Bern i 849 .

[Тӧвлевонм, А. F.,] Upplysningar till geologisk öfversiktskarta öfver Sreriges berggrund. - Sveriges Geolog. Undersökn., Ser. Ba, nr 6. Stockholm I90I.

Unger, Frans von, Über den Einfluss des Bodens auf die Vertheilung der Gewächse, nachgewiesen in der Vegetation des nordöstlichen Tirols. - Wien 1836 .

WAHLenberg, Göran, Flora lapponica. - Berlin 1812.

- De vegetatione et climate Helvetiae septentrionalis. - Zürich ${ }_{1} 8_{13}$.

—, Flora Carpatorum principalium. - Göttingen 18 I 4.

—- Flora Suecica. Ed. 2. - Upsala 1833-38. ("1833»).

WANGERIN, W., Die montanen Elemente in der Flora des nordostdeutschen Flachlandes. - Schrift. Naturforsch. Gesellsch. in Danzig, N. F., Bd 15, h. I and 2. Danzig 1920.

Warming, E., Den Danske Planteverdens historie efter Istiden. - Köbenhavn 1904.

- Dansk Plantevækst. I. Strandvegetationen. 2. Klitterne. -- Köbenhavn 1906 and 1907.

—- Oecology of plants. - Oxford 1909 .
und Graebner, P., Lehrbuch der ökologischen Pflanzengeographie. 3. Aufl. Berlin 1914-1917. (\$1914»).

Watson, H. C., Topographical Botany. $2:$ d ed. - London 1885.

Vidal DE LA Blache, P., Tableau de la géographie de la France. - In: E. Lavisse, Histoire de France illustrée. I: I. Paris I 903.

IVIEGNER, G., Boden und Bodenbildung in kolioidchemischer Betrachtung. - Dresden 1918.

Tierhapper, Fr., Conioselinum tataricum, neu für die Flora der Alpen. - Österreich. Botan. Zeitschr., Jahrg. I9ıг, Nr. I. Wien 19гі.

Wiesner, J., Untersuchungen über der Lichtgenuss der Pflanzen mit Rücksicht auf die Vegetation von Wien, Cairo und Buitenzorg (Java). - Sitz. ber. math, naturw. Kl. Akad. d. Wissensch. Abth. I. Bd 104. Wien r 895.

- Die Lichtgenuss der Pflanzen. - Leipzig 1907.

WiLldenow, C. L., Grundriss der Kräuterkunde. - Berlin 1792.

ZIEGLER, J., Ueber phänologische Beobachtungen und thermische Vegetations-Konstanten.

- Jahresber. d. Senckenberg. naturf. Gesellsch. für 1878/79. Frankfurt a. M. I 879 . 


\title{
APPENDIX I. \\ THE CONTINENTAL SPECIES IN THE FLORA OF SOUTH SWEDEN.
}

\author{
SLMMIRY ACCOUNTS OF THEIR ELROPEAN DISTRIBUTION
}

\section{REMARKS:}

I. The species are grouped according to their normal mode of occurrence in SouthEastern or Eastern Europe. The types of vegetation of which I have made use for this purpose are named and described on p. 233.

2. The types of distribution are indicated by figures, which are given in the outline on pp. $238-241$.

3. As to the European distribution area I have made an effort to state as exactly as possible its limits in Russia and its westerly or north-westerly limits in Central or Western Europe. For the rest, I must confine myself to referring to the taxonomic handbooks.

4. Being compelled to economize space as much as possible, I have made use of many abbreviations. To the following it may be necessary to supply explanations: a. N., S., E., W., NE., NIV., etc. = the North etc., the North-East etc. or the northern etc., the north-eastern etc.

b. $\mathrm{MI}=$ the middle part of a district; that is, a zone across a district between a northern and southern or eastern and western part of the district;

WM., EM. etc. = the western, eastern etc. part of such a zone.

c. C. = an area in the centre of a district.

d. Roman figures (capitals) are employed to indicate the abundance of a species within an area as follows: $I=$ very rare, II = rare - scattered, III = fairly common -- quite common.

e. The absence of a species in a district is denoted by ().

f. D. T. = the type of distribution.

g. V. T. = the type of vegetation.

4. To the statements about the Russian distribution there are given references to the literature by figures, to which a key is to be found in the list of literature below. Concerning the East-Russian governments of Perm, Vyatka, Kazan, Simbirsk, Samara, Ufa, and Orenburg, as well as the Baltic Provinces, Esthonia, Livonia, Courland, and Lithuania, however, no references are given, all statements in these cases being taken from the works of Korshinsky 1898 and Lehmann $1895-96$. If in other cases no references are given the statements are taken from the compilation of Herder 1890 . [The statements in this work, being taken, as it seems, without sufficient criticism often from too old and obviously dubious works, are to be looked upon very critically].

6. "Russia" is here used to cover the European part of the Russian Empire before I 9 14, except, however, Poland in its extension as a Russian principality and Fin- 
land together with East-Karelia [viz. in its extension as a phyto-geographical district according to, for instance, Conspectus Florae Fennicae in its latest parts and O. R. Holmberg, Hartmans Skandinaviens Flora, häfte I, 1922].

7. In the list of literature below are given all floristic works of which I have made use for my enquiries into the distribution of species; but works concerning Denmark, Norway, Sweden, and Finland are excluded. (These works will be given in a special part of this paper.)

The works are cited in a highly abbreviated form, but many of them are given in a more complete manner in the list on pp. $379 \mathrm{ff}$.

As to the publications of the learned socities mentioned below I have made use of abbreviations, as follows:

Brandenb. = Verhandl. d. botan. Vereins d. Provinz Brandenburg.

Dorpat Acta $=$ Acta Horti botanici Univers. Jurjevensis.

Dorpat Schrift. = Schriften d. Naturforsch. Gesellsch. bei d. Univers, zu Jurjev.

Dorpat Sitz $b$. = Sitzungsberichte d. Naturforsch. Gesellsch. bei d. Univers. zu Jurjev.

Engl. Jahrb. = Botanische Jahrbücher herausgegeben von A. Engler.

Forsch. $=$ Forschungen zur deutschen Landes- und Volkskunde.

Kazan $=$ Travaux Soc. Natural. à l'Univers. de Kazan.

Kharkov = Travaux Soc. Natural. à l'Univers. de Kharkov.

Kiev = Mémoirs Soc. Natural. de Kiev.

Kolozvart = Értesitö. Sitzungsber. d. Medizin.-Naturwissensch. Sect. d. Siebenbürg.

Museum-Vereins, 2, Naturwissensch. Abt.

Mag. Lap. = Magyar Botanikai Lapok.

Moscow = Bullet. Soc. Natural. de Moscow.

Odessa $=$ Zapiski novoryssiskago obsčestva estestvojspytatelej.

Petrogr. Bull. $=$ Bulletin de la Jardin imp. de St. Pétersbourg.

Petrogr. Acta $=$ Acta Horti Univers. Petropolitani.

Petrogr. Scripta $=$ Scripta botanica Horti Univers. Petropolitani.

Petrogr. Trav. = Travaux Soc. Natural. de St. Pétersbourg.

Prag $=$ Sitzungsber. d. Böhm. Gesellsch. f. Wissensch., Math.-naturw. Classe.

Riga $=$ Korrespondenzblatt d. Naturforsch.-Vereins zu Riga.

Veg. Erde $=$ Engler und Drude, Die Vegetation der Erde.

Wien = Sitzungsber. d. Math.-naturw. Kl. d. Akad. d. Wissensch. in Wien, Abth. I. $Z .-B .=$ Verhandl, der zoolog.-botan. Gesellsch. in Wien.

Ö. B. Z. = Österreich. botan. Zeitschr.

Ascherson und Graebner "1896". - Becker 1910. - Domin 1907. - Drude, Atlas der Pflanzenverbreitung. [Berghaus, Physikalischer Atlas, Abt. V.] Gotha 1887. Hayek 1904. - Hegi, Illustrierte Flora von Mitteleuropa mit besonderer Berücksichtigung von Deutschland, Oesterreich und der Schweiz. München r9o6-. - Hermann, Flora von Deutschland und Fennoskandinavien sowie von Island und Spitzbergen. Leipzig 1912. - Kenner, Monographia Pulmonariarum. Innsbruck 1878. - Kükenthal 1909. - Nyman, Conspectus Florae Europeae. Örebro I878-1890. - Schneider, Illustrierte Handbuch der Laubholzkunde. Jena 1906 and 1912. - Wolf, Monographie der Gattung Potentilla. Biblioth. Botan. Bd. I6, H. 71. Stuttgart 1908.

Russia. Flora caucasica critica, 1, 2, 3: $4-9,4: 2$ in "Tiflis, Botan. sad trudy», Vyp 9 and 10, r904-1913; $3: 3,4: 1$ and 6 in Petrogr. Trav. 3I-34, 1901-r 908. 
Gobi, Über die Wirkung der Waldaischen Höhe auf die geographische Verbreitung der Pflanzen im Zusammenhang mit einer Skizze der Flora des westlichen Theiles der Gouvernement Novgorod. Petrog. Trav. 7, I 876 [Also as a I)issert.]. In Russian. Herder I 892 . - Koeppen i 888 , is89. - Lehmann i 895 .

1: Alechin 1909. - 2: Id. I910. - 3: Id. I9 3, Dorpat Acta 14: I, Vladim. 4: Antonoy r 888, Petrog. Trav, 19, Novg. - 5: Bekelor' i 886, Petrogr. Scripta i: I, Ekaterinosl. - 6: Borozikov 1909. - 7: Chesterikor r909, Odessa 33, Khers. 8: Chirjaer I904, Khark. 38: 1, Khark. - 9: Id. I9I3, Khark. 46, Khark. 10: Drobor 1906, Petrogr. Trav. 25:3, Terr. Don. - 11: Engelhardt I866-67, Petrogr. Scripta I, Smol. - 12: Fedtshenko I 897 , Moscow I I, Pechora-distr. - 13: Filerov 1902. - 14: Id. 1910. - 15: Gilssen r899, Petrogr. 'Trav. 29, Petrogr. - 16: Golisyn 1905, Dorpat Acta 5: 4, Tula. - 17: Günther I880, Petrogr. Trav. I I, ()lonets. - 18: Ispolntov r 898, Petrogr. Trav. 28: 3, Pskov. - 19: Id. 1902, Dorpat Acta 3 , Taur. - 20: Id. 1905, Petrogr. Trav. 34, Novg. - 21: Ivanitzky 1882, Engl. Jahrb. 3, Vologda. - 22: Id. I 890 , kngl. Jahrb. i r, Vologda. - 23: Jaczerskij 1 895 , Moscow N. S. 9, Smol. - 24: Keller 1901, Kaz. 35: 4, Sarat. - 25: Kolmovsk 1 899, Petrogr. Trav. 29:3, Norg. - 26: Komarov i 896. - 27: Korshinsky i 898.

28: Kosso-Poljansky I91 1, Dorpat Acta I2, Voron. - 29: Id. I9 13, Dorpat Acta I4, Voron. - 30: Kossinsky ig I 3, Petrogr. Bull. I 3, Kostr. - 31: Id. I 9 15, Petrogr. Bull. I 5, Kostr. - 32: Knshevsky I9 1 2. - 33: Kultshitskaja \& Endaurov'a 1906. 34: Kupffer I 895, Dorpat Sitzb. I I, Courl, and Livon. - 35: Id. I 899, Riga 42, Courl. - 36: Id. 1905. - 37: Id. 1905, Riga 48, Esth., Liv., Courl. - 38: Id. 1907, Riga 50, Esth., Liv., Courl. - 39: Id. \& Sehbert 1904, Riga 47, Fsth. the Hoften Islands. - 40: Kuznecor' I 888 , Petrogr. Trav. I 9, Archang.: the districts of Shenkursk and Cholmogorsk. - 41: Lackschewilz \& Kupffer 1904, Riga 47, Esth., I.iv., Courl. - 42: Lilvinor "I 886 ", Moscow 4 I, N. S. I (1887), 2 (1889), Tamb. - 43: Meinshausen 1878. - 44: Michailoz'sky 1903. - 45: Miljutin 1889, Moscow N. S. 2, Moscow. - 46: Montrésor i 898 , Kiev I 5: 1-2, Kiev. - 47: Naumov 1 903. -- 48: Nenjukov 1902, Dorpat Acta 3: r, Niz. Norg. - 49: Id. I 9 I 2, Dorpat Acta 1 3: I, Niz. Novg. - 50: Noropokrozsky 1906. - 51: Id. 19 14. - 52: Paczoski i 890. 53: Id. "I 897 ". 54: Id. 1904. — 55: Id. I 908, Odessa 31, Taur. 56: Id. 1909, Odessa 34, Kiev. - 57: Id. 1909, Odessa 34, Khers. - 58: Perfiljer, 1908, Petrogr. Trav. 37, Vologda: Velsk-distr. - 59: Id. \& Chirjaev I9r 4, Khark. 47: r, Vologda: Vologda. — 60: Pelunnikor" "I897". - 61: Pohle rgo2. - 62: It. 1903. - 63: Id. 1907, Petrogr. Bull. 7: 1, Northern Russia (only Monocotyledonae).

64: Puring 1898, Petrogr. Trav. 28: 3, Pskov. - 65: Id. 1899, Ibid. 29: 3, Pskov.

66: Id. I900, Ibid. 30:3, Pskov. - 67: Rehmann i 87 I, Verhandl. d. Naturforsch. Verein in Brün 10 , the N. shore of the Black Sea. - 68: Saljesstii 1900. 69: Savenkov 19 14, Khark. 47: 1, Archang.: Pechora. - 70: Schmalhausen I886. 71: Selenezka 1906, Zapiski imp. novoryssiskago Univers. Odessa Io2, the Crimea. -

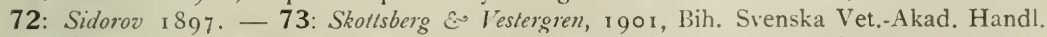
27, Osel. - 74: Sprygin 1900. - 75: Sukaczci 1902. - 76: 1d. 1903. 77: Taliev 1894, Kaz. 27:6, Niz. Novg. - 78: 1d. 1906, Petrogr. Bull. 6: 4, Niz. Novg. - 79: Timofeev 1904, Khark. 38: 1, Khark. - 80: L'grinsky 19 I 2, Khark. 45, Khark. - 81: Ustrjeczky 1906, Dorpat Acta 6: 4, Archang.: Pinega.distr. - 82: Zalessk!' I9 I 4, Khark. 47: I, Khark. - 83: Zinger r 910, Kiev I 9, Kiev. - 84: Akinfijer I 895 , Khark. 28 , Ekaterinosl. - 85: Krassnor i 886.

Poland and Galicia. Blocki, (). B. Z. 36 and $37,1886-1887$. Id., Mag. 
Lap. 7, 1908 (Lemberg). - Herbich, Z.-B. Iо, 1860. - Pax I9 1 8. - Rostafinski, Florae Polonicae Prodromus. Z.B. 22, I 872 . - Tomaschek, Z.-B. 9, I0, and I2, I 859 , I860, 1862 (Lemberg). - Woloszczak, Z.-B. 24, I874 (Javorov). - Zapalovicz, Conspectus Florae Galiciae criticus, T. I-3, Krakow i 906 - I 9 I I.

Balkan. Adamovicz, Veg. Erde I 1, I909. - Beck von Mannagetta, Veg. Erde 4, I901. - Boissier, Flora orientalis, Genève I $867-88$. -- Brandza, Flora Dobrogei, Bucuresci I 898 . - Fritsch, Z.-B. 44, I894. - Id., Mitteil. naturw. Vereins f. Steier-

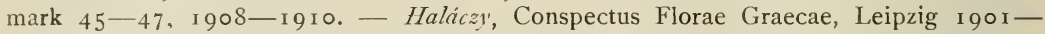
ig08. -- Kanitz, Plantas Romanae hujusque cognitas [Melleklet a Magyar Növenytani lapok 3-5, Évfolyamához], Klausenburg (Kolozvart) I 879-1881. — Murbeck, Lunds universitets årsskrift 27, I89 I (Bosnien, Hercegovina). — Pančic, Z.-B. 6, Serbien. Rohlena, Prag 1902, nrs 32 and 39 (Montenegro). - I'elenozsky, Flora Bulgarica, Prag I 89 I.

Austria-Hungary. Beck von Mannagctta, I890, L. Austria. - Id., I907, Eastern Alps. - Bela, Mag. Lap. 1 I, I9 I 2, N. Hung. - Budai, Mag. Lap. I 2, I 9 I 4, the Biikk-mountain. - Id., Mag. Lap. I 3, I 9 I 5, Komit. Borsod. - Čelakovsky', Prodromus der Flora von Böhmen, Prag 1867. - Chyzcr, Mag. Lap. 4, I905, N. Hung., espec. Komit. Zemplén. - Dalla Torre \& Samtheim, Flora der Gefürsteten Grafschaft Tirol, des Landes Vorarlberg und des Fürstenthumes Liechtenstein, 6: $\mathrm{x}-3$, Innsbruck 1906 - I912. - Domin, Prag 1902, nr. 58, 1902, Bohemia. - Duftschmid, Die Flora von Ober-Österreich, I: I-3, III, IV, Linz I $870-85 .-G o d r a$, O. B. Z. 22, I872, Peterwardiener Grenz-Regiments nr. 9. - Gönz, Kolozsvart I 5: 1, I890, Komit. Udvarhelyer. - Hay'ek, Flora von Steiermark, I and II: I, Berlin I908- I4. - Id., Die Pflanzendecke Österreich-Ungarns 1, Wien I9 I4-igr6. - Heuffel. Z.-B. 8, i 858, Banat. Temes. - Keller, Ö. B. Z. 1 5 , 1865, Komit. Neutra. - Kerner, Die Vegetationsverhältnisse des mittleren und östlichen Ungarns und angrenzenden Theile Siebenbürgens, Ö. B. Z. г 7-29, I 867-1879. - Id. I 888. — Lanyi, Mag. Lap. I 3, I 9 I 5 , Komit. Csongrad. - Markus, Ö. B. Z. I 5, I865, Neusohl. - Panćic, O. B. Z. 28. I 878, Banat. - Pax, Veg. Erde I and Io, I898 and I9o8, the Carpathians. Podpera, Z.-B. 54, I 904 , Bohem. - Pospichal, Flora des oesterreichischen Küstenlandes. Teschen 1 $897-99$. - Sagorski \&o Schneider, Flora der Central-Karpathen mit specieller Berücksichtigung der in der hohen Tatra vorkommenden Phanerogamen und GefässCryptogamen, I and II, Leipzig I891. - Prodan, Mag. Lap. 9, I9 10, Bácska. Id., Mag. Lap. I 3 and I 4, I9I5-I6, Bacs-Bodrog. - Schlosser Eo Furkaš-Vukotinović, Flora Croatica exhibens stirpes phanerogamas et vasculares cryptogamasque in Croatia, Slavonia et Dalmatia sponte crescunt etc. Agram i869. - Simonkai, Enumeratio florae Transsilvanicae vasculares critica. Budapest I886. - Thaisz, Mag. Lap. 10, I9 I I, Komit. Bereg.

Germany. Ascherson, Flora der Provinz Brandenb. I and 3, I864. - Ascherson S. Graebner 1898-99. - Beckhaus i 893. - Buchenau, Flora des nordwestdeutschen Tiefebene 1894. Kritische Nachträge 1904. - Döll, Flora von Baden, Carlsruhe I 857-62. - Drude I885. - Id., Isis Jahrg. I895. - Id., I902. - Eichler, Gradmann und Meigen, Ergebnisse der pflanzengeogr. Durchforsch. von Würtemb., Baden und Hohenzollern. Beilage Jahresh. Vereins Vaterl. Naturk. in Würtemb. und Mitteil. Bad. botan. Vereins. I-IV, I905-1907, I909. - Fiek i 88 I. - Fuckel, Nassaus Flora, I856. - Gradmann 1900, Schwäb. Alb. - Graebner I90 I, - Höck, Berichte d. deutsch. botan. Ges. I I, I 893. - Id. "I 896". - Kirchner, Flora von Stuttgart und Umgebung, i 888. - Klinggraeff I88I. - Marson, Flora von Neuvorpommern und der Insel Rügen und Usedom, 1869. - Niedenzu, August Garckes Illustrierte Flora 
von Deutschland. 21. Aufl,, 1912. - Prahl, Kritische Flora d. Prov. SchleswigHolstein. 2. Th., 1890. - Preiss 1911. - Id. 1912. - Id. 1921. - Kitschl, Flora des (irossherzogthums Posen, 1850 . - Schübler 1/artens, Flora von Würtemberg. Tübingen, $8_{34}$ - S Shulz, forsch. I1, I 898 . - Id., Ibid. I3, I90I. - Id., Ibid. 16, I907. - Vollman, Flora von Bayern. Stuttgart 1914. - Wïnsche E. Schorler,

I)ie Pflanzen Sachsens. I I. Aufl., I9 I 9.

Switzerland. Jaccard rS95. - Schinz \& Keller, Flora der Sichweiz, Th. I and 2. Zürich 1909 .

Italy. Bertoloni, Flora italica. Bologna $1833-54$. - Parlatore, Flora Italiana, vol. 6-io. Firenze $1884-1896$.

Spain. Willkomm \& Lange, Prodromus Florae Hispanicae. Stuttgart i 870-r880.

P'ortugal. Coutinho, A. I. P., Flora de Portugal. rgr3.

France. Acloque I903. - Ml., Flore du Sud-Ouest de la France et des Pyrénées. I 904. - Id., Flore de l'Ouest de la France. 1904. - Id., Flore du Nord-Est de la France. 1904. - Rouy \& Foucaud, Flore de France, 1893-19r3. L Thurmann 1849.

Belgium. Wildemand \&o Durand, Prodrome de la Flore Belge, T. III r 899.

Holland. Prodromus Florae Batavae, I: 1 1901; 1: 3 1904. - Garjeanne, Handboeck voor de nederlandsche Flora. Neppel 1907.

England. Hooker i 884. - Watson I 883. - Williams, Prodromi florae Britannicae specimen, P. I-IO, I90I-19I2.

Irland. Moore More, Contributions towards a Cybele Hibernica. Dublin I 866.

\section{STEPPE SPECIES.}

a. The halophytic steppe species.

Artemisia laciniata Willd. - Almost the whole of S. Sib. (27); in W. to NE. Orenb. Austria: Laasee; C. Germ.: Bernburg in Anhalt and, formerly, Artern in Thuring. Öland II (chiefly the S. part) - D. T. IV. Also V. T. I c.

Artemisia rupestris L. - Almost the whole of $\mathrm{S}$. Sib., reaching from this area a little inside the Ural Mountains in Orenb. and Ufa (27). - Esth.: Hapsal, the islands Moon and Ösel: Courl.: Tuckum. - C. Germ.: Bernburg in Anhalt, Artern and Borksleben in Thuring. - Öland III, Gotl. II. - D. T. IV.

Atriplex pedunculatum L. - Turkest.; S-most Russia: Polt. (70), Khers. (52, 67), Ekaterinosl. (72), Taurida (54), Terr. Don. (6), Astrakh. (70). - C. Germ. in the S. part of the Prov. Saxony. - On the shores of the Baltic in Denm.; SF. Swed.: Smål., Öland, Gotl., Skåne; Germ.: in E. to Greiswald (Kolberg?, cf. Preuss r 9 I 2, p. 96); on the E. Baltic shores very rare and, as far as I know, only recorded from Esth.: Hapsal and the islands Moon and Worms. On the shores of the North Sea: in SE-most Engl. I, Belg. I, Holl., NW. Germ., Denm., S. Swed.: Bohuslän-Skåne. D. T. I: 5 .

Bassia hisula (L.) Aschers. - Persia and Turkest. - See Plate 13. As to S. Russia I have made use of the statements in papers $32,54,55,67,70$. - D. T. I: 5 . [Lepidium latifolium L.] - Widely distrib. in the Turkest. and Pontic steppe distr. Spread in S. and C. Europe (especially on the coasts of the Mediterr.), probably, at least in $\mathrm{C}$. and $\mathrm{W}$. Europe, as an introduced plant. (cf. Busch 1913, p. I02). 
Drôme, and Alpes-Maritimes], St. Gallen, Rottweil, Kreuznach (on the Rhine), Grabfeld, Thuring., Magdeb., the Havel, and the Oder; in Cassub. I. In Silesia, the Kingd. Saxony, and Bavar. (except Grabfeld): o. SE-most Swed.: see the map p. 299; [Courl, formerly?] Esth.: Hapsal, Harrien, Kosch-Räsa. - D. T. I: I c. Also V. T. 1: c. Peucedanum oreoselinum (L.) Moench. - SW. and M. Russia; in N. and E. to Petrogr. (43), Pskov (18), [Tver, Smol., Moscow, Vladim.?], Mog. (53), Kaluga (14), Tula (16). N. Tamb. (42), Pensa (75), Sarat. (24), M. Simb., SE. Kaz.; [Taurida: o; Terr. Don. ?]. In C. Europe and the Baltic distr. in W. to: SE., C. and NE. France, the Saar-distr., Hessen (Butzbach), the Harz, Ehra, Wendland, SE. Holst., Bornh., Skåne I, Öland I, and Gotl. I. - D. T. II: 2 (- III: 2). Also V. T. r: c and 2.

Phleum Boehmeri Wib. - See Plates 5 and 18 . - D. T. II: 2 b. Also V. T. r: c.

Poa bulbosa L. - S. Russia; abund. in the steppe-zone, further N. rare and, probably, only as a colonist or accident. In M. Russia it is stated from Vilna (Hermann), Volh.: Shitomir (53), [Kiev: Radom.? (53)], Orel (68), Moscow, I (7o). Widely and often abundantly distrib. in S. and C. Europe [in almost the whole of France]. In the Baltic distr. lacking in large parts. Can be considered a real native only in a few of its localities in this district. It is found, probably only as a colonist in SE-most Engl.: Norfolk, the flat region of Belg., the Rhine-Province, Westphalia, and Hanover. In Denm. only on Bornh. In SE. Swed. abund. on Öland, much less on Gotl. and in E. Skåne in Alvar-pavement or in sandy places. As to the rest some scattered occurr. in the coast-region to the neighbourhood of Stockholm in the N., many times being a doubtless introduced colonist but sometimes appearing as a native. D. T. I: 4 .

Potentilla arenaria Borkh. - S. and M. Russia; in N. to Esth., Vilna (53), Minsk (53), Orel (14), Moscow (60), Ryaz. (53), Pensa (75), Niz. Novg. (48), S. Kaz. - In the lowlands of $\mathrm{C}$. Europe and in the Baltic distr. a few scattered minor areas or isolated occurr. In Switzerland, o; in Tirol, o (accord. to Dalla Torre \& Sarntheim). The IV-most occurr. in C. Europe are: Basel, Kolmar, Kreuznach, Bingen, Frankfort a/M., Würzburg, Rudolstadt, Erfurt, Nordhausen; as to the distribution in W. of the Baltic distr. see Plate 3 and 6. - D. T. I: c - II: 2. Also V. T. 2.

Potentilla rupestris L. - N. America; Sib. Alt., Baik., orient., and Dah.; Cauc., and Transcauc. (Ledebour). - S. and C. Europe; in W. and N. to C. Spain, the highlands in C. France (Ain, Rhône, Loire, Puy-de-Dôme, Haute Loire, Tarn), Alsace, SE. Belg., the valley of the Nahe, Eifel, the lower Lahne, the Harz, and Lusatia. In the Baltic distr. only in .NE. Germ. (in W. to Luckau, Neuzelle, Frankfort a. d. O., Buckow, and Schwedt), and S. Sived. (see the map p. 326) [and Grodno? (53)]. -- D. T. [IV].

Pulsatilla patens (L.) Mill. - Almost the whole of Russia; in the SE-most part, $\circ$; in N. recorded from the Pinega distr. of Archang. ( 62 and 81 ) and from the distr. on the upper Pechora on the river Uchta ( 12 ). - In the Danub. region and E-most C. Europe I; in W. to Lower Austr. and Bohem.; isolated farther in W. at Munich. In the Cassub, region in W. to C. Silesia, Lower Lusatia (Guben), C. Brandenb. (Trebbin, Köpenick and Pasewalk), W. Prussia (Neustadt); Gotl. I; Ångermanl. I; S. Finl. I (Tavastehus and the Karel. Isthmus). - D. T. II: I b. Also V. T. I : c, 2, 3 , and 6 [cf. Hayek 1904; Graebner 1901; Kupffer 1905, p. 68].

Ranunculus illyricus L. Turkest. - See Plate I 3. - D. T. I: I.

Silene viscosa (L.) Pers. - Turkest. S. Russian steppe distr.; in C. Russia rare as an accidental colonist; in N. to [Kiev? (53)] S. Pod. (53), Kursk ( 1 ), Tamb. (42), Sarat. (24), Simb., S. Kaz., and S. Perm. in the steppes. [Orel, Tula (16), Ryaz. (14), 
Kaluga (14), Moscow (6o), Vladim. (13), Niz. Novg. (77, 48), Volodga (2 I) as a co. lonist]. - In C. Europe only one or two occurr. in Bohem., probably as an accident. Distrib. on the shores of the S. Baltic Sea (see p. 325). - D. 'T. I: I.

Stipa pennata L. (= eupennata Aschers. \& Graebn.). - S. and SE. Russia; in N. to Volh.: Vladimir-Volynsk (70), Kiev (53), Chernig. (53), Kursk (r), Orel (r4), Moscow (6o), Niz. Novg. (48), NE. Kaz., S. Vyatka, S. Perm. - 'The distrib. in C. Europe seems not to be fully investigated, the species being confused with the S. European S. mediterranea (Trin. \& Rupr.). Accord. to Vollman S. eupennata is almost lacking in Bav. The occurr. in the region around the Middle Rhine and in N. Germ., however, would seem to belong to $S$. eupennata. It is recorded from France by Ascherson \& Graebner, but its distrib. in this region seems to be not yet determined. The mainpart of $S$. pennata coll. in S. France is certainly to be referred to $S$. mediterranea. Rouy only deals with the coll. species. In Germ. the WV. limit may be as follows: Alsace, Pfalz, Hessen, Thuring., the Harz, W. Brandenb., Garz and Pyritz in Pomer., and IV. Prussia on the Vistula. Outside the Danub., Austr., and Bohem. plains, however, there are only a few minor isolated areas or occurr.; in the Kingd. Saxony, o. - In S. Swed. it occurs in Västergötland very sparsely in two localities in Falbygden: the parishes of Vartofta-Åsaka (Bondegården) and Dala (Stenåsen); formerly also at Valtorp in the same district (cf. Sernander I 908). - D. T. [I: I c-I: 3].

Veronica spicata L. - See Plate I6 and the map p. 310. - D. T. II: 2. Also V. T. I: $\mathrm{C}$ and 2.

Viola pumila Chaix. - The distrib. would scarcely seem to be fully known at present. - S. Russia; accord. to Becker ( $19 \mathrm{Io}$ ) and other recent records in N. to Liv.:O Osel (Becker and 73), Kiev (Becker), Tula (16), Sarat. (Becker and 24), Niz. Novg. (49), Vladim. (3), S. Kaz., S. Perm. - In C. Europe in W. to Charente-Infer., Deux-Sèvres, Cher, Oise, Lorraine, Frankfort a. M., Magdeburg, and Lenzen. Becker (1. c.) records the species also from SE. England (Huntingdon). However, Williams does not mention it. In S. Swed. only on Öland, III and Gotl, III (not in Västergötl.), cf. pp. $2 S_{2}$ and 292. - D. T. I: 4-II: 2. Also V. T. I: c.

\section{c. The species of the meadow steppe.}

Adonis vernalis I. - See Plate 14. - D. T. I: I c.

Anemone silvestris L. - See Plate I 7. - D. T. II: 2. Also V. T. 3.

Asperula tinctoria L. - See Plates 5 and I 5. - D. T. I: I c-II: 2. Also V. T. 3. Aster linosyris (L.) Bernh. - S., especially SW., Russia; in N. to S. Minsk (53), Volh. (53), Polt. (53), Orel (53), S. Chernig. (53), Voron. (28), [Tamb.? (42)], Sarat. (24), Sarepta (70). - In almost the whole of S. and C. Europe; in NW. and N. to C. France, SE. Belg., Westphalia, the Harz, W. Brandenb., Penkun (on the Oder), N. Posen (Labishin); Öland II and Gotl. I. - D. T. I: 4.

Centaurea jacea L. - As a critical study of the Swed. types of this collective species, and also, as I suppose, of the Russian ones, has yet to be undertaken and as the species has been greatly spread by agency of man, I must confine myself to mentioning that the distrib. of the species as a native seems to follow the type II: 2 . Also V. T. 3 .

Crepis praemorsa (L.) Tausch. - See Plate 17 and the map p. 315. - D. T. II: 2 -III: 2. Also V. T. 3 .

Fragaria viridis Duch. - S. and M. Russia; in N. to NE. Petrogr. (I 5), W. Novg. (26), Kostr., S. Volodga (2 I), N. Vyatka, S. Perm. - Throughout S. and C. Europe; 
in W. to NE. Spain, almost the whole of France (in W. I), SE. Belg. I, Hanover I (Meppen, Harburg, Fallersleben), E. Holst., Jutl. (especially in E. and NE.), SE. Norw. (in NW. to, approximately, the Skiens-Fjord and Froen), S. Swed. in N. to SE. Värml. (Ölmehärad), Närike, SE. Västmanl., and SE-most Gästrikl., Finl.: Åland. - D. T. II: 2 b. Also V. T. 3 .

Inula ensifolia L. - SW. Russia; in N. to Volh. (53), Kiev (53), Polt. (53), Orei (53), Kursk (r), Tula (16), Tamb. (42). - In W. to N. Italy, Hung., Austr., Bav. (Deggendorf), Bohem., SIV. Poland, and Galic. - S. Swed.: Västergötl. at Österplana on Kinnekulle (cf. "Svensk Botanisk Tidskr." I 922 , h. I, p. I 42). - D. T. I: I (I: r b). [nula vrabelyiana Kern.], a transition form between I. ensifolia and I. salicina, occurs in S. Swed. on Gotl. (cf. Lindman in "Botaniska Notiser" rglo, pp. 3 I ff.).

Polygala comosa Schkuhr. - S. and M. Russia, in N. to NE. Petrogr. ( 15 ), [OlonetsKarel.] SW. Vologda (2I, 59). - - In W. to NE-most Spain, C. France (in NW. to Maine-et-Loire), SE. Belg., SE. Hanover (Fallersleben), Altmark (Arneburg), SE. Mecklenb. (Mirow and Teterow). SE. Swed. (see the map p. 3r6). Finl.: OlonetsKarel. I. - D. T. II: 2. Also V. T. 3.

Prunella grandiffora Jacq. - S. and M. Russia; in N. to Liv. (Kokenhusen), Vilna, N. Minsk (53), Mog. (53), Smol., Kaluga (14), Moscow (60), Ryaz., Tula (16), Pensa (75), Niz. Novg., S. Kaz., N. Ufa, S. Perm. - S. and C. Europe, in W. to NE. Spain, almost the whole of France (W.: I, NW-most: o); SE. Belg. (I); the RhineProv., NE. Westph., Altmark, E. Mecklenb.; Denm. (I) and S. Swed. (See Plate 6). D. T. II: 2 b. Also V. T. 3 .

Ranunculus polyanthemos L. - Almost throughout Russia; recorded in N. from the Pinega-distr., S. of the Kania-Penins. (62, 8I). - The species is abundantly spread in the $\mathrm{E}$. of $\mathrm{C}$. Europe and in the Cassub. distr. Its limit can not yet be accurately determined, however, probably because of the existence of transgrediant forms into $R$. nemorosus DC. R. polyanthemos is said to be lacking in Switzerland, the whole of France, Belg., Holl., and NIV. Germ. (e. g. in Hanover). In Scandin. where the true $R$. nemorosus seems to be lacking $R$. polyanthemos is widely distrib. (see p. $3 \mathrm{rg}$ ). D. T. II: 2 c. Also V. T. 3 .

Senecio integrifolizs (L.) Clairv. $[=S$. campestris (Retz) DC. $]$ - The distrib. would seem as yet, not to be accurately determined a critical taxonomic study of the species having still to be undertaken. - In Russia the species is said to be widely distrib. in the Meadow-Steppe distr. from Kiev (70) and Pod. (70) in W. to Niz. Novg. $(48,77)$, SE. Kaz., and S. Perm in NE. Besides, the species is said to occur in the Ural Mountains ["in rupibus vel decliviis lapidosis cum apricis, tum umbrosis atque in montibus usque ad regionem alpinam supra limitem arborum ascendit", Korshinsky I 898, p. 230] and to reach on this rout the coast of the Arctic Ocean. From there it seems to be spread eastwards in N. Sib., as well as westwards to NE-most Norw. in W. - It is found also i SE. and C. Europe, and in the western parts of the Baltic region, in general rare, in W. to [the C. Jura and the Vosges] Bav. (Augsburg, Lechfeld), the Lower Main, Thuring., and the centr. part of N. Germ.; in NE. Germ. only in E. Prussia (Sensburg), but a few occurr. also in Courl., Esth., and Petrogr. In SW. Scand. (see Plate 6). It also has an area in SE. Engl., in NW. to, approximately, a line from Dorset to N. Lincoln. - D. T. [II: 2]. Also V. T. 3.

Seseli libanotis (L.) Koch. - The species is somewhat polymorphus. In Sib. and E. Europe there exists a type, "sibirica L." Accord. to 70 , however, this type is not fully distinguishable from the more westerly type, an assertion very reasonable 
because of the chief character of the form being the lobateness of the leaves, a character in a high degree variable with the Umbelliferae. The Swedish type seems to be widely distrib. in SW. and C. Russia, reaching in E., at least, into Vladim. (13); in N. it is recorded from, at least, Petrogr. (43), perhaps SW. Archang. (40). As regards S. Russia I have seen reliable records from Ekaterinosl. (72), Taur. (54), and Khark. (47). - Throughout C. Europe; in NW. to SE-most Engl. (I), N. France (Seine-etInfer., Marne), C. Belg., the Rhine-Prov., Thuring. (Höxter), SE-most Hanover (Hildesheim), the Harz, Stassfurt, Stendal, Frankfort a. d. O., Bärwalde, Stettin (very rare, however, in N. Germ. W. of W. Prussia); farther in W. two isolated occurr.: Warnemünde and Heiligenhafen in E. Holst., to which there are to be added several stations in S. Denm. (see p. 334). SE. Swed. (see p. 334). - D. T. II: 2 b]. Also V. T. 3.

Trifolium montanum L. - S. and M. Russia; in N. to Petrogr. (43), Tver, Yarosl., W. Vologda (2 I), Kostr., S. Vyatka, C. Perm. - In W. to C. Spain, SE., C. and NE. France, SE. Belg., the Rhine-Prov., E. Westph., Hanover (the town), Gifhorn, Altmark, W. Brandenb., E. Necklenb. (Neubrandenburg and Warnemünde), E-most Holst. (Oldenburg); SE. Scand. (see the map on p. 301); S-most Finl.: Aland, the A bo. distr., Nyland, S. Tavastl., and Iadoga-Karel. - D. T. II: 2. Also V. T. 3.

Viola rupestris Schm. - Almost the whole of Russia; but it seems to be pretty rare or lacking in the S-most parts (I have seen records from Pod. (70), Kiev (53, 56), Khark. (79), Terr. Don. (70), Sarat. (24), W. Sam., and S. Orenb. - The whole of C. Europe (in the Alps abundantly spread); in W. to the highlands of SE. France, Lorraine, Bingen, Marburg, and the Harz. In the Baltic distr. in W. to Altmark, W. Brandenb. and Pomer. Widely distrib. in Scand. and Finl. (see the map on p. 3r9). It is recorded from N-most Engl. (Durham and Westmoreland, I). - D. T. II: 2 c-III: 2 c. Also V. T. 2 and 3 .

\section{SPECIES OF THIN PINE-FORESTS ON DRY SANDY SOIL.}

Astragalus arenarius L. - See Plate 19. - D. T. III: I.

Carex ericetorum L. - Almost throughout Russia, except the S-most part; in S. I have seen records from Volh. (53), Kiev (53), Chernig. (53), Khark. (47), Tamb. (42), Sarat. (24), W. Sam. In N. it is recorded as far as in [Lapp. Imandr.] Archang: on the Pinega (8I), W. Vologda (58) [E. Vologda: "sehr gemein" (2 I)]. -- It reaches its W. limit in E. and NE. France; it does not exist in Belg. and, probably, not in Holl., but nevertheless has a few occurr. in SE-most Engl.; in NIV. Germ. chiefly in the E. parts; in Denm. spread in Jutl., Zeal. and on Bornh.; in SE. Norw. to about Voss and Dovre: Kongsvold in NW.; in Swed. to Jämtl. (I) and Angermanl. (I) in N.; in almost the whole of Finl. (recorded in N. as far as Lapp. Inarensis). - D. T. II: 2 c -III: 2 c. Also V. T. I: c.

Dianthus arenarius L. - Accord. to Ascherson \& Graebner, the area seems to be a Cassub. one. The Russian distrib.-area, however, is at present undeterminable because of the existence of transition forms into other species. - The W. limit of the species is as follows: [Galicia] NW. Silesia (Grünberg), Frankfort a. d. O., Neudamm, Schwedt a. d. O., Garz, Wolgast. In the E., however, the species is lacking in the Pomer. and Prussian coast regions. In S-most Swed.: in Skåne and in W-most Blekinge. It does not exist in the county of Bohus, and, at least not nowadays in Hall. and Gotl.] In Finl. in the SE. and E. parts, I; in N. to Kuusamo $\left(66^{\circ} 30^{\prime}\right)$. - D. T. III: I b. 
Gypsophila fastigiata L. - See Plate 21. - I). T. III: $\mathbf{I}$ b.

Koeleria grandis (Bess.) Domin. - Accord. to Domin 1907, in WM. Russia; in S. to Volh., Kiev, and Chernig.; in E. to Moscow, in N. to the Pinega-distr. of the Gov. of Archang; in W. to Warsaw and Ledletz. - The species was observed in I92 I in S. Swed.: in E. Uppland, at Kapellskär in the parish of Rådmansö, by Erik Almquist; cf. Svensk Botanisk Tidskr. I 922 , h. 4. - D. 'T. III: I b.

Potentilla leucopolitana P. J. Müller. - The coll. P. collina is represented in the flora of SE. Swed. by several types, the most important of which probably is to be referred to the species mentioned. [I have in hand a fairly detailed study concerning the Swed. Potentillae collinae]. Accord. to Wolf I908, the distribution area of this species seems to be a Cassub. one, the centre of its area being located in Silesia, Poland, and E. and W. Prussia. I have seen the species in S. Swed. frequently on Öland and, besides, on Gotl., in SE. Småland, and Blekinge (Karlskrona and Kristianopel). - D. T. [III: I b].

Pulsatilla pratensis (L.) Mill. - Accord. to Hayek 1904, the Linnaean form (perhaps the only one in Swed.) has its area chiefly located in the Cassub. distr., reaching in W. to Posen, NE. Brandenb., E. Mecklenb., and S. Scand. (see the map on p. 333). This type is said to be replaced farther W. by the very allied "species" $P$. nigrescens Störck., which is distrib. in Bohem., Silesia, the Kingd. Saxony, Thuring., the Harz, Brandenb., W. Pomer., Mecklenb., Wendland, Schlesw., and Holst. Accord. to Ostenfeld I9II, both these types are to be found in Denm., "P. nigrescens", however, being the type more widely spread. Perhaps, this form also is to be found in Skane. I received one statement as to its existence there, but this needs verification. - D. T. [III: $\mathrm{I}$ b.].

\section{SPECIES OF THIN XEROPHYTIC FOLIFEROUS FOREST.}

[Agrimonia pilosa Ledeb.] - This Sarmatian species is said to have been found once on Oland at Kastlösa (cf. Svensk Botan. Tidskr. I918, p. 24I). The statement seems to me to need verification.

Ajuga genevensis L. - S. and M. Russia; seems to be distrib. chiefly in the zone of the "transitions-teppe"; in N. to Courl. and S. Liv., Vitebsk, Minsk (53), Kaluga (14), Moscow (6o), Vladim. (13), S. Vyatka, NE. Kaz. - It occurs in almost the whole of France. The NW. limit runs through C. Belg., S. Limburg, Eifel, on the Lahne, through E-most Westph., Wendland at Lauenburg, and Lübeck. In Scand. only in Skåne (I) - D. T. II: 2 b. Also V. T. $1: c$ and 2.

Cotoneaster melanocarpa Lodd. - Probably, the species is distrib. in almost the whole of S. Sib. and Russia (cf. 27, p. 148 and 53 , I, p. 203). In S. it is recorded from Odessa (7), Khers. (57), Ekaterinosl. (53), Taurida (53), Terr. Don. (53), Sarat. (24); in N. from [Lapp. Ross.] Archang. (53), SW. Vologda (59), N-most Perm. - Reaches its W. limit already in Transsylv. (several stations), in Poland (at least at Krakau), E. Prussia (Lück); but pretty widely distrib. in Scand. (see Plate 12); in Denm. only on Bornh.; E. Finl., in N. to Lapp. Ross.: Kantalaks, Ponoj etc. - D. T. II: I b[-II: 3 sub.-Arctic variant.]

Cynanchum vincetoxicum (L.) Pers. - See Plate 18 and the map p. 352. - D. T. II: 2 b. Also V. T. r: b. [Obs. As to the Dacian and N. Balkan. regions the map on Plate 18 may be erroneus; cf. Simonkai 1886.$]$

Dracocephalum Ruyschiana I. - See Plate 20. - D. T. [III: I.] Also V. T. I: c. 
Laserpitium latifoizum I. - W. Russia; in N!a, X. and S. to Esth., Lith.: Troki, Minsk: Minsk (53), S. Tver (53), Smol. (53), Kaluga (53), E. Tula (16), E. Orel (53), Kursk (53), Polt. (53), Bessar. (53). - It reaches its NW-European limit in SE. and C. France (Basses-Pyrénées, Tarn, Gironde, Deux-Sèvres, Plateau Central, Paris, Lorraine], Eifel, Hessen, Hildesheim, Neuhaldensleben, Neuruppin, Gollnow in l'omer., Zeal., and S. Norw., SE. Swed., SW-most Finl. (see Plate 12). - D. T. [III: 2, a Cassub.-Central European variant]. Also V. 'T. 6.

Lactuca quercina L. - The species is said to exist in two types: sagittata W. \& K. and stricta $\mathrm{W}$. \& K., the last-mentioned being the one represented in the S. Swed. flora. Accord. to Beck 1890 , however, sagittata is identical with var. inlegrifolia Bogenh. and is only a shadow modification of the Linnaean type. - L. "stricta W. \& K." is recorded from SW. Russia: Bessar. (70), Pod. (70), Khers. (7) [L. sagittata has a larger area in S. Russia.]; the mainpart of its distrib. is to be found in the Dacian and Danubian zone and in Lower Austria. Besides it is recorded from Czechoslov. (I), Unter-Franken (at Karlstadt), Thuring. II (in N. to the Harz and Barby), the Kingd. Saxony (Leipzig and Bernstadt), Gotl. (Lilla Karlsö). - 1). T. I: 2.

Potentilla fruticosa L. - Widely distrib. in N. America and almost the whole of Sib., reaching in $W$. into the Governments of Perm and Orenb. (27). - In the Baltic distr. in Courl., I (on the bank of the Abau river at Kandau, Klein-Dselden), NW. Esth., I (Fall, from Fähna to Kaddak), NE. Gotl., I (three occurr. in the parish of Hejnum), S. Oland II. -- In the W. Alps: the Maritime Alps on the French-Italian frontier, $1850-2550$ m. a. s. (S. Martin-Vesubia, Entracque, Valgieri). In the E. Pyrénées: several localities in the sub-Alpine and Alpine-regions from Basses-Pyrénées in W. In Gr. Brit. in NW. York., Durham, Westmorel., and Cumberl., I. In W. Ireland in N. Clare and Galway, I. - D. T. IV.

Pulmonaria angustifolia L. (cf. Kerner 1878 , p. 3). - SW. and M. Russia; in S. to S. Pod. (Kerner), Kiev $(53,70)$, Polt. (70), Khark. (47), Kursk (Kerner), Tamb. (Kerner), Sarat. (24), W. Sam.; in N. to Esth. (Fall), Dorpat, the Valdai-Hill (Kerner), Smol., Moscow (60), SE. Vladim. (13), ["Kazan-Perm" (Kerner)], Pensa (Kerner), Simb. (Kerner). - Widely distrib. in C. Europe; in W. to SE. France [Tarn, Cantal, Puy-deDôme, Saône-et-Loire, Côte-d'Or], Baden (the plain on the Rhine), Hessen (to Rheingau and Kassel), the Harz (Huy), Altmark (Salzwedel), Brandenb., I (in NW. to Nauen, Oderberg and Schwedt), Pomer. (Garz and Püritz), Zeal., and S. Swed. (see Plate 4). Further in W. from this boundary it occurs isolated in two localities in NW. France (Normandy) and in a few localities in S-most Engl. on the opposite side of the Channel in Hampshire, Dorset and on the Isle of Wight (Williams). - D. T. II: 2-III: 2. Also V. T. r: c.

Rosa Jundzillii Bess. - Accord. to Ascherson und Graebner: [Trans.-Caucasia, Arm.] S. Russia; "durch den grössten Theil des Gebites," [i. e. C. Europe, Hung., N. Balk.] "im südlichen und nördlichen Theile selten oder fehlend." - S. Swed: Gotl. on L. Karlsö.

Vicia cassubica L. - SW. and M. Russia; in S. to, approximately, Bessar., [the Crimea $(70,53)$ ] Kiev (53), N. Chernig. (53), [Khark., Terr. Don. and Voron.?] Orel (53), Tula (16), Tamb. (42), Sarat. (24), M. Simb., SW. Orenb.; in N. to SW. Esth. (39), Vilna (53), Vitebsk (Hermann), N. Minsk (53), Mog. (53), Smol., Tver, Yarosl. (53), Moscow (60), Vladim. (13), and Kaz. Besides, it occurs in Cauc. (70, 53). Within this extensive area, however, the species seems to be absent or to be rare in many parts. - In the S. of the C. European mountains distrib. westwards to C. Spain; in 
N., however, only in NE. part of $a$. Europe, in an isolated area of C. France, and in the Baltic region. Its $W$. limit in C. Europe and in the Baltic distr. is as follows: Lower Austria, N. Bav., Pfalz, Hanau, W. Thuring. (Rothenburg), the Harz, Hildesheim, Celle, Wendland, Lauenburg, Lïbeck (Steinburg), Schleswig (Midsunde), NE. Jutl., S-most Norw. (Christiansand-Lyngör, Bamle), S. Swed. (see the map p. 346). The isolated area in C. France includes, wholly or partly: Maine-et-Loire, Indre-et-Loire, Indre, Vienne, Vendée, Gironde, Dordogne. - D. T. III: 2.

Vicia pisiformis L. - S. and M. Russia (rare in the steppe distr.); in N. to Vilna, S. Minsk (53), Orel (53), S. Moscow (6o), SE. Vladim. (13), Niz. Novg. (77), NE. Kaz., SE. Vyatka, S. Perm. - In C. Europe and the Baltic distr. in W. to: Wallis (Fully), Côte-d'Or, Haute-Saône, Haute-Marne, Marne, Meuse, the Rhine-Province (the valley of the Aar), Nassau (Wetzlar), Kassel, Hameln, Hildesheim, Braunschweig, Neuhaldensleben, Arneburg, Schwerin, Templin, Neubrandenburg, Ueckermünde, SE. Norw., and C. Swed. (see Plate 12). - D. T. II: 2.

Vicia tenuifolia Roth. - S. and M. Russia; in N. to Poland, Liv., Grodno (53), Minsk (53), Mogil. (53), Orel (53, 14), Kaluga (14, 70), Tula (16), Niz. Novg. (77, $48)$, S. Vyatka, S. Perm. - In W. Europe in almost the whole of France; lacking, however, in Switzerl. and Tirol. In NW. to Lorraine (Jura), the valley of the Nahe and Lahn, the Harz, Braunschweig, Neuhaldensleben, Tangermünde, Havelberg, Grabow, Dassow, SE-most Holstein, E. Schleswig, the island Alsen, Jutl., [Göteborg] Skåne II, SE-most Småland I, Östergötland I, Öland III, Gotl. II. - D. T. II: 2 b.

Viola elatior Fr. - Seems to be widely distrib. in S. and M. Russia. In N. to Esth., Liv. (Becker), Grodno (53), Mog. (53), Kaluga (Becker), S. Moscow (60), Vladim. (г3), Niz. Novg. (7i), S. Vyatka, S. Perm. - In C. Europe in W. to E. France [from Ain and Isère in S. to Seine-et-Marne (I), Marne, Aube, and Lorraine in N.], the M. Rhine (e. g. at Bingen, Mainz, Speier), Unter-Franken (Schweinfurt), Thuring., Magdeb., in Saxony, and Silesia [? in N. Germ. as to the rest]; Öland II. - D. T. II: 2 . Also V. T. I: $\mathrm{c}$ and 4 .

\section{SPECIES OF THE FLOOD MEADOWS.}

Cnidium venosum (Hoffm.) Koch. - See Plate 20. - D. T. III: ז. Also V. T. 6. Dianthus superbus L. - SW., M. and N. Russia; I have seen recent records as under. In SE.: Volh. $(53,70)$, Kiev $(53,70)$, Polt. (70), N. Khark. $(47,79,82)$, Ekaterinosl. (72), Terr. Don. (70), S. Sarat. (24), SIV. Simb., E. Ufa; in N.: the mouth of Pechora $\left(\mathbf{1}_{2}, 69\right)$, the Kania-Penins. $(62,81)$, and the whole of the Russ. and Fenn. Lappl. to N-most Norw.: the Porsanger-Fjord and the neighbourhood of Haparanda in W. - Its W. limit in Europe runs as follows: N. Spain, Gironde, Landes, the Pyrénees and the Cevennes, Auvergne on the Allier, Indre, Cher, Paris, Burgund, on the Upper Saône, the Vosges, Eifel, Wetterau, Reinhardswald, Hildesheim, Schnackenburg, Schleswig, NE. Jutl., S. Hall., Skåne. In Finl. in N. and E.; in W. not S. of C. Österbotten. - D. T. III: 2 c.

Inula bratannica L. - Almost the whole of Russia; in N. to Petrogr.: Novo-Ladoga (r5), Olonets-Karel. (Hermann), S-most Archang. at $62^{\circ}(40)$, the whole of Vologda (2I). - In W. to NE. Spain, C. and NE. France (Auvergne, Châtellerault, Paris, Marne), SE. Belg. (the valley of the Meuse), Holl., NW. Germ. (on the rivers), S. Jutl. and the Danish Islands, S-most Swed.: S. Hall., Skåne, Öland, and Gotl. - D. T. II: 4 . 
Ononis arvensis I. (= hircina Jacq.). - See Plate 19. - D. 'I. II: 3.

Petasites spurius (Retz.) Rchb. - S. and M. Russia, but rare, as it seems, in SW.; in N. to Petrogr.: on the Luga (43), S. Novg. (25), SW-most Archang.: Sydromskaia $62^{\circ}(40)$, the whole E. of Vologda (2 I). - Outside Russia only in Dobrudsha, Transsylv., Poland on the Vistula, N. Germ. On the rivers and the seashores; in S. to the Warthe, Küstrin on the Oder, Spandau on the Havel, Dessau on the Elbe, Kalbe, and Stassfurt on the Saale; in IV. to the mouth of Elbe.], Denm. on the islands Falster, Möen, Zeal., and Bornh. (on the Baltic shores), S-most Swed.: in Skane (a few occurr. on the S. sea-shore and on the shore of the lake Ringsjön) and on Oland (one occurr. on the shore of the Strait of Kalmar). - I). 'T'. II: $\mathbf{I}$.

Scutellaria hastifolia I. - Cauc. SW. Russia, in N. and E. to Petrogr. (43), Vilna, Smol., Moscow (6o), Vladim. (I 3), Kostr., S. Vyatka, Simb., Sarat. (24). Voron., T'err. Don. - In W. to NE. Spain, SE. and C. France the valleys of the Rhone and the Loire (from Nevers to Nantes)], Pfaiz, Hunnsrück, Siegen, Oberhessen, NW. Harz, $\mathrm{N}$. of Magdeburg, Wendland, the mouths of the Elbe and the Weser; SE. Swed. (see the map on Plate Io), S-most Finl. Lacking in S. Germ. S. of [Austr.] Lower Bav., Franken, and Pfalz. - D. T. II: 2. Also V. T. 8.

Veronica longifolia L. Throughout Russia. Pretty abundantly spread in the regions around the Baltic Sea; in NW. Germ II, in Denm. (Jutl. and Schleswig) I; Swed. see p. 364; Norw. in SE. (to Lillehammar in N.) and in the N-most part from Alten and Inner Finmarken eastwards. C. Europe pretty rare in lower regions (not in the Alps and the Carpathians) reaching its W. limit already in the valley of the Rhine (not in France and ?Belg.). - D. 'T. II: $3-4$, sub-Arctic variant.

\section{SPECIES FOUND IN CONIFEROUS FORESTS.}

Chimaphila umbellata (L.) Nutt. - M. Russia, in S. to Volh. (53), Kiev (53), Polt. (70), Khark. (8, 47), Kursk (70), Tamb. (42), Sarat. (24), S. Sam., N. Orenb.; in N. to S. Petrogr. (43), S. Novg. (26), Tver, Yarosl., Kostr., N. Vyatka, C. Perm $\left(59^{\circ}\right)$. - In W. to Zürich (not in the Alps), Baden (the valley of the Rhine), Mainz, Giessen. Göttingen, Hanover (the town), Celle, Lïneburg, SE. Holst., Zeal., SE. Norw., S. Swed, [See the map on Plate I 2], SW. Finl. [in NE. to N. Savolaks and N. Karel.] - D. 'T. III: 2 .

Geranium bohemicum L. - In general rare in W. and C. Russia; I have seen records from Pod. (53), and Voron. (53), [Khers ?], Lith., Courl. (35), Pskov (1 8), Petrogr. (43), W. Novg. (26), [Olonets (1 7)], E. Moscow (60), Vladim. (1 3), Orenb. N. Balkan, as it seems, II. A few scattered occurrences in Hung., Galic., and in the SE. parts of C. Europe [Tyrol, Switzerl., Bohem., and Upper-Lusatia (at Rothenburg)]; in S. Scandin. (see the map on Plate Io), S. Finl., in N. to Satakunta, S. Tavastl., S. Savolaks, and Onega-Karelia. - D. T. [III: I].

Picea abies (L.) Karst. - D. T. III: 2 c.

Pinus silvestris L. - D. T. III: $3 \mathrm{~b}-\mathrm{II}: 2 \mathrm{c}$. - See the maps in the works of e. g. Drude I887, Dengler I904 and 191 2, Koeppen 1889, G. Andersson I896, Hesselman \& Schotte 1906, Hemberg I904 etc.

Pyrola chlorantha Sw. - M. and N. Russia; in S. approximately to Volh. (53), Kiev (53), Chernig. (70), Khark. (9), Kursk (70), Tamb. (42), Sarat. (24). WV. Sam., SE. Ufa, N. Orenb. - In Plate 22 is shown the W. and N. limits in Europe. D. T. III: 3 b (-II: 2 c). Also V. T. 6 . 


\section{SPECIES FOUND IN MESOPHYTIC THIN FORESTS.}

Calamagrostis anundinacea (L.) Roth. - Cauc. M. and N. Russia; in S. to Pod. (70), Kiev (53), Khark. (70), [Terr. Don. ?] Tamb. (42), Sarat. (24), W. Sam., SW. Ufa, S. Orenb. - As to the W. and N. limit in Europe see Plate 22. - D. T. III: 2. Also V. T. 3 and 5 .

Campanula cervicaria L. - (S.) M. Russia; in S. to [Bessar. and Khers.?] Volh. (53), Kiev (53), Ekaterinosl. (70), Khark. (47, 82), Kursk (1), Voron. (28), Tamb. (42), Tula (16), S. Simb., M. Sam., S. Orenb.; in N. to [Olonets; see the map on Plate I I ], E. Novg. (4), almost the whole of Vologda (2 I), N. Perm $\left(60^{\circ} 30^{\prime}\right)$. - In W. and NW. to the departements of $\mathrm{H}^{\text {te }}$ Savoie, Savoie, Rhône, Loire, Puy-de-Dôme, Cher, Indre, Loiret, Aube, Marne, and Ardennes; further on to Eifel, the Hunsrück, the valley of the Lahn, Lippe, Springe, Hildesheim, Braunschweig, Magdeburg, Pritzwalk, Kremmen, Prenzlau, Garz, Stettin. - As to the distrib. in Scand. North see Plate I I. D. T. II: 2 - III: 2 . Also V. T. 3 and 4 .

Campanula persicifolia L. - Almost the whole of Russia; in S. less abundant (I have not seen statements from Taur., Stauropol, and S. Sarat.); in N. to (Olonets) NE. Novg. (62, 63), SW. Vologda (19), M. Vyatka, M. Perm. - In W. Europe it is lacking in the Brit. Isl. and in the flat regions of NW. France, Belg., and Holl. In Hanover a few occur.; SE. Holst.; in Jutl. II, in SE. Norw. (to Slidre and Ringebu in N.), in S. Swed. and S. Norrl. (in N. to C. Dalarne and S. Angermanl.), S. Finl. (in N. to S. Österbotten, N. Tavastl., C. Savolaks, and Onega-Karelia. - D. T. II: 2 b (- III: 3 ). Also V. T. 3 and 4 .

Heracleum sibiricum L. - Almost the whole of Russia; reported from the Kania Peninsula $(46,35)$ and in the whole of the Pechora-distr. (59). - It reaches its SW. limit in C. Europe, where, however, its distrib. seems not to be definitely determinated because of confusion between it and the W. European H. sphondylium L. (branca ursina All., accord. to Hermann 1912). It is not reported from Tyrol and Switzerl. In Bav. a few occurr. in the Alps (to Allgäu in W.), in Ober-Pfalz and Ober-Franken; in the Rhine-Prov. at Gummersbach (Berghaus); it is not found in Hanover; in W. Brandenb.? (accord, to Ascherson \& Graebner 1. c.). In Holst. at Altona and in the Propstei (Prahl I 890). It occurs in Denm., but the nature of its distrib. seems not yet to be established. In Norw. in N. to $68^{\circ} 35^{\prime}$ (Trondenes), lacking, however, in the western coast-region. In Swed. especially in the E. and C. parts, in N. to Jämtl. and Medelpad. In Finl. in N. to M. Österbotten, Kajana, Keret-Karel., Imandra-Lappm., and the Kola Peninsula. - - D. T. II: 2 c - II: 2 . Also V. T. 4.

Inula salicina L. - In almost the whole of Russia; in N. to [SE. Olonets ( 17 )] SW. Archang.: Shenkursk (40), Vologda: Ust-Syssolsk (21), M. Perm (60 $\left.30^{\prime}\right)$. - It is lacking in the flat regions of Belg., Holl., and NW. Germ. (not found in Hanover); also in Gr. Brit. but it has oné, very remarkable occurr. on Irel. (Galway: Lough Derg near Portumna). It is found in SE. Holst. and in great parts of Denm. (not in Schleswig), in SE. Norw. [to the Skiens Fjord and Hedemarken $\left(60^{\circ} 42^{\prime}\right)$ in W. and N.], in S. Swed. (see Plate 7), in S. and E. Finl. (Åbo, Tavastehus, Pomoric-Karel.). - D. T. II: 2 b Also V. T. 3 and 4 .

Luzula pallescens (Wg.) Bess. - Concerning this species I need only refer to the paper of Samuelsson, shortly to be published.

Melampyrum nemorosum L. - See Plates 8, 9, 10, and I6. - D. T. II: 2 -III: 2. Also V. T. 3 . 
Scorzonera hunilis L. - W. and C. Russia; in S., E., and N. to Bessar., Kiev (53), Chernig. (53), Khark. (80), Voron. (29), Tamb. (42), Tula (16), Ryaz. (27), Moscow (6o), Smol., Wr. Pskov (I8), P'etrogr. (43). - In W. Europe it is lacking on the Brit. Isl. and in the flat regions of the NW. European mainland. In W. (ierm. its boundaries are remarkable: (SE. Belg.) Pfalz (Hochwald), Kreuznach, Unter-Schwaben, OberFranken, the Khön, the Thuring. Forest, the Hainleste, Halle, Zerbst, Magdeb., Hanover (the town), the Aller, and the E. part of Friesland. - Distrib. in the whole of Denm., in SE. Norw. (the Amts of Christiansand and of Smaalene), in S. Swed. (in N. to SE. Dalarne and S. Gästrikl.), and in S-most Finl. (Aboland, Nyland, S. Karel., and Karel. Isthm. - D. 'T. III: 3 .

Selinum carvifolia L. - M. Russia; in S. to Volh. (53), N. Pod. (70), [Kiev and Chernig.? (53)], Polt. (70), Khark.: Roublevka (47), Kursk (1), Tamb. (42), Sarat. (24), M. Sam., SW. Ufa, S. Perm; in N. to [Karel. Isthmus], Petrogr. (43), W. Pskov (I 8), Novg., Kostr., Vologda (the town; 59), N. Vyatka, M. Perm. - In NW. Europe it is lacking in the central plateau of France, on the Brit. Isl. (There are one or two uncertain reports from E. Engl.: N. Lincoln and (ambridge.), WV. Belg., and Holl. In NW. Germ. in W. to SE. Hanover, Hamb., and E. Holst. Widely distrib. in Denm., in SE-most Norw. (around the Christiania Fjord); in S. Swed. (see Plate 7); S-most Finl. (in Aboland, Nyland, S. Karelia, Karel. Isthmus). - D. T. III: 3. Also V. T. 4.

Thalictrum simplex L. - As a taxonomic critical study of this species has still to be undertaken, it is at present impossible to determine its distribution. Probably, the S. Swed. species is an E. European one, which is distrib. over almost the whole of Russia and rare in the E. part of C. Europe and in N. Germ. (in W. to Nauen and Usedom accord. to Ascherson \& Graebner 1898). [In SW. and C. Europe a very closely allied species, Th. Bauhini Crantz is pretty widely distributed.] In Denm. the S. Swed. type occurs pretty rarely, chiefly on Bornh., and Zeal., and in NE. Jutl. If the form »Th. rariflorum Fr.» is included, it is distrib. over almost the whole of Scandin. and Finl. (cf. Hjelt, Conspectus Vol. iii, Pars ii, p. I6o). - D. T. [II: I b - II: 2 c]. Also V. T 3 and 4 .

Trifolıum spadiceum L. - M. Russia, in S. to N. Pod. (70), N. Kiev (70), Chernig. (70), Khark. (80), Voron., Tamb. (42), Pensa, N. Simb., E. Ufa, N. Orenb.; in N. to [Onega-Karel.], Archang.: Shenkursk (40), the whole of Vologda (2 I), N. Perm. - In W. to NE. Spain, the highlands of SE. France (to Auvergne and Doubs in NIV.), the Rhine-Province (Venn), Eifel, the Rhön, the Thuring. Forest. On the N. Germ. plain it occurs rarely as a colonist. It is not yet reported from Hanover; but it is reported from Holst. and Zeal. by Prahl 1890 and Lange 1897 . In general as a colonist, it is distrib. in C. Swed. and S. Norrl.; in S. to Oland (where it occurs, as it seems, as a native in wood-meadows), Östergötl. and Västergötl.; in N. still pretty abundantly in Medelpad and is observed in $\mathrm{N}$. as far as Norrbotten in Nederluleå. In Finl. in $\mathrm{N}$. to Österbotten, Kuusamo, and Onega-Karel. - D. T. III: 2. Also V. T. 4 .

\section{GROVE SPECIES.}

Acer platanoides L. - S. and M. Russia; in SE, reported from Terr. Don. (70), S. Sam., and SW. Orenb.; in N. to [Olonets: SWI. of the Lake Onega; "in forests" (I 7)] NE. Novg. [as an undoubted native observed only once (4)], S. Vologda ["strauchartig und blüht nicht, aber unzweifelhaft wild. Zwischen $59^{\circ}$ und $60^{\circ \prime \prime}(22)$ ], Vyatka: "frequens", C. Perm. - In NW. Europe it reaches its limit in NE-Spain, the highlands of E. and 
C. France (the species being often a fugitive from cultivation its distrib. as a native can hardly be determined), SE. Belg., Sauerland, the Deister, Neuhaldensleben, Mecklenb. It occurs sparsely in Denm.: S. Jutl., Falster, Zeal., and Bornh.; in SE. Norw. (in N. to Voss and Storelvdal); S. Norrl. (see the map in Andersson \& Birger 1912); in S. Finl. pretty rare (in N. to Satakunta, S. Savolaks, and Olonets-Karel.). - D. T. II: 3 - III: 3 .

Anemone hepatica L. - [See Ulbrich, Engler's Botan. Jahrb. Bd. I 8]. WM. Russia in S., E., and N. to Pod. (53), Kiev (53.), Chernig. (53), Mogil. (53), Smol. (23), NE. Kaluga (Flerov r 9 ro, pp. 484 ff.), [Ryaz.] Vladim. (r 3 ), Yarosl., SW. Vologda: Grjassovetz (2 I), Tver, W. Pskov (I8), Petrogr. (43). - In W. and NW. to SE. France: in the Vosges, Bourgogne, in the departments of: Nyons, Var, Bouches-du-Rhône, Gard, Aveyron, Lozère; in the Corbières and the Pyrénées, in Landes; [it is said also to have isolated occurr. in Normandy and in the neighbourh. of Paris, (Rouy)], Lothr., Bingen, Hessen: Herborn, E. Westph., Hanover: Soltau, Holst., almost the whole of Denm. (see the map in Ostenfeld 1911 ), Norw. (in N. to Bodö, $67^{\circ} 16^{\prime}-17^{\prime}$; in the W. coast region to Hardanger in N., I), S. Norrl. (in N. to N. Dalarne and Lule Lappmark). SW. Finl. in N. to N. Satakunta (perhaps, S. Österbotten: Bötom), S. Tavastl., S. Savolaks, LadogaKarel. - D. T. III: 2 b - III: 3 (a Cassubian variant).

Anemone ranunculoides L. - (See Ulbrich l. c.). - Cauc. Almost the whole of Russia; in S. I have seen reports from Khers. (70), Ekaterinosl. (5), Khark. (e. g. 79), Terr. Don. (e. g. $5 \mathrm{I}$ ), Sarat. (24), the whole of Sam. and Orenb.; in N. to [Olonets] Archang. : on the Pinega S. of the Kania Peninsula (6I, 8I), W. Vologda (2 I, 59), Vyatka: Vyatka, S. (M.?) Perm. - In W. and NW. Europe it occurs in E. and NE. France [reported also from W. France: Landes, Gironde, and Normandy (Rouy)], C. Belg., SE. Holl., Osnabrück, SE. Hanover (I), E. Holst., in large parts of Denm. (see the map in Ostenfeld I III), in SE. and (in a few scattered areas) N. Norw., in N. to the Maalselv and the Bals Fjord, $69^{\circ} 4 \mathrm{I}^{\prime}$; in S. Swed. (see p. 368 ) and S. Norrl. (in N. to Jämtl., I and Ångermanl., I), S. Finl. in N. to Satakunta, S. Tavastl., and Olonets (perhaps Onega) -Karelia. - D. T. II: 2 - III: 3 b.

Bromus Benekeni (Lge.) Syme. - S. and M. Russia; I have seen reports in S. from Bessar., Khers. (70), Ekaterinosl. (72), Khark. (e. g. 79), Voron., Sarat. (24), Pensa (74), Sarepta (70), SE. Simb., SE. Kaz., E. Ufa, S. Perm; in N. to Esth., N. Pskov: Porchov (18), Vilna, Minsk (53), S. Mogil. (53), Kaluga (70), Moscow (60), [Kostr.] Vladim.: Vladimir (13), Niz. Novg., SW. Kaz., S. Perm. - As the species is often confused with the W. species B. ramosus, its W. limit is not yet accurately determined. Accord. to Lange (Overs. over Kongl. Danske Vidensk. Selsk. Forhandl. I 873, 2, pp. 85 ff.) it is found in SE. France: Lozère and in the neighbourh. of Belfort; in W. Switzerl. at Geneva), in W. Germ. in Baden, Hessen., Westph. (Lippstadt), Harz at Thale, Prov. Saxony (e. g. Helmstedt, Neuhaldensleben), C. Brandenb., Rügen. As to the distrib. in the Scandin. North see the map in Samuelsson 1922 a. - D. T. III: 2 (- II: 2 ).

Corydalis cava Schwg. \& K. - I am not sure of its distrib. in Russia. Accord. to the statements I have seen, its occurr. are in general pretty rare in SW. and WM. Russia; in S., E. and N. to Bessar. (70), Khers. (70), Kiev (53), Chernig. (53), Kursk (70), Terr. Don. (70), [Sarepta (70)], Moscow (60), Kaluga, Smol. (1 I), Mogil. (53), S. Minsk (53), Vilna, SW. Courl. (4I). - In W. to NE. and C. Spain, SE. France (in W. and N. to Ain the French Jura, Saône, and Lothr.), the Rhine-Prov., Westph., [Hanover: a native ?], E. Holst., Denm. (it is found in all the provinces, but in many districts it is not common), Skåne, Öland, [NE. Smål.: S. Tjust, V. Ed (this report needs con- 
firmation). As a relic of former cultivation it occurs in some places further to the $\mathrm{N}$. of SE. Swed.). - I). T. II: 2 (a Cassubian variant) - III: 2 b.

[Corydalis solida Sw.]. - As a real native this species does not exist in Swed., but it might be said to be represented in the Swed. flora by the very closely allied species C. laxa lir., which in certain respects holds an intermediate position between C. solida and the Central European C: pumila Rchb. (See Fries, Nov. florae sueciae. Mantissa tertia, $1842-45$ ). C. laxa occurs in Swed. only in the E-most part of C. Swed., in Uppl. and Södermanl. It is also reported from Alland and the SW. Finnish mainland. However, it is said in this region not to be distinguishable from $\mathrm{C}$. solida the two species being merged into each other. A close investigation of this remarkable species has still to be undertaken.

Gagea minima (L.) Ker-Gawler. - In S. and II. Russia; in N. to Olonets (71) Archang.: between the Pinega and the Mesen, "in woods" (62), E. Vologda: "widely distrib. as an introduced plant" (2I), S. Perm. - In W. to W. Switzerl., Ingolstadt, Schweinfurt, Thuring., Göttingen, Neuhaldensleben, lirankfort a. d. Oder, Pomer., Mecklenb. at Waren and Doberan (near Rostock), E. Holst. (a few occur.); I lenm. II. (Schleswig o); Norw.: the neighbourh. of Christiania and at Bergen (a native ?); Swed., in N. to S. Värml., SE. Dalarne, and the coast region of Norrland (in N. to Västerbotten: Umeå as a fugitive from cultivation or introduced.); S. Finl., in N. to S. Osterbotten $\left(63^{\circ}\right)$, S. Tavastl., Olonets-Karel. - I). T. II: 2 c. Also I. T. 3 and 6.

Lathyrus vernus (L.) Bernh. - Almost the whole of Russia; rare in the S-most part. As to the $\mathbb{W}$. and $N$. limit see the map on Plate 22 . - I). 'T. II: $2 \mathrm{c}$ - III: $3 \mathrm{l}$.

Lonicera xrlosteum L. - Almost the whole of Russia, in N. to SW. Archang. (40), the whole of Vologda $(2 \mathrm{I})$, N. Perm $\left(6^{\circ} \mathrm{I}^{\circ} \mathrm{O}^{\prime}\right)$. - Distrib. over NE. Spain and almost the whole of France; it is lacking in the Brit. Isl., the Belg. flat region, and the whole of Holl. In Hanover rare and, probably, often introduced, more abund. and as a real native in S. Holst. In W. Denm. rare and totally absent in some regions. S. Norw., in N. to Vang, Lom, and Storelvdal. The whole of S. Swed.; S. Norrl. (see the map in Andersson \& Birger 1912 ); Finl., in N. to N. Osterbotten, Kajana, and Onega-Karel. (Powjenez). - 1). T. II: 4 . Also V. T. 3 and 6.

Poa remota Forselles. - As there is some confusion between this species and P. Chaixii Vill. and P. hybrida Gaud., its distribution is not yet accurately determined. It seems to be widely distributed in M. Russia and C. Europe (cf. Lindman, Engler's Jahrb. Bd 4t, I9 10 and Korshinsky 1898, p. 475). Accord. to lindman l. c. it is reported in WC. Europe from NW. Switzerl., Pfalz, Darmstadt, Westph. (the Brilon), Braunschw. (I)römling), Hanover (the town), Lauenb., Propstei, Zeal., Norw. to Salten in N. (not in SW.). In Swed. from Skåne to Lule Lappmark (Kvickjock). Cf. p. 367. - I). T. III: 2 c].

Pulmonaria obscura Du Mort. [=officinalis I. var. immaculata Opiz]. - There are different opinions as to the distinction between this type and $P$. officinalis $L$. vera. Accord. to the statements given by Kerner in his monograph on the genus (Kerner I 878 ), obscura has a more NE. distribution than officinalis. Kerner has seen obscura in N. and M. Russia from: The Lake Onega, Petrogr., on the Valdai hill, Moscow, Kazan, Kiev, and Warsaw; from I)obrudsha, Hung., Galiz., Germ., Switzerl., E. France (Besancon), SE. Belg., Denm. (Zeal.). [Russian specimens of officinalis vera he has only seen from Kherson.] As to the Scandin. distrib. of obscura see Plate Ir. - 1). T. [III: 2].

Ranunculus cassubicus L. - See Plate 15. - D. T. III: I b. 
Thalictrum aquilegiifolium L. - W. and C. Russia, in S., E., and N. to Volh. (53), Kiev (53), Kursk (2), Voron. (70), Tamb. (42), Ryazan (33), Niz-Novg., Vladim. (13), Kostr., NE. Novg. (4) [Olonets-Karel. (17)]. - In W. and NW. to SE. France (in Auvergne and the Jura), the lowland on the upper Rhine, Thuring., Brandenb. (I), Pomer. (E. of the Oder), S-most Swed.: Skåne and S-most Smål., SE-most Finl.: Ladoga-Karel. and Olonets-Karel. - D. T. III: 2.

Ulmus foliacea Gilib. - S. Russia, in N. to Grodno (53), Minsk (53), Volh. (53, Koeppen), Chernig. [f. suberosa (Ehrh.) (44)], Kursk (1), Tamb. (42), Sarat. (24), [S. Samara and S. Orenb. (cf. Korshinsky 1898$)$ ). - The species reaches its W. limit in France where, however, its distrib. as a native can hardly be determined the species being abundantly cultivated over the whole of the country. As a real native it is lacking in Belg., Holl., NW. Germ. (at least in the Rhine-Prov., Westph., Hanover and Holst.), and in Denm. In SE-most Swed. on Öland and Gotl., II. - D. T. [I: 4.] Also V. T. 3 .

Uimus laevis Pallas. - Almost the whole of Russia, in N. to [Onega-Karel.] SW. Archang.: to $63^{\circ}$ on the rivers in "Auenwälder" (40), W. Vologda: in E. to Ustjug $(21,58,59)$, the whole of Vyatka, N. Perm. - The species being abundantly cultivated its W. and NW. limit in Europe can hardly be determined. Accord. to Schneider 1906 , p. 213 it is found as a real native in S. and E. France. It it said to occur as a native in SE. Belg., Westph. (a few scattered occurr.) [in Hanover: Bremer-Waide and in Holst. and Schleswig very sparsely; ? native]. A real native on Öland, I, in the C. part of the island. SE. Finl. rare, in N. to S. Satakunta, S. Karel., and Onega-Karel. - D. T. II: 2 c (-III: 2 c).

Viola mirabilis L. - Almost the whole of Russia. - As to its W. and N. limits in Europe see Plate 22. - D. T. II: 2 c - III: 3 b.

\section{SPECIES OF MARSH ASSOCIATIONS.}

Achroanthes monophyllos (L.) Beene. - See Plate 21. - D. T. III: 2.

Alopecurus ventricosus Pers. - The species being confused with certain forms of $A$. pratensis its Russian distribution seems not yet to be accurately determined. Accord. to 53 it does not occur in Poljesje and the neighbour. governments of W. and C. Russia. Accord. to Korshinsky 1898 it occurs in E. Russia in the steppe districts (Samara, Orenburg, and Perm) and "in decliviis lapidosis montium jugi Uralensi borealis". Accord. to statements in recent publications it is widely distrib. in S. Russia on the shores of the Black Sea and the Caspian Sea as well as in the steppes: Ekaterinosl. (72), Taurida (54), Khark. (8, 47), Kursk (76), Tamb. (42), Sarat. (24). In the herb. of the Upsala Botanical Museum I have seen the species from Sarepta. From Turkest. it is reported by Regel (Descript. plant. etc., Petrogr. Acta, Bd. 7 , Fasc. I, I880, p. 654)]. In N. Russia it is certainly distrib. on the shores of the Arctic Ocean (cf. Conspectus Fenn., Pars iii, p. $35^{6}$ and 62) and is said also to be found for some distance inland (in the neigbourh. of the town Vologda accord. to 59?). - Outside Russia it occurs in the Scandin. North (see p. 372). It is also said to exist in Switzerl. and in SE. France (Puy-de-Dôme) - reports which require verification. A critical taxonomic study is certainly necessary. - D. T. [II: I b]. Also V. T. I: a.

Arabis Gerardi Bess. - M. Russia; in N. to SW. Archang.: Shenkursk (40), Petrogr. (43), S. Novg.: Borovitsh (26), W. Pskov (18), Smol. (1 1 ), Tver, Vladim. (13), 
Niz. Novg., E. Kaz.; in S. to Pod. (70), Volh. (53), Kiev (70), Polt. (70), Chernig. (53), Orel (68), Kaluga ( 14$)$, Tamb. (42), Sam. - Pretty rare i C. Europe. [It is said to occur over almost the whole of lirance (Rouy), a statement which possibly needs confirmation]. In $\mathrm{N}$. Germ. only in the $\mathrm{E}$. part, in W. to Pomeran. (Massow), Brandenb. (Frankfort a. d. Oder and the neighbourh. of Berlin), Magdeb., Thuring. [Isolated in E. Holland, accord. to Hermann.] Denm., o; in Scandin. only on Gotland: a few occurr. in the peat soil of drained fens ("myrar") or on railway-beds. Finl. o. D. T. III: 2. Also V. T. 4 and 6.

Bidens radiatus Thuill. - Seems to be rare throughout its distribution area. I have seen it reported from the following Russian Governm.: Chernig. (53) and Kiev (46), on the Injepr; Khers. (52), Sarepta (53), Petrogr. several occurr. (43, I5), Orenb. In C. Europe there are a few occurr. in M. Germ. and in N. France (in the departments of Meuse, Aube, Haute-Saône, Seine-et-Oise, Loir-et-Cher, Jura). N. Germ. only in E. Preuss. Denm. : a few occurr. in Zeal. C. Swed.: observed in a few localities in N. Smål., Värml., Västergötl., Närike, and SE. Dalarne. In Finl. reported from N. Österbotten, Tavastehus, Åboland, Savolaks, Karelian Isthmus, Olonets-Karelia. - D. T. [II: 2].

Calla palustris L. - M. and N. Russia, in S. to Volh. (53), Kiev (53), Chernig. (44), Kursk (70), Tamb. (42), N. Terr. Don.: Artsheda (75), Tula (16), M. Simb., and N. Ufa; in N. to [Keret-Karel.] SW. Archang.: Shenkursk (40), the whole of Vologda ( 21$)$, N. Perm. - In C. Europe and the Baltic district it reaches in W. and N. to Tyrol, Switzerl.: Kanton Luzern at Sempach, the Vosges (on the Lake Retournemer), Elsass, Lothr., E. Belg. in the Ardenn., almost the whole of Holl. and Denm., SE. Norw. in Gudbrandsdalen to $6 \mathrm{r}^{\circ} \mathrm{I}^{\prime}$ in N., almost the whole of Swed. and Finl. D. T. III: 3 (b).

Cardamine parviflora L. - Accord. to 53 it occurs in sandy places on the shores of the rivers in W. and S. Russia: especially on the Pripet, the Dnjepr, the Sosh, the Vorskla, the Don, and the Volga, reaching in N. to [Novg. (Hermann)] Minsk, Volh., Chernig., Kursk, Voron., Tamb., Sarat., and Sarepta (accord. to 3); it is also reported from Vladim. (3, I 3 ), and Kazan. - In N. Germ. its occurr. are pretty rare, in S. and W. to Silesia, Anhalt, Magdeb., and the lower Elbe. In Denm. no occurr.; a few occurr. scattered over C. Swed. in Ostergötl., Södermanl., Västergötl., Dalsl., and Värml. on shores in the regions around Lake Vänern; Närike, Västmanl., and SE. Dalarne; S. Finl. a few occurr. in Aboland, Nyland, S. Karelia, Karel. Isthm., and Satakunta. It is said to occur over a large area in S. and C. France along the Rhône, the Loire and some of the tributaries of the L., as well as on the IV. sea coast from the lower Loire in $\mathrm{N}$. to Les Landes in S. - D. T. (II: 2).

Carex vulpina $\mathrm{L}$. - As no distinction has been made between this species and the closely allied western $C$. nemerosa Rebent., its distribution cannot at present be accurately determined (cf. Samuelsson 1922 b.). Certainly, however, all reports from Russia may be referred to $\mathrm{C}$. vulpina. That being so this species is widely distrib. through almost the whole of Russia, reaching in N. to SW. Archang. (34), Vologda (19, 36, 37), N. Vyatka, N. Perm. - I am not able to state the W. limit of the species in Europe. As to the distrib. in the Scandin. North see above p. $37 \mathrm{I}$ and the map in Samuelsson 1. c. - The distrib. resembles the type II: 2 .

Cirsium oleraceum I. - M. and N. Russia, in S. to Pod. (70), Kiev (70), Polt. (70), Chernig. (70), Khark. (47), Kursk (70), Tamb. (42), Sarat. (24), MI. Simb., M. Sam., and SW. Orenb.; reported in N. from SIV. Archang: Slobodka-Ignatevskaja, 
Koleshskaja (40) and in the Pinega-district (81), Vologda ("im ganzen Gebiet gemein" $2 \mathrm{I}$, 59). - In W. Europe it occurs in E., (C.) and N. France, almost the whole of Belg. and Holl., NW. Germ. (rare and lacking in the NW-most part); abundantly spread over Holst., Schleswig, and almost the whole of Denm., Skåne and S. Hall., a few occurr. in Västergötl.; SE. Norw. (I, in the lower parts), SE-most Finl. (Karel. Isthm., Olonets- and Onega-Karelia). - D. T. III: 3.

Euphorbia palustris L. - The Russian distrib. cannot yet apparently be determined. Accord. to 53 the species does not exist in WM. Russia and accord. to 60 its occurr. in Moscow are very uncertain. I have seen the following statements in recent publications. In the Balt. coast regions: Petrogr. (43), Esth., Liv., Courl., Lithuan.; in S. and SE. Russia: Khers. (32), Ekaterinosl. (72), Khark. $(8,47)$, Chernig. (44), Tamb. (42), Sarat. (24), Sam., Ufa, Orenb., Simb., Vladim.: on the Oka (13) [E. Vologda "gemein" (2 I )?]. - In W. Europe the species is pretty widely distrib. It is almost lacking in some parts of France: on the Mediterranean, in C. France, in Brittany, and in Lorraine. It does not exist in the Brit. Isl. (see, especially, Williams I $90 \mathrm{I}$ ) or in Belg. On the other hand it is said not to be rare in Holl. and has a number of occurr. in NW. Germ. to about the Weser in W.; it is, however, very rare in Westph. and occurs in Holst. only in the S-most part. Denm. O; SE-most Norw.: on the sea-coast from Hvalöerne to Christiansand; in NW. of S. Swed., Öland, and Gotland (cf. above p. 37 I). - D. T. II: 2 b.

Geranium palustre L. - Almost the whole of Russia; it is rare or lacking in the S-most parts, accord. to 53 it does not exist in S. Bessar., S. Khers., Taurida, S. Terr. Don. In N. it is reported from [Onega-Karel.] E. Novg. (62), Vologda ("sporadically", 2 I), Archang.: the Pechora-district at the mouth of the Pechora (69), Vladim. ("frequens", 28), Kazan, Simb., Sam. - In W. and NW. to SE. France: E. Pyrenees, Savoie, $\mathrm{H}^{\text {te }}$ Savoie, the French Jura, $\mathrm{H}^{\text {te }}$ Saône, the Vosges; Alsace; Eifel, Westph. (Osnabrück), SE. Hanover (in NW. to the town Hanover and Ülzen), Hamburg, E. Holst., and E. Schleswig; the Danish Isl.: Lolland, Falster, and Zeal.; SW. Swed. (cf. p. 370); SE. Finl., in N. to Åboland, S. Tavastl., S. Savolaks, Onega-Karel. D. T. II: 2. (- III: 2 ).

Scirpus radicans Schkuhr. - M. Russia, in S. approximately to Volh. (53), Kiev (53), Chernig. (70), Tamb. (42), E. Ufa; in N. to Petrogr. (43), Novg. (26), [Vologda ("stellenweise", 2 I)] Yarosl. (70), Kostr. (3I), NW. Kazan. - In C. Europe and the Baltic district in SW. and W. to Salzburg, E. and N. Bav.: Passau, Deggendorf, Regensburg, Nürnberg, Aschaffenburg; Pfalz, Thuring., Anhalt, Magdeb., Hamburg, SE-most Holst. I (Mecklenb.: o). In Scandin. a few occurr. in SE.-most Norw. (Hiterdal) and C. Swed, in (Värmland, Västmanland, NW. Uppland, Närike, and NW. Södermanl.). In SE-most Finl.: S. and Ladoga-Karel. (cf. Sernander 1910, pp. 278 ff.) D. T. III: 2 .

Scolochloa festucacea (Willd.) Link. - M. Russia, in S. approximately to Volh. (53), Minsk (53), Chernig. (70), Polt. (70), Orel (70), Tamb. (42), Sarat. (24), M. Sam., SW. Orenb.; in N. to [Onega-Karel.] NE. Novg. (4), Kostr. (31), NW. Kazan. Scattered occurr. in the Baltic district in S. and W. to Warsaw, Konin, Mogilno, Stettin, W. Brandenb. (in several places), E. Mecklenb. In S. Swed. only in Östergötl. (cf. p. 37 I). In S. Finl., in N. to Satakunta, N. Tavastl., N. Savolaks, and Onega-Karel. - D. T. III: I.

Senecio palustris (L.) Hook. - M. Russia; in S. to Volh. (53), Kier (53), Polt. (70), Kursk (70), Chernig. (70), Khark. (47), Tamb. (60), S. Simb., SE. Orenb.; in 
N. to Liv., W. Pskov (18), Mogil. (53), Moscow (60), S. Perm. In the Baltic district it is to be found often abundantly as far 11 . as $\mathrm{N} W$-most France and $5 \mathrm{~F}$. most Fingland. In ( . Europe only one or two occurr. in Bohem. In Hung., however, it is pretty widely distrib. In the whole of Denm.; Skane 1I; in the rest of S. Swed. it has had or has a few accidental occurr., in $X$ to Lake Hjiilmaren. - 1). T. Baltic.

Sonchus palustris L. - S. and SF. Kussia; in N. to Courl.] Warsaw (Hermann), Volh. (70), Pod. (70), Kiev (70), l'olt. (70), Khark. (e. g. S), Tamb. (42), Tula (16), Moscow (6o), Niz. Novg. (78), SF. Kazan, N. Ufa, SIl. ()renb. Accord. to 21 in Vologda: "stellenweise"]. - Distrib. chiefly in N. (ierm., Holl., and Belg.; it is found also in Sl-most Engl. and in France, chiefly in the N.most part (cf. Senecio palustris). In M. and S. Germ. cnly a few occurr. In NII. Germ.: rare in Hanover, in Holst. only on the Balt. coast. In Ienm.: on the Baltic coast of S-most JutI., Schleswig and the Isl. It formerly had one occurr. as a native in S-most Swed., on the borders of skane and Blekinge (cf. Wahlstedt, in "Botaniska Notiser" I) I I, P). 17). - D. T. [I: 3 , a Cassubian variant].

Viola uliginosa Bess. - WM. and C. Russia. 53 shows that its area in $\mathrm{W}$, is restricted to the basin of the 1)njepr. In N., F., and S. approximately to Petrogr. (Becker 1910 and 43), [Novg. (53)] Pskov: the W. shore of Lake Pskor (66), Varosl. (53)], Vladim.: Melenki (13), Moscow (Becker and 60), Kaluga (53), Tula (16) Xil. Tamb. (42), Orel (53), Kursk (53), Chernig. (53), Polt. (53), X. Kiev (Becker and 5.3), N. Volh. (53), NIT. Galiz (Becker). - A few scattered occurr. in the Dacian and Danubian regions, in $\mathrm{W}$. to Krain (Becker). A few occurr. in the E. part of C. Germ.: in Silesia (especially. Lpper Lusatia), Thuring. (at least formerly), Pomer. formerly. It is found in Schleswig at Hadersleben and on Bornh.; scattered occurr. in SF. Swed.: Skåne (in NW. at Allerum and in NE. at Kristianstad), Blekinge at Brömsebro, several occurr. in SE-most Smål. on the rivulets (in the parishes of Arby, Mortorp, Hossmo, Ljungby and Madesjö), Öland (Vickleby; in forest swamps), Ostergötl. (in the neighbourhood of the Lake Båven), Uppl. (in F. at Norrtälje, several occurr. on and in the neighbourhood of the Daläls, one or two occurr. in C. part of the country $\mathrm{N} I \mathrm{l}$. of Upsala). S. Finl.: a few occurrenc. on Åland, in Aboland, S. Satakunta, Nyland, S. Tavastl. (cf. Ascherson in Verhandl. d. Botan. Vereins Prov. Brandenburg, Bd. 37 (1895). pp. x ff.). - D. I. III: I (b).

\section{SPECIES ()F WATER-PLAN' ASSUCIATIONS.}

Elatine triandra schkuhr. - Its distrib. may of course be looked upon as very incompletely known, and certainly mistaken statements are often to meet with. It seems not to be found in $\mathrm{W}$. Europe (W. of C. France) but to be widely distrib. through C. Europe and large parts of the Baltic distr. westwards from C. Russia. From Russia I have, however, only seen the following statements of recent years: (Onega-Karel.] Vladim. (13), Moscow (60), Novg. (26), and Petrogr. (43). If "H. callitrichoides Nyland." is included in this species (cf. Conspectus Fenn. Vol. 4, Pars iii, P. 72 ), there are to be added: Kursk (70) and Kostr. (3 I) - In I)enm., 0 . It is found in large parts of swed. from Blekinge in the $\mathrm{S}$. to the lower Torne aily in the $\mathrm{N}$. (see p. $37+$ ). In Finl. scattered occurr., in $\mathrm{N}$. to $\mathrm{N}$. Usterbotten, Kemi-Lappmark, and Pomoric Karel. - D. 'T. HI: 2 .

Trapa nalans L. - Widely distrib. over large parts of $\therefore$. and C. Asia. From Russia there are many old reports accord. to which the species might be distril, over 
almost the whole of S. and M. Russia. On the other hand, the species nowadays seems to be observed very seldom. Perhaps the older statements concern finds of fossil nuts or cultivated specimens. Accord. to 53 the species occurs in several places in the basin of the Dnjepr at Minsk, Mogil. (Komel), Voih., Kiev, and Chernig. I have also seen more recent reports from Khark.: the neighbourhood of Koupjansk (8), Taurida: at the mouth of the Dnjepr (54), Pensa: Syri (74), in the Lower Volga (85), Courl.: in the Lake Klauzan, S. of Jacobstadt (Lehmann, Kupffer etc.). - From SE. Europe the species extends its area westwards with scattered occurr. in S. and C. Europe, reaching in W. to C. France: the depart. of Maine-et-Loire and Sarthe. In these regions, however, it may often be cultivated or a relic of former cultivation. See, especially as to the Swed. distrib., Malmström I 920 and the publications cited in this paper. - D. T. [I: 4 .

\section{IO. SPECIES OF MOOR-ASSOCIATIONS.}

[Betula humilis Schrank.] - M. Russia (see Koeppen I 889); I have seen the following recent reports: in N. to S. Petrogr. (43), E. Novg. (4, 20), SW. Archang.: the Shenkursk-distr., about $62^{\circ}(40)$, W. Vologda: the Velsk-distr. (58), Yarosl. and Kostr. (Koeppen), Vladim. (I3), NW. Kaz., N. Perm; in S. to N. Orenb., NE. Ufa, Ryaz. (Koeppen), E. Tula (16), Orel (68), Kursk and Chernig. and Kiev (Koeppen), Volh. (53). - In N. Poland and N. Germ. I, in S. and W. to NE. Posen (Mogilno, Bromberg, Czarnikau), Brandenb. (Arnswalde, Oranienburg), Lauenb. - In C. Europe a number of occurr. in the prae-Alpin regions: Upper Bav., Baden, Würtemb., and at St. Gallen in Switzerl. - In the Scandin. North in SE. Swed. : NE. Smål. at Forserum ( only formerly; cf. Svensk Botan. Tidskr. I 909, pp. (8), ( ( 3$),($ I 59), (162); and 1915, p. 470 ). - D. T. III: $1-2$.

Ledum palustre L. - N. and M. Russia, in S. to NIV. Kiev (53), SW. Chernig. (44): N. Orel (68), N. Tamb. (in S. to Morshansk; 42), C. Simb., E. Ufa. - Its W. limit does not extend beyond the E. part of C. Europe: the C. Carpath. [It is said to have been found recently in E. Alps], Bohem., the Kingd. Sax. (to about the Elhe and the Moldau in W.; isolated, however, at Jena, Neustadt a. d. Orkla, and Schleiz), SE. Hanover, Lauenb., Lübeck. Denm., o. Almost the whole of Swed. (in S. Swed. considerably less abundant in SW, than in NE., ct. p. 375); in Norw.: in the SE-most part a few occurr. in the neigbourh. of the Swed. border, in the N-most part pretty abundant in Inner-Finmark and in the valley of Reisen in Tromsö Amt.; in Finl. throughout the country. - D. T. III: I c. 
IIPENIIX II.

\section{VEGETATION.ANALYSES}

\section{RE.MLRKS:}

1. Explanatory text to the tables is given on p. 283 , and pp. $288-291,340$ -342 , and 360 .

2. The analyses do not claim to be complete with regard to mosses and lichens. As a rule, such plants have been included only when they are of physiognomic importance.

The determination of the mosses and of the lichens has been done by myself in the field, when that was possible; in other cases it has been done by specialists. Iector Hjalmar Möller and the Rev. Sigfrid Medelius have determined the mosses gathered, the former dealing mainly with those from Oland. Docent G. E. DU Riviz has determined the lichens. I desire to express my warmest thanks to these gentlemen for their valuable help in this matter.

3. Descriptions of the areas analysed in Tables $\mathbf{I}-3$ and $5--7$.

\section{TABLE 1.}

The Sarmatian type. 1. Öland: Persnäs Lundby: I6 $\mathrm{m}^{2}$. Level ground with shallow soil formed of dark brownish-grey mild humus mixed with sand and gravel resting on the pavement. 25. VII. 19 I8. - 2. D:0 För S. Greda: $16 \mathrm{~m}^{2}$. Almost level ground; calcareous moraine. Uppermost $10 \mathrm{~cm}$. sandy, dark brownish-grey mild humus. 28. VII. 1918. - 3. D:o Ventlinge Mörbylilla: $16 \mathrm{~m}^{2}$. Almost level ground. $50 \mathrm{~cm}$. gravel and uppermost $10-20 \mathrm{~cm}$. sand mixed with mild humus resting on alum shale. 20. VIII. 1918. - 4. D:o I'ickleby between the Church-village and Beijershamn: $9 \mathrm{~m}^{2}$. ( iently sloping old beach formed of sand abundantly mixed with mild humus (10 $\mathrm{cm}$.) resting on slate-gravel. 31. VII. 1917. - 5. D:o Ventlinge Mörbylilla: $9 \mathrm{~m}^{2}$. Close to $\mathrm{nr}$ 3. The ground slopes gently towards $\mathrm{SE}$; otherwise as $\mathrm{nr}$ 3. 8. VI. I918. 6. D:o S. Möckleby Albrunna: $9 \mathrm{~m}^{2}$. ()n the edge of an oak-forest close to the Alvar; the ground slopes gently towards SIV; limestone-pavement covered with $20-30 \mathrm{~cm}$. calcareous gravel mixed with mild humus. 8. VI. I 9 I 8. - 7. D:0 Hulterstad: Gösslunda: $4 \mathrm{~m}^{2}$. Level ground on the edge of the Alvar; $20-30 \mathrm{~cm}$. mild humus somewhat mixed with gravel resting on the limestone-pavement. 13. VIII. 1917. - 8. Golland: Stora Karlsö: $4 \mathrm{~m}^{2}$. Level ground; mild humus mixed with gravel resting on the limestone-pavement. 4. VI. 1917. - 9. Oland: IIulterstad Gösslunda: $+\mathrm{m}^{2}$. Like nr 7 but with a little more loose soil. I7.IX. 1917. - 10. D:o Forilunda Eriksöre: $2 \mathrm{~m}^{2}$. Limestone pavement on the Alvar covered by $3 \mathrm{~cm}$. moraine-gravel and $20 \mathrm{~cm}$. coarse sand strongly mixed with mild humus. I6. VII. 1917. - 11. D:0 Segerstad on the Alvar $W$. of the church: $2 \mathrm{~m}^{2}$. Level ground. Soil-profile: $a \mathrm{i} 8 \mathrm{~cm}$. black mild humus, $b \quad 8 \mathrm{~cm}$. mild humus mixed with sand and gravel, $c$ I $2 \mathrm{~cm}$. morainegravel on the level limestone bed. 21 . VII. 1917. - 12. D:0 Repplinge Strandtorp: 
I $\mathrm{m}^{2}$. The ground slopes gently towards $\mathrm{W}$; darkbrown mild humus mixed with sand and splits of limestone. 27. VI. I92 I. - 13. Like $\mathrm{nr}$ 1 2. - 14. D:o S. Möckleb ' Getlinge: I $\mathrm{m}^{2}$. Level ground on the Alvar; $10 \mathrm{~cm}$. dark-brown mild humus mixed with sand. I. VIIl. I9I7. - 15. Västergötland: Falbygden S. Kyrketorp: I $\mathrm{m}^{2}$. On the south-western gently sloping side of a calcareous moraine hillock; uppermost darkbrown mild humus mixed with sand and limestone splits. I 1. IX. I920. - 16. D:0 d:o Falköpings $l: a$ Bestorp: I $\mathrm{m}^{2}$. Like $\mathrm{nr}$ i 5. 8. VIII. I $92 \mathrm{I}$.

The Subatlantic type. 1. Blekinge: Ringamåla $N$. Hoka: $16 \mathrm{~m}^{2}$. On the southern side of a hillock covered by sparse oak-forest; the ground slopes about $10^{\circ}$ towards the broad valley of a rivulet; the uppermost layer of the soil is a grey-brownish sandy gravel mixed with humus. I. VII. 19 8 . - 2. Uppland: Rasbo Karby: $4 \mathrm{~m}^{2}$. On the gently sloping southern side of a sandy moraine-hillock surrounded by arable fields. 24. IX. 1920. - 3. D:o Almunge Länna: $4 \mathrm{~m}^{2}$. On the edge of a forest growing on sandy moraine rich in boulders; the ground slopes gently towards $\mathrm{S}$ and an arable field. 24. IX. 1920. - 4. Östergötland: Kättilstad: $4 \mathrm{~m}^{2}$. On the side of a morainehillock formed of sand, clay and boulders sloping about $10^{\circ}$ towards $\mathrm{S}$ and an arable field. 22 . VIII. 1921. 5. - Smaland: Arby Olsbo: I $^{2}$. Western gently-sloping side of a gravel-hillock. I 7. VII. I9 19. - 6. D;0. Ilghult Stenbrohult: On the gently-sloping southern side of a gravel-hillock covered by a sparse oak-forest. I9. VII. I920. 7. D:o Tveta: I $\mathrm{m}^{2}$. Western slope of a gravel-hillock. i 8. VII. i 920 - 8. D:o Mörlunda: I $\mathrm{m}^{2}$. Like $\mathrm{nr}$ 7. I6. VII. I919. - 9. Östergötland: Gryt Högved: I m². On the southern side of a moraine hillock formed of sand and gravel sloping about $10^{\circ}$ towards S and an arable field. 29. VII. 1920. - 10. Smaland: Misterhult Kolhorva: I $\mathrm{m}^{2}$. On the gently-sloping western side of a small gravel-os, close to an arable field. I6. VII. I9 9. - 11. D:0 Virserum Ekeflo: i $\mathrm{m}^{2}$. On the north-western side of a gravel-hillock sloping about $10^{\circ}$ towards an arable field. I 5. VII. 1920. 12. D:o Vrigstad Köpstad: I $\mathrm{m}^{2}$. On the gently-sloping eastern side of a gravel-hillock close to an arable field. 9. VIII. I9 19. - 13. D:o Gärdserum Rorsıad: I m². On the south-western side of a small gravel-os sloping about $10^{\circ}$ towards an arable field. 24. VII. I920. - 14. D:o a:o Falenum: Like nr I3. 24. VII. I920. - 15. D:o Trysenum Fageliik: I $\mathrm{m}^{2}$. On the southern side of a sandy moraine-hillock sloping about $7^{\circ}$ towards an arable field. 27. VII. I920. - 16. Södermanland: Ludgo Aspa: I $\mathrm{m}^{2}$. On the gently sloping southern side of a sandy os close to the shore of a lake. I 5. IX. 1920.

\section{TABLE 2.}

The Sarmatian type. I. Öland: Kastlösa Penåsa: 25 squares, each $4 \mathrm{~m}^{2}$. On level ground on the Alvar; soil-profile: $a 20-35 \mathrm{~cm}$. dark-brown mild humus mixed with sand, $b 50 \mathrm{~cm}$. and more calcareous gravel. In the middle of July r9r9. II. Vestergötland: Vartofta-Asaka Bondegairden: io squares, each $4 \mathrm{~m}^{2}$. On de southern side of a ridge formed of calcareous gravel and boulders sloping about $15^{\circ}$ towards an arable field; the uppermost layer of the soil is dark-brown mild humus. IO. IX. 1920. [Cf. Sernander I 908, pp. 52 ff.] - III. Östergötland: Hcda Norrö: I 6 squares, each $4 \mathrm{~m}^{2}$. On the side of a moraine-hill sloping $5^{\circ}-10^{\circ}$ towards $\mathrm{S}$ and arable fields. The moraine chiefly is formed of calcareous gravel mixed with numerous splits of limestone, the uppermost layer of the soilis darkbrown mild humus. I3-I4. IX. I920. - 
IV. Smailand: Mrililla (i). Arena: Io squares, each $\mathrm{I} \mathrm{m}^{2}$. On the southern side of an os-ridge formed of Archaean coarse sand and gravel; sloping about $12^{\circ}$ towards the river Emån. 17. VII. 1920. - 1. Fotland: Iamblingbo Gervalds: $+\mathrm{m}^{2}$. On the southwestern slope of a limestone mound. The shallow loose soil (about $\mathrm{I} 0 \mathrm{~cm}$.) consists of clay rich in lime mixed with mild humus, gravel and splits of limestone. 9. VI. 1917. - 2. Öland: Böda Byerum: $4 \mathrm{~m}^{2}$. L Level ground on the Alvar-pavement; the shallow soil consists of $13-17 \mathrm{~cm}$. mild humus mixed with calcareous sand and gravel. 8. VIII. IоI6. - 3. D:o Ifulterstad Gösslunda: $4 \mathrm{~m}^{2}$. Like $\mathrm{nr} 2$, but the soil only 5-10 cm. 13. VIII. 1917. - 4. Gotland: Vamblingbo Sibbjerns: $1 \mathrm{~m}^{2}$. Like $\mathrm{nr} 2$, but the soil 10-15 cm. 7. VI. 1917. - 5. Mland: Mörlylanga Borgby: I $\mathrm{m}^{2}$. Level ground on the Alvar; $10 \mathrm{~cm}$. darkbrown mild humus mixed with sand resting on 50 $\mathrm{cm}$. and more calcareous gravel. 13. VIII. 1920. - 6. Smäland: Virserum Ramsebo: I $\mathrm{m}^{2}$. On the southern side of an os formed of Archaean gravel and coarse sand, sloping about $15^{\circ}$ towards $S$ and a marsh. (Cf. p. 304.) 15. VII. 1920.

The subatlantic type. - I. M̈stergötland: Högby' Skogsiö: 16 squares, each I m². On a southern unshaded slope between an arable field and a lake; the soil is sand, somewhat mixed with clay. Inclin. about $15^{\circ}$. I I-I2. IX. I920. II. Ippland: Brilinge Fr.xan: $\mathrm{I} 2$ squares, each $\mathrm{I}^{2}$. On the south-western unshaded slope of an os; the uppermost soil is fine gravel and coarse sand. Inclin. about $10^{\circ}$. 4. X. 1920.

The areas 1-12 in this table all have the size of $1 \mathrm{~m}^{2}$ and are situated on southerly exposed sandy slopes of oses or moraine-hillocks.

1. Blekinge: Backaryd, 7. VIII. I919. — 2. Småland: Linneryd, 6. VIII. :919. 3. D:o Vissefjärda, 5. Vill. r919. - 4. D:o Mortorp, 3. VIII. I919. - 5. D:0 Ryssby (in the county of Kalmar), 4. VII. 1919. - 6. D:o Järeda, I5. VII. I920. 7. D:o Lannaskede, 3. VIll. 1921. - 8. D:o Vrigstad, 7. VIII. 1921. - 9. Östergötland: St. Annae, 31. VIl. 1920. - 10. Södermanland: Iudgo, I6. IX. 1920. 11. Uppland: Gamla Upsala, 28. IX. 1919. - 12. Västmandland: Kolbäck, 28. 1.X. г 920 .

\section{TABLE 3 .}

I, II, III. Skine: Iitaby Vitemölla: I and II 5 squares, III Io squares, each $2 \mathrm{~m}^{2}$. Almost level ground immediately inside the Psamma-dunes of the sea-shore. IIII. 1920. For the placing at my disposal of these analyses I am greatly indebted to Professor R. Sernander. - IV. C̈lland: Glömminge: Io spuares, each $+\mathrm{m}^{2}$. On a sandy slope exposed towards $\mathrm{SW}$; inclin. about $10^{\circ}$. The vegetation almost close. 3 . IX. 1920. - V. D:O N. Nöckleby Dörby': It squares, each $4 \mathrm{~m}^{2}$. Level ground; coarse sand; vegetation close. 4. IX. I920 - VI. D:o (iârdby': ro squares, each $4 \mathrm{~m}^{2}$. Like $\mathrm{nr} \mathrm{V}$. - 1. Skine: Hhus Espet: $16 \mathrm{~m}^{2}$. The eastern slope of a grand old dune. Inclin. about $15^{\circ}$. The vegetation almost close. 3. VII. I9I8. -2. Öiand: Böda IIngegärd: $+\mathrm{m}^{2}$. The eastern gently-sloping side of a »grey dune» surrounded by pine-forest. The distance from the Psamma-dunes of the sea-shore is $50 \mathrm{~m}$. 3. VIII. r9 8 . - 3. D:o Sandby Aby: $4 \mathrm{~m}^{2}$. The southern slope of an old, small dune. Inclin. about $10^{\circ}$. The ground bare in about a quarter of the area. 24. IX. 1917. - 4. D:o Gärdby: Like nr 3. ro. VI. 1918. - 5. D:o Vickleby: $+\mathrm{m}^{2}$. The western slope of the Ancylus shore-deposit; inclin. very small. The uppermost layer of the soil is sand mixed with dark greyish-brown humus. Vegetation close. 
31. VII. I916. - 6. D:o Böda Getterum: $9 \mathrm{~m}^{2}$. The western slope of a »grey dune»; inclin. about $10^{\circ}$. The ground bare in about a quarter of the area. 7. VIII. 19r6. - 7. D:o Bredsätra: $9 \mathrm{~m}^{2}$. On the western gently-sloping side of the sandy Litorina shore-deposit. Vegetation almost close. 17. VI. 1918. - 8. Gotland: Vamblingbo Lingsarve: $9 \mathrm{~m}^{2}$. On the almost level top of the broad Ancylus shore-deposit; vegetation close. Soil-profile: $a$ 1 $2-15 \mathrm{~cm}$. dark-brown sand mixed with humus; $b$ $20 \mathrm{~cm}$. and more sandy gravel with numerous mollusc-shells. 9. VI. I9 7 . — 9. D:0 Sundre Austre: $9 \mathrm{~m}^{2}$. Almost level ground. 9. VI. I917. - 10. Skane: Snogeholm. Accord. to Samuelsson 1910, pp. $38 \mathrm{ff}$.: a drift sand district; in a zone with character of a pine-heath» (with abundant Cladinae and Cladoniae) between a pine-forest rich in herbs and a Psamma-association.

\section{TABLE 5 .}

I. Uppland: Järlasa Bredsjö: ro squares, each $\mathrm{I} \mathrm{m}^{2}$, situated in different places in the edges of birch-aspen-woods close to cultivated marsh-ground. 7. X. I920.

The areas $\mathrm{I}-9$ are all the size of $\mathrm{I} \mathrm{m}^{2}$.

1. Smailand: Tingsais Djuramaila: Birch-aspen-wood on a dry slope facing a lake. 7. VIII. 1919. - 2. D:o Misterhult Jämserum: The edge of an oak-limetree-wood close to the shore of a lake. 20. VI. 1920. - 3. D:o Tysenum Fagelvik: Sparse oakwood on the slope of a moraine hillock. 27. VII. I920. - 4. Östergötland: Börnum Passdal: Like nr 3. 30. VII. 1920. - 5. Södermanland: Kjula Nastorp: Sparse wood of oaks, birches and aspens on a moraine hillock close to a marsh. 5. IX. I 92 1. -6 . Uppland: Knivsta Tra: Birch-aspen-wood on the sloping transition zone between a moraine rich in boulders and a clay-field. 23. IX. 1919. - 7. D:0 Jumkil Bolandet: Sparse birch-aspen-wood close to a marsh. 3. X. 1920. - 8. Smailand: Dädesjö Boldö: very sparse birch wood (to great extent, of course, thinned by the hand of man) on the southerly exposed slope of a hill close to a peat-bog. I I. VII. 1920. -- 9. D:0 Mörlunda Kängsebo: The north-western slope of an os with a very sparse wood of birches, pines and oaks, facing a marsh. I6. VII. I $92 \mathrm{I}$.

\section{TABLE 6 .}

1 and 2. Öland: Ventlinge at the Church.village: The vegetation covered an area of two har or so in the edge of the Alvar on rather damp but shallow soil. 20. VIII. I $919 .-3$ and 4. D:o Kastlösa Penaisa Alvar: At the top of a small hummock. [Those small hummocks, $2-5 \mathrm{dm}$. in height, are characteristic of certain parts of the Alvar. Probably, they are chiefly caused by the ground being heaved up by the freezing of the water included in the marly, shallow snil.] 3. X. I 920.

\section{TABLE 7 .}

All squares are from the Alvar of $\mathrm{S}$. Öland. The analyses were made at the beginning of June 1918 (cf. p. 329 ). 
TABLES $1-7$ 


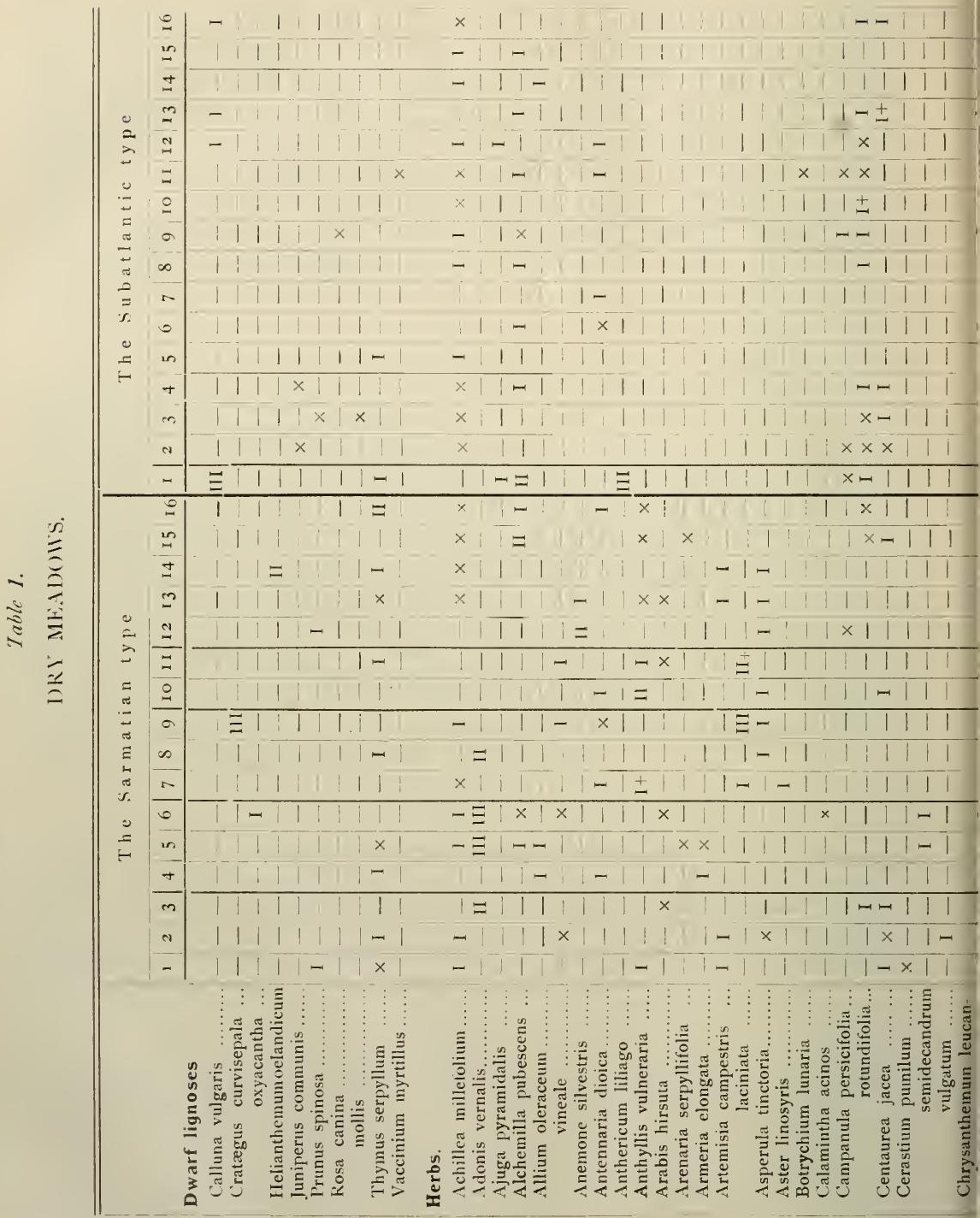




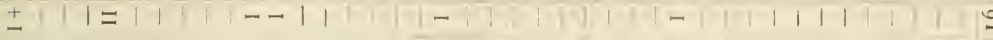

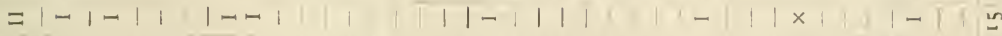

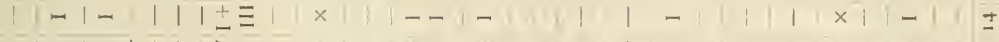

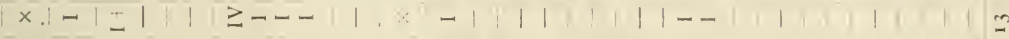

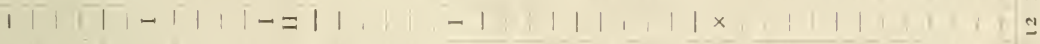

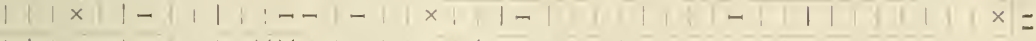

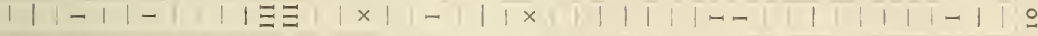

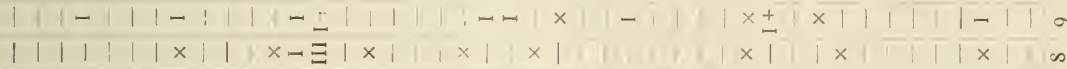

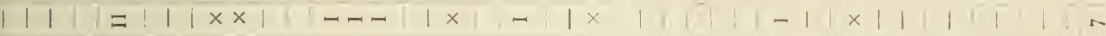

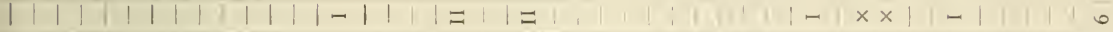

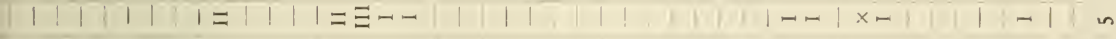

$$
\begin{aligned}
& \text { | | | | | | |- |- | | }
\end{aligned}
$$

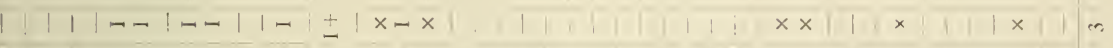

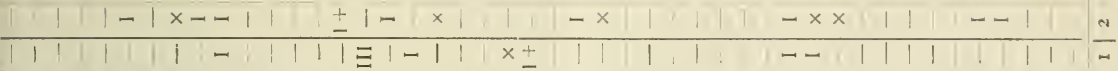

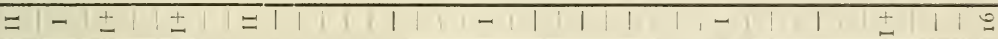

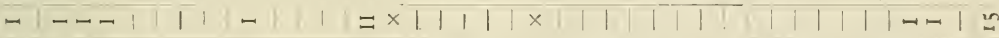

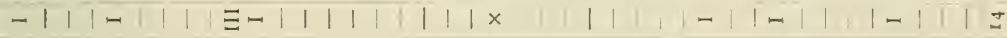

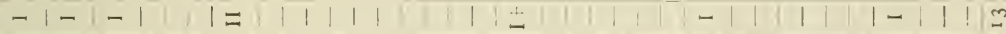

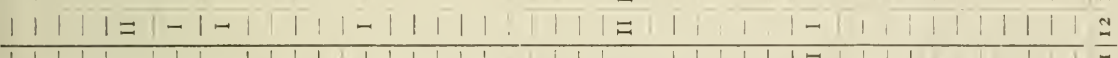

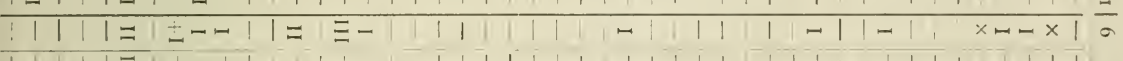

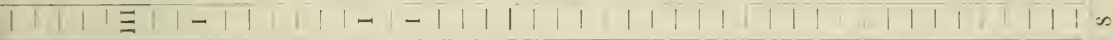

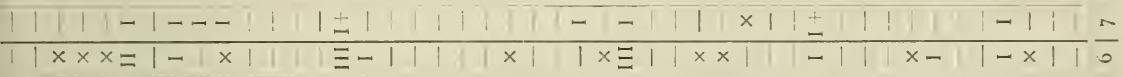

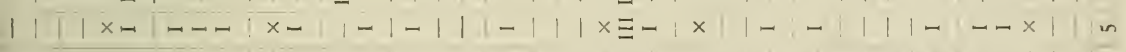

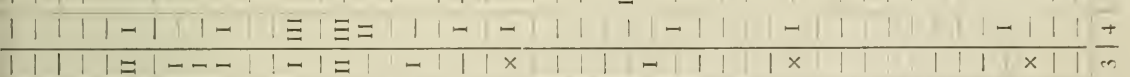
$1|1| 1-1|-1|-1=z$

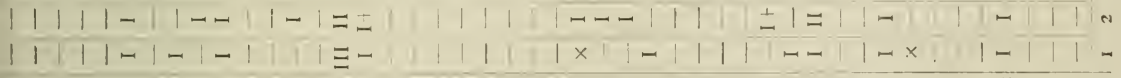




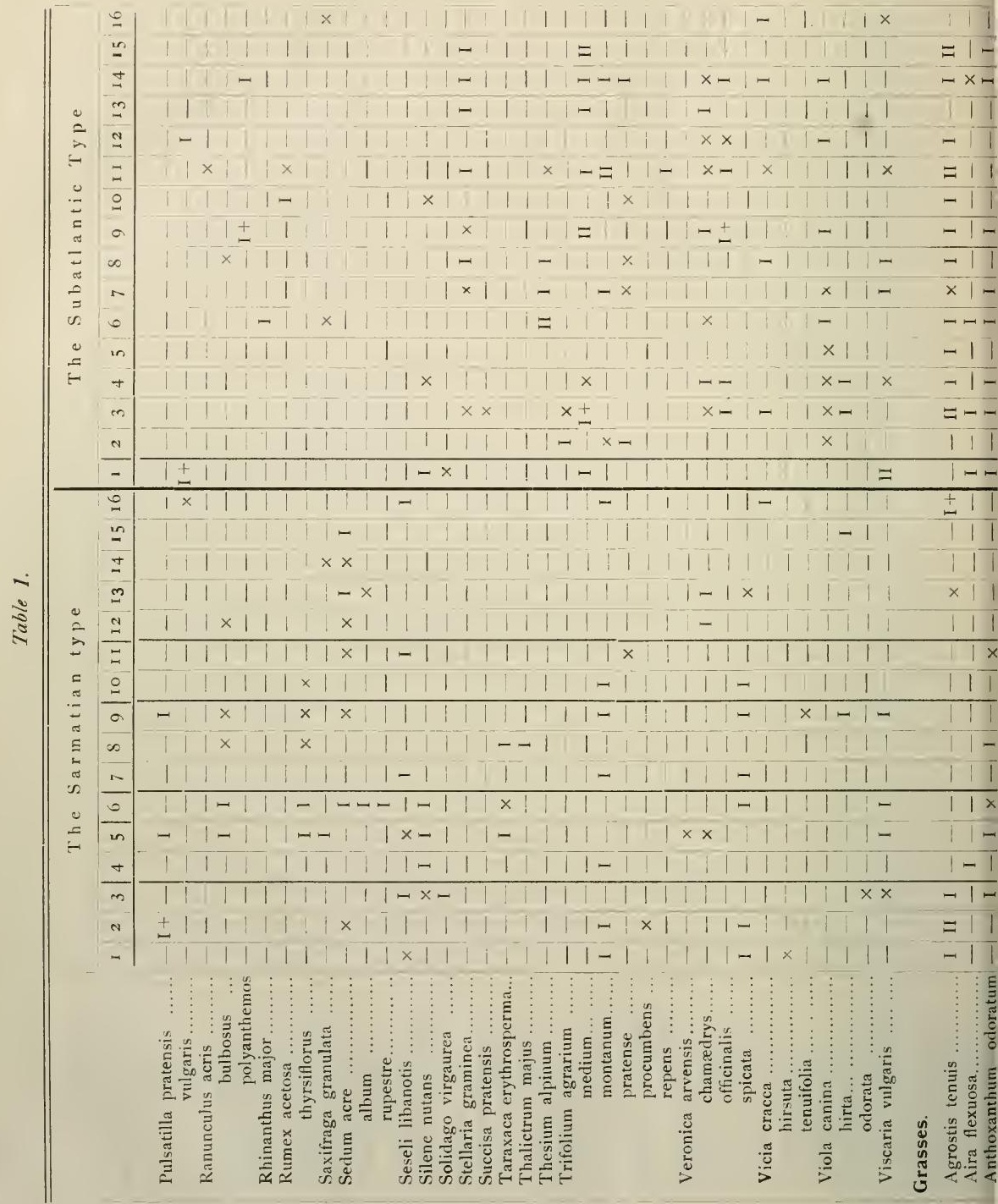




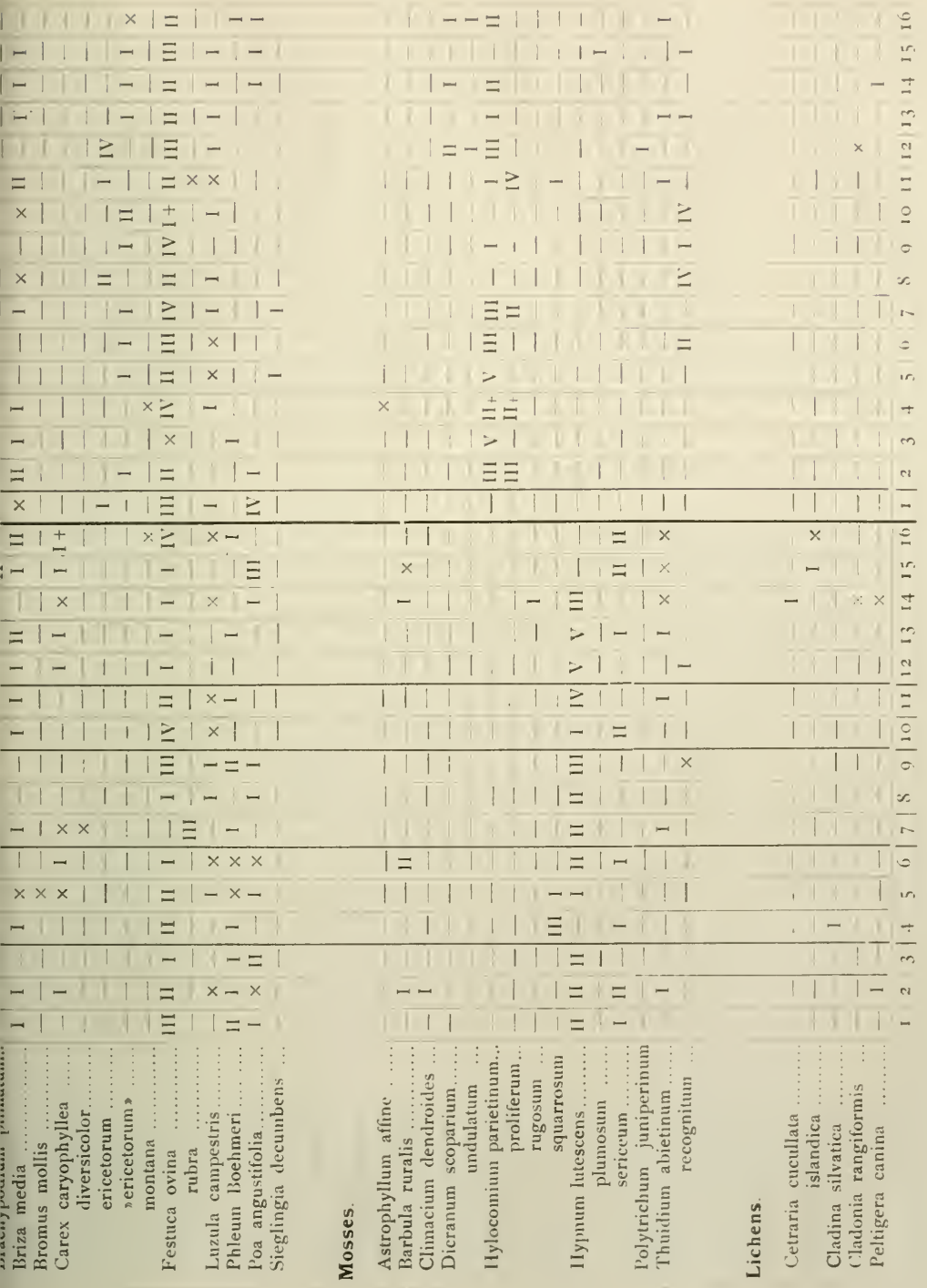




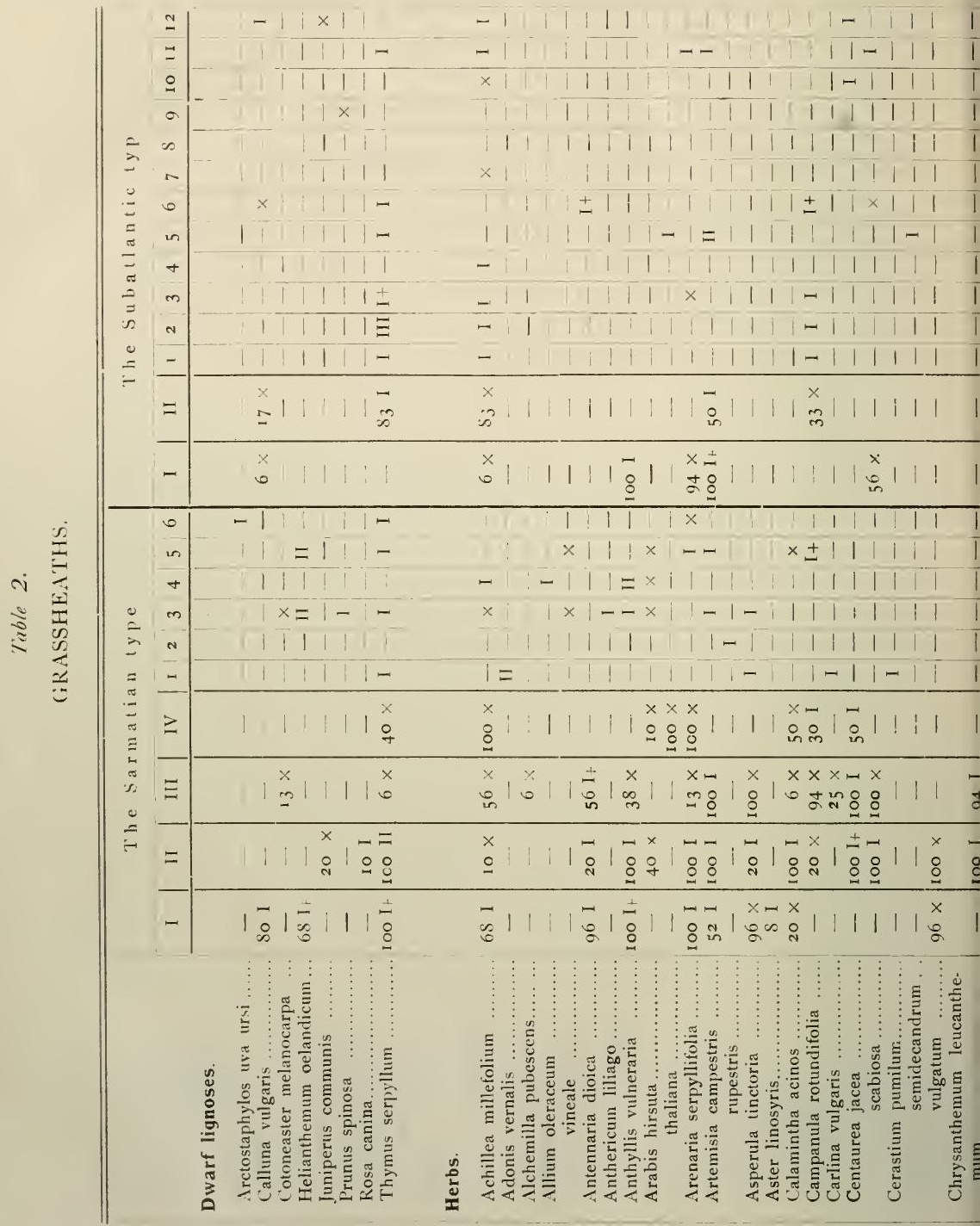




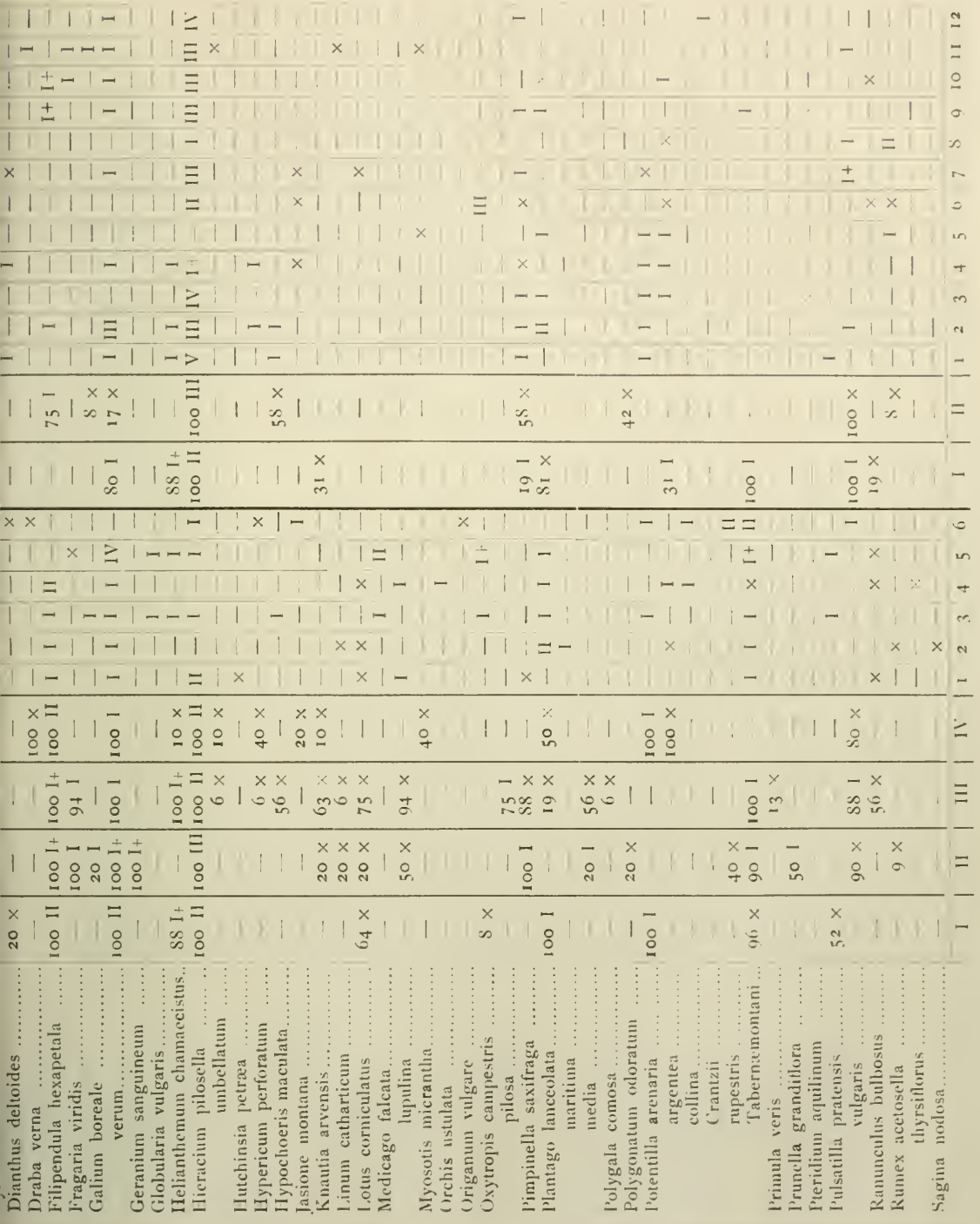




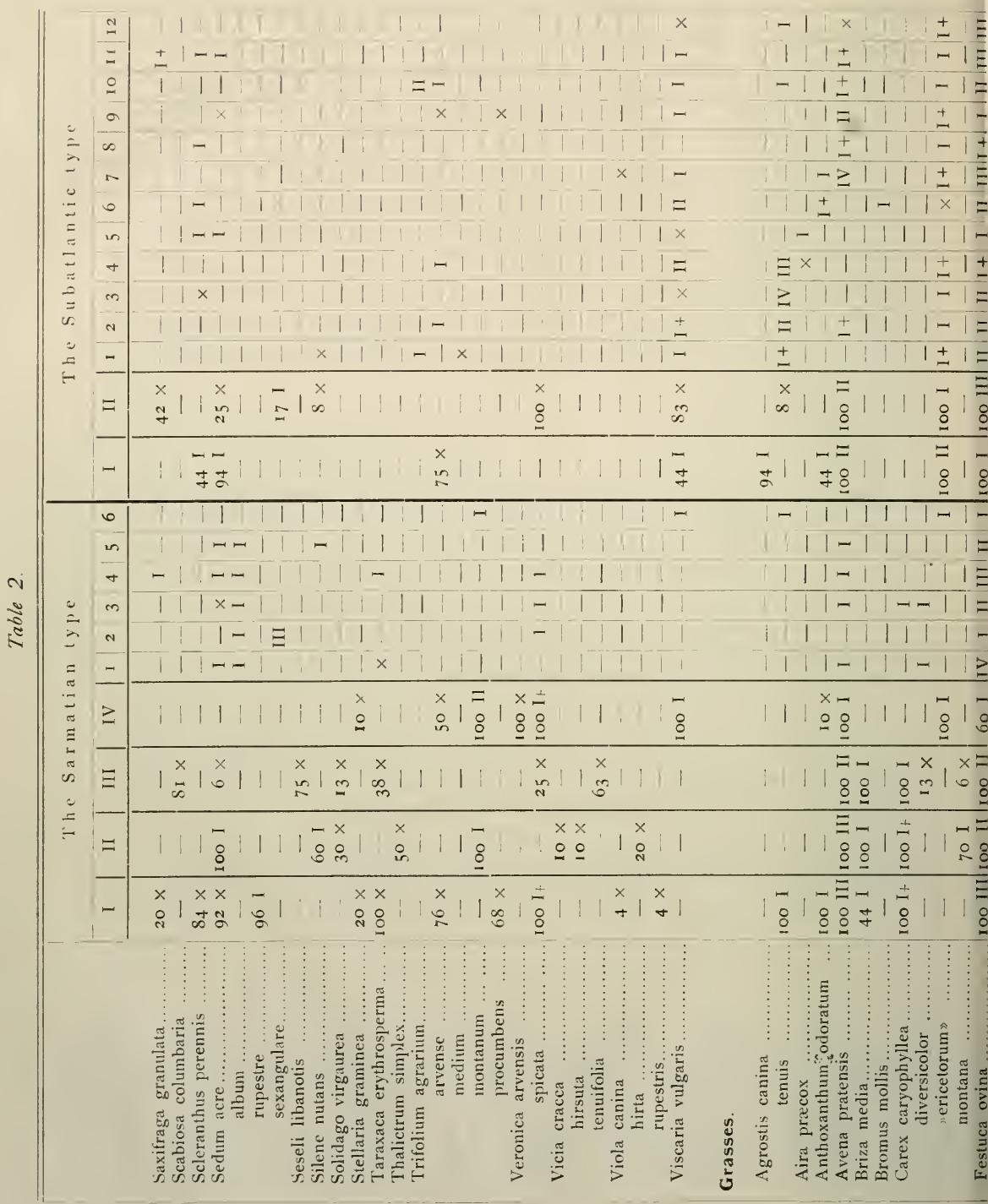


THE CONTINENTAL FLORA OF SOUTH SIVEDEN 427

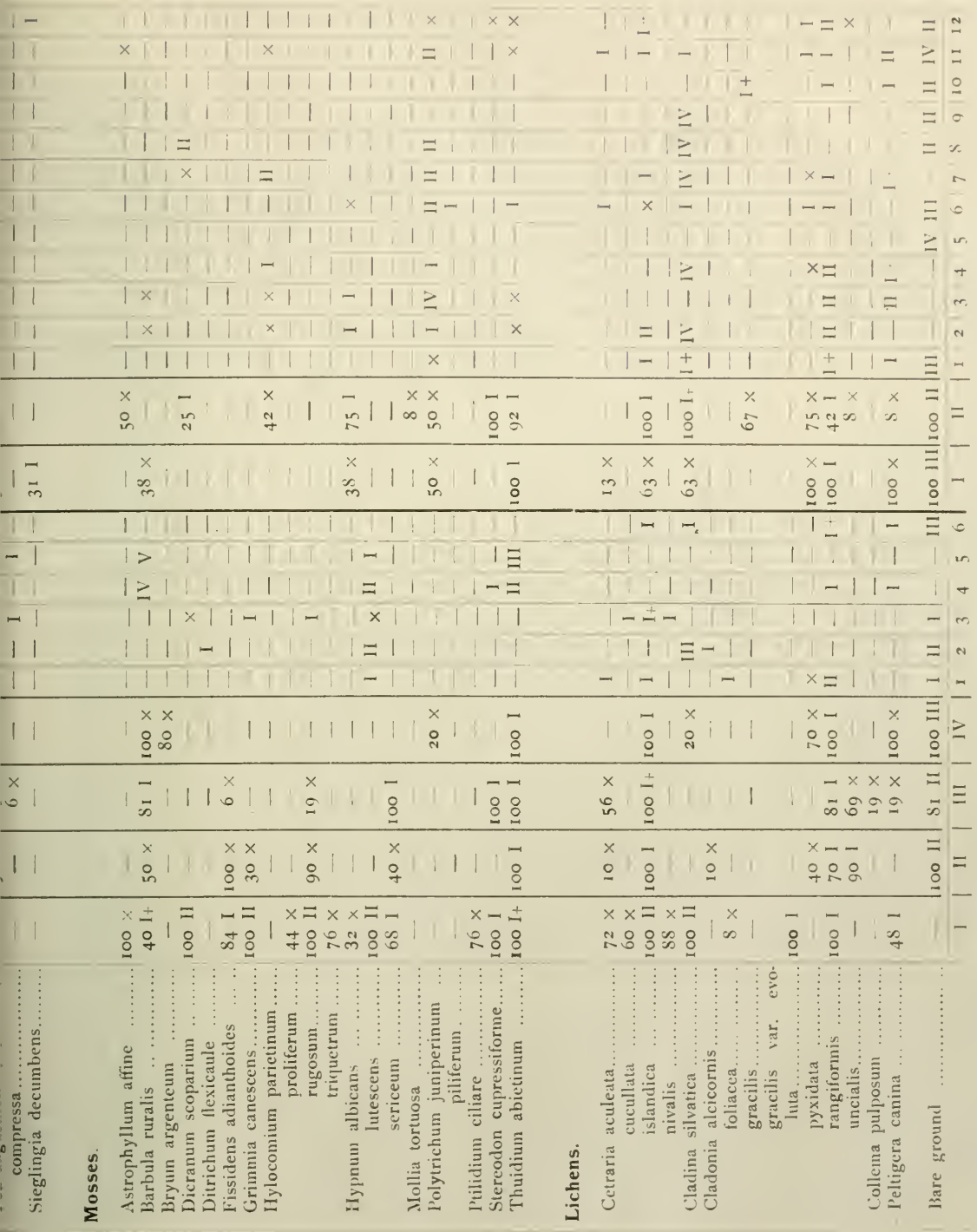


Table 3.

SARMATIAN SAND-GRASS HEATHS.

\begin{tabular}{|c|c|c|c|c|c|c|c|c|c|c|c|c|c|c|c|c|}
\hline & 1 & II & III & IV & $\mathrm{V}$ & VI & I & 2 & 3 & 4 & 5 & 6 & 7 & 8 & 9 & 10 \\
\hline \multicolumn{17}{|l|}{ Dwarf lignoses. } \\
\hline Calluna vulgaris $\ldots \ldots \ldots \ldots$ & - & - & - & - & $77 \mathrm{I}$ & - & -1 & - & - & & - & - & - & - & - & \\
\hline pelandicum & & - & — & - & - & 501 & - & - & & $\cdots$ & - & - & - & - & - & \\
\hline is communis. & 201 & - & - & - & - & - & - & - & -- & - & - & - & -1 & - & - & - \\
\hline serpyllum. & $100 \mathrm{II}$ & $100 \mathrm{II}+$ & $100 \mathrm{II}$ & 1001 & $100 \mathrm{I}+$ & $1001+$ & $I_{+}$ & - & II & III & II & 1 & III & I & & + \\
\hline \multicolumn{17}{|l|}{ Herbs. } \\
\hline Achillea millef & - & - & $50 \quad 1$ & - & $\ldots$ & - & - & - & - & - & - & - & - & $x$ & - & \\
\hline Allium oler & - & - & - & - & - & - & - & - & - & - & - & I & - . & - & - & \\
\hline & - & - & - & - & - & - & - & - & $=$ & -- & 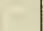 & I & - & - & - & \\
\hline Androsace se & 201 & - & 201 & So $x$ & & - & I & - & - & - & - & - & - & I & - & \\
\hline icum rar & 601 & $100 \mathrm{I}$ & - & - & - & - & - & - & - & $\cdots$ & - & - & 一 & - & - & \\
\hline a ............... & - & $100 \mathrm{I}+$ & $40 \mathrm{I}+$ & - & - & -- & - & - & - & - & - & - & - & $\times$ & - & \\
\hline ifolia $\ldots \ldots$. & - & - & - & 1001 & - & - & - & - & - & -- & $\bar{I}$ & $\overline{\mathrm{II}+}$ & - & 1 & - & \\
\hline 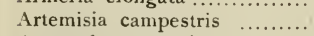 & IOO I & So 1 & So I & $100 \mathrm{I}$ & 1001 & $100 \mathrm{I}+$ & $\overline{1}$ & - & I & I & II & - & - & I & I & \\
\hline Astragalus arenarius ........... & $80 \mathrm{I}+$ & - & - & - & - & - & - & - & - & - & - & - & - & $\underline{-}$ & - & \\
\hline Botrychium lunaria .................... & - & - & $20 \mathrm{I}$ & - & - & - & - & - & - & - & $-\infty$ & - & - & - & & \\
\hline inos ............. & 一 & - & - & $20 \times$ & $s_{4} \mathrm{I}$ & 1001 & - & - & - & - & - & - & - & I & - & \\
\hline ifolia.......... & - & - & - & 201 & - & - & -1 & 一 & - & - & $I+$ & - & - & - & - & \\
\hline Cerastium p & - & -. & - & $\ldots$ & - & - & - & - & - & - & - & - & - & $x$ & - & \\
\hline adrum ... & $60 \mathrm{I}$ & $\cdots$ & $100 \mathrm{I}$ & - & - & - & I & - & - & I & - & - & $x$ & $\mathrm{I}+$ & I & \\
\hline Convolvulus & - & - & - & - & - & - & - & - & - & - & - & - & -1 & $x$ & - & \\
\hline Dianthus arenarius .. & - & $100 \mathrm{I}$ & - & - & - & - & I & - & - & - & - & - & - & - & - & \\
\hline delt & - & - & - & 601 & $91 \mathrm{I}$ & $10 \times$ & - & - & 1 & I & I & I & - & - & - & \\
\hline Erodium cicutarium .. & - & - & - & - & - & - & - & - & - & - & - & - & - & I & - & \\
\hline Euphrasia stricta ..... & - & - & - & $90 \mathrm{I}+$ & - & - & - & - & - & - & I & -- & 一 & - & - & \\
\hline Filago minima $\ldots \ldots \ldots \ldots$ & - & - & 501 & - & - & - & $\overline{\mathrm{III}}$ & - & $\overline{1}$ & $\bar{I}$ & $\bar{\mu}$ & $\overline{-}$ & $\bar{I}$ & & $\overline{I+}$ & \\
\hline $\begin{array}{l}\text { Galium verum } \ldots \ldots \ldots \ldots \ldots \ldots \\
\text { Gypsophila fastigiata } \ldots \ldots \ldots \ldots\end{array}$ & 1001 & $100 \mathrm{I}+$ & 10011 & $100 \mathrm{I}+$ & $100 \mathrm{I}+$ & $1001+$ & III & - & - & $\underline{I}$ & III & 1 & 1 & 1 & $1+$ & \\
\hline Helianthemum chamaecistus... & - & - & - & - & $2 \bar{S} \mathrm{I}$ & $1001+$ & - & - & - & - & - & - & - & $\times$ & - & \\
\hline Helicl & So 1 & - & 40 II & - & - & - & I & - & - & - & - & - & - & 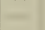 & - & \\
\hline Hieracium pilosella ............ & - & - & - & $100 \mathrm{II}+$ & $100 \mathrm{II}$ & $90 \mathrm{II}+$ & - & - & I & I & I & I & - & I & $\mathbf{I}+$ & \\
\hline & - & $40 \mathrm{I}$ & Io $\mathrm{I}$ & - & - & - & 1 & $x$ & $x$ & - & - & - & - & - & - & \\
\hline Holo & - & - & - & - & 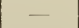 & - & - & -- & - & 1 & - & - & - & - & - & \\
\hline Hypericum perforatum... & - & - & - & -- & - & $20 \mathrm{I}$ & - & - & - & - & - & - & -- & 一 & $=$ & \\
\hline Jasio & & - & $60 \mathrm{I}+$ & 1001 & $35 \mathrm{I}$ & - & -. & - & I & - & - & - & - & - & - & + \\
\hline Lotus cornic & - & - & 301 & - & - & - & - & - & - & - & - & - & & - & - & \\
\hline Medicago falca & - & 一 & - & $10 \mathrm{I}$ & - & - & - & - & - & - & I & - & - & - & - & \\
\hline $\operatorname{lup}$ & - & 一 & - & - & - & - & - & -- & - & - & - & - & - & $x$ & - & \\
\hline Myosotis micrantha ........ . & - & - & - & - & - & - & - & - & - & - & T & 一 & - & $x$ & -- & \\
\hline Pimpinella saxifraga $\ldots \ldots \ldots \ldots$ & So I & $100 \mathrm{I}$ & 301 & - & - & $10 \times$ & I & & - & - & I & & & $\overline{1}$ & $\overline{\mathrm{J}}$ & \\
\hline 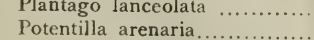 & - & - & & $\begin{array}{ll}50 & 1 \\
70 & I\end{array}$ & - & - & - & - & - & - & - & I & 一 & $\begin{array}{l}\text { I } \\
\text { I }\end{array}$ & 1 & \\
\hline arg & - & & - & $20 \times$ & $7 \times$ & - & - & - & - & - & - & 1 & & $x$ & & \\
\hline Tabernæmontani & - & - & & $20 \mathrm{I}$ & & - & - & - & - & - & I & -. & - & I & & \\
\hline
\end{tabular}




\begin{tabular}{|c|c|c|c|c|c|c|c|c|c|c|c|c|c|c|c|c|}
\hline & I & II & III & IV & V & VI & I & 2 & 3 & 4 & 5 & 6 & 7 & 8 & 9 & 10 \\
\hline Pulsatilla pratensis .. & IOO I & $20 \mathrm{I}$ & $10 \mathrm{I}$ & $100 \mathrm{I}+$ & - & - & II & - & I & I & I & - & I & II & IV & + \\
\hline Ranunculus bulbosus ...... & $-x$ & $\ldots$ & - & $40 \mathrm{I}$ & - & - & - & & - & — & - & - & & I & 1 & $\therefore$ \\
\hline Rumex acetosella .............. & $=$ & $=$ & 501 & So $x$ & $56 I$ & - & - & - & - & - & - & - & & $\times$ & 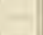 & 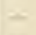 \\
\hline thyrsiflorus ........... & $=$ & 一 & $=$ & $\ldots$ & (x) & - & - & - & 一 & $=$ & $1=$ & I & 一 & $x$ & $=$ & $=$ \\
\hline Saxifraga granulata .......... & $\ldots$ & $=$ & - & $=$ & $=$ & - & I & - & $=$ & - & - & - & $=$ & I & $x$ & - \\
\hline tridactylites .... & - & + & 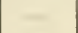 & $30 \times$ & 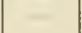 & $10 \times$ & - & - & $=$ & - & 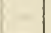 & 一 & - & - & 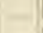 & 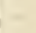 \\
\hline Scabiosa columbaria .... & - & $\cdots$ & 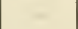 & 301 & - & $=$ & - & - & - & -5 & $=$ & - & $=$ & $=$ & - & - \\
\hline Sclersnthus perennis............ & - & - & $20 I$ & $100 I$ & $56 \times$ & - & - & - & I & - & 一 & IV & - & 一. & - & - \\
\hline Sedum acre $\ldots \ldots \ldots \ldots \ldots \ldots$ & $40 \mathrm{I}$ & - & 501 & 1001 & $91 \times$ & $80 \times$ & - & $=$ & - & 1 & I & 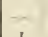 & I & I & I & + \\
\hline album & - & - & - & - & - & $100 \times$ & -- & 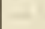 & - & - & & I & - & $x$ & - & - \\
\hline rupestre................. & - & - & - & - & 701 & I OO I & $=$ & $一$ & - & - & - & 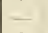 & - & I & - & - \\
\hline Silene nutans ........ & $\because$ & - & - & $100 \mathrm{I}$ & - & - & - & - & - & - & - & I & - & $x$ & I & - \\
\hline Stellaria graminea............... & - & - & - & $50 \times$ & - & - & F & - & - & - & - & - & - & - & - & -.. \\
\hline Taraxaca erythrosperma ...... & - & - & -- & $10 \times$ & - & $10 \times$ & - & 一 & - & - & $\ldots$ & - & - & I & - & 一 \\
\hline Teesdalea nudicaulis .......... & - & - & $50 \mathrm{I}$ & - & & - & - & - & - & - & - & - & - & - & - & - \\
\hline Thalictrum majus .............. & $=$ & - & - & - & - & $\ldots$ & - & - & - & - & - & - & - & $x$ & $x$ & - \\
\hline Trifolium agrarium ............ & - & - & $20 \mathrm{I}$ & - & - & -- & - & - & - & - & -- & -- & $=$ & $1-$ & - & - \\
\hline arve & - & - & $50 \mathrm{I}$ & IOO I & $77 \times$ & - & - & - & 一 & - & - & I & - & - & $=$ & - \\
\hline proc & - & - & - & So I & $21 \times$ & $=$ & - & - & $\ldots$ & - & $=$ & 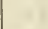 & - & 一 & 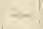 & - \\
\hline rep & - & - & - & $30 \times$ & - & $=$ & - & - & 一 & - & $x$ & $=$ & - & - & - & - \\
\hline Trimorpha acris $\ldots \ldots \ldots . . .$. & - & - & - & - & $7 \times$ & $10 \times$ & - & $\mathbf{r}^{-1}$ & $=$ & - & - & - & - & I & - & 一 \\
\hline Veronica chamædrys...... & - & - & - & $=$ & - & - & - & - & - & $-\cdots$ & - & - & - & - & $x$ & 一 \\
\hline spicata $\ldots . . . .$. & - & 一 & - & 一 & $35 \times$ & $70 \times$ & 一 & - & - & - & $\mathrm{I}+$ & - & - & I & - & \\
\hline verna & -- & 一 & $\ldots$ & - & - & & - & - & - & - & - & - & - & - & I & - \\
\hline Vicia angustifolia .............. & - & - & $\longrightarrow$ & So $x$ & - & - & - & - & - & - & - & - & - & - & - & 一 \\
\hline 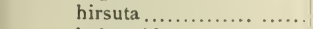 & - & 一 & - & - & - & - & $t_{1}$ & - & - & $\cdots$ & - & - & - & I & - & - \\
\hline lathyroides $\ldots \ldots \ldots \ldots \ldots$ & - & -. & - & 1001 & - & - & - & - & - & - & - & - & - & 一 & - & - \\
\hline Viola canina $. . . \ldots \ldots \ldots \ldots \ldots . . .$. & - & - & $60 \mathrm{I}$ & $70 \times$ & $42 \times$ & So $\times$ & 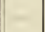 & 一 & $x$ & 1 & - & - & - & - & I & + \\
\hline rupestris $\ldots \ldots \ldots \ldots \ldots \ldots$ & $20 \mathrm{I}$ & $60 \mathrm{I}$ & 501 & $10 \times$ & - & - & - & - & $\times$ & - & - & 一 & - & - & $x$ & 一 \\
\hline tricolor $\ldots \ldots \ldots \ldots \ldots \ldots$ & - & -- & $20 \mathrm{I}$ & 一 & $14 \times$ & & - & - & $x$ & -- & - & - & - & - & $\cdots$ & - \\
\hline \multicolumn{17}{|l|}{ Grasses. } \\
\hline Agrostis $t$ & - & - & - & 50 I & $100 \mathrm{I}+$ & $100 \mathrm{It}$ & - & - & $x$ & - & $\mathrm{I}+$ & I & - & $=$ & $x^{2}$ & - \\
\hline Aira flexuosa........ & $一$ & -+ & - & $-\ldots$ & 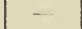 & - & - & - & - & - & $1-$ & $=$ & - & 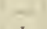 & - & + \\
\hline Anthoxanthum odoratum . & - & - & 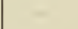 & $100 \mathrm{I}$ & - & - & - & - & I & $+\infty$ & 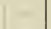 & & $=$ & I & - & - \\
\hline Avena pratensis $\ldots . . .$. . & -- & $=$ & 一 & - & $100 \mathrm{II}$ & $100 \mathrm{I}+$ & I & - & - & - & - & I & - & - & I & - \\
\hline Bromus mollis ...... & - & - & - & $70 \mathrm{I}$ & - & 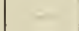 & - & - & $=$ & I & - & $=$ & - & I & - & - \\
\hline Carex arenaria ........ & $60 \mathrm{I}$ & -. & $100 I$ & $100 \mathrm{It}$ & - & - & I & I & - & - & - & 一 & I & - & IJ & + \\
\hline ericetorum .... & - & 一 & - & $50 \mathrm{I}+$ & 1001 & $100 \mathrm{I}$ & - & $\rightarrow$ & $=$ & - & - & -- & - & - & - & - \\
\hline ligerica ....... & - & - & - & - & - & - & - & 一 & $x$ & I & - & - & - & - & - & - \\
\hline obtusata $\ldots \ldots \ldots \ldots$ & - & $=$ & - & - & 一 & - & - & - & - & IV & -1 & - & - & - & - & - \\
\hline Corynephorus canescen...- & $100 \mathrm{II}$ & - & $100 \mathrm{III}$ & $90 \mathrm{I}$ & 一 & - & 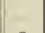 & I & I & - & -1 & - & I & - & - & + \\
\hline Elymus arenarius .............. & - & 一 & - & 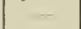 & - & - & I & - & - & - & - & 一 & - & - & - & $=$ \\
\hline Festuca ovina (vera) ....... & - & - & 一 & - & - & $100 \mathrm{It}$ & - & - & $一$ & I & II & 一 & I & - & - & $=$ \\
\hline sovinas (coll.) & - & - & - & - & - & - & - & - & - & - & 一 & - & - & III & II & + \\
\hline rubra $\ldots \ldots \ldots \ldots$ & - & - & - & - & - & - & - & - & - & - & - & 一 & - & 一 & - & + \\
\hline rubra var. arenaria. & - & - & $40 \mathrm{I}$ & - & - & - & - & - & - & - & -- & - & - & - & - & - \\
\hline sabulosa $\ldots . \ldots \ldots \ldots$ & $100 \mathrm{II}$ & 100 III & 50 II & 1001 & $100 \mathrm{I}+$ & 1001 & I & II & I & II & - & III & II & $=$ & $=$ & - \\
\hline Koeleria glauca ............... & $100 \mathrm{I}$ & $100 \mathrm{I}$ & $20 \mathrm{I}$ & - & $100 I$ & $100 I$ & II & - & I & I & - & $=$ & I & - & - & $\rightarrow$ \\
\hline Luzula cam & - & - & $10 \mathrm{I}$ & $70 \mathrm{I}$ & $63 I$ & $10 \times$ & - & $=$ & 一 & $=$ & - & 一 & - & 一 & I & - \\
\hline I'hleum Boehmeri... & - & - & & So I & 911 & 1001 & - & - & $\times$ & - & I & - & - & - & I & $\sim$ \\
\hline Poa angustifolia .... & - & - & $10 I$ & $30 \mathrm{I}$ & - & - & F & - & - & I & II & $=$ & - & 一 & I & $T$ \\
\hline compressa ...... & - & - & & $10 \times$ & - & - & $1-$ & - & $=$ & - & I & 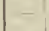 & 一 & - & - & $\div$ \\
\hline Psaınma arenaria ... & - & $=$ & $=$ & - & & $=$ & I & - & - & - & - & 1-1 & ! & - & - & - \\
\hline
\end{tabular}




\begin{tabular}{|c|c|c|c|c|c|c|c|c|c|c|c|c|c|c|c|c|}
\hline & I & II & III & IV & $\mathrm{V}$ & VI & $\mathbf{I}$ & 2 & 3 & 4 & 5 & 6 & 7 & 8 & 9 & 10 \\
\hline \multicolumn{17}{|l|}{ Mosses. } \\
\hline Barbula ruralis & $20 \mathrm{I}$ & $20 \mathrm{I}$ & $60 \mathrm{I}+$ & 8o I & $7 \times$ & $10 \times$ & - & - & - & II & - & - & II & II & II & \\
\hline Cleve & - & - & - & - & - & $10 x$ & - & - & - & - & - & - & - & - & - & 一 \\
\hline Climacium dendroides. & - & - & - & $20 \mathrm{I}$ & - & - & - & - & - & - & - & - & - & - & - & - \\
\hline nia canescens ..... & IOO I & $100 \mathrm{~V}$ & $40 \mathrm{I}$ & - & - & 601 & - & - & - & - & - & II & III & - & I & - \\
\hline Hylocomium parietinum ..... & - & - & - & - & $7 \times$ & - & - & - & - & - & - & - & - & - & $\therefore$ & - \\
\hline Hypnum albicans ................ & - & - & - & $30 \times$ & - & - & - & 一 & - & - & - & - & - & - & - & - \\
\hline & $-\ldots$ & - & - & $40 \times$ & - & - & - & - & - & I & - & - & - & $1+$ & - & - \\
\hline Polytrichum juniperinum & - & - & - & $30 \times$ & - & $50 \mathrm{I}$ & - & - & - & 一 & - & $\mathrm{I}+$ & - & - & $x$ & - \\
\hline piliferum & $\ldots$ & - & $20 I$ & - & - & - & - & - & - & 一 & - & - & - & - & - & - \\
\hline I'tilidium $\mathrm{c}$ & - & - & - & - & $7 \times$ & - &.- & - & - & - & - & -1 & - & -- & - & \\
\hline St & - & - & - & I00 I & - & $100 \mathrm{I}$ & III & - & - & - & - & - & - & - & $\ldots$ & - \\
\hline Thuidium abietinum..... & - & - & - & $90 \mathrm{I}$ & - & - & I & - & - & IV & - & - & - & I & II & \\
\hline \multicolumn{17}{|l|}{ Lichens. } \\
\hline Cetraria aculeat & IOO III & 100 II & $100 \mathrm{IV}$ & - & $49 \times$ & $100 \mathrm{I}+$ & - & III & I & - & - & - & I & II & 一 & \\
\hline cucullata & - & & - & - & - & - & - & - & - & I & 一 & - & - & $\bar{T}$ & 一 & \\
\hline islandica & - & - & - & 100 III & $100 \mathrm{I}+$ & $\mathrm{IOO} \mathrm{I}+$ & I & - & II & I & - & - & II & I & -1 & - \\
\hline - nival & - & - & - & $-\overline{-}$ & $\begin{array}{lll}100 & \mathrm{I} \\
100 & \mathrm{~V}\end{array}$ & 1001 & & & $\bar{u}$ & $\bar{T}$ & - & $\bar{U}$ & I & E & $\bar{I}$ & 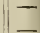 \\
\hline $\begin{array}{l}\text { Cladina sil } \\
\text { Cladonia fi }\end{array}$ & $100 \mathrm{II}$ & 401 & $\begin{array}{cc}60 & \text { II } \\
10 & I\end{array}$ & $10011+$ & 100 & 100 & - & 10 & - & 1 & - & II & E & - & -1 & 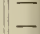 \\
\hline faconid & $20 \mathrm{I}$ & - & $40 \mathrm{I}$ & - & - & $30 \times$ & - & - & $x$ & - & - & - & - & - & - & 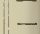 \\
\hline $\mathrm{ft}$ & $100 \mathrm{II}$ & $100 \mathrm{II}$ & - & $\ldots$ & - & - & - & - & - & - & - & - & - & - & - & - \\
\hline g & - & - & - & - & $100 \mathrm{It}$ & Ioo It & - & - & - & - & - & - & $\ldots$ & - & - & \\
\hline p & - & - & $10 \mathrm{I}$ & $50 \mathrm{I}$ & - & $10 \times$ & - & - & - & - & - & - & $x$ & - & - & \\
\hline r & - & - & $60 \mathrm{III}$ & $100 \mathrm{I}$ & $7 \times$ & $10 x$ & I & I & - & I & - & - & $\mathrm{I}_{+}$ & I & I & \\
\hline & - & - & - & So $x$ & $49 \times$ & $40 \times$ & - & I & $x$ & - & - & - & - & - & - & \\
\hline Evernia pr & - & . & $3^{\circ} \mathrm{I}$ & - & - & - & - & - & - & $\ldots$ & - & - & - & - & - & $\ldots$ \\
\hline Parmelia furfuracea ........... & 一 & 一 & Io I & -- & - & - & - & - & - & - & - & - & - & - & - & \\
\hline physo & - & - & $50 \mathrm{I}$ & - & - & - & - & - & - & - & - & - & - & - & - & \\
\hline Peltig & - & - & - & So I & $.7 \times$ & - & I & -. & - & - & - & - & - & - & I + & \\
\hline Stereocaulon paschale ........ & - & - & - & $100 \mathrm{I}$ & - & - & - & - & - & - & - & - & - & -. & - & \\
\hline tomentosum....... & - & - & - & - & $84 \times$ & So $x$ & - & - & - & 一 & - & - & - & - & - & - \\
\hline \multicolumn{17}{|l|}{ Fungi. } \\
\hline Tulostoma mammosum & - & $20 \mathrm{I}$ & - & - & - & - & - & - & - & - & - & |- & - & - & -- & \\
\hline
\end{tabular}




\section{Table 4.}

\section{THE FLORA UN SOUTHERLY EXPOSED ROCKY ESCARPMEN'TS IN SOUTH-}

\section{EASTERN SWEDEN.}

I. SW Smailand: Ramkvilla Holmeshult; 2. NE Smailand: Gladhammar Botorp; 3. D.o: Iljorted Fagersand; 4. D:o: Hallingeberg Hjortstad; 5. Östergötland: Oppcby Drabo; 6. D:o: Kisa (iummetorp; 7. D:0: d:0 Örneström; S. I):o: Tjärstad Räckskog; 9. D:o: d:o S. Krågedal; 10. D:o: Gryt Heinsjön; 11. D:o: Mogata Sörby; 12. Södermanland: Vărdinge Mölnbo; 13. D:o: Västerljung Hagstugan; 14. D:0: Hyltinge Tunatorp; 15. 1):0: d:0 Långdunker; 16. D:o: L. Malma Kroksätter 17. D:o: Gåsinge Forsbro; IS. D:o: d:0 Svinsjön; 19. D:0: Stenkvista Helleberga; 20. Lppland: Alsike Morga; 21. D:o: Upsala-Näs Vreta.

\section{Trees and shrubs.}

Acer platanoides.

Arctostaphylos uva ursi

Berberis vulgaris

Betula verrucosa

Calluna vulgaris

Corylus avellana .....

Cotoneaster integerrima

melanocarpa

Cratægus oxyacantha

Fraxinus excelsior

Juniperus communis

Lonicera xylosteum

Picea abies

Pinus silvestris

Populus tremula

Prunus cerasus padus spinosa

Pyrus malus

Quercus pedunculata

Rhamnus cathartica

Ribes alpinum

grossularia

Rosa canina

$$
\text { villosa }
$$

Rubus cæsius idxus

Salix caprea suberectus (coll.

Sambucus nigra

Solanum dulcamara

Sorbus aucuparia suecica.

Tilia europæa

Vaccinium vitis idæa

Viburnum opulus

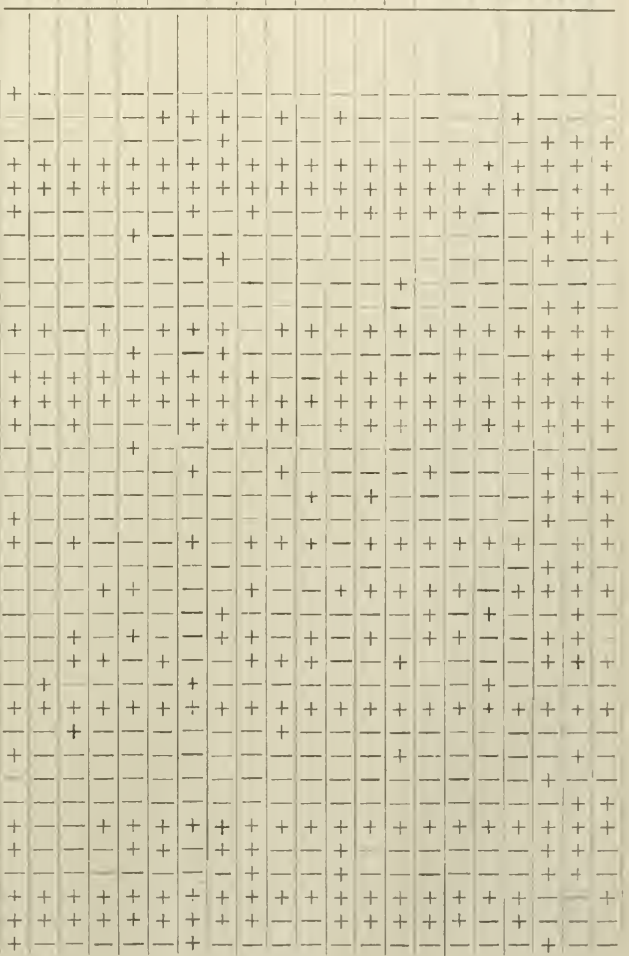




\section{Herbs}

Achillea millefolium

Arabis hirsuta....

Arabis thaliana

Artemisia campestris

Asplenium septentrionale

trichomanes

Astragalus glycyphyllus

Calamintha acinos

Campanula rotundifolia

Chamænerium angustifolium

Chelidonium majus.

Cirsium arvense

\section{lanceolatum}

Clinopodium vulgare

Crepis tectorum

Cynanchum vincetoxicum

Cystopteris fragilis

Dryopteris filix mas

Epilobium collinum

Filago arvensis

Filipendula hexapetala

Fragaria vesca

Galeopsis bifida ...

$$
\begin{aligned}
& \text { specios } \\
& \text { tetrahit }
\end{aligned}
$$

Geranium lucidum

pusillum

Robertianum

sanguineum

Hieracia cymosa

rigida.

vulgata

Hieracium pilosella ...

Hypericum montanum perforatum

Hypochoeris maculata

Jasione montana

Lactuca muralis

Lathyrus niger silvestris

Myosotis arvensis Origanum vulgare

Plantago lanceolata.

Polygonatum odoratum

Polygonum dumetorum

Polypodium vulgare

Potentilla argentea

Tabernæmontani

Rumex acetosella

Saxifraga granulata.

Scleranthus perennis

Scrophularia nodosa

Sedum acre.

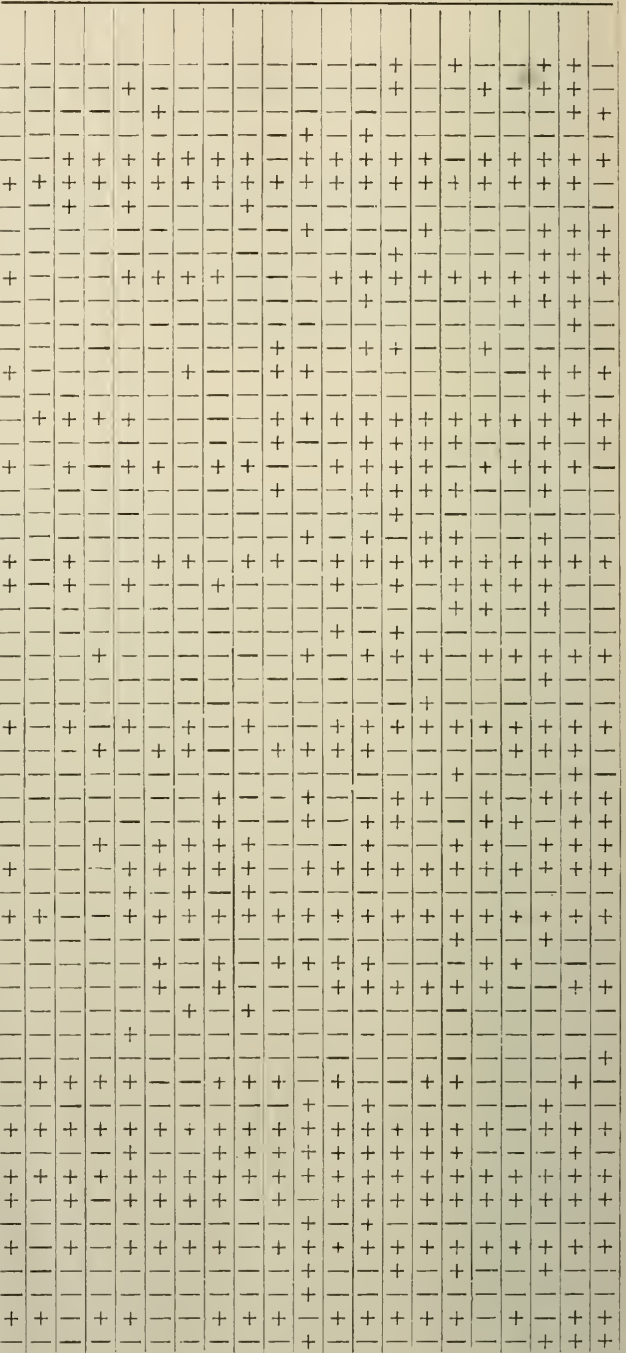




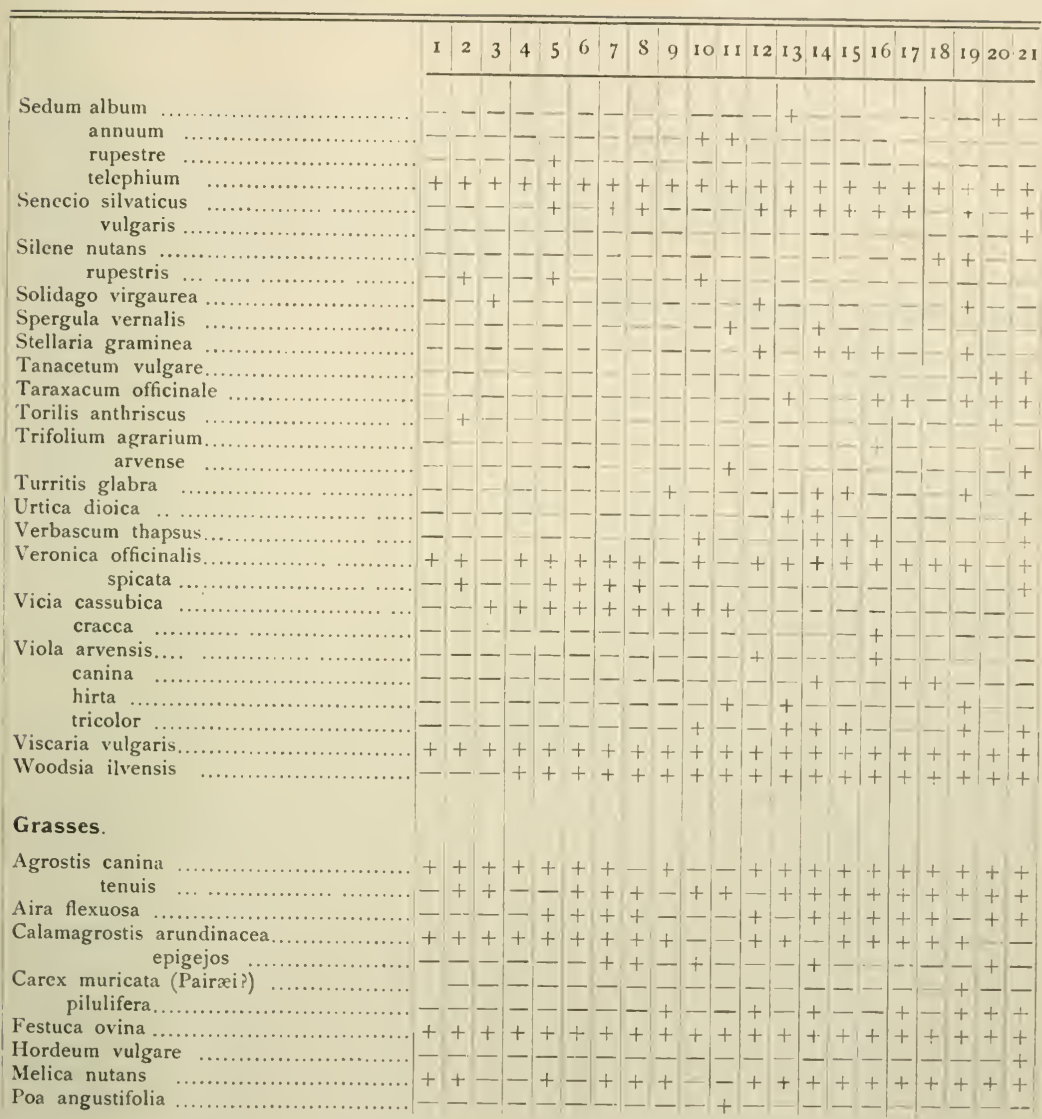


Table 5.

WOOD-MEADOWS IN SOUTH-EASTERN SWEDEN.

I and I-7 Calamagrostis arundinacea-ass.; 8 and 9 Arnica montana-ass.

\begin{tabular}{|c|c|c|c|c|c|c|c|c|c|c|}
\hline & I & 1 & 2 & 3 & 4 & 5 & 6 & 7 & 8 & 9 \\
\hline \multicolumn{11}{|l|}{ Under-shrubs (tree-seedlings) and herbs. } \\
\hline Achillea millefolium & - & $\cdots$ & - & - & - & - & $x$ & - & $x$ & $x$ \\
\hline Ajuga pyramidalis ............ & - & - & - & - & $x$ & - & $x$ & - & - & - \\
\hline Alchemilla pubescens........... & - & - & - & - & - & - & - & - & I & $x$ \\
\hline Anemone hepatica ........... & $10 \times$ & - & $\times$ & - & I & $x$ & I & - & - & $x$ \\
\hline nemoros & - & $x$ & - & - & $\overline{-}$ & - & - & - & - & $\bar{x}$ \\
\hline $\begin{array}{l}\text { Antennaria dioica } . . . . \\
\text { Arnica montana }\end{array}$ & $10 \mathrm{I}$ & - & - & - & 1 & - & - & - & I & I \\
\hline $\begin{array}{l}\text { Arnica montana ........... } \\
\text { Campanula persicifolia }\end{array}$ & $\operatorname{so}_{0}(x)$ & $(x)$ & - & $(\bar{x})$ & - & - & $\overline{(x)}$ & $\overline{(x)}$ & II & II \\
\hline Campanula $\begin{array}{c}\text { persicifolia } \\
\text { rotundifolia } \ldots \ldots \ldots\end{array}$ & $20 \times$ & $x$ & - & ( & - & - & $(x)$ & $\begin{array}{l}(x) \\
x\end{array}$ & - & $\left(\begin{array}{l}x \\
\mathrm{I}\end{array}\right.$ \\
\hline Chrysanthemum leucanthemum. & - & - & - & - & - & - & - & - & I & I \\
\hline Cirsium heterophyllum ...... & - & - & - & - & - & $x$ & - & - & - & - \\
\hline Convallaria majalis...... & $30(\mathrm{I})$ & I & III & I & - & II & - & - & - & - \\
\hline Filipendula hexapetala ... & Io (I) & - & - & I & - & - & - & - & $(\dot{x})$ & - \\
\hline Fragaria vesca $\ldots \ldots \ldots \ldots$ & - & - & - & - & - & $\bar{T}$ & I & - & - & - \\
\hline Galium boreale. & $70 \times$ & - & - & - & - & I & $x$ & - & I & - \\
\hline verum............ & Io $(\mathrm{I})$ & - & - & I & - & - & - & - & - & - \\
\hline Geranium sanguineum & - & - & - & II & - & - & - & - & - & - \\
\hline silvaticum .. & $40 \times$ & - & $x$ & $x$ & - & $x$ & I & $x$ & - & - \\
\hline Geum rivale ......... & $10 \times$ & - & - & - & - & - & - & - & - & - \\
\hline Helianthemum chamaecistus & - & - & - & - & - & - & - & - & I & - \\
\hline Hieracium pilosella............ & - & - & - & - & - & - & - & - & $x$ & I \\
\hline umbellatu & I0 $\times$ & - & - & - & - & - & - & - & - & - \\
\hline Hypericum quadrangulum. & $70 \times$ & - & - & - & $x$ & I & $x$ & I & - & - \\
\hline Hypochoeris maculata....... & - & $x$ & -_ & - & - & - & - & - & I & - \\
\hline Laserpitium latifolium ... & $10 \times$ & - & I & $(x)$ & (I) & $\mathrm{I}+$ & - & $(x)$ & - & - \\
\hline Lathyrus montanus..... & $100(\mathrm{I})$ & I & I & - & - & I & I & $x$ & I & I \\
\hline Lotus corniculatus .. & - & - & - & - & I & - & - & $x$ & I & I \\
\hline Melampyrum nemorosum & $20(\mathrm{I})$ & III & II & - & II + & - & $\mathrm{II}+$ & $I+$ & - & - \\
\hline pratense .. & - & I & - & - & - & - & - & - & - & I \\
\hline Pimpinella saxitraga & - & $(x)$ & - & - & - & - & - & - & - & - \\
\hline Polygala vulgaris $\ldots \ldots$ & - & - & - & - & I & - & - & - & $(x)$ & $x$ \\
\hline Polygonatum odoratum & - & - & $(x)$ & - & -. & - & - & - & - & - \\
\hline Populus tremula .......... & $20 \times$ & - & - & - & - & $\mathrm{x}$ & $x$ & - & - & - \\
\hline Potentilla erecta ............... & $100 \mathrm{I}+$ & I & - & - & I & I & $x$ & I & I & I \\
\hline 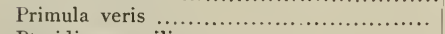 & - & - & $x$ & - & I & - & - & - & - & - \\
\hline Pteridium aquilinum $\ldots \ldots \ldots \ldots \ldots \ldots \ldots \ldots \ldots$ & $20(\mathrm{I})$ & - & - & - & - & - & - & - & - & - \\
\hline Pulmonaria angustifolia $\ldots \ldots \ldots \ldots \ldots \ldots \ldots$ & - & - & - & - & - & - & - & - & I & - \\
\hline 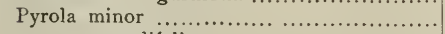 & $10(x)$ & - & - & - & - & - & - & - & - & - \\
\hline rotundifolia .. & $10 \times$ & - & - & - & - & - & - & - & - & - \\
\hline Ranunculus acris................ & $10(x)$ & - & - & - & - & - & - & - & - & - \\
\hline polyanthemos .... & - & - & - & I & I & - & - & - & - & $x$ \\
\hline Rubus saxatilis ............ & $40(\mathrm{I})$ & - & - & - & - & I & $x$ & - & - & - \\
\hline Rumex acetosa ....... & - & - & $x$ & -- & I & - & - & - & - & - \\
\hline Scorzonera humilis.... & - & - & - & - & - & $x$ & - & - & $\mathrm{II}+$ & - \\
\hline Selinum carvifolia ... & $20(x)$ & - & - & - & - & $x$ & - & $x$ & - & - \\
\hline Serratula tinctoria & $60(x)$ & - & - & - & - & I & - & $x$ & - & - \\
\hline
\end{tabular}




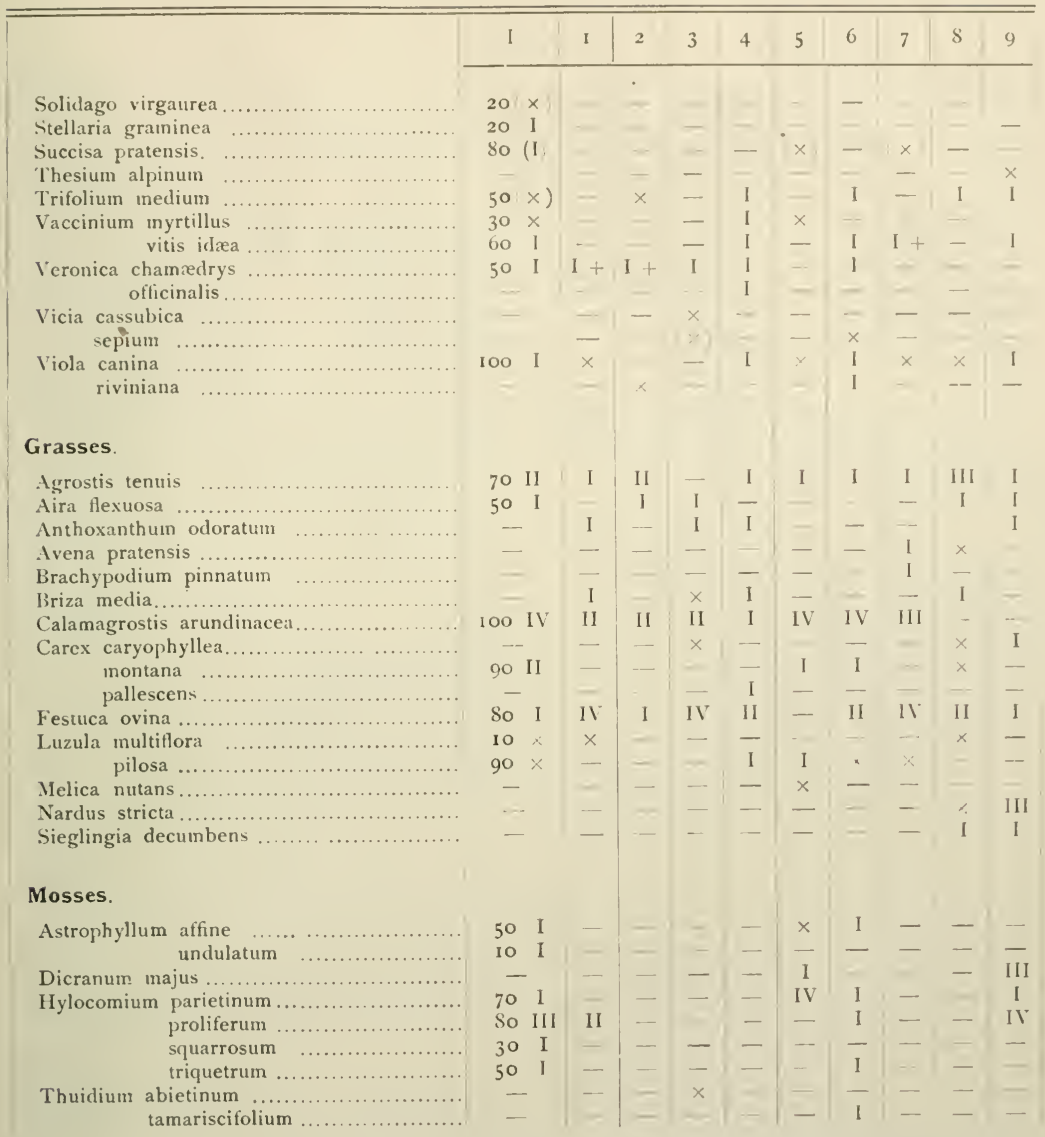

The degree of covering being within parentheses the species was represented in the areal only as young, not-flowering specimens. 
Table 6.

DWARF-SCRUBS OF POTENTILLA FRUTICOSA ON THE ALVAR OF ÖLAND.

\begin{tabular}{|c|c|c|c|c|c|c|c|c|c|}
\hline & 1 & 2 & 3 & 4 & & I & 2 & 3 & 4 \\
\hline Under-shrubs. & & & & & Ranunculus polyanthemos... & $x$ & -- & - & - \\
\hline Potentilla fruticosa & $\mathrm{V}$ & IV & IV & IV & Selinum carvifolia ............ & - & I & - & - \\
\hline Rosa cinnamomea ............ & - & I & & - & Serratula tinctoria....... & - & I & - & - \\
\hline Salix repens $\ldots \ldots \ldots \ldots \ldots \ldots$ & II & II & - & IV & Seseli libanotis .......... & $x$ & - & - & - \\
\hline Thymus serpyllum & - & - & $x$ & $x$ & Succisa pratensis & $x$ & - & $x$ & $x$ \\
\hline Herbs. & & & & & Viola stagnına & - & $\cdots$ & $x$ & - \\
\hline Centaurea jacea.. & $x$ & - & - & - & Grasses. & & & & \\
\hline $\begin{aligned} \text { Filipendula } & \text { hexapetala } . . . . . \\
& \text { ulmaria } \ldots . . . \ldots .\end{aligned}$ & $\stackrel{x}{-}$ & $\overline{\text { IV }}$ & $\times$ & $x$ & $\begin{array}{l}\text { Agrostis stolonifera } \ldots \ldots \ldots \\
\text { Calamagrostis epigejos ....... }\end{array}$ & $\underline{I}$ & $\bar{I}$ & - & - \\
\hline Galium boreale............... & I & $\ldots$ & - & - & Carex muricata (Pairæi?)... & $x$ & - & - & - \\
\hline $\begin{array}{l}\text { palustre } \quad \ldots \ldots \ldots \ldots \\
\text { verum } \ldots \ldots \ldots \ldots\end{array}$ & $x$ & I & - & - & $\begin{array}{l}\text { tomentosa }_{1} \ldots \ldots \ldots \\
\text { Festuca ovina } \ldots \ldots \ldots \ldots \ldots\end{array}$ & II & - & $\bar{x}$ & $\overline{\mathrm{I}}$ \\
\hline Geranium sanguineum ...... & - & I & - & - & Molinia coerulea & - & $x$ & III & III \\
\hline Geum rivale $\ldots \ldots \ldots \ldots \ldots$ & II & I & -. & - & Sesleria coerulea & I & - & IV & II \\
\hline Helianthemum vulgare ...... & $\times$ & 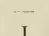 & - & - & Mosses. & & & & \\
\hline $\begin{array}{l}\text { Inula salicina } \ldots \ldots \ldots \ldots \ldots \\
\text { Lathyrus pratensis } \ldots \ldots \ldots \ldots\end{array}$ & I & $\begin{array}{l}1 \\
x\end{array}$ & - & $\overline{-}$ & Ctenidium molluscum & - & -- & II & I \\
\hline Linum catharticum .......... & - & - & $x$ & - & Dicranum scoparium........ & - & - & I & - \\
\hline Plantago lanceolata & $x$ & - & - & - & Fissidens adianthoides ...... & - & - & I & - \\
\hline Potentilla erecta ... & I & - & $x$ & $x$ & Hylocomium proliferum ... & $\mathrm{V}$ & - & - & - \\
\hline $\begin{array}{c}\text { Primula farinosa } \ldots \ldots \ldots \ldots \\
\text { veris }\end{array}$ & $\bar{x}$ & - & $\times$ & - & $\begin{array}{r}\text { triquetrum } \ldots \\
\end{array}$ & I & III & - & $\bar{H}$ \\
\hline veris..... & $x$ & - & & - & Hypnum lutescens............ & - & II & - & 111 \\
\hline
\end{tabular}

Table 7.

VEGETATION WITH PLANTAGO TENUIFLORA ON THE ALVAR OF ÖLAND.

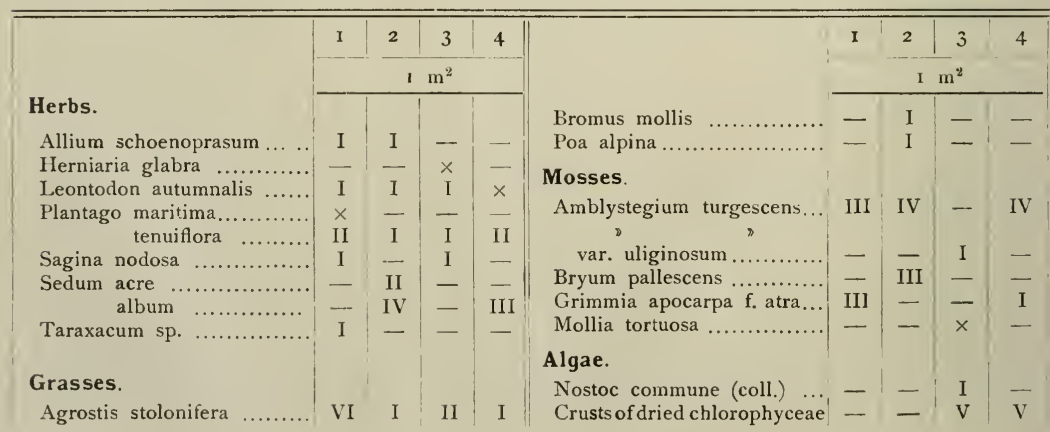




\section{INIEEX OF VASCULAR PLAN'TS.}

To the regetation-analyses in Appendix II there are not given references. The tage-numbers printed in heavy lype refer to pages on which distribution-maps are given.

Acer campestre 338 .

》platanoides $230,367,407$.

» tataricum 338 .

Achillea millefolium 288, 303, 304 .

Achroanthes monophyllos 240, 335, 370, 37 I, 4 I0; Pl. 21.

Adonis vernalis 239, 291, 328, 331, 399; Pl. It.

Agrimonia eupatoria $338,340,344,349$. * pilosa 240,402 .

Agrostis tenuis 288, 289, 303, 304 .

Ajuga genevensis 344,402 .

Alchemilla pubescens 304 .

Allium montanum 28r, 29r, 298-300, $309,328,332,333,396$; Pl. 6.

» schoenoprasum 357 .

Alopecurus pratensis 363 .

» ventricosus $370,372,4 \mathrm{IO}$.

Anacamptis pyramidalis 276 .

Anchusa officinalis 293 .

Andropogon gryllus 238 .

Anemone hepatica $234,367,408$.

» ranunculoides $234,367,368$, 408 .

» $\quad$ illvestris $239,29 \mathrm{I}, 328,33 \mathrm{I}$, 399; Pl. I 7.

Antennaria dioeca 303 .

Anthemis tinctoria 293 .

Anthericum liliago $276,289,332$.

》 ramosum 289 .

Arabis Gerardi 370,376, t10.

» hirsuta 320 .

* thaliana 305 .

Arctostaphylos uva ursi $302-305$.

Arenaria serpyllifolia 303,304 .

Arnica montana 342 .

Artemisia campestris $289,29 \mathrm{I}, 299-30 \mathrm{I}$, $306,308,309,311,314,320$, 321,396 ; Pl. 5 .
Artemisialaciniata $24 \mathrm{I}, 28_{3}, 29 \mathrm{I}, 298$, 328,395 .

rupestris $241,282,328,395$.

scoparia $24 \mathrm{I}$.

Asparagus officinalis 357 .

Asperula aperina 239 .

» tinctoria 239, 299, 300, 314. $315, \quad 322, \quad 328, \quad 331-335, \quad 399$; Pl. 5 and 15 .

Aster amellus 329 .

» linosyris $239,291,328,399$.

Astragalus arenarius $240,289,293,300$, 327,401 ; Pl. I 9.

$\gg \quad$ austriacus 238 . cicer 336 .

exscapus 238 .

„ glycyphyllus 304, 306 .

Atriplex pedunculatum 239, 282, 395 .

Avena pratensis $284,288,289,306$, 3 I $3,314$.

Bassia hirsuta $239,282,298,328,330$, 395 ; Pl. 13.

Betula humilis 414 .

» nana 324 .

Bidens radiatus $370,371,376,41 \mathrm{I}$.

Brachypodium pinnatum 284, 303, 305 .

Briza media 288,304 .

Bromus Benekeni $367,408$.

erectus 284 . inermis 284,363 .

Bunias orientale 363 .

Bupleurum aureum 240.

Calamintha acinos 305,320 .

Calamagrostis arundinacea $240,338,3+1$, $3+7,406 ; \mathrm{Pl}, 22$.

Calla palustris $240,370,4$ I I.

Campanula bononiensis 239 . 
Campanula cervicaria 34 r, 348, 406; Pl. I I. patula $3^{6}{ }_{3}$.

persicifolıa $304,348,406$. rotundifolia $288,289,303,304$. sibirica 239 .

Cardamine parviflora 370, 371, 376, 411.

Carex arenaria 285,289 .

》 caryophyllea 289,304 . ericetorum $240,285,289,303$. $304,306,401$.

laevigata 234 .

》 ligerica $24 \mathrm{I}, 285,286,289,292$. $298,328,335,396$.

montana 306 .

obtusata $24 \mathrm{I}, 282,289,291,298$, $300,328,396$.

ornithopoda 335 .

praecox $239,28 \mathrm{I}, 285,286,29 \mathrm{I}$, 336.

vulpina 370,37 I, 375, 4 I I.

Carpinus betulus 230 .

Cenolophium Fischeri 240.

Centaurea jacea 291, 299, 300,305,306, 3 I $5,399$.

phrygia 239.

scabiosa 293.

Chimaphila umbellata $240,320,365,405$; P1. I 2 .

Cichorium intybus 363 .

Chrysanthemum leucanthemum 304.

Cinna pendula 368 .

Cirsium oleraceum 240, 370, 4 I I.

Clinopodium vulgare $305,338,340$.

Cnidium venosum $240,241,332,364$, 404 ; Pl. 20.

Convallaria majalis $33^{8}$.

Corispermum Marschallii $24 \mathrm{I}$.

Corydalis cava $367,368,375,408$. intermedia 367 .

laxa 409.

pumila 335,367 .

solida $367,308,409$.

Corynephorus canescens 285,289 .

Cotoneaster melanocarpa 299, 303, 347, 402 ; Pl. I 2.

Crepis praemorsa 239, 28I, 29I, 299, $300,303,307,308,314,315,3$ I ,
32 I $-323,332,335,342,349,399$;

Pl. 17 .

Cynanchum vincetoxicum 239, 332, 338, $340,352,402$; Pl. 9 and $\mathrm{I} 8$.

Delphinium elatum 239.

Dianthus arenarius $240,289,293,300$, 327,401 .

carthusianorum 329,336 .

deltoides 289,305 .

superbus 364,404 .

Draba muralis 335,$357 ; \mathrm{Pl}$. Io.

» nemorosa 294, 396.

》 verna 305 .

Dracocephalum Ruyschiana 240, 299, $305-307, \quad 326,333,344,402$; Pl. 3,4 and 20 .

Elatine triandra $373,4 \times 3$.

Erica tetralix $324,375,379$.

Eryngium campestre 329, 332, 334.

Euphorbia amygdaloides 234 . palustris $370,4 \mathrm{I} 2$. virgata 363 .

Evonymus verrucosa $239,33^{8}$.

Fagus silvatica $230,233,243,379$.

Festuca ovina $288,289,3 \circ 3,304$. pratensis 363 .

» rubra $28_{4}, 2 S_{5}$. sabulosa $289,293$.

Filipendula hexapetala 288,289 .

Fragaria viridis $281,288,291,299,300$,

$$
308,315,399 \text {. }
$$

» vesca $303,304,33^{8}$.

Fumana vulgaris 276 .

Gagea minima 367,408 .

» spathacea 367 .

Galium saxatile 379 . verum $288,289,304,305,320$.

Geranium bohemicum $335,366,405$; Pl. I 2.

» palustre $239,370,4$ I 2 .

» pratense $3^{6} 3$.

» sanguineum $338,340,345,349$.

» silvaticum 338 .

Geum aleppicum 239.

Globularia vulgaris 276 . 
Glyceria lithuanica 368 .

Gypsophila fastigiata $240,293,300,327$, 328,402 ; Pl. 21 .

Helianthemum "canum Baumg.» 276. chamaecistus 288,289 , $305,320,321$. oelandicum 276,289 .

Helichrysum arenarium 289, 291, 300, 327,$396 ; \mathrm{Pl} .5$.

Heracleum sibiricum 240, 360, 406. sphondylium 360,406 .

Herniaria glabra 305 .

Hieracium cymosum 304 .

" echioides 239

" pilosella $288,289,303,304$.

"umbellatum 304 .

" vulgatum 304.

Holosteum umbellatum 239, 292, 300, $327,397$.

Hypericum elegans 238 .

\ montanum $303,307,346,347$.

$\gg$ perforatum 304 .

Ilex aquifolium 246.

Inula britannica $240,364,375,404$.

》 ensifolia $274,298,299,322,328$, 400.

» salicina $320,348,406$; Pl. 7 .

》vrabelyiana 298,400 .

Iris arenaria 238.

Isatis tinctoria $282,292,324,325,397$.

Jasione montana 305 .

Juncus squarrosus 379 .

Juniperus communis $3 \circ 3$.

Knautia arvensis 303.

Koeleria xcristata" 284 .

》glauca $240,241,286,289,291$, $298,300,327,397$.

» grandis $240,242,402$.

Lactuca quercina $238,274,360,403$.

Laserpitium latifolium $240,300,304$, 34 I, 349, 403; Pl. 7.

Lathyrus heterophyllus $304,307,326$; Pl. 4.
Lathyrus montanus 304 .

niger 304,340 .

sphaericus 276 .

vernus $240,367,409 ;$ Pl. 22.

Lavatera thuringiaca $239,294$.

Ledum palustre $240,335,374,414$.

Lepidium latifolium 294, 395.

Lonicera xylosteum 367,400 .

Lotus corniculatus 305 .

Luzula campestris $288,289,304$. pallescens 360,406 .

Lysimachia nemorum 2,34 .

Malva alcea 294.

Medicago falcata 288, 291, 300, 315, 332,397 .

minima 291, 300, 327, 397.

Nelampyrum arvense $294,397$. cristatum 340, 349; Pl. 7 . nemorosum $239,332,338$, $34 \mathrm{I}, 350,37$ I, 406; Pl. 8, 9 , 10 , and 16 .

Melandrium album 363 .

Nelica ciliata 239, 281, 292, 299, 309, $324,335,357,397$; Pl. 10. nutans $304,33^{8}$.

Melilotus albus $36_{3}$.

Mulgedium tataricum 328 .

Myosotis micrantha 306 .

Narthecium ossifragum 379 .

Omphalodes scorpioides 240.

Ononis arvensis (= hircina) $240,3^{6} 3$, 375,405 ; Pl. 19.

Orchis militaris 276 . Dustulata 276 .

Origanum vulgare 338,340 .

Oxytropis campestris 299, 305-307, 331; Pl. 3 .

pilosa 239, 291, 298, 299. $306,328,331,334,397$.

Petasites spurius $241,242,364,405$.

Peucedanum oreoselinum $286,292,298$, 300,398 .

Phleum Boehmeri 239, 284-291, 299, $300,304,306-308,314$, 
$320-323,332,398 ;$ Pl. 3, 5, and 18 .

Phleum pratense $3^{6} 3$.

Picea abies $240,243,365,405$.

Pimpinella saxifraga $288,303,304,320$.

Pinus silvestris $240,338,365,405$.

Plantago lanceolata $288,289,304$.

tenuiflora $238,283,298,328$, 329, 396; Pl. I 3 .

Poa angustifolia $288,289,303,304$.

" bulbosa 239, 292, 300, 306, 309, $324,327,331,357,398$.

remota 367,407 .

Polygala comosa 28r, 291, 299, 300, $314-316,316,320,322$, $323,334,335,400$.

vulgaris 304 :

Polygonatnm odoratum 305,338 .

Polygonum bistorta $3^{6} 3$.

Populus tremula $233,304,338,34 \mathrm{I}$.

Potentilla alba 240 .

arenaria $290,291,296,299$, $303-3 \circ 7,326,332-335$, 398 ; Pl. 3 and 6 .

» argentea 289,305 .

erecta 338 .

fruticosa $241,329,360,403$.

leucopolitana $293,304,305^{--}$

$307,402$.

rupestris 241, 291, 298, 299, $304,305,307,309,325$, 326, 333,398 .

sterilis 234 .

Tabernaemontani $288,289,304$, 306,307 .

Primula veris 304 .

Prunella grandiflora 239, 281, 291, 299, $322,332-335,400$; Pl. 6 .

Prunus fruticosa 338 .

padus 338 .

spinosa 338 .

Pteridium aquilinum 303,338 .

Pulmonaria angustifolia 299, 303-307, $326,332,335,344,403$; Pl. 3 and 4 .

obscura 320, 368, 409; Pl. I I. officinalis 367,409 .

Pulsatilla nigrescens Störck» 333,402 .
Pulsatilla patens 291, 298, 328, 331, 398 .

\) pratensis $240,242,289,293$, $300,304,305,306,314$, $327,331-335,333,402$; Pl. 3 .

» vernalis 313,314 .

" vulgaris $304,320,321$.

Pyrola chlorantha 240, 366, 405; Pl. 22.

Quercus pedunculata $229,233,338-340$, 349.

Ranunculus cassubicus 239, 368, 409; $\mathrm{Pl} I 5$.

illyricus $238,292,298,329$, 33 I, 398; Pl. I 3 .

polyanthemos $240,28 \mathrm{I}, 29 \mathrm{I}$, $296,299,300,308,314-$ 32 I, 319, 34I, 342, 349, 400 .

Rhamnus frangula 338 .

Rhus cotinus 239 .

Rosa Jundzillii 360,403 .

villosa $3 \circ 3$.

Rubus saxatilis $33^{8}$.

Rumex ucranicus $24 \mathrm{I}$.

Salvia pratensis 294 .

Saxifraga granulata 320 .

Scabiosa columbaria 306 .

Scilla non scripta 234 .

Scirpus radicans $370,371,376,412$.

Scleranthus perennis $289,305-307$.

Scolochloa festucacea $240-242,370$ $37 \mathrm{I}, 4 \mathrm{I} 2$.

Scorzonera humilis $240,348,407$.

$$
\text { » purpurea } 329 \text {. }
$$

Scutellaria hastifolia $335,356,364,365$, 405; Pl. Io.

Sedum acre 289,305 .

» album $306,335,356,357$.

» rupestre 306 .

Selinum carvifolia 240, 320, 341, 347, 407 ; Pl. 7 .

Senecio integrifolius $291,298,300,328$, $332,335,400 ; \mathrm{Pl} .6$. palustris $24 \mathrm{I}, 242,370,37 \mathrm{I}, 4 \mathrm{I} 2$ vernalis 294 . 
Serratula tinctoria 320,340 .

Seseli libanotis $281,291,299-301,315$, $320,322,332,334,400$.

Sesleria coerulea 284 .

Sieglingia decumbens 304 .

Silene chlorantha 238 .

» nutans 304 .

》tatarica 239.

》viscosa $292,298,311,324,325$,

$$
372,398 \text {. }
$$

Solidago virgaurea 338 .

Sonchus palustris $240,370,371,413$.

Sorbus suecica 340 .

Stellaria graminea 288 .

Stipa capillata 239,$284 ; \mathrm{Pl}$. 14.

» pennata $284,291,298,299,322$, $328,331,333,399$.

Symphytum officinale 363 .

Syringa vulgaris 239 .

Tanacetum vulgare 357 .

Teucrium scorodonia 234 .

Thalictrum aquilegiifolium $368,4 \mathrm{I} 0$.

$$
\text { » majus } 276 \text {. }
$$

"simplex $347,407$.

Thesium alpinum $303,305,307$; Pl. 4 . » ebracteatum $329,332,334$.

Thymus serpyllum $3 \circ 3,304,306$.

Tilia argentea 239 .

Trapa natans $373,4 \mathrm{I} 3$.

Trifolium alpestre $239,329,332,334$; Pl. 6.

- arvense 289 .

» medium $303,304,338$.
Trifolium montanum $239,28 \mathrm{I}, 290,29 \mathrm{I}$, $299,301,304,306,307,308$, $315,322,323,332,401$. spadiceum 360,407 .

Ulex europaeus 246

Ulmus foliacea $230,367,368,375,410$. laevis $367,368,375,410$.

Vaccinium myrtillus 338 . vitis idaea $3 \circ 3,338$.

Veronica chamaedrys 303 .

$$
\text { longifolia } 240,364,403 \text {. }
$$

montana 234 .

officinalis 304 .

spicata 239, 286, 29I, 299, $300,306-310,310,321$, 322,$399 ;$ Pl. 3 and 16.

Vicia cassubica $304,346,349,403$.

- cracca 303.

» pisiformis 299, 347, 404; Pl. 12.

» silvatica 347 .

» tenuifolia $239,359,404$.

Vinca minor 234.

Viola alba 276. elatior 359,404 .

» mirabilis $234,240,367,4$ I0; Pl. 22.

* pumila $282,292,328,399$.

» rupestris $240,28 \mathrm{I}, 289,291,296$, $299,300,303,3$ I 5,3 I 8,319 , $32 \mathrm{I}, 322,334,40 \mathrm{I}$.

- uliginosa $370,371,376,+13$.

Viscaria vulgaris $289,304,320$. 



\section{CONTENTS}

CHAP.

IN'TRODUC'TION

1. THE HISTORY OF TAXONOMIC PHY'TOGEOGRAPHY AND ITS PRESENT OBJEC'T AND PRINCIPLES

II. SURVEY OF THE CONTINENTAL EIEMENT IN THE EUROPEAN FLOR.I

Definition of the continental element

The continental element in the flora on the Middle European plain

III. THE ECOI.OGY OF CONTINENTAL SPECIES AND PHYSIOGRAIHY

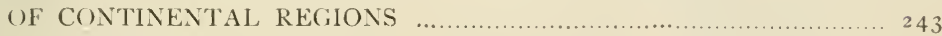

The climate and the ecology of continental species .......................... 244

The nature of continental soil and the ecology of continental species ... 249

Continental geographical conditions and the general features in the distribution of continental species in Europe.

IV. CONTINENTAI, FEATURES IN THE PHYSIOGRAPHY OF SOUTH SWEDEN

The degree of continentality of the South Swedish climate ............... 255

The nature of the soil in South Sweden .................................. 262

V. THE HISTORY OF THE SOUTH SWEDISH FLORA ................... 268

VI. SURVEY OF THE CONTINENTAL ELEMENT IN THE SOUTH SWEDISH FLORA

VII. ME'THODS AND PRINCIPLES FOR THE ENQUIRY INTO THE DISTRIBUTION OF CONTINENTAL SPECIES IN SOUTH SWEDEN .... 277

VIII. THE MODE OF OCCURRENCE OF STEPPE SPECIES IN SOUTH SWEDEN

Halophytic steppe species ................................................. 282

Species of Stipa steppe, the sand steppe, and the meadow steppe $\ldots \ldots \ldots 28_{3}$

Sarmatian psammophilous species

IX. DISTRIBUTION OF STEPPE SPECIES AND SARMATIAN PSAMMOPHILOUS SPECIES IN SOUTH SWEDEN

The possibilities of occurrence of the species in South Sweden, if the vegetation were unaffected by human interference

The distribution of the species and arable land in South Sweden ....... 3 I I

The distribution boundaries of the species in South Sweden 
PAGF

Isolated occurrences of the species in South Scandinavia ................... 367

The two branches in the South-Scandinavian distribution .................. 333

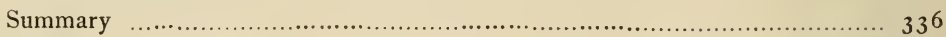

X. SPECIES BELONGING TO THE THIN FOLIFEROUS FORESTS OF

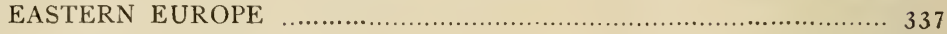

The mode of occurrence of the species .................................. 337

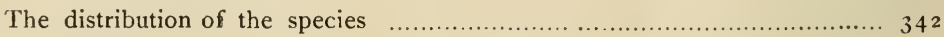

The distribution of Cynanchum vincetoxicum in the south of Sweden. "The Cynanchum problem »................................................... 35 I

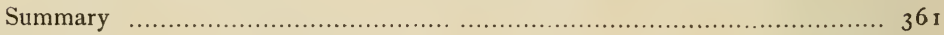

XI. THE OTHER CONTINENTAL SPECIES IN THE FLORA OF SOUTH

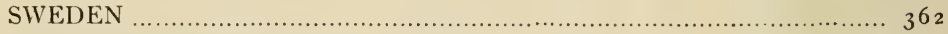

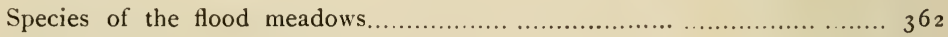

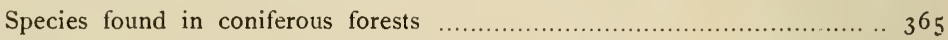

Grove species .............................................................. 366

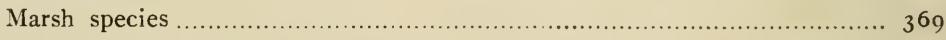

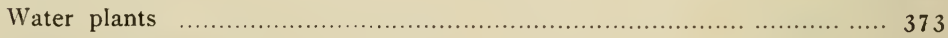

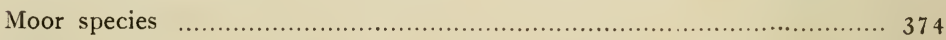

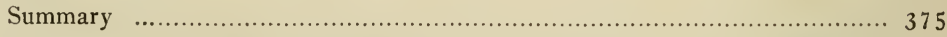

XII. CONCLUSIONS ABOUT THE POSITION OF THE SOUTH SWEDISH

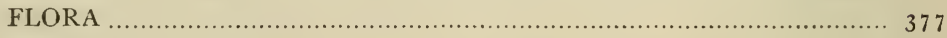

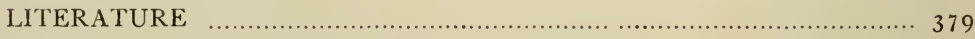

APPENDIX I. The continental species in the flora of South Sweden. Summary accounts of their European distribution ............................ $39 \mathrm{I}$

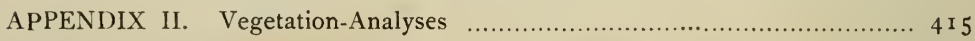

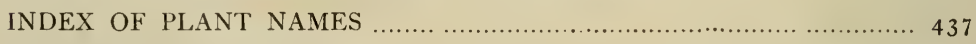

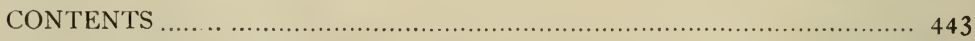

PLATES $3-22$. 

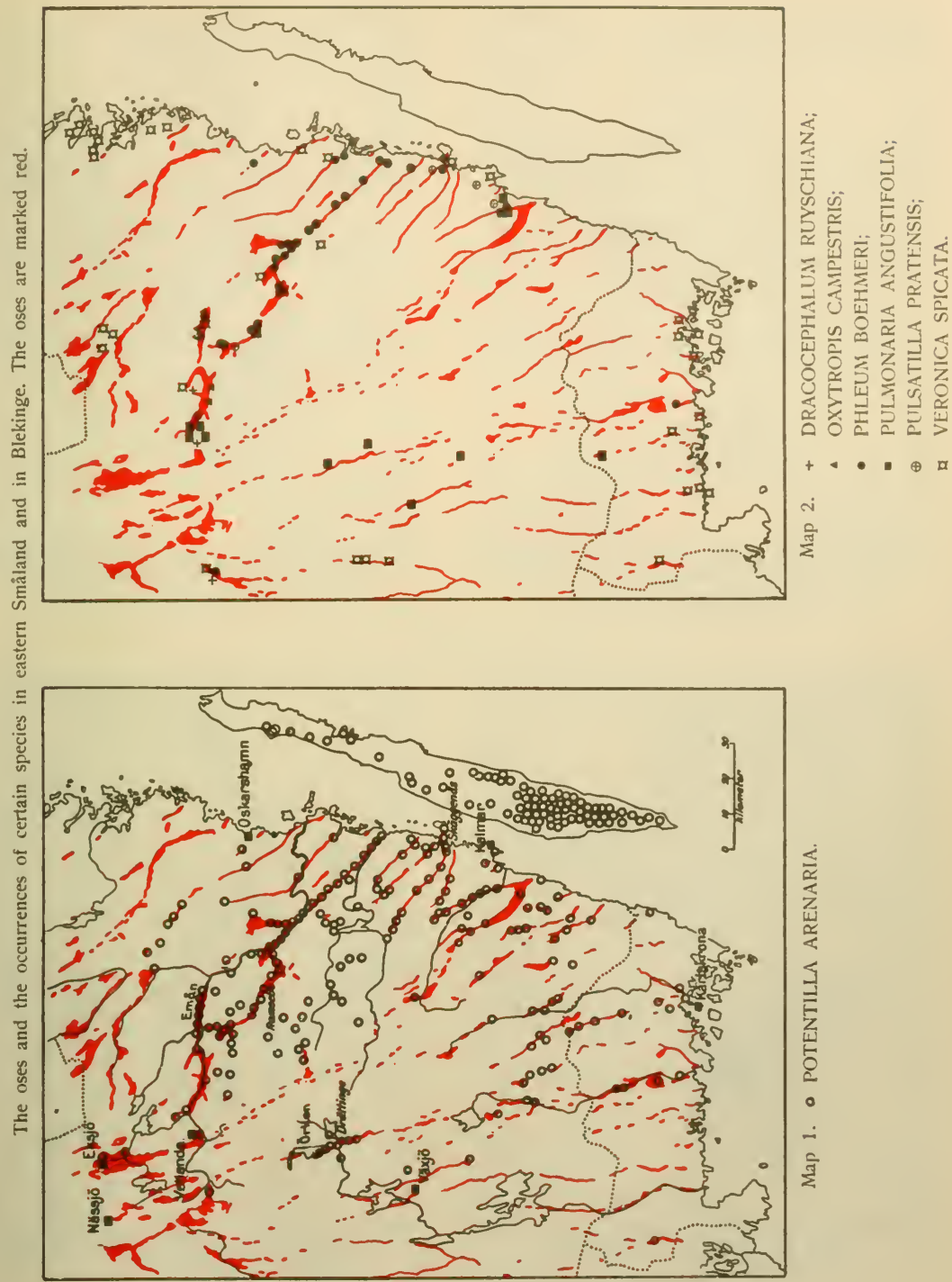


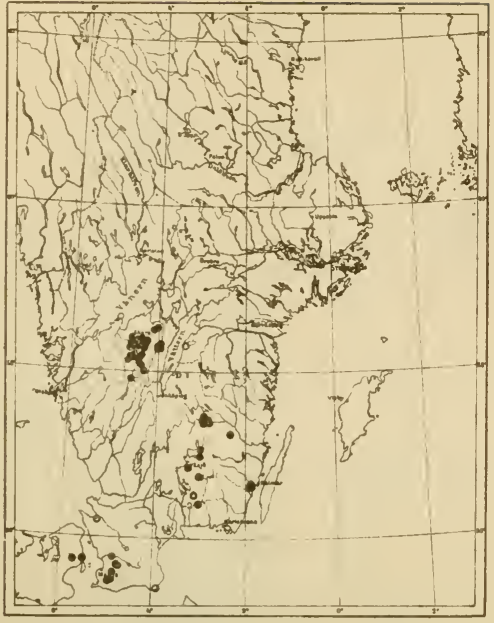

Map 1. PULMONARIA ANGUSTIFOLIA in the Scandinavian North.

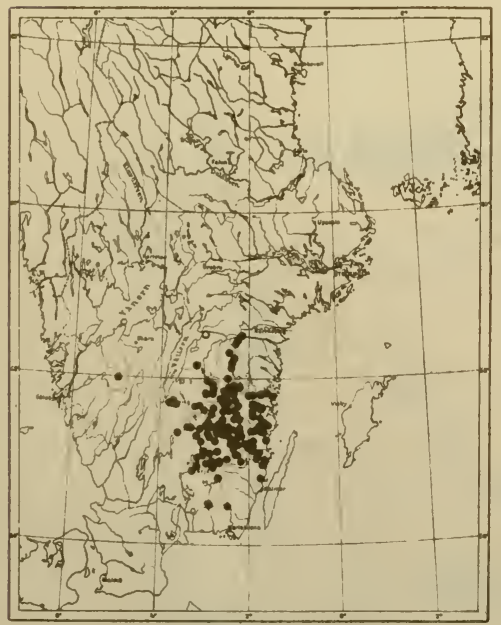

Map 3 THESIUM ALPINUM

in the Scandinavian North.

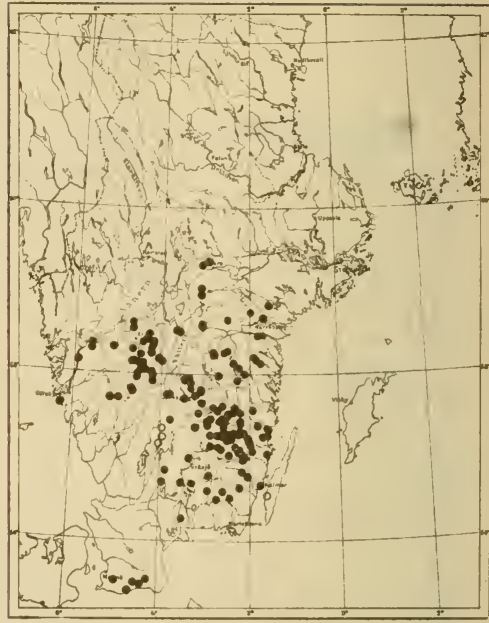

MaP 2. LATHYRUS HETEROPHYLLUS in the Scandinavian North.

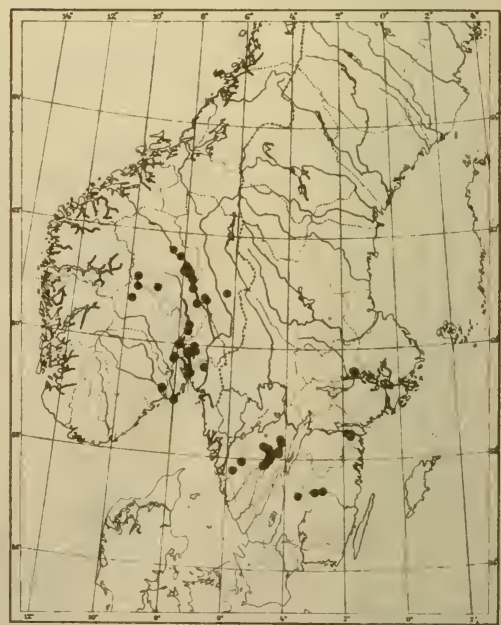

Map 4. DRACOCEPHALUM RUYSCHIANA in Scandinavia and Denmark. 


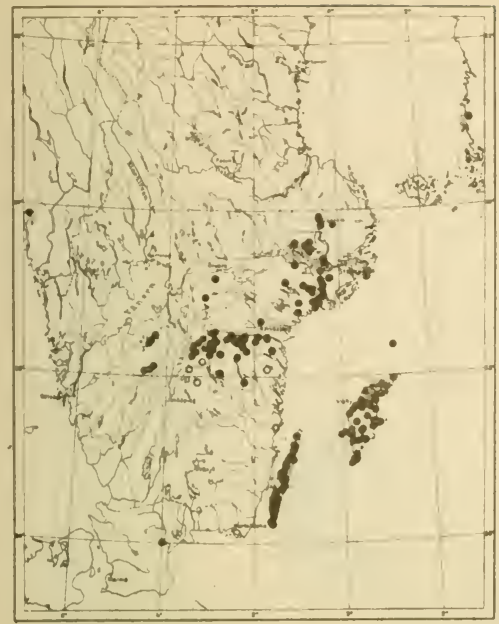

Map 1. ASPERUI.A TINCTORIA in Fennoscandia.

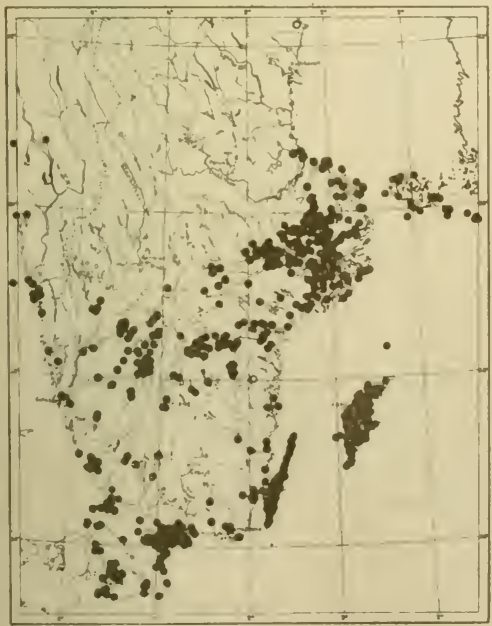

Map 3. ARTEMISIA CAMPESTRIS

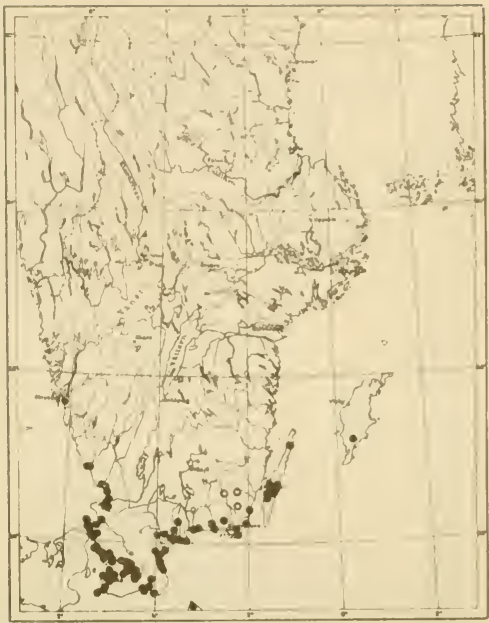

Map 2. HELICHRYSUM ARENARIUM in lennoscandia.

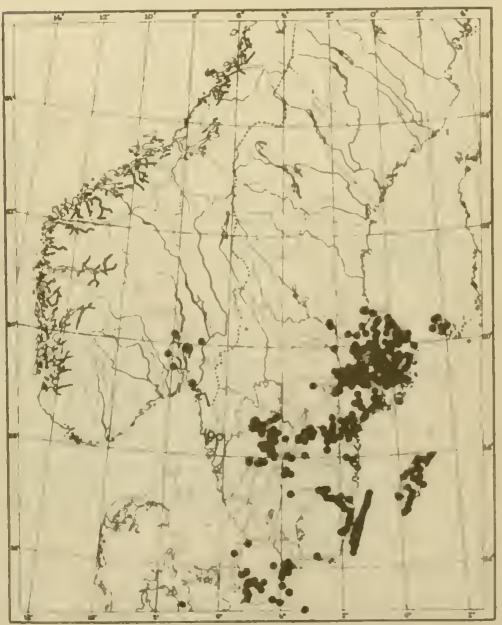

Map 4. PHLEUM BOEHMERI in Sweden. - uncertain or accidental occurrences. 
The occurrences of certain species in North-Western Europe.

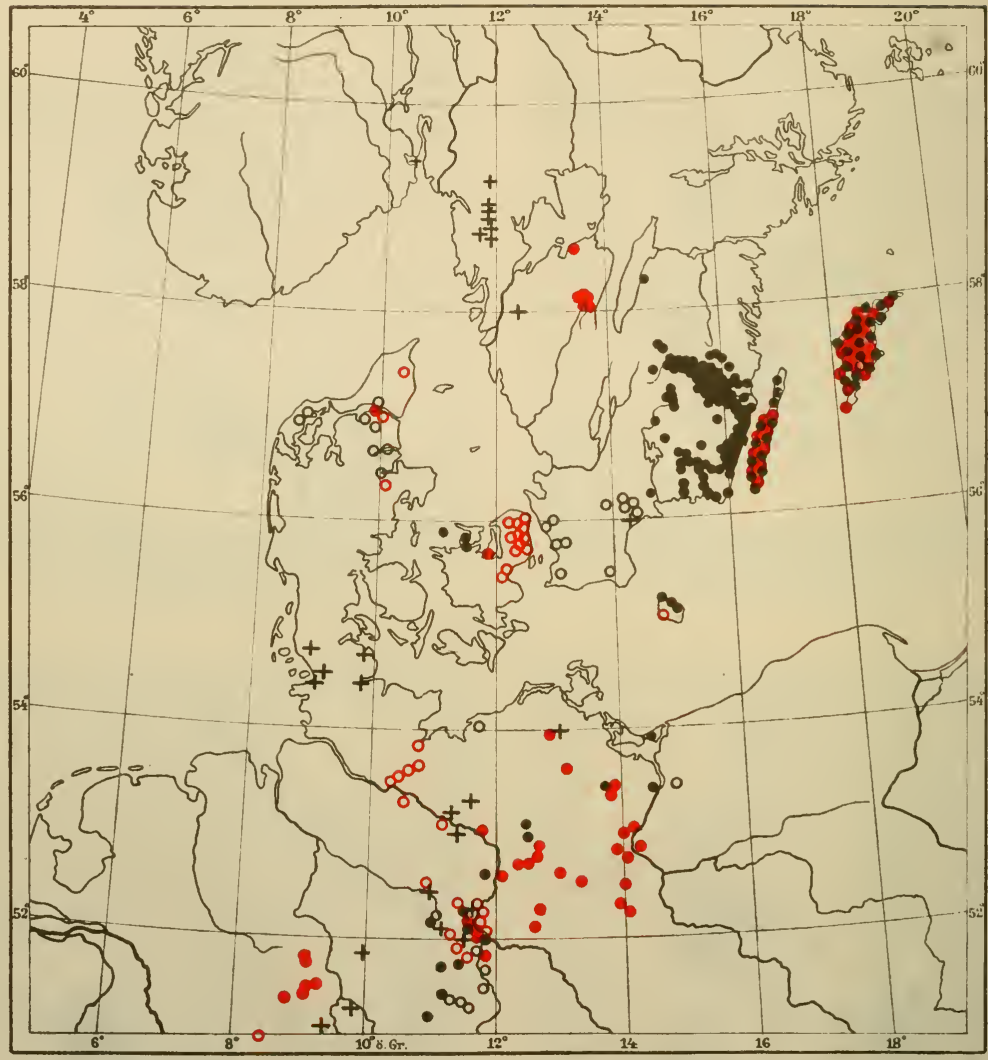

+ ALLIUM MONTANUM;

- potentilla arenaria;

- prunella grandiflora;

Occurrences east of the limits in North Germany are not marked. 


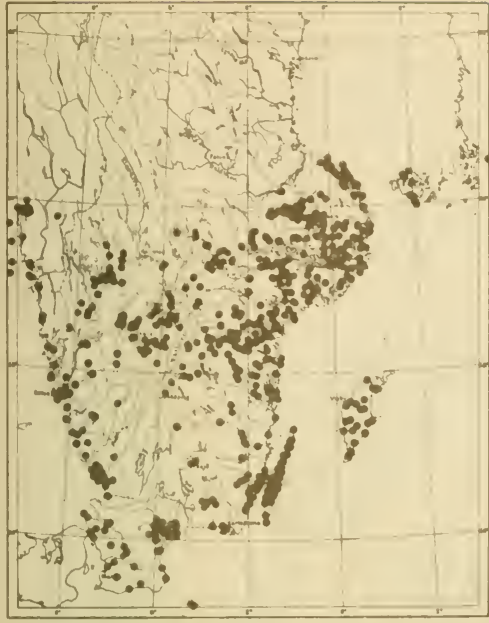

Map 1. SELINUM CARVIFOLIA in Sweden.

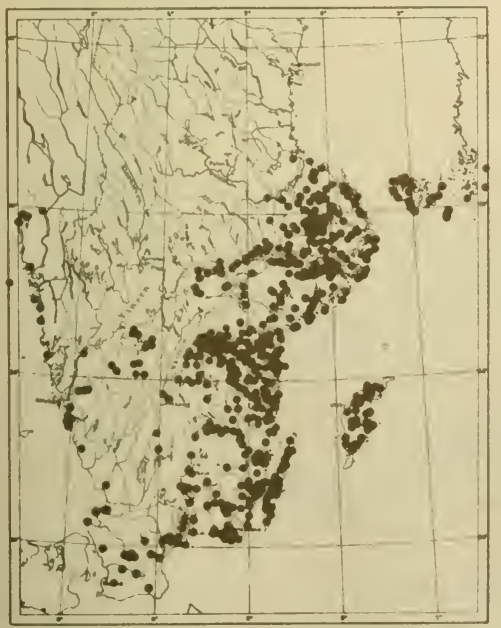

Map 3. MELAMPYRUM CRISTATUM in Sweden.

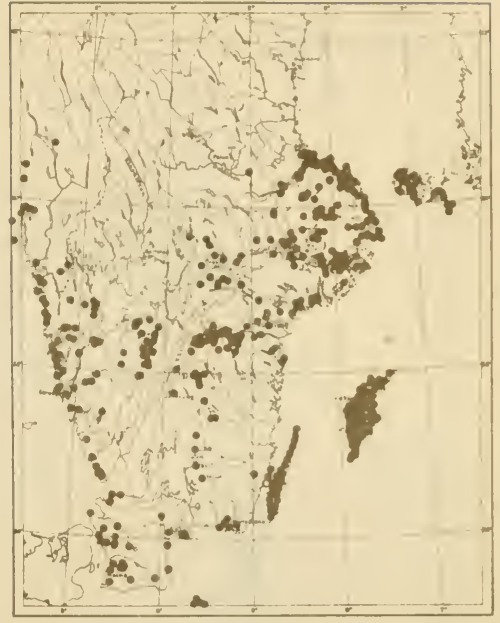

Map 2. INULA SALICINA in Sweden.

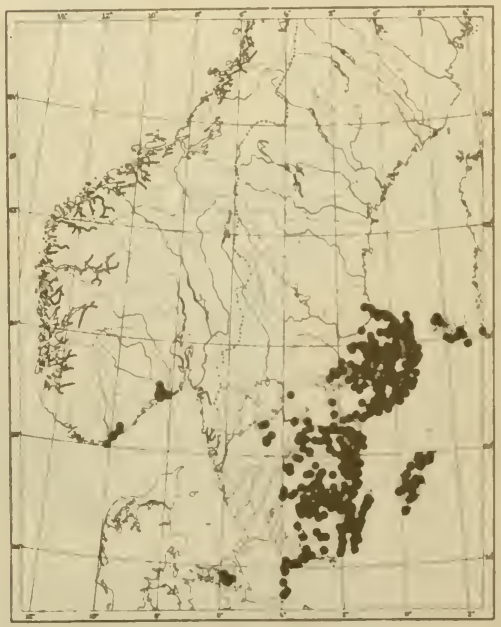

Map 4. LASERPITIUM LATIFOLIUM in the Scandinavian North.

- uncertain or accidental occurrences. 
MELAMPYRUM NEMOROSUM in Uppland.

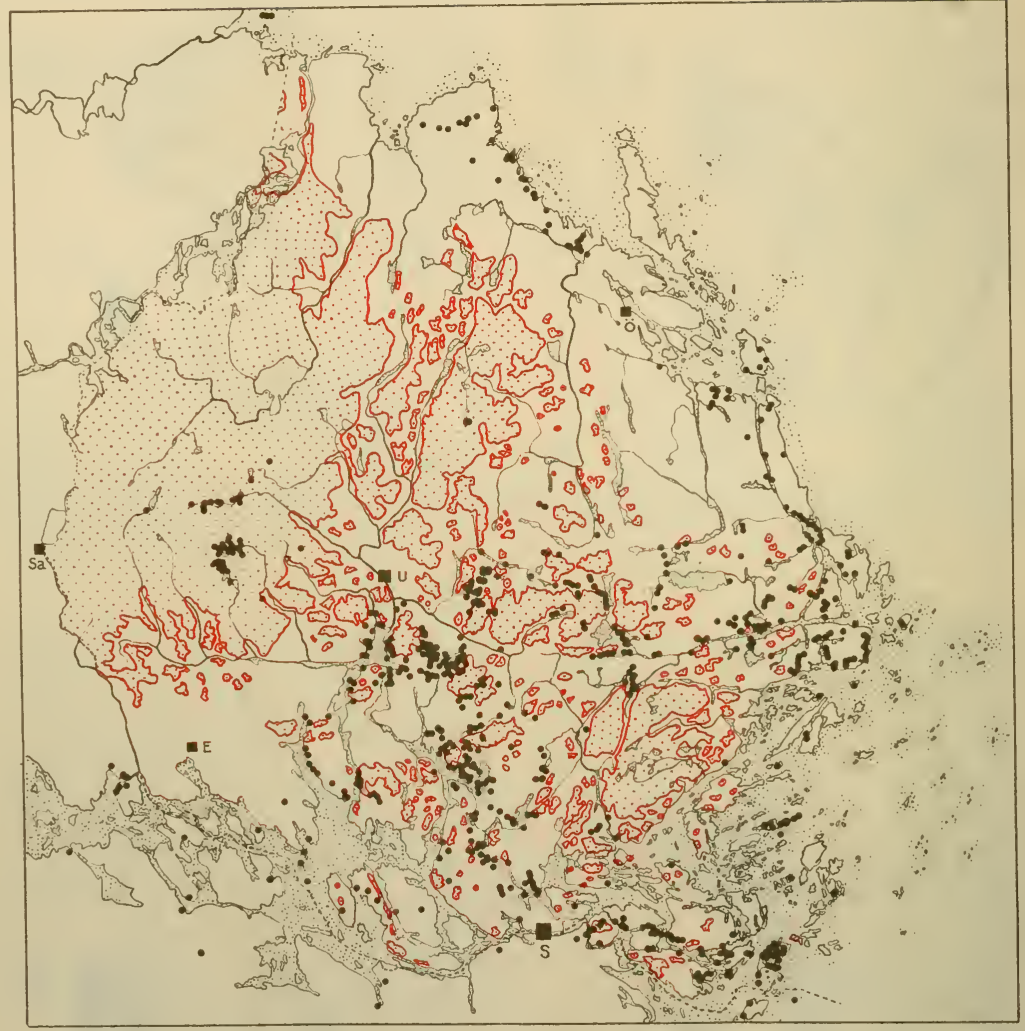

- occurrences of MELAMPYRUM NEMOROSUM. The area covered with red dots shows the extent of the land-surface at the beginning of the passage grave-period, about 2300 в. C. (After Eriksson 1912).

S: Stockholm; U: Upsala; Sa: Sala; Ö: Öregrund; E: Enköping. 
CYNANCHUM VINCETOXICUM and MELAMPYRUM NEMOROSUM

in South-Eastern Sweden.

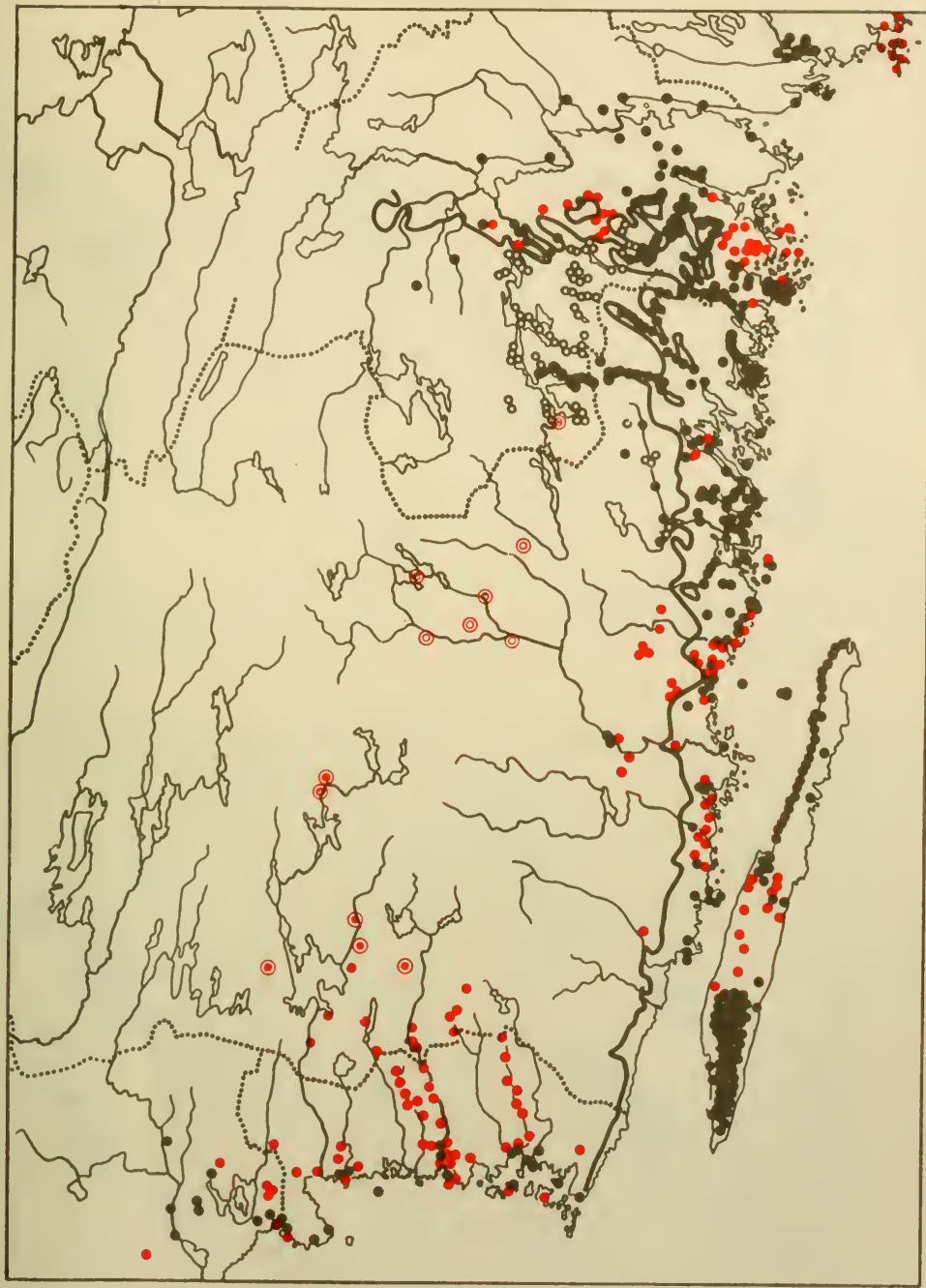

- CYNANChum VINCETOXICUM; - melampyrum NEMOROSUM;

(?) and - more or less uncertain occurrences of Melanipyrum;

- certain southerly exposed escarpments lacking Cynanchum; the shore-line about at the time of the maximum extension of the Ancylus Lake is schematically marked (according to Munthe after Sundelin 1919). 


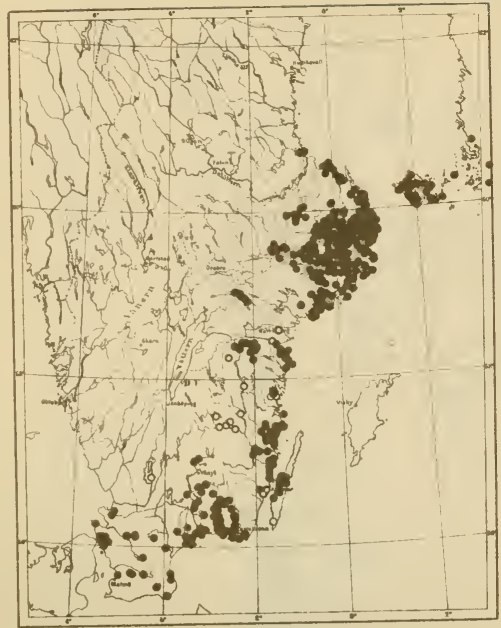

Map 1. MELAMPYRUM NEMOROSUM in Scandinavia.

(cf. Plate 14)

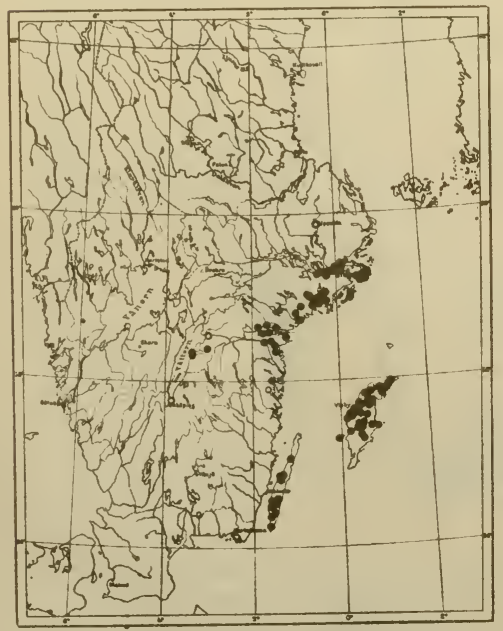

Map 3. MELICA CILIATA

in the Scandinavian North.

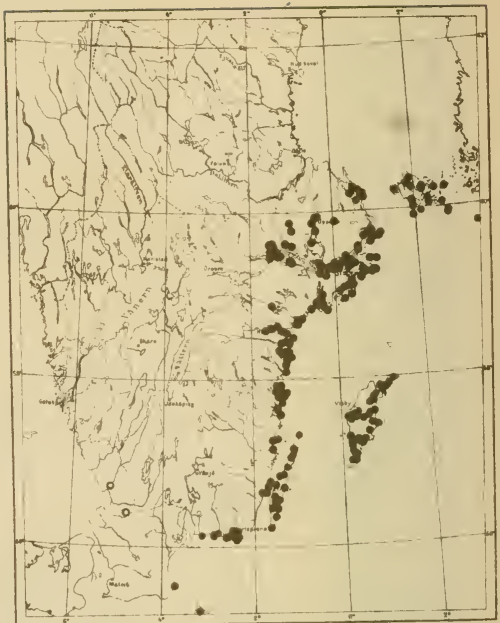

Map 2. SCUTELLARIA HASTIFOLIA in Scandinavia.

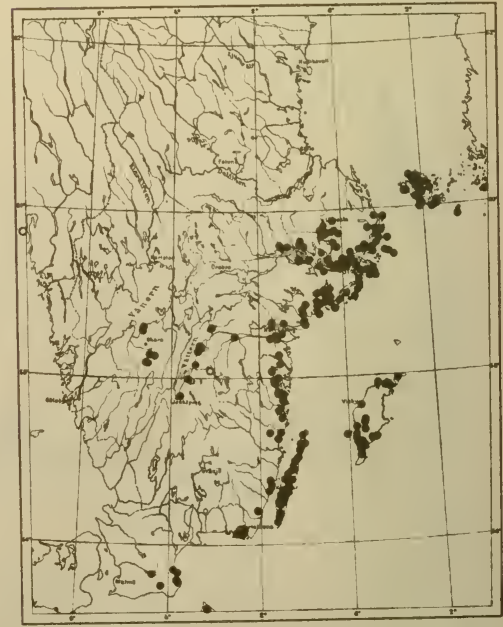

Map 4. DRABA MURALIS in the Scandinavian North. 

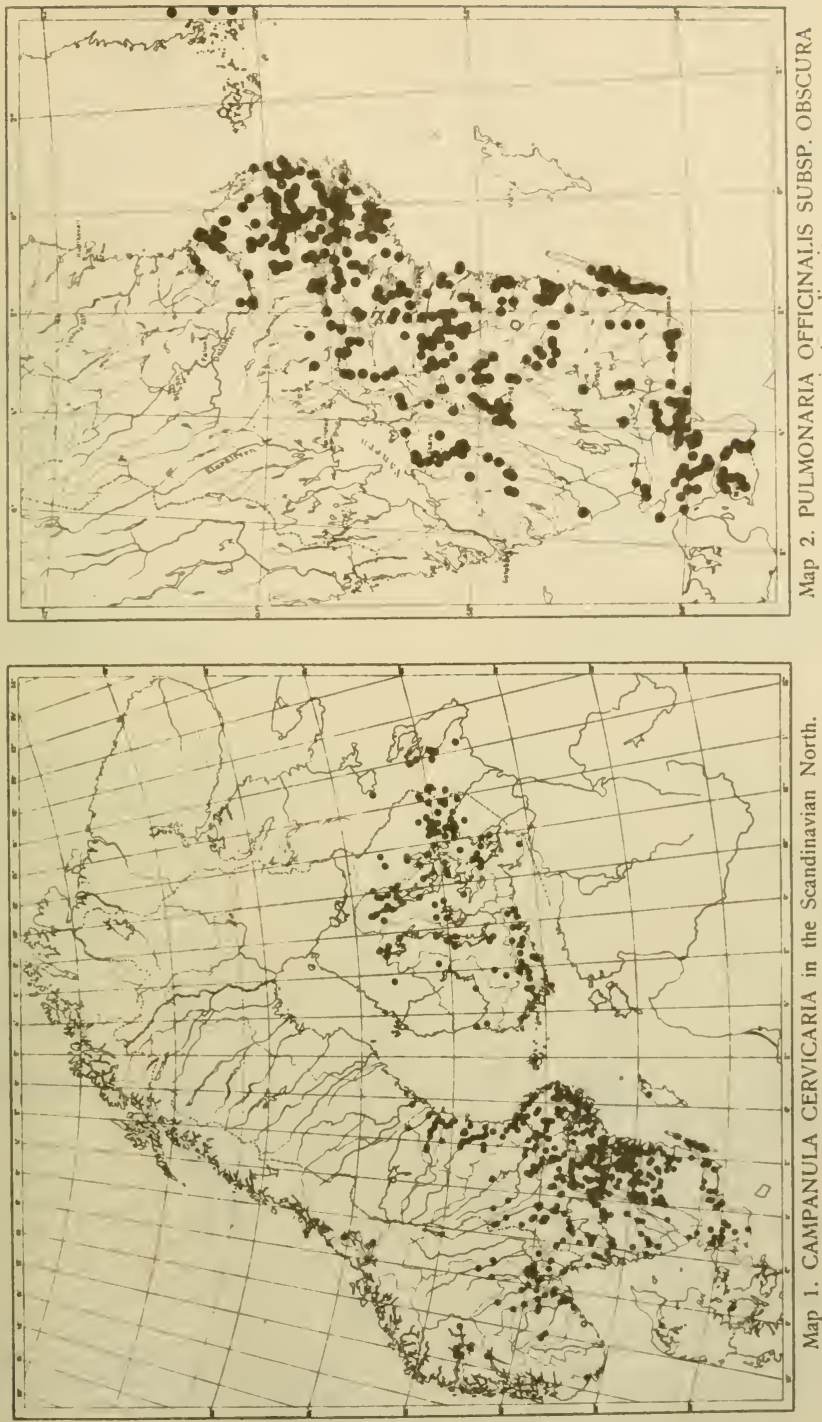

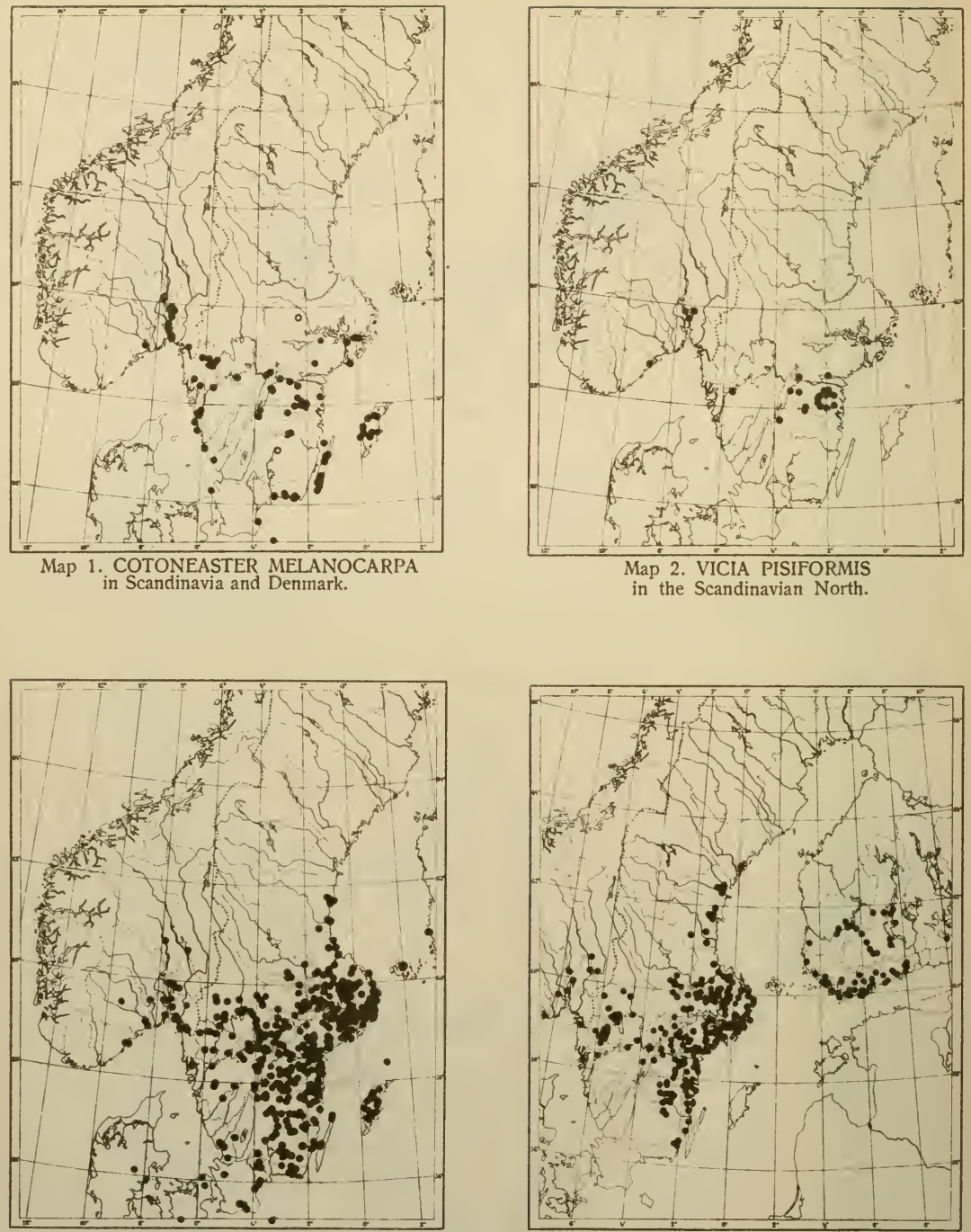

Map 3. CHIMAPHILA UMBELLATTA

Map 4. GERANIUM BOHEMICUM in Scandinavia and Denmark.

in Scandinavia, Denmark and western Finland.

- uncertain or accidental occurrences. 


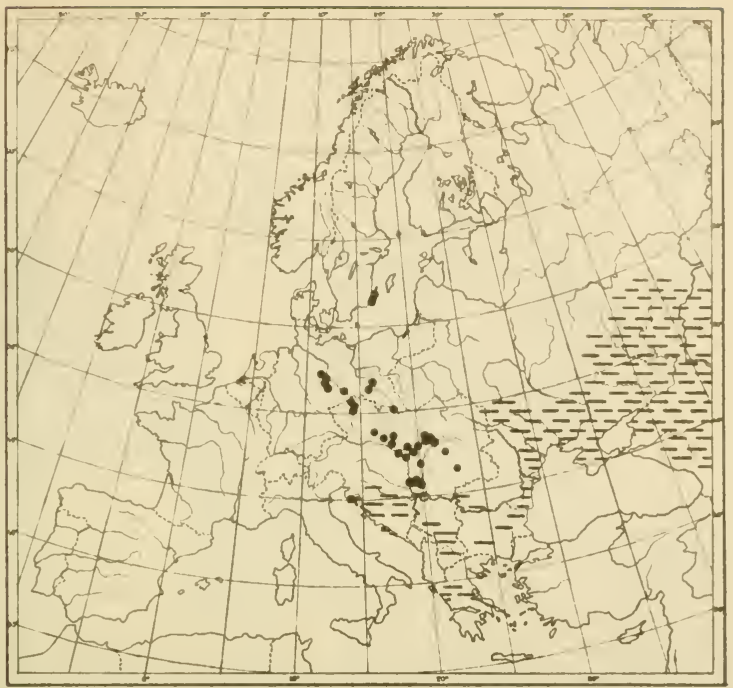

Map 1. RANUNCULUS ILLYRICUS L. (Pontic distribution).

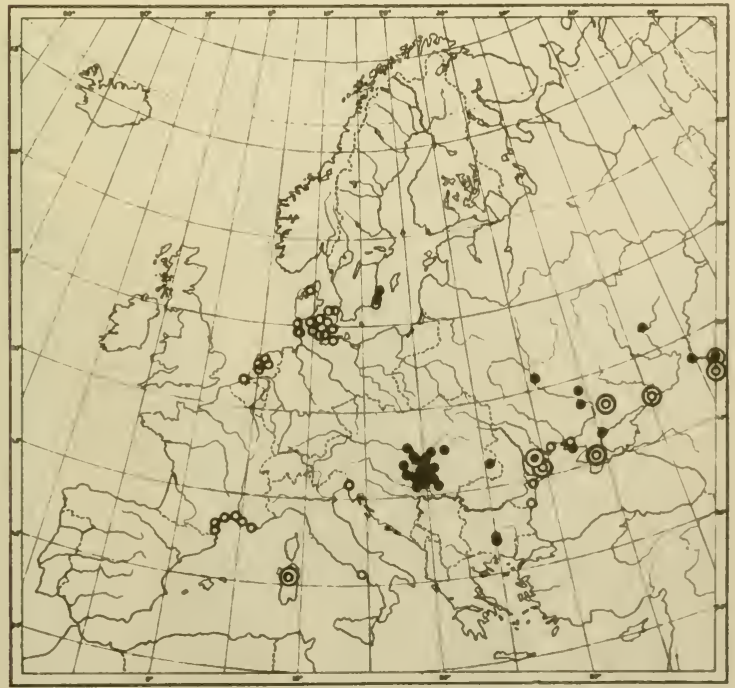

Map 2. PLANTAGO TENUIFLORA W. \& K. (Pontic distribution) and BASSIA HIRSUTA (L.) ASCHERS. (Pontic-Subatlantic distribution);

- occurrences of PLANTAGO TENUIFLORA; o occurrences of BASSIA HIRSUTA;

$\bigcirc$ and (อ occurrences the position of which is not exactly known. 


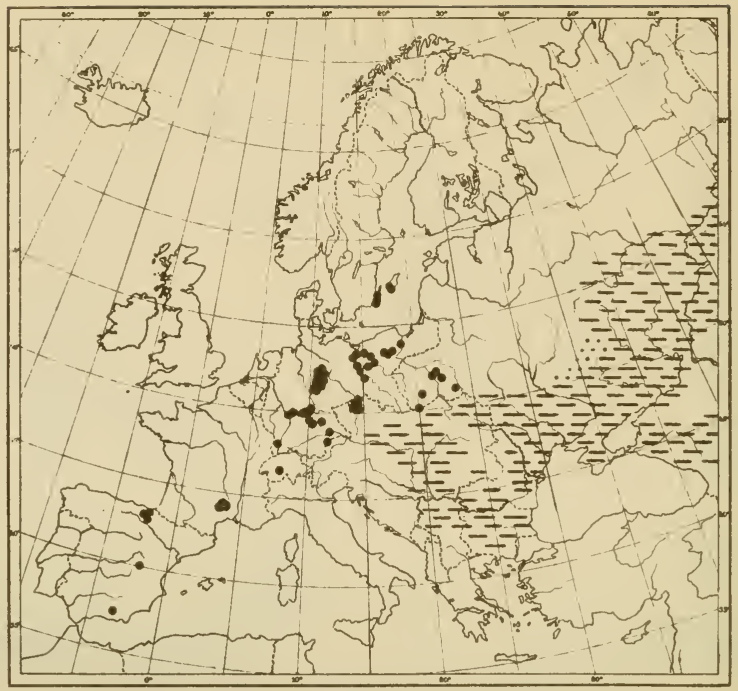

Map 3. ADONIS VERNALIS L. (Pontic distribution).

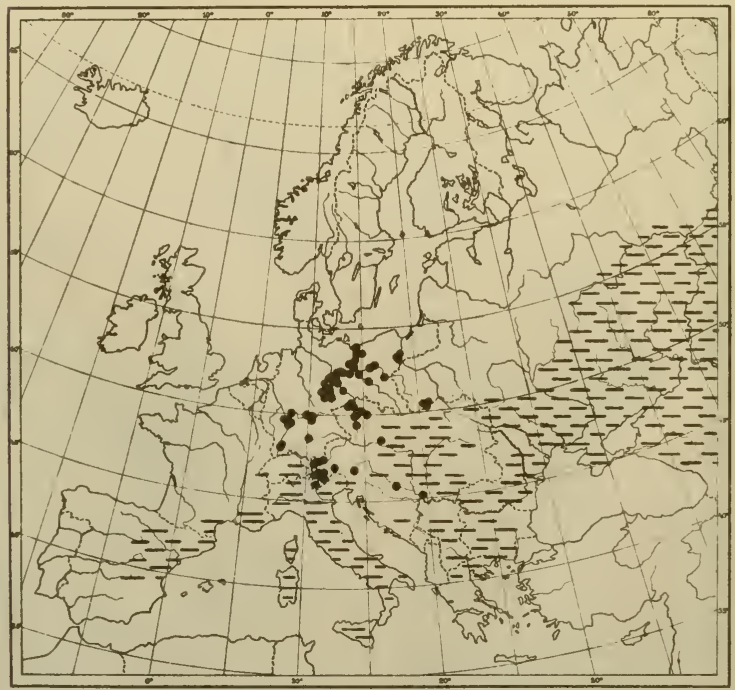

Map 4. STIPA CAPILlATA L. (Pontic - South European distribution). 


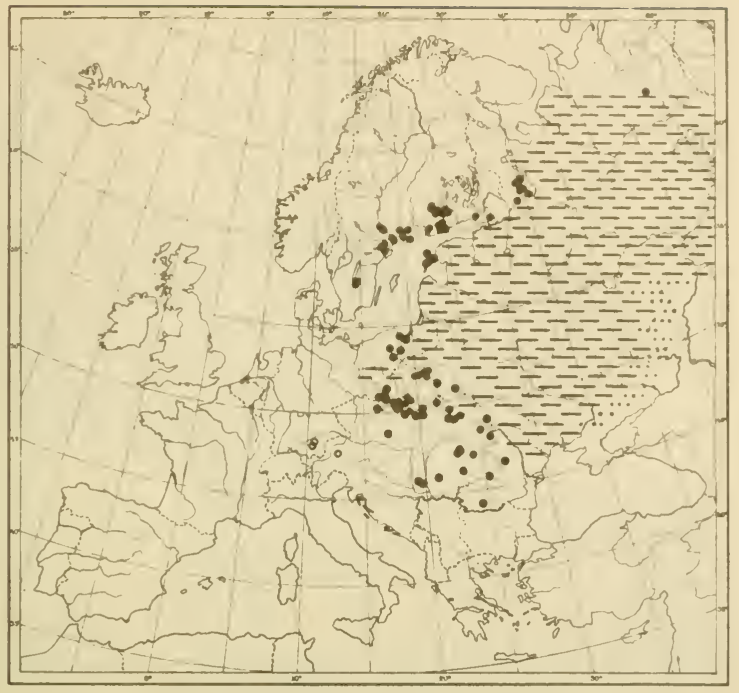

Map 5. RANUNCULUS CASSUBICUS L.

(Transition type between Subarctically Ponticosarmatian and Subarctically Sarmatian distribution).

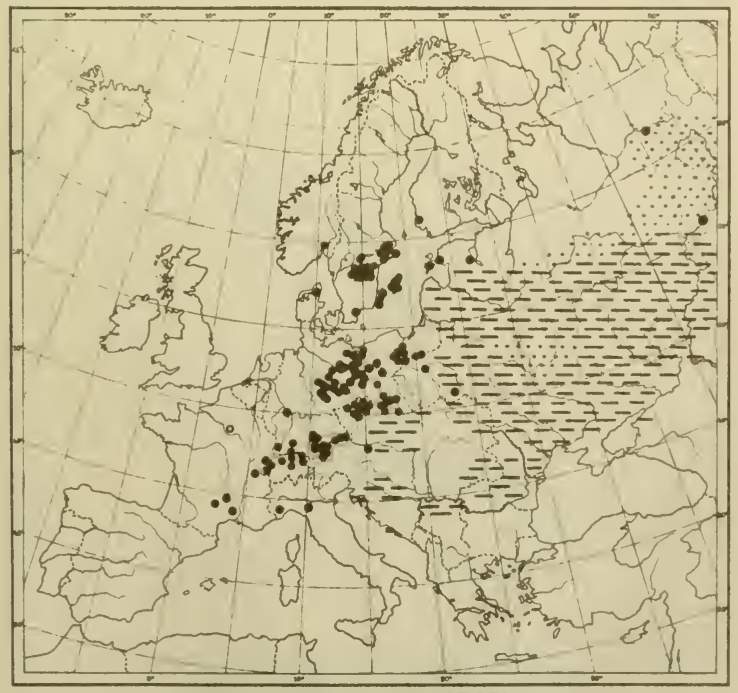

Map 6. ASPERULA TINCTORIA L.

(Ponticosarmatian - Central European distribution). 


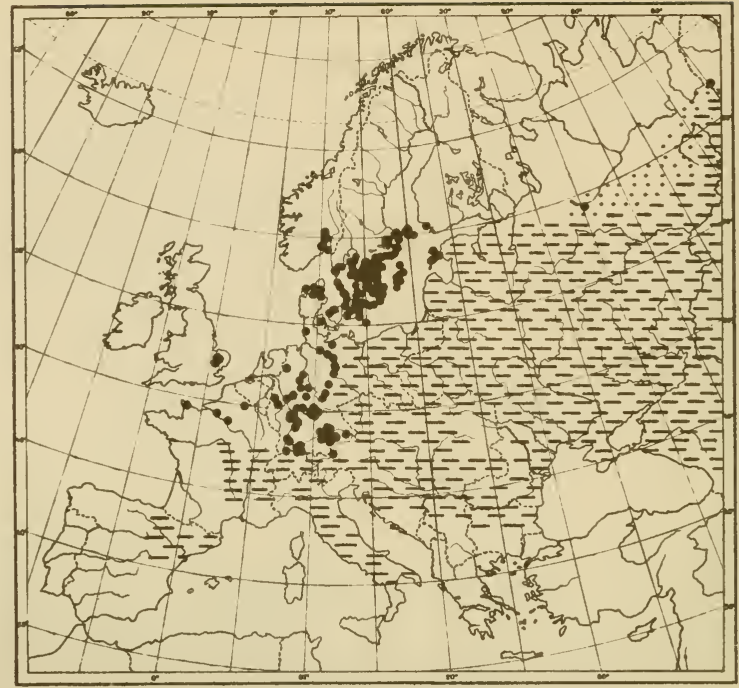

Map 7. VERONICA SPICATA L.

(Ponticosarmatian - Central European distribution).

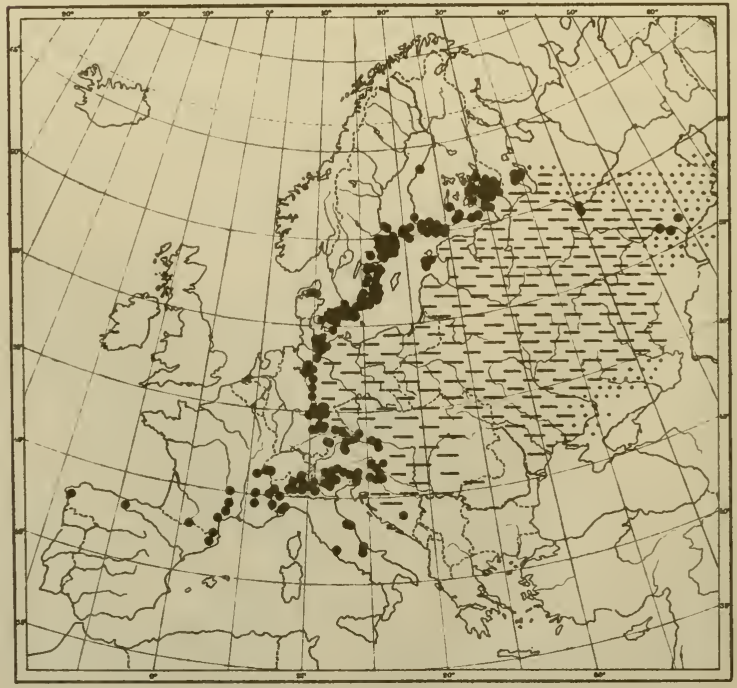

Map 8. MELAMPYRUM NEMOROSUM L.

(Transition type between Ponticosarmatian - Central European and Sarmatian - Central European distribution). 


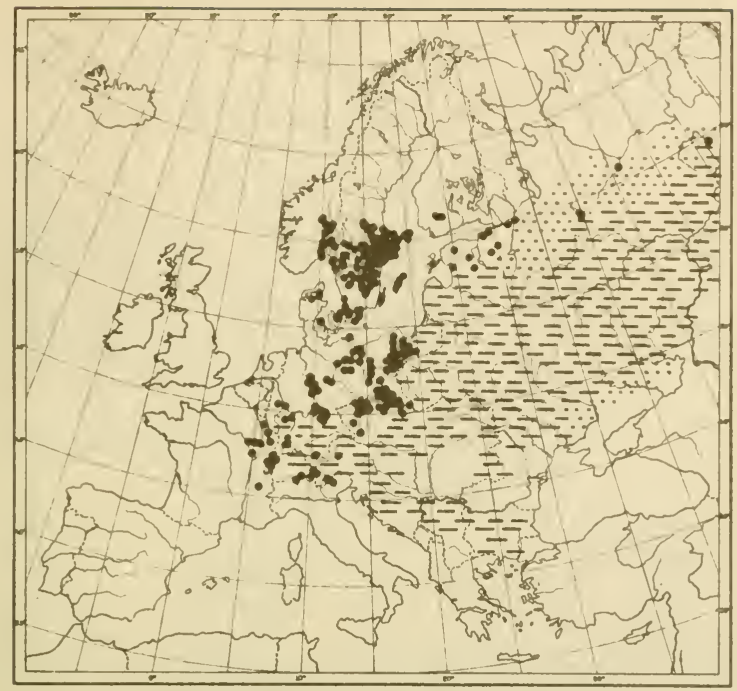

Map 9. CREPIS PRAEMORSA (L) TAUSCH

(Transition type between Ponticosarmatian - Central European and Sarmatian - Central European distribution).

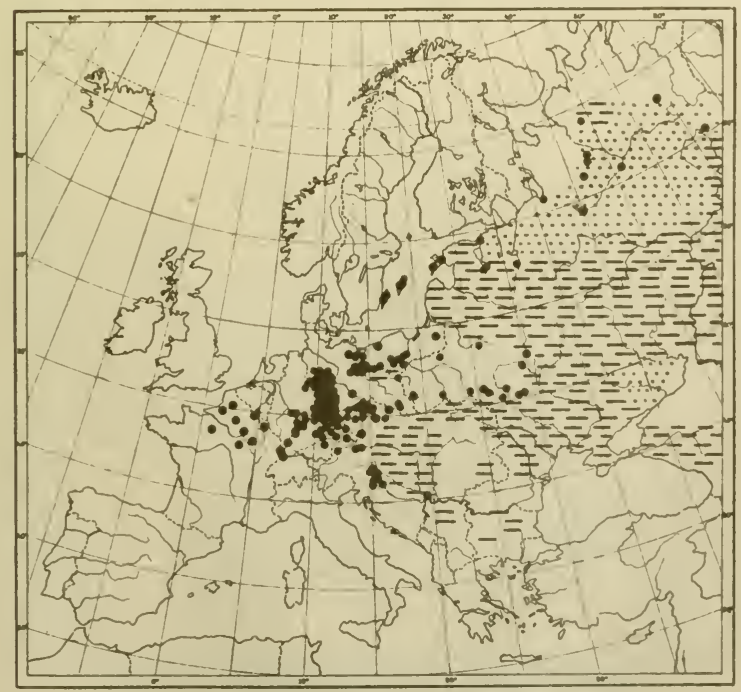

Map 10. ANEMONE SILVESTRIS L.

(Ponticosarmatian - Central European distribution). 


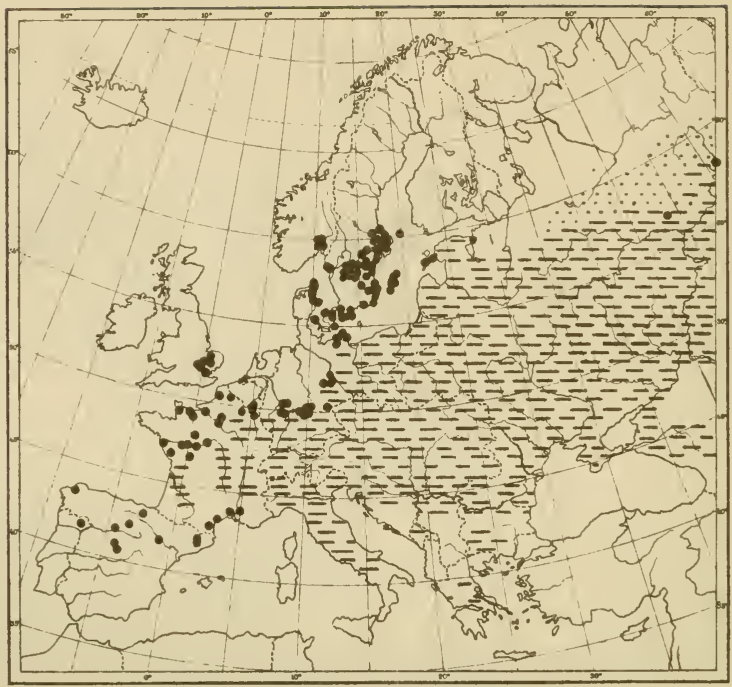

Map 11. PHLEUM BOEHMERI WIB.

(Ponticosarmatian - Central European distribution).

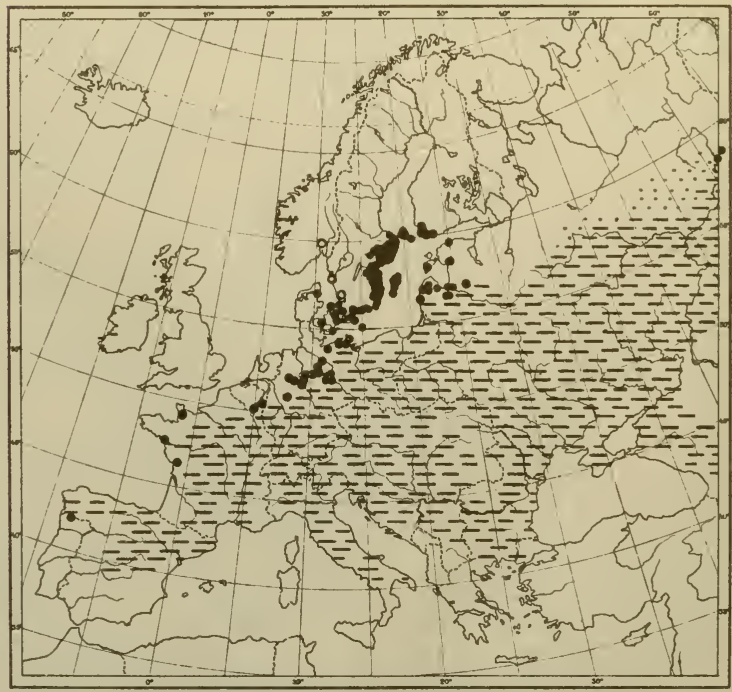

Map 12. CYNANCHUM VINCETOXICUM (L.) PERS.

(Ponticosarmatian - Central European distribution). 


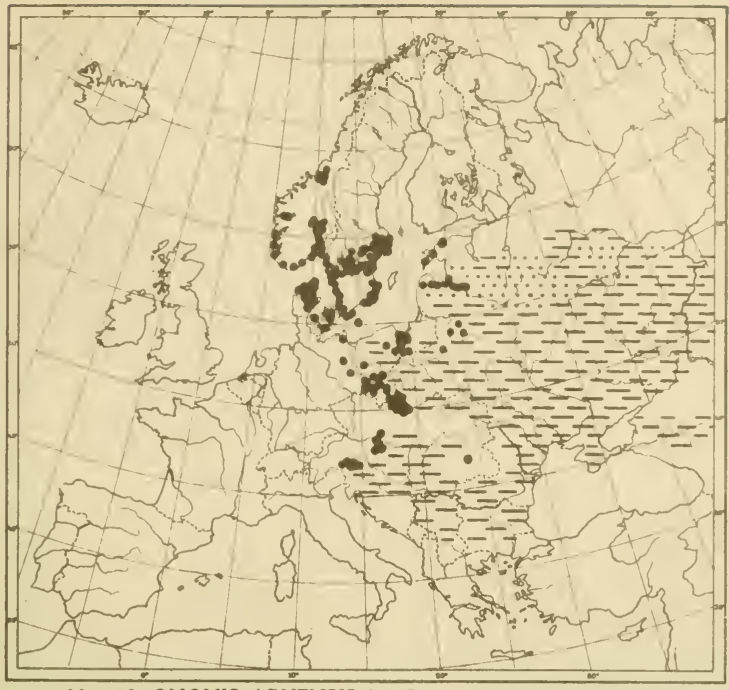

Map 13. ONONIS ARVENSIS L. (Pontic - Baltic distribution).

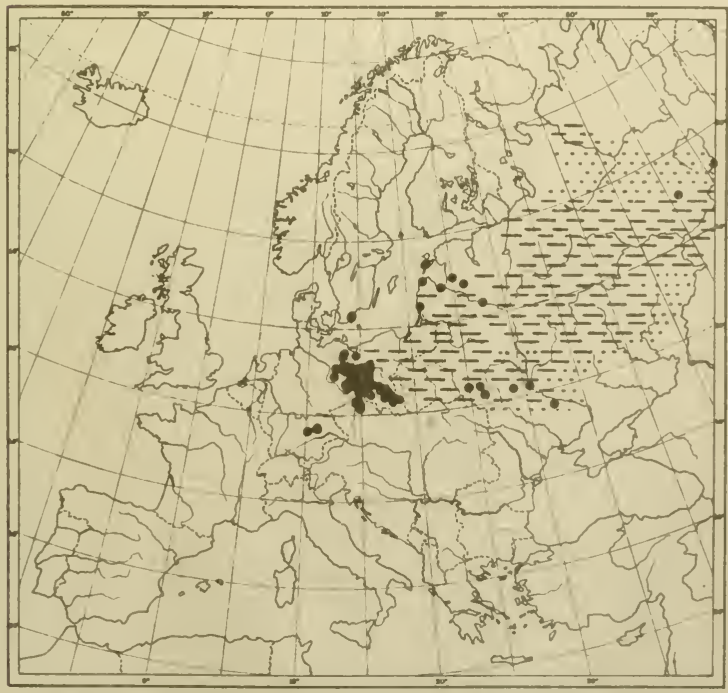

Map 14. ASTRAGALUS ARENARIUS L. (Sarmatian distribution). 


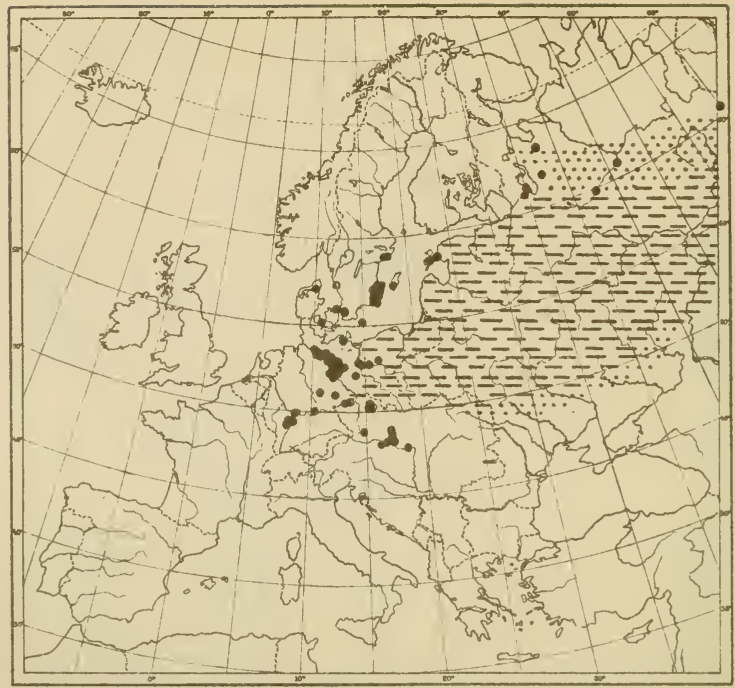

Map 15. CNIDIUM VENOSUM (HOFFM.) KOCH (Sarmatian distribution).

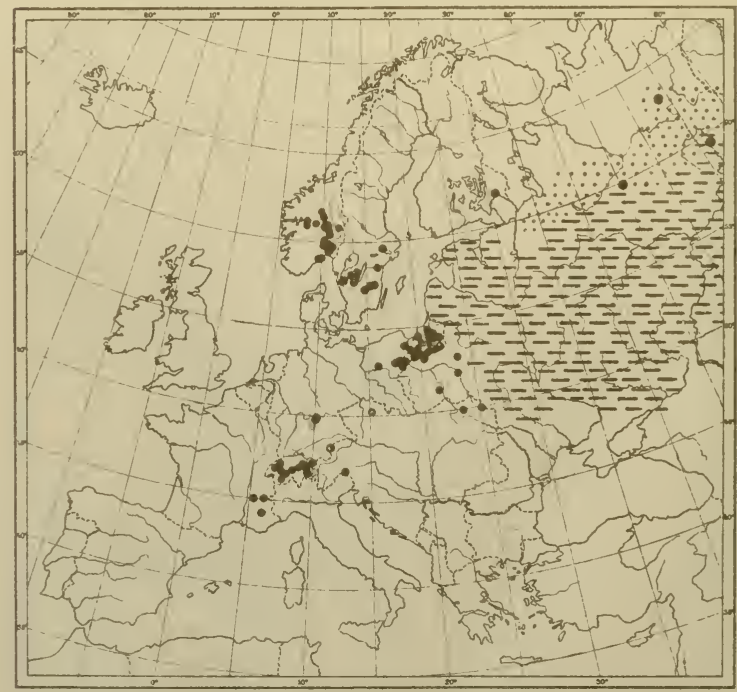

Map 16. DRACOCEPHALUM RUYSCHIANA L. (Sarmatian distribution). 


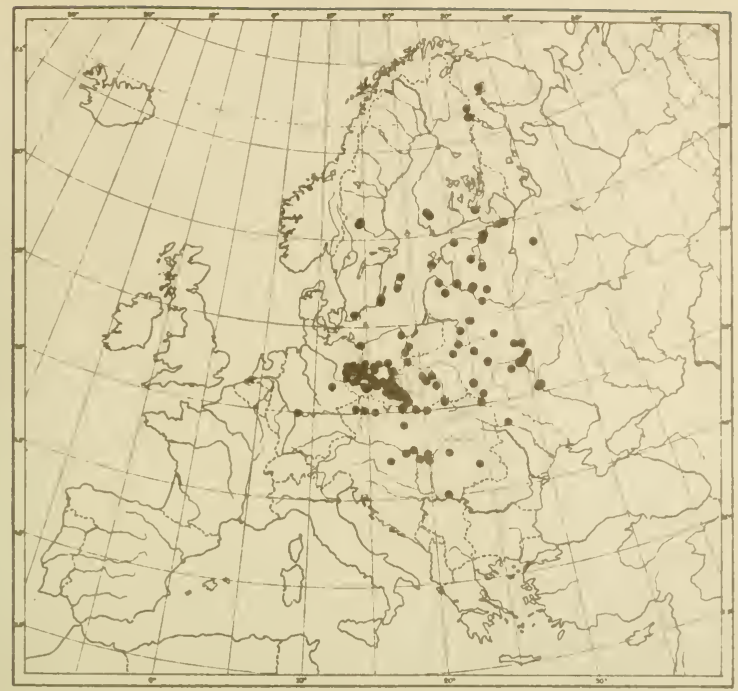

Map 17. GYPSOPHILA FASTIGIATA L. (Cassubian distribution).

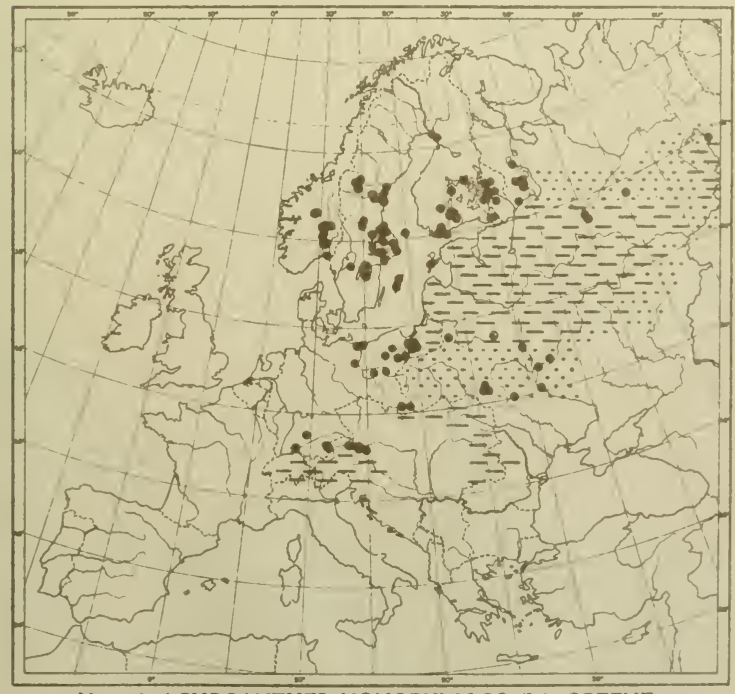

Map 18. ACHROANTHES MONOPHYLLOS (L.) GREENE (Sarmatian - Central European distribution). 


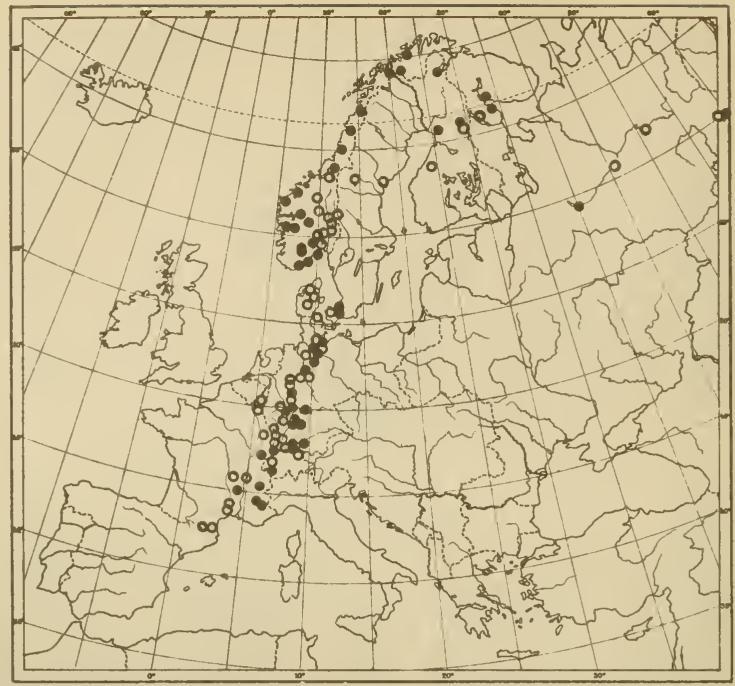

Map 19. PYROLA CHLORANTHA L. and CALAMAGROSTIS ARUNDINACEA (L.) ROTH. - Westernmost and northernmost occurrences; - occurrences of Pyrola chlorantha; o occurrences of Calamagrostis arundinacea. (Subarctically Baltic - Central European distribution).

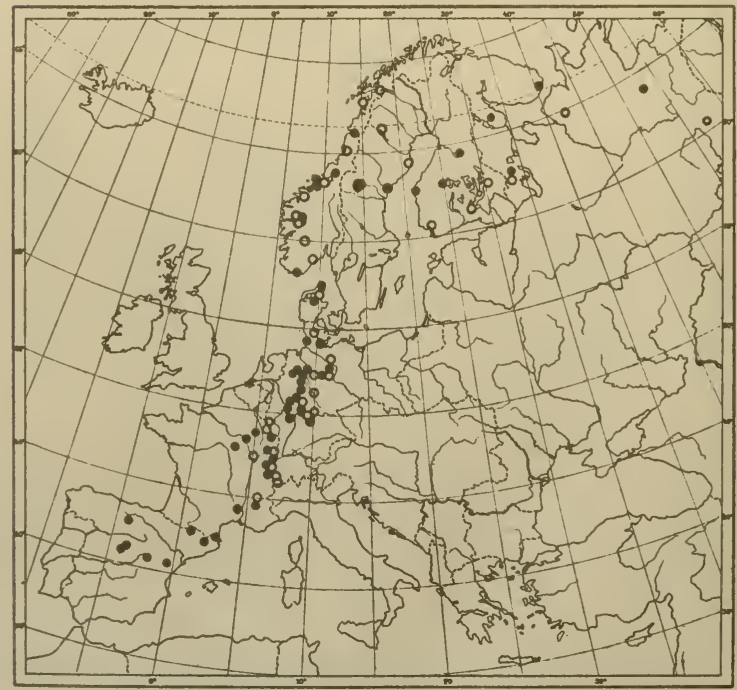

Map 20. LATHYRUS VERNUS (L.) BERNH. and VIOLA MIRABILIS L. Westernmost and northernmost occurrences; - occurrences of Lathyrus vernus; o occurrences of Viola mirabilis. (Subarctically Baltic - Central European distribution). 
(1)

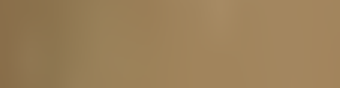

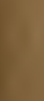

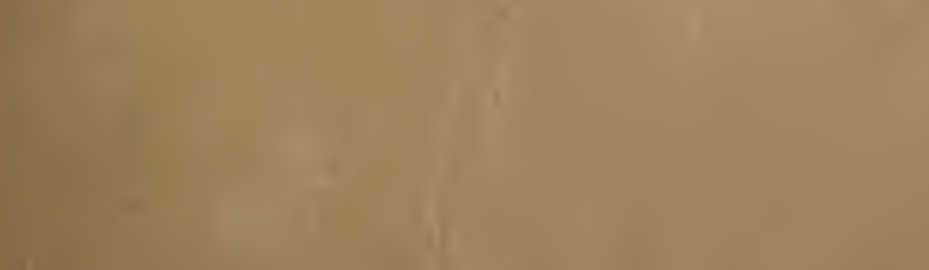

11

$=$

$x^{4}$

$x$ it

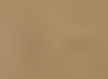

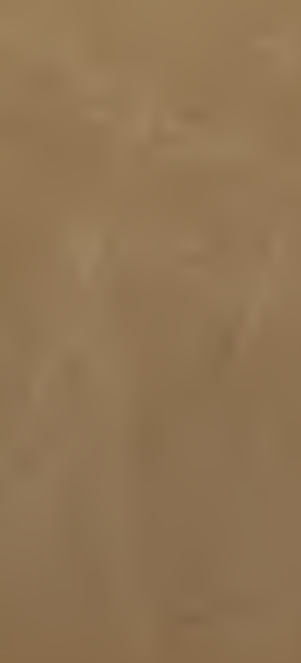



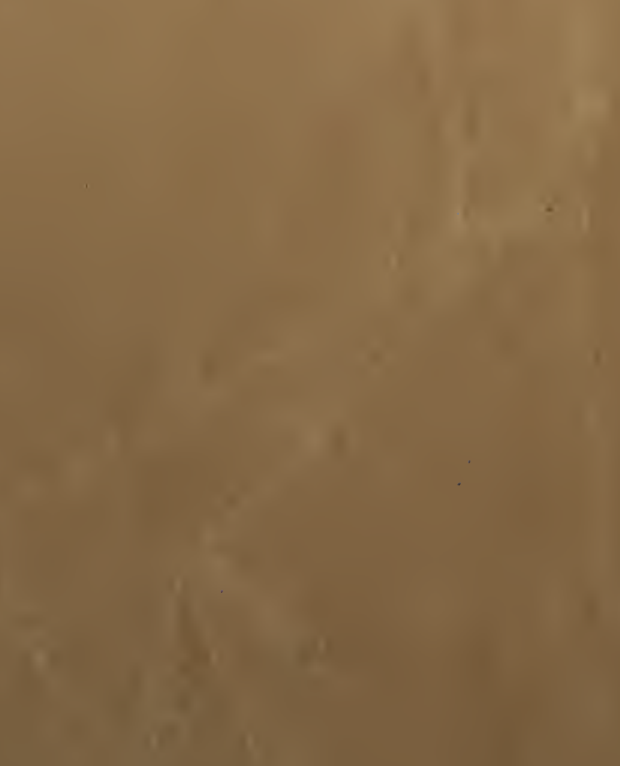


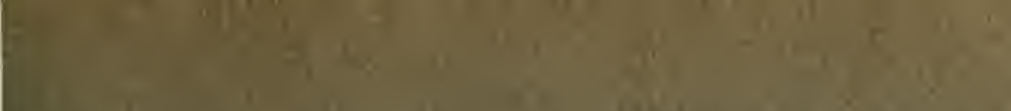

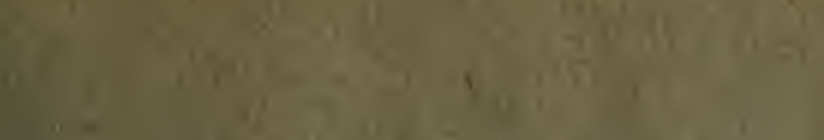
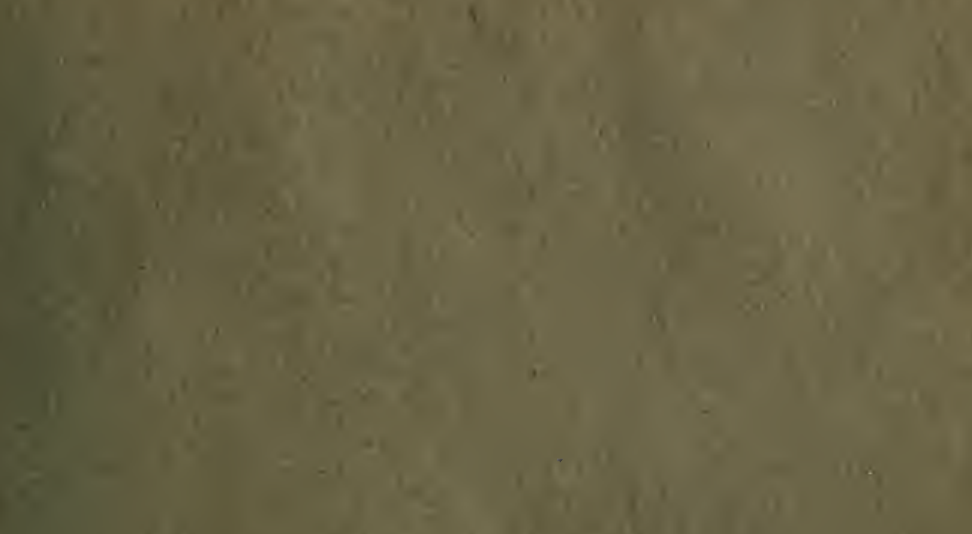

.

I.

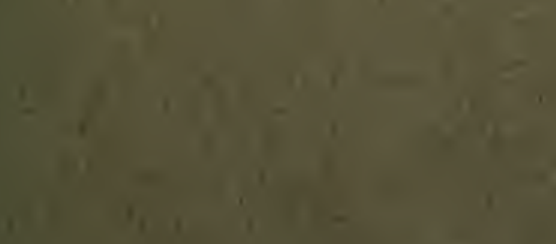

1

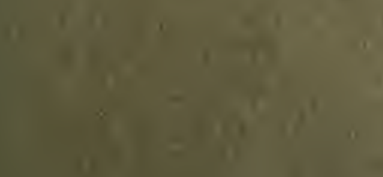

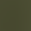

a
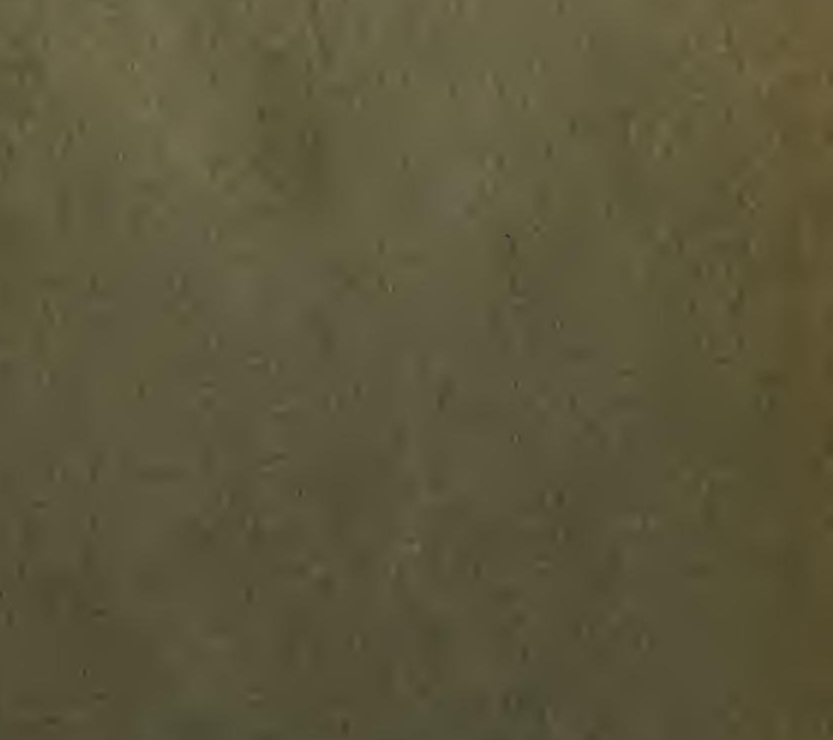

1

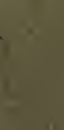

w. 
P.

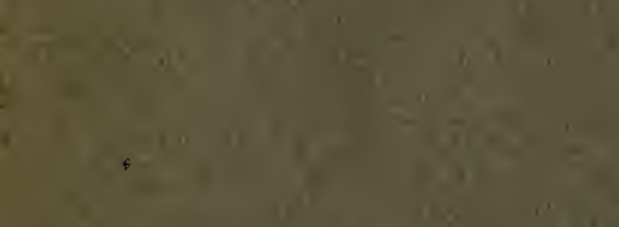




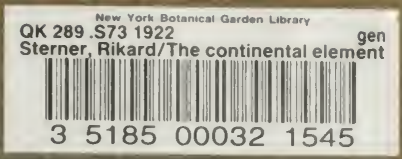


